\title{
APLICAÇÃO DE MÉTODOS BIBLIOMÉTRICOS E DA "CO-WORD ANALYSIS" NA AVALIAÇÃO DA LITERATURA CIENTÍFICA BRASILEIRA EM CIÊNCIAS DA SAÚDE DE 1990 A 2002.
}

SUELI GONSALEZ SAES

Tese apresentada ao Programa de Pós
Graduação em Saúde Pública da
Faculdade de Saúde Pública
Universidade de São Paulo
obtenção do título de Dara
Saúde Pública.

Área de Concentração: Epidemiologia Orientador: Prof. AUGUSTO HASIAK SANTO

SÃO PAULO 2005 
Autorizo exclusivamente para fins acadêmicos e científicos, a reprodução total ou parcial desta tese, por processos fotocopiadores. Ao usá-lo, cite a fonte.

Assinatura:

Data: 
Aos meus queridos pais Antonio e Luiza,

Pela dedicação e amor incondicional.

Tudo, sempre! 
"Existe somente uma idade para a gente ser feliz, somente uma época na vida de cada pessoa em que é possível sonhar e fazer planos e ter energia bastante para realizá-los a despeito de todas as dificuldades e obstáculos. Uma só idade para a gente se encantar com a vida e viver...Essa idade tão fugaz na vida da gente chama-se Presente e tem a duração do instante que passa".

Mario Quintana

Às minhas filhas Anna Carolina e Anna Luiza Com todo meu amor. 
Ao meu orientador Professor. Augusto Hasiak Santo, agradeço profundamente pela oportunidade, orientação e apoio na realização deste trabalho. 
"El mejor homenaje que puede tributarse a las personas buenas es imitarlas."

Concepción Arenal

Ao Prof. Pere Escorsa Castells, da Universidade Politécnica da Catalunya, agradeço profundamente pela oportunidade, orientação e acolhida durante a realização do trabalho nessa Universidade.

Ao Prof. Ramón Maspons Bosch, da Universidade Politécnica da Catalunya, amigo de todos os momentos, agradeço pela dedicação e o apoio imprescindível, no acompanhamento das análises de "co-word", realizadas neste trabalho.

À Dra. Elicet Cruz, do IALE Tecnologia, agradeço pelo carinho e apoio profissional, durante minha permanência na Universidade Politécnica da Catalunya.

À Coordenação de Aperfeiçoamento de Pessoal de Nível Superior, CAPES, agradeço pela bolsa de estudos concedida. 
Ao Dr. Júlio César Rodrigues Pereira, do Departamento de Epidemiologia, da Faculdade de Saúde Pública, pela amizade e pelo auxílio na realização das análises bibliométricas deste trabalho.

Ao Dr. Ricardo Oliva, da Agência Nacional de Vigilância Sanitária, por possibilitar o acesso às bases de dados utilizadas para realização deste trabalho.

Ao Marcello Sampaio Di Pietro, da Coordenadoria de Avaliação e Integração de Dados Institucionais da Universidade Federal de São Paulo, pelo apoio profissional e sua generosa disponibilidade, que garantiram a utilização dos potenciais da informática na realização deste trabalho.

Ao Dr. Luiz Jacintho da Silva, meu chefe, que soube entender minhas ausências.

À Maria Luisa dos Santos Marchi, pela amizade e incentivo nos principais momentos.

À Yeda Lopes Nogueira, pela generosidade e amizade de sempre.

E todos aqueles que de alguma forma estiveram ao meu lado neste trabalho. 


\section{RESUMO}

Saes, S.G. - Aplicação de Métodos Bibliométricos e da "Co-Word Analysis" na Avaliação da Literatura Científica Brasileira em Ciências da Saúde de 1990 a 2002. São Paulo; 2005. [Tese de Doutorado - Faculdade de Saúde Pública da Universidade de São Paulo]

Analisou-se neste trabalho a produção científica brasileira, no campo da Saúde, por meio da pesquisa de publicações, constantes da base de dados "web of Knowledge", no período de 1990 a 2002. A pesquisa incluiu 3.066 revistas desse campo do conhecimento. Nesse período foram contabilizadas 38.349 publicações. Os métodos bibliométricos tradicionais e a "co-word analysis" foram utilizados como instrumento de análise para medir a atividade científica no campo da saúde. 0 pacote estatístico, Statistical Package for Social Science SPSS, foi utilizado para a obtenção dos indicadores bibliométricos tradicionais. Demonstraram-se as etapas de trabalho e a potencialidade da "co-word analysis". Foram estudadas as palavras que representam os descritores e identificadores na base de dados e estas foram relacionadas com outras variáveis como autores, ano de publicação e filiação da publicação. Para tal, utilizouse o "Tétralogie", um software que aplica tratamentos estatísticos para conseguir que o grau de co-ocorrência entre as palavras seja representado como distâncias no espaço. Desta forma, as palavras podem ser visualizadas como pontos no espaço, por meio dos mapas tecnológicos e a distância entre elas será representativa de sua coocorrência ou afinidade. Os mapas tecnológicos permitiram a identificação de redes de cooperação entre pesquisadores e instituições, bem como identificação de "clusters" entre autores e as palavras descritoras do 
campo de conhecimento estudado. Esta abordagem para a área de avaliação em Ciência e Tecnologia demonstrou ampliar as análises bibliométricas tradicionais, e pode incrementar as atividades de planejamento e definição de ações estratégicas indicando, para onde e como se poderiam dirigir esforços para desenvolvimento do campo estudado.

\section{PALAVRAS CHAVE:}

Análise Bibliométrica, Bibliometria, Co-ocorrência de palavras, "Tétralogie", Ciência e Tecnologia (C\&T), Avaliação da Pesquisa Científica, Cienciometria, Ciências da Saúde, Brasil. 


\section{ABSTRACT}

Saes, S.G.-Application of Bibliometric Methods and "CoWord Analysis" of Brazilian Scientific Literature in Health Sciences, 1990-2002. São Paulo; 2005. [Tese de Doutorado - Faculdade de Saúde Pública da Universidade de São Paulo]

This work analyzed Brazilian scientific production in the health sciences field by analysis of publications present in the database "web of knowledge" in the period from 1990 to 2002. The study covered 3,066 journals in this field of knowledge. During this period a total of 38,349 Brazilian publications were found. Bibliometric analysis and "co-word analysis" were used to measure the scientific activity in health sciences. A statistical software package (Statistical Package for Social Science - SPSS) was used to determine traditional bibliometric analysis. The words representing descriptors and identifiers in the database had been studied and the relationship to other variables such as authors, publication year, and affiliation within the publication was determined. For this analysis, the "Tétralogie" software that applies statistical methods to measure the co-occurrence among words and represents this measure as distances in space was used. In this way, words can be visualized as points in space on a map. The maps and distances between words will represent the co-occurrence or affinity between keywords. The technological maps have shown networks of cooperation among researchers and institutions, as well as identification of "clusters" of authors and a hierarchy of the descriptive keywords. This approach for evaluation of science and technology demonstrated an extension of the traditional bibliometric analysis and showed that it could improve planning activities by identification of strategic actions 
pointing to where and how efforts for improvement in the field of health sciences should be directed.

\section{KEY WORDS :}

Bibliometric Analysis, Bibliometrics, "Co-Word Analysis", Science and Technology (S\&T), Scientific Research Evaluation, Scientometrics, Health Sciences, Brazil. 


\section{ÍNDICE DE ILUSTRAÇõES}

\section{Lista de Quadros}

Figura 1 - Número de publicações científicas brasileiras . . . . . . . 49

Figura 2 - Crescimento da produção científica brasileira ........50

Figura 3 - Número de citações em artigos científicos brasileiros ..51

Figura 4 - Curva das publicações e citações ................52

Figura 5 - Tendência de citações por ano, para publicações brasileiras . ..............................

Figura 6 - Curva da média de autores, publicações brasileiras . . . 554

Figura 7 - Curva do Percentual de publicações com colaboração . . . 555

Figura 8 - Número de autores por publicação $\ldots \ldots \ldots \ldots \ldots \ldots \ldots$

Figura 9 - Distribuição anual das publicações brasileiras . . . . . . 56

Figura 10 - Distribuição do número de autores brasileiros, segundo

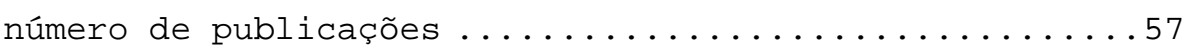

Figura 11 - Distribuição das publicações no campo da saúde, segundo localidade onde são editadas $\ldots \ldots \ldots \ldots \ldots \ldots \ldots \ldots$

Figura 12 - Distribuição das publicações, segundo localidade .....59

Figura 13 - Produção científica brasileira, de acordo com a "Lei de Bradford" ..........................6

Figura 14 - Núcleo das revistas mais produtivas, de acordo com o Grupo 1 de Bradford ....................... 61

Figura 15 - Áreas do Conhecimento de maior produtividade de publicações brasileiras ...................62

Figura 16 - Produtividade por Áreas do Conhecimento ............64

Figura 17 - Produção científica por Tipo de Documento ..........66

Figura 18 - Distribuição das publicações brasileiras, segundo tipo

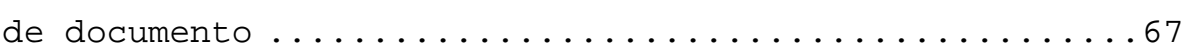

Figura 19 - Publicações científicas brasileiras, classificadas por Tipo de Documento ......................68 
Figura 20 - Número de artigos segundo o idioma de publicação . . . .668

Figura 21 - Percentual publicações brasileiras, segundo o idioma de

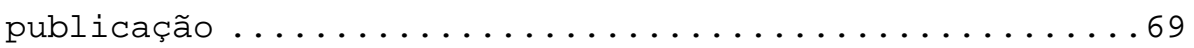

Figura 22 - Composição dos "clusters" de acordo com os padrões da produção científica brasileira ...............71

Figura 23 - Relação do "cluster" 1 das publicações brasileiras, com as áreas do conhecimento ....................74

Figura 24 - Relação do "cluster" 2 das publicações brasileiras, com as áreas do conhecimento ....................75

Figura 25 - Relação dos "cluster" 3 e 4, das publicações brasileiras, com as áreas do conhecimento ..........76

Figura 26 - Percentual dos Descritores segundo a freqüência de ocorrência ............................ 81

Figura 27 - Descritores e Identificadores, segundo as vinte primeiras maiores freqüência de ocorrência ..........81

Figura 28 - Ocorrência da palavra "Dengue", nas publicações brasileiras ........................... 83

Figura 29 - Fragmento da matriz de co-ocorrência de descritores, segundo $1 \%$ das palavras de maior freqüência $\ldots \ldots \ldots . . .86$

Figura 30 - Zoom da matriz de co-ocorrência de Descritores . . . . . 87

Figura 31 - Fragmento da matriz de co-ocorrência de "DE", segundo 1\% das palavras de maior freqüência . .............87

Figura 32 - Descritores liderado pela palavra "epidemiology" .....88 Figura 33 - Mapa segundo matriz de co-ocorrência de descritores ...89 Figura 34 - Fragmento da matriz de descritores ..............90 Figura 35 - Descritores liderados pela palavra "anxiety" ........90 Figura 36 - Artigos e citações segundo a palavra "anxiety" .......91 Figura 37 - Artigos e citações que contém a palavra "anxiety" . . ..92 Figura 38 - Fragmento da matriz de co-ocorrência de descritores ...93 Figura 39 - Lista de descritores ..................... 93 
Figura 40 - Mapa dos "clusters", segundo matriz de co-ocorrência de descritores ............................95

Figura 41- Mapa segundo matriz de co-ocorrência de descritores . ...95

Figura 42 - Identificadores, liderado pela palavra "expression" e "protein" ........................... 97

Figura 43 - Percentual dos Identificadores, segundo sua freqüência

de ocorrência $\ldots \ldots \ldots \ldots \ldots \ldots \ldots \ldots \ldots \ldots \ldots \ldots$

Figura 44 - Grupo 4 de descritores ..................... 99

Figura 45 - Cruzamento de descritores e identificadores .........101

Figura 46 - Cruzamento de descritores e identificadores ......... 102

Figura 47 - Cruzamento de descritores e identificadores .........103

Figura 48 - Cruzamento de descritores e identificadores ..........104

Figura 49 - Cruzamento de descritores e identificadores .........105

Figura 50 - Autores do "cluster ecology" segundo publicações brasileiras ...........................107

Figura 51 - Mapa de autores do "cluster" ecology, segundo descritores ..........................107

Figura 52 - Mapa de autores do "cluster" ecology, segundo descritores .............................108

Figura 53 - Mapa tecnológico de autores e descritores do "cluster ecology ............................. 109

Figura 54 - Mapa tecnológico de autores e descritores do "cluster ecology", segundo publicações brasileiras ..........110

Figura 55 - Evolução do Grupo "Forattini" no Tempo .............111

Figura 56 - Matriz de descritores e autores do "cluster ecology", segundo as publicações brasileiras ............112

Figura 57 - Curva de carga para a contagem do campo de endereços, segundo as publicações brasileiras ..............113

Figura 58 - Rede de colaboradores do "cluster ecology", segundo as publicações brasileiras ......................114 


\section{SUMÁRIO}

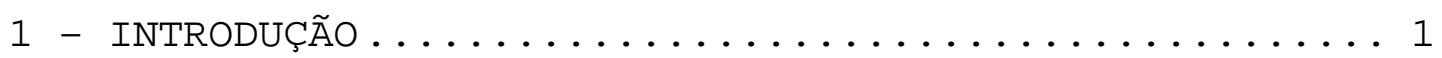

2 - SITUAÇÃO ATUAL DA CIÊNCIA E TECNOLOGIA (C\&T) NO

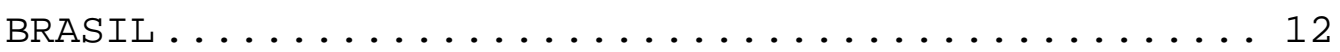

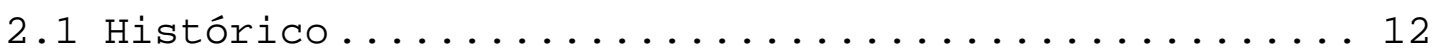

2.2 Recursos Humanos em C\&T no Brasil........... 15

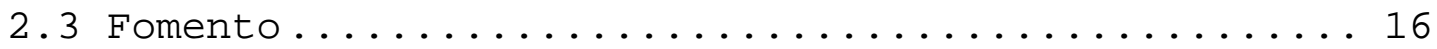

2.4 Setor produtivo......................... 17

3 - AVAliAÇÃo EM CiÊnCiA e teCnOlogia............... 19

3.1 Bibliometria ........................ 19

3.2 Indicadores Bibliométricos ............... 22

3.3 Co-ocorrência de Palavras - Co-word Analysis..... 25

4 - OBJetivos............................ 31

4.1 Objetivo Geral....................... 31

4.2 objetivos Específicos .................. 31

5 - MATERial e mÉtodos $\ldots \ldots \ldots \ldots \ldots \ldots \ldots \ldots \ldots \ldots \ldots \ldots \ldots \ldots \ldots$

5.1 Universo do Estudo ..................... 32

5.2 Busca dos dados $\ldots \ldots \ldots \ldots \ldots \ldots \ldots \ldots \ldots \ldots, 34$

5.3 Análises Bibliométricas .................. 34

5.3.1 Tratamento dos Dados................... 35

5.4 "Co-Word Analysis" ..................... 36

5.4.1 Tratamento dos Dados para a "Co-Word Analysis" 36

5.4.2 Características do Software "Tétralogie" ...... 36

5.5 Processo de Tratamento da Informação............ 40

5.5.1 Pré-Tratamento dos Dados..................40 40

5.5 .2 Estrutura da "BASEDEDONNEES" ..............4 40 
5.5.3 Tratamento dos Dados................... 44

5.6 Matrizes e Mapas Tecnológicos .............. 44

5.6.1 Métodos Estatísticos Integrados ............ 46

5.7 Limitações do Estudo ..................... 47

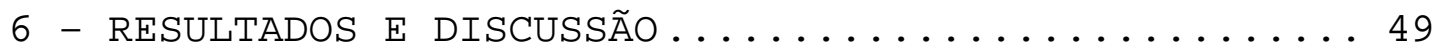

6.1 Análises Bibliométricas ................. 49

6.2 "Co-Word Analysis" ..................... 77

7 - CONSIDERAÇÕES FINAIS .................... 116

8 - REFERÊNCIAS BIBLIOGRÁFICAS ............... 127 


\section{1 - INTRODUÇÃO}

"A ciência e a tecnologia constituem, hoje, fatores preponderantes no processo de desenvolvimento econômico e social de qualquer país". (Marcovitch-1986) Esta frase, apesar de ter sido escrita há mais de uma década, guarda os mesmos fundamentos, é repetida em conferências e aberturas de fóruns de discussão de Ciência e Tecnologia (C\&T). É consenso não só entre os atores envolvidos com as questões relacionadas com 0 desenvolvimento científico, tecnológico e de inovação. Para Arlington, 1998, em função das atuais características do processo econômico "... os investimentos em pesquisa básica, tecnologia de ponta e ensino da ciência e engenharia são fundamentais para o alcance de metas nacionais relativas ao desenvolvimento econômico e social de melhoria da saúde, do bem estar, da competitividade econômica e da segurança nacional".

Ciência e Tecnologia constituem a mola mestra que impulsiona o processo de desenvolvimento econômico e social das nações. Não há dúvida sobre a relevância da C\&T para a sociedade contemporânea. o conhecimento é hoje o elemento fundamental para a geração de desenvolvimento. Neste contexto, a divulgação científica, além de contribuir para a democratização do conhecimento, aproxima o cidadão comum dos benefícios que ele tem direito de reivindicar para a melhoria do bem-estar social, dando-lhe uma visão mais clara sobre as verdadeiras causas e efeitos dos problemas que enfrenta no dia-a-dia. (Carneiro, 2002 ) .

Nos países em desenvolvimento, como o Brasil, a necessidade de equacionar problemas sociais e impulsionar o crescimento econômico coloca o campo da Ciência e Tecnologia no centro de qualquer estratégia e política de desenvolvimento 
sustentado. Cresce, portanto, a necessidade de não somente fomenta-1o, nas esferas pública e privada, mas também de fazê-lo de forma ordenada e consistente, orientada por uma visão de futuro, perfeitamente articulada com as necessidades e demandas dos cidadãos.

Ao longo das últimas décadas, apesar de limitações e dificuldades enfrentadas pela comunidade científica brasileira, parece inegável que o país deu um salto considerável em matéria de ciência e tecnologia. 0 Brasil conta hoje com uma base significativamente sólida para empreender um novo salto e buscar objetivos mais ambiciosos, fazendo da C\&T um poderoso instrumento de transformação social e desenvolvimento econômico.(UNESCo, $2003)$.

Algumas iniciativas, como a do próprio Conselho Nacional de Desenvolvimento Científico e Tecnológico (CNPq) quando desenvolveu em novembro de 1998 o seu Plano Institucional, evidenciam esta necessidade para o Brasil na introdução de seu planejamento estratégico quando afirma que "... o conhecimento científico e tecnológico, neste final de século, constitui o cerne das próprias transformações que atingem todos os aspectos da vida humana. De um lado, a progressiva conversão da ciência em força produtiva e de competitividade internacional consolida suas vinculações com as formas de poder e torna inquestionável sua relevância econômica, social e política. Por outro lado, os custos crescentes da produção científica e tecnológica e a crise de financiamento público ampliam significativamente os desafios institucionais". ( CNPq, 1998).

É ainda extremamente relevante 0 fato de que 0 desenvolvimento do conhecimento se distribui desigualmente. Leta, em seu trabalho de 1996, mostra como sendo indicativo desta distribuição o fato de que 7 países (USA, Grã-Bretanha, Alemanha, Japão, França, Canadá e Rússia) eram responsáveis por $75 \%$ dos artigos científicos publicados nos mais importantes periódicos 
científicos a cada ano, sendo que o restante do planeta, com 83\% da população mundial, é composto de países "consumidores" desse conhecimento. (Leta e Meis-1998)

Em um artigo publicado em 15 de julho de 2004 no jornal "A Folha de São Paulo", Bonalume Neto, aponta para esta desigualdade "... Que o mundo é desigual, muitos sabem. Noruegueses vivem bem mais e melhor... como costuma revelar o Índice de Desenvolvimento Humano, divulgado ontem pelo PNUD (Programa das Nações Unidas para o Desenvolvimento)" e se reporta a um estudo, de autoria de David King (2004), sobre o estado da arte da ciência no planeta, onde evidencia que a situação tende a piorar cada vez mais, pois os países ricos, como a Noruega, investem muito mais e melhor em ciência e inovação tecnológica do que os mais pobres.

Dois estudos publicados recentemente apontam que o Brasil vem alcançando bom desempenho na divulgação de seus resultados de pesquisa e, conseqüentemente, aumentando a visibilidade entre os países empenhados em produzir ciência e tecnologia.

0 estudo produzido pela National Science Foundation, agência do governo dos Estados Unidos, , em agosto de 2004, faz um balanço do número de artigos de ciência e engenharia publicados nas mais importantes revistas entre os anos de 1988 e 2001. 0 resultado é um notável crescimento da produção de países da Ásia e da América Latina. Nesta última região, o número de artigos publicados quase triplicou nesse período, com destaque para o Brasil que quadruplicou suas publicações e respondeu, em 2001, por 44\% do desempenho regional. Em 2001, o Brasil produziu 7.205 artigos, contra 1.766 publicados em 1988. Uma análise per capita, no entanto, revela maior desempenho em C\&T na Argentina e no Chile. Entre os anos de 1999 e 2001 esses países ultrapassaram 75 artigos publicados/milhão de habitantes, enquanto que no Brasil esse índice não alcançou 39 artigos/milhão de habitantes. (Rodrigues, 2004). 
Por sua vez, o trabalho de autoria de $\mathrm{King}^{8}$ em julho de 2004, publicado na revista científica, "Nature", mostra que apenas 31 países, incluindo o Brasil, estão representados no 1\% dos mais importantes artigos científicos, ou seja, aqueles que foram os mais citados por outros cientistas. 0 resultado foi um ranking dos 31 países que produzem as pesquisas mais citadas no mundo, no qual o Brasil ocupa a $23^{a}$ posição e a condição de único representante da América Latina. King ${ }^{8}$ fez comparações entre a produção de artigos desses 31 países mais significativos na ciência mundial, mostrando que esse grupo responde por $98 \%$ dos artigos mais citados dentre todos. Os outros 162 países do mundo contribuíram com os $2 \%$ restantes. No entanto, existem olhares críticos para esses resultados, como o de Rodrigues (2004) quando diz "...A repercussão desses estudos, ao tempo que premia o esforço do pesquisador brasileiro, também reforça o papel dos índices bibliométricos como quase que exclusivos indicadores de produção de C\&T. Assim, ao lado da comemoração pelas boas notícias, cabem algumas reflexões sobre o significado desses dados..." (Rodrigues, 2004)

Assim, numa sociedade competitiva em escala mundial, implementar o conhecimento técnico e científico é tarefa indispensável para o desenvolvimento econômico e social, principalmente para os países em desenvolvimento que são "consumidores" do conhecimento técnico e científico, de forma a identificar suas necessidades e peculiaridades.

Porém, o pano de fundo da implementação do conhecimento científico e tecnológico é a existência de recursos limitados e uma exigência cada vez maior de racionalidade e objetividade na aplicação dos parcos recursos disponíveis. (Black-1997)

Considerando que um fundamento básico para a implementação de qualquer sistema é "...que os resultados refletem os sistemas que o produzem" (Turnock-1997) e que, ainda nas palavras de Turnock, "...para melhorar algo devemos ser 
capazes de controlá-lo; para controlá-lo devemos ser capazes de entendê-lo e para entendê-lo devemos ser capazes de medi-1o", torna-se indispensável estudar, para conhecer e medir, a produção científica para a implementação desse conhecimento, superação das dificuldades e alcance dos pressupostos de racionalidade e objetividade.

A habilidade para avaliar o patamar científico das nações é vital para os governos, negócios e fundações que devem decidir as prioridades científicas e de investimento.

Nos Estados Unidos, a liderança do "National Science Foundation" uma agência independente do governo americano, em avaliar as fronteiras da ciência, pesquisa e educação é demonstrada, em parte, pelas importantes avaliações internas e externas de desempenho, produzidas pelo órgão, que são utilizadas de forma crescente pelo congresso americano e pelos escritórios de gestão e orçamento de Ciência e Tecnologia para tomada de decisão .

$\mathrm{Na}$ Europa, o "L'Observatoire des Sciences et dês Techniques - L'OST" tem o papel principal de produzir os indicadores quantitativos que se relacionam às atividades científicas, tecnológicas e de inovação. Seu relatório de 2002, "Science \& Indicateurs" permitem interpretar e analisar a posição científica e tecnológica da França e de seus sócios europeus, em seus contextos, nacional e no mundo. 0 "OST" produz os indicadores que permitem os atores da ciência e da tecnologia discutir em sentido amplo a política da pesquisa e de elaborar sua estratégia. (www.obs.ost.fr).

0 RICYT - Rede Ibero-americana de Indicadores de Ciência e Tecnologia, foi constituído pelo Programa Ibero-americano de Ciência y Tecnologia para o Desenvolvimento (CYTED) a partir de uma proposta surgida do Primeiro encontro Ibero-americano sobre Indicadores de Ciência e Tecnologia realizado na Argentina no 
final de 1994. Porém concretizou-se em abril de 1995. Atualmente executa o projeto de "Construção de um sistema interamericano de ciência, tecnologia e inovação - Plataforma Básica", financiado pela Organização de Estados Americanos (OEA). Seu objetivo é construir um sistema de informação que reflita as necessidades dos países americanos, concebido como una rede complexa que potencialize a escala regional em suas capacidades nacionais e sub-regionais, nesta matéria. (www.ricyt.edu.ar).

No Brasil, 0 Ministério da Ciência e Tecnologia - MCT, divulga os indicadores nacionais de ciência e tecnologia (C\&T) por meio de sua página na Internet e em publicação impressa, cuja última versão foi editada em 2002. No segundo semestre de 2003 teve início o processo de atualização das informações com a reformulação de tabelas e gráficos, que se estendeu até 2004, com a inclusão de dados disponíveis até abril daquele ano. A discussão sobre os indicadores e a sua representatividade é uma preocupação do ministério que busca gerar informações mais completas e acuradas, para subsidiar os posicionamentos da sociedade e do governo.

Outras duas iniciativas que ocorreram em 2004, vêm ao encontro das necessidades na área de avaliação em C\&T no país e devem ser creditadas à Fundação de Amparo à Pesquisa de São Paulo - FAPESP, que desenvolveu um serviço inédito, que facilita a busca pela internet de informações voltadas à produção e análise de indicadores de ciência, tecnologia e inovação. Trata-se do FAPESP.Indica. Este serviço tem como finalidade ajudar pesquisadores, gestores e outros interessados na consulta de informações para a produção e análise de indicadores de ciência, tecnologia e inovação CT\&I. (Vogt e Gusmão, 2004) A segunda deveu-se ao lançamento da edição 2004 dos "Indicadores FAPESP de CT\&I", centrada na análise da evolução mais recente dos esforços de C\&T paulistas, no contexto mais amplo da dinâmica nacional e 
internacional do setor, na entrada do novo século. (Gusmão, 2004 ).

Há várias maneiras de medir a produção científica dos países e seu impacto geral na ciência, nenhuma das quais é perfeita. Um artigo pode ser muito citado por outros cientistas de forma negativa, por exemplo. Mas, em geral, e em grandes conjuntos de dados, quanto mais citado, mais impacto tem uma pesquisa.

Os diálogos entre cientistas e pesquisadores vêm sendo estudados desde os anos 50 por meio das chamadas redes de comunicação científica. No entanto, a proliferação desses estudos deu-se a partir da década de 60 com Solla Price, pesquisando a mensuração da literatura científica por meio da análise de citações - bibliometria. Nessas análises percebe-se que a ciência é construída por meio de diálogos estabelecidos entre o autor citado e aquele que o cita; outro aspecto relevante abordado é o direcionamento evolutivo da ciência e tecnologia. (Pinto e Lima2002)

A "Gestão de Ciência e Tecnologia" - enquanto um campo de conhecimento e de prática na busca permanente por maior racionalidade na aplicação de recursos e maior eficiência e eficácia nos resultados atingidos tanto na geração quanto na utilização do conhecimento científico, torna-se instrumento indispensável para os gestores públicos e privados, pois fornece as principais técnicas de avaliação do desenvolvimento do conhecimento, utilizando os recursos da Bibliometria. Estas são questões fundamentais na gestão de C\&T, sendo vasta a bibliografia relacionada. (Luukkonen-Gronow, 1987)

Como em qualquer outro campo social ou econômico, o diagnóstico de situação é instrumento fundamental para o estabelecimento, planejamento e implementação de políticas e atividades transformadoras. Para tanto é necessário avaliar e 
comparar todo momento, o desenvolvimento e a produção científica e tecnológica, estudando e identificando os determinantes e condicionantes desta produção, mapeando as instituições e os pesquisadores com relação a resultados alcançados, as potencialidades, as disponibilidades e as necessidades. (Kostoff, $1994)$.

Em documento elaborado para discussão de uma nova agenda em C\&T para o Brasil, os analistas do Banco Mundial abordam a questão de o país estar preparado para as mudanças no setor "... o ritmo acelerado da mudança tecnológica requer, rapidamente dos países, habilidade para produzir, avaliar, e selecionar o conhecimento. Os governos compreendem hoje as vantagens de uma estrutura e de políticas de ciência e tecnologia que, de um lado, permita a autonomia e a criatividade máximas para investigadores, e de outro, assegure a relevância da pesquisa e de seus resultados, em conformidade às necessidades do desenvolvimento econômico e social". (Holm-Nielsen et al, 1996)

A moderna "inteligência" utiliza de forma crescente os métodos e os indicadores da Bibliometria e da Cienciometria, que permitem tratar, com ajuda da Informática, grandes quantidades de dados. Particularmente, estas ferramentas são imprescindíveis para a elaboração de mapas tecnológicos. Estes mostram um panorama detalhado das linhas de investigação na área a ser estudada, por meio da análise do que se está publicando o patenteando. Tratados dinamicamente, ou seja, comparando mapas de diferentes períodos, podemos seguir a evolução no tempo das tecnologias e das linhas de investigação, "... conhecer as relações e interações entre os diferentes elementos bibliográficos: investigadores, campos do conhecimento, setores..., tentando descrever o conteúdo das atividades e sua evolução, e seguindo fronteiras movediças". (Callon et al, 1993)

Uma das formas de análise ainda não muito difundida no nosso meio, pelo menos no que diz respeito à avaliação da 
produção científica, tecnológica, é a co-ocorrência de palavras ou "co-word analysis". No entanto, está mais comumente associada ao tema indexação de trabalhos científicos, biblioteconomia e trabalhos relacionados com o termo "webmetria". Este termo foi proposto por Almind e Ingwersen em 1997, como sendo um ramo da informetria voltado à análise quantitativa do conteúdo e da estrutura das "home-pages" da "Word Wide Web". A co-ocorrência de palavras estuda o aparecimento conjunto de duas ou mais palavras representativas em campos tais como: títulos de artigos científicos ou patentes, resumos ou "abstracts", palavras-chave ou "key-words" em descritores e identificadores ou mesmo, no texto. As análises bibliométricas em geral, nos permitem detectar as áreas, "clusters" ou programas de investigação em que se subdivide um campo determinado, mas não nos permitem entrar no conteúdo dos documentos. Para consegui-lo é indispensável abordar a análise de palavras nos títulos, abstracts, descritores, identificadores e texto, já que estas palavras explicam o conteúdo dos próprios documentos. Com a análise de "co-word", mapas tecnológicos podem ser obtidos e assim visualizarmos a estrutura do conhecimento que existe por trás do documento, bem como o que o tornou possível. 


\section{2-SITUAÇÃo ATUAL dA CIÊNCIA E TECNOLOGIA NO BRASIL}

\subsection{HISTÓRICO}

0 desenvolvimento formal da ciência brasileira tem suas raízes no Instituto Oswaldo Cruz, no Rio de Janeiro. A história da ciência e da tecnologia no Brasil remonta ao início do século $\mathrm{XX}$, com as pesquisas de dois grandes cientistas: o médico sanitarista oswaldo cruz, pioneiro na medicina experimental no País e responsável pelas primeiras iniciativas na área de saúde e saneamento, e Carlos chagas, que atribuiu à pesquisa básica a grande descoberta da doença que leva o seu nome. Assim, a ciência brasileira tem fortes raízes na área médica aplicada. (Tundisi2003) Na área agrícola, o Instituto Agronômico de Campinas, IAC, fundado por D. Pedro II em 1887, voltou às suas atividades, no início do século passado, para a resolução de problemas do setor, e, na década de 20, a pesquisa básica realizada pelo IAC já contribuía para o melhoramento genético das culturas de café e de algodão. Hoje, o Brasil tem mais de 60 mil cientistas e tecnólogos em atividade e está entre os 20 países que mais publicam artigos científicos em revistas internacionais. (Almeida et al, 1999)

Este universo de C\&T somente começa a ganhar estrutura quando é criado o Conselho Nacional de Pesquisas, hoje Conselho Nacional de Desenvolvimento Científico e Tecnológico (CNPq), e a Coordenação de Aperfeiçoamento do Ensino Superior (Capes), no início de 1950. Nos três decênios seguintes, o Brasil, em comparação com outros países de industrialização recente, construiu um expressivo parque de pesquisa. 0 modo como ele se construiu acompanhou, em vários aspectos, o modelo de 
industrialização em sua etapa de substituições de importações. Algumas das características básicas da pesquisa e desenvolvimento (P\&D) naquele momento eram a horizontalidade e pouca seletividade e estavam vinculadas ao modelo então predominante na produção científica, que buscava, prioritariamente, criar uma massa crítica de recursos humanos qualificados.

Entretanto, 0 predomínio do modelo nacionaldesenvolvimentista gerou a necessidade de buscar alguma articulação entre a produção técnico-científica e a produção agrícola e industrial. São exemplos dessa articulação para o desenvolvimento tecnológico, a criação da Empresa Brasileira de Pesquisa Agropecuária (Embrapa) e dos departamentos de P\&D de empresas estatais, como o CENPES da Petrobrás, bem como a articulação entre o Instituto Tecnológico da Aeronáutica (ITA) e a Empresa Brasileira de Aeronáutica (Embraer).

No campo dos mecanismos de fomento, devem ser lembrados, além da Finep e CNPq, o Fundo de Tecnologia do Banco Nacional de Desenvolvimento Econômico (Funtec/BNDE). Porém, praticamente não se verificou extensão deste modelo para o campo das políticas sociais, a não ser em raras exceções como o Programa de AutoSuficiência Nacional em Imunobiológicos (PASNI).

Desde 1980, vem se fortalecendo a articulação entre países em torno da idéia de que a pesquisa em saúde é uma ferramenta importante para a melhoria da situação de saúde das populações, bem como, para a tomada de decisões na definição de políticas e no planejamento em saúde. Isso tem contribuído para a melhoria das ações de promoção, proteção, recuperação e reabilitação da saúde e a diminuição das desigualdades sociais. Organizações internacionais na área de saúde, com destaque para a Organização Mundial da Saúde (OMS), vêm desempenhando papel importante nesse movimento, no qual o Brasil deve buscar maior participação. 
Investindo cerca de $\odot, 7 \%$ de seu Produto Interno Bruto (PIB) em Ciência e Tecnologia, o Governo Federal consolidou, em meados dos anos 80 do século passado, a pesquisa acadêmica no País. Foram cerca de 60 mil os cientistas e tecnólogos em atuação no Brasil. Embora ainda seja um número pequeno em relação à população brasileira, representa um significativo avanço quando comparados há décadas anteriores e às nações do terceiro mundo. Toda esta organização institucional resultou no aumento da produtividade científica e em uma continuidade na formação de recursos humanos. Nos anos 90, o Brasil passou a formar 2.500 doutores por ano, em todas as áreas de ciência. Há um amplo suporte do governo federal aos programas de formação de mestres e doutores, no Brasil e no exterior. Este esforço resultou na diversificação das áreas de ciência básica, no aumento de programas de pós-graduação e no aumento significativo da produção científica publicada no País e no exterior em revistas indexadas.

0 recente estudo realizado por $\mathrm{King}^{8}$ em 2004, mostrou que vários países melhoraram em muito sua classificação. Por exemplo, entre 1993 e 1997, o Brasil produziu 0,84\% dos artigos científicos indexados no mundo, isto é, registrados em banco de dados. De 1997 a 2001 esta produção elevou-se ao percentual de $1,21 \%$.

Apesar dos avanços ocorridos, o país ocupa ainda uma modesta posição no panorama internacional da produção científica. Ainda assim, conseguiu construir uma tradição que se caracteriza pela capacidade de gerar internamente a imensa maioria dos recursos financeiros utilizados para o funcionamento da capacidade instalada de pesquisa e formar a quase totalidade dos recursos humanos para a pesquisa, de técnicos a doutores, dentro de suas fronteiras.

Esses dois fatos distanciam claramente 0 Brasil do panorama de pesquisa em saúde existente na maioria dos países em desenvolvimento. Como ocorre em vários países, a área da saúde 
também representa o maior componente de toda a produção científica e tecnológica. ( $2^{\mathrm{a}}$. Conferência Nacional de C\&T/I, $2004)$.

\subsection{RECURSOS HUMANOS EM C\&T NO BRASIL}

Entre os fatos mais promissores ocorridos no panorama da formação de recursos humanos para a pesquisa no país, na última década, destacam-se a criação do Programa Institucional de Bolsas de Iniciação Científica (PIBIC) e a descentralização geográfica dos programas de doutorado. Esta descentralização se for acompanhada de fluxo sustentado de recursos para as regiões Nordeste, Norte e Centro-Oeste, como está previsto na operação dos fundos setoriais do Ministério da Ciência e Tecnologia (MCT), poderá contribuir para a correção de uma das sérias distorções na distribuição de recursos humanos em pesquisa, que é sua intensa concentração geográfica.

Ainda há carências importantes no que se refere ao desenvolvimento tecnológico no Brasil, sobretudo as relacionadas com a escassez de centros de excelência, profissionais e instituições capacitados para a gestão de processos de inovação, que se ajustem às exigências de qualidade e segurança dos órgãos reguladores.

A área de pesquisa em saúde em geral não difere das outras áreas quanto à distribuição de recursos humanos, porém apresenta alguns componentes mais concentrados que a média, como a pesquisa médica e odontológica em São Paulo, e outros menos concentrados, como a saúde coletiva, em que a presença da região Nordeste situa-se acima da média de participação ${ }^{19}$. ( $2^{\mathrm{a}}$. Conferência Nacional de C\&T/I, 2004). 


\subsection{FOMENTO}

o esforço governamental para fomentar a pesquisa em saúde é bastante significativo, mas insuficiente. No plano federal destacam-se as atuações do Ministério de Ciência e Tecnologia, por meio das suas agências de fomento (CNPq e Finep), do Ministério da saúde por meio de suas instituições (Fundação Oswaldo Cruz, Instituto Nacional de Câncer, Instituto Evandro Chagas) e da contratação de projetos com grupos de pesquisa em diversos centros do país. Cabe ainda mencionar, a atuação do Ministério da Educação, especialmente na formação de recursos humanos e na disseminação de informações científicas por meio da Capes. No âmbito estadual destacam-se o papel dos institutos de pesquisa vinculados às secretarias de saúde e algumas agências de fomento (FAPs), em particular a Fundação de Amparo à Pesquisa do Estado de São Paulo (Fapesp) que, a partir da última década, vem desenvolvendo programas de apoio à pesquisa estratégica, de alto impacto nacional e internacional, em saúde. O Ministério da Saúde participa com cerca de $20 \%$ do total de desembolso público na pesquisa em saúde, enquanto o Ministério da Agricultura por meio da Embrapa comparece com quase o dobro (39\%). Esse quadro mostra a necessidade de um deslocamento do papel do Ministério da Saúde para uma posição central na estruturação do fomento a pesquisa em saúde. Isso significa aumentar a capacidade indutora em P\&D em Saúde aproximando-a das necessidades da política de saúde.

\subsection{SETOR PRODUTIVO}

Não é fácil quantificar os esforços de Ciência, Tecnologia e Inovação em Saúde no país. Para as atividades de Pesquisa e Desenvolvimento (P\&D) em empresas, os dados são bastante precários, havendo pouca informação sobre o campo da saúde. Calcula-se que no Brasil, em 2000, foram investidos cerca de US\$ 13 bilhões em P\&D, recursos estes majoritariamente do 
governo, aplicados em atividades desenvolvidas por instituições de ensino superior. 0 baixo investimento por parte do setor privado é atribuído ao caráter fortemente internacionalizado do complexo produtivo da saúde. Esta característica levou as empresas que vieram se instalar no país a optar pela realização de atividades de $P \& D$ em suas matrizes no exterior. ( $2^{\mathrm{a}}$. Conferência de C\&T e Inovação-2004).

Segundo Guimarães (2002) “... O empresariado brasileiro nunca teve uma participação consistente no esforço nacional de C\&T. Estima-se que, hoje, essa participação situe-se entre $10 \%$ e $20 \%$ do orçamento total de C\&T no país, o que é bem pouco diante do tamanho do parque industrial".

0 complexo produtivo da saúde é formado por três grandes componentes, as indústrias químicas e de biotecnologia (fármacos, testes diagnósticos, vacinas e hemoderivados), as indústrias mecânicas, eletrônicas e de materiais (equipamentos, órtese e prótese e materiais de consumo) e as organizações de prestação de serviços. Nos últimos anos, os segmentos dos dois primeiros componentes apresentaram déficit comercial significativo, atingindo cerca de US\$3,5 bilhões em 2001. Deste déficit na balança comercial, $70 \%$ decorreu de relações com países desenvolvidos e $30 \%$ de relações com paises que apresentam nível de desenvolvimento compatível com o brasileiro. 


\section{3 - AVALIAÇÃo EM CIÊNCIA E TECNOLOgIA}

"A palavra avaliar vem do latim "valere". Esta apresenta, entre outras acepções, a de ser merecedor ou digno de alguma coisa. A avaliação, dentro de um determinado ramo do conhecimento, permite dignificar o saber, quando métodos confiáveis e sistemáticos são utilizados para mostrar à sociedade como tal saber vem-se desenvolvendo e de que forma tem contribuído para resolver os problemas que se apresentam dentro de sua área de abrangência". (Mugnani, Jannuzi e Quonian, 2004)

\subsection{BIBLIOMETRIA}

As técnicas quantitativas de avaliação podem ser subdivididas em bibliometria, cienciometria, informetria e, mais recentemente, webmetria. Todas têm funções semelhantes, mas, ao mesmo tempo, cada uma delas propõe medir a difusão do conhecimento científico e o fluxo da informação sob enfoques diversos. Existe, ainda, muita dificuldade em estabelecer onde termina uma e começa a outra.

Freqüentemente os termos bibliometria e cienciometria são utilizados indistintamente. Muitos são os autores que definem este conjunto de ferramentas para o estudo e avaliação da produção de publicações.

As primeiras noções do conceito de bibliometria remontam o início do século XIX. 0 primeiro estudo sobre os problemas desta disciplina se atribui a Cole e Eales em 1917. Gross e Gross em 1927 foram os primeiros a contabilizar, além dos documentos científicos, as citações que os investigadores faziam em seus próprios documentos de trabalhos publicados anteriormente. Anos mais tarde, surgiu a palavra "bibliometria", termo atribuído a Pritchard para referir-se ao método de análise da informação escrita baseado na estatística de indicadores bibliográficos, 
ainda que alguns autores franceses atribuam a Paul otlet várias décadas antes, em sua obra intitulada Traité de documentatión em 1934. (Escorsa e Maspons-2001)

A Bibliometria se interessa principalmente pelos problemas de gestão das bibliotecas e dos centros de documentação, o que inclui a contagem de artigos e publicações assim como estudos mais detalhados sobre uma disciplina determinada, segundo Callon em 1993.

Segundo Pritchard em 1993 a Bibliometria é a ciência que estuda a natureza e o curso de uma disciplina, mediante a estatística e a análise das diversas facetas da comunicação escrita.

A Bibliometria é a exploração estatística das publicações. (Quoniam, 2001)

Considera-se Bibliometria o conjunto de estudos que tratam de quantificar o processo da comunicação escrita e a natureza e evolução das disciplinas científicas, tal e como se refletem na literatura, mediante a contagem e análise de diversas características da referida comunicação.

A Bibliometria é uma ferramenta de medida baseada na aplicação de métodos estatísticos e matemáticos que têm por objeto facilitar a comparação e a compreensão de conjuntos de referências bibliográficas. (Rostaing, 1995)

A Cienciometria, no entanto, designa aqueles trabalhos dedicados a análise quantitativa da atividade científica e técnica. (Callon ${ }^{15}$ et al, 1993)

Essa disciplina é dedicada exclusivamente à análise dos documentos relatados por investigadores e técnicos. De alguma forma, tenta identificar as leis que regem a atividade científica. A Cienciometria tem por objetivo o estudo dos aspectos quantitativos da criação, difusão e utilização da 
informação científica e técnica e a compreensão dos mecanismos da investigação como atividade social. A cienciometria busca as leis que regem a ciência, daí sua denominação de "ciência das ciências" por De Solla Price em 1963.

A Cienciometria é o resultado da convergência de dois movimentos, o americano, centrado no estudo da ciência das ciências; $e$ o dos países do Leste Europeu, especialmente a União Soviética, com uma corrente denominada Naukovodemia. No primeiro caso, os estudos iniciais desenvolvidos estão associados ao nome de Derek de Solla Price, graças a seus livros publicados nos anos sessenta, em especial "Little Science, Big Science". O movimento da Naukovodemia tem um objetivo similar ao dos americanos, ou seja, estudar científicamente a atividade de investigação para favorecer seu desenvolvimento. A primeira publicação desse grupo aconteceu em 1926 com um artigo de Borichevski, onde ele anuncia a constituição de um novo campo de investigação focado para o estudo da natureza intrínseca da ciência. (Escorsa e Maspons, 2001)

As ferramentas cienciométricas ajudam emergir, com maior ou menor êxito e precisão, as fronteiras de um campo de investigação, os limites de uma disciplina, as variações que afetam essas disciplinas, as relações de influência que tem lugar no curso da elaboração de uma informação. Ajudam emergir a partir de alguns indícios deixados por seus atores no curso de suas práticas, as redes que constituem os campos da ciência.

A terminologia, no entanto, continua sendo confusa, sem que os especialistas se coloquem totalmente de acordo. Não obstante, nos últimos anos estas técnicas são objeto de um interesse crescente entre a comunidade científica assim como no mundo industrial.

A Cienciometria se baseia nas análises e computo de determinados indicadores bibliométricos, como autores de artigos, 
citações que aparecem na bibliografia de cada artigo, palavras contidas nos títulos, resumos, textos, descritores e identificadores das publicações. 0 termo bibliometria é amplamente utilizado para quantificar os processos de comunicação escrita.

A bibliometria estaria então inserida na cienciometria, "... que nasce na confluência da documentação científica, a sociologia da ciência e a história da ciência, com objetivo de estudar a atividade científica como fenômeno social e mediante indicadores e modelos matemáticos" (Bordons; Zulueta, 1999, p. 791)

\subsection{INDICADORES BIBLIOMÉTRICOS}

Para Escorsa e Maspons, 2001, existem três grupos principais de indicadores, primeiro, os que mostram o tamanho e as características da produção científica ou tecnológica; segundo os que estudam o impacto das publicações, medido através das citações que recebem; e terceiro os que evidenciam os aspectos estruturais da ciência, que são os indicadores relacionais de primeira e segunda geração. Enquanto este último grupo serve para a elaboração dos mapas tecnológicos, os dois primeiros, denominados indicadores de atividade, constituem o núcleo em torno do qual se avalia a investigação.

0 indicador bibliométrico básico mais simples consiste na contagem do número de publicações de determinados grupos, instituições ou países e sua distribuição. A simples contagem dos elementos bibliográficos como, autores, organismos, revistas, artigos, empresas, patentes, temas, datas de publicação, é geralmente considerado como uma medida da produtividade deste elemento. Em cifras absolutas estes indicadores podem ser interessantes, pelas evoluções temporais destas medidas são sempre muito mais significativas. Conhecer a velocidade ou a 
aceleração que experimentam certos indicadores pode ser de capital importância na tomada de decisões.

o primeiro grupo de indicadores pode também se denominar indicadores de publicação e medem a qualidade e o impacto das publicações. (Spinak, 1998) No âmbito dos indicadores de publicações existem três leis básicas em bibliometria: (Dahal 1998, Sancho 1990)

- Lei de zipf que trata da freqüência da ocorrência de palavras no texto.

Esta lei, formulada claramente por George Kinsley Zipf, professor de lingüística da Universidade de Harvard, teve seus precursores nos trabalhos de Pareto e Estoup, respectivamente em 1896 e 1916, (Rousseau, 2002) afirma que "se as palavras que ocorrem, num texto de tamanho considerável, forem listadas em ordem decrescente de freqüência, então a graduação de uma palavra na lista será inversamente proporcional à freqüência da ocorrência da palavra".

- Lei de Lotka que trata da produtividade dos autores em termos de publicações científicas.

Esta lei afirma que a proporção de autores que contribuem com um único trabalho deve ser $60 \%$ do total de autores.

- Lei de Bradford que trata da distribuição dos artigos pelas diferentes revistas.

Em 1934 Bradford formulou uma lei empírica para literatura científica em periódicos nos seguintes termos: "Se revistas científicas são organizadas em ordem decrescente de produtividade de artigos em determinado assunto, eles podem ser divididos dentro de núcleos de periódicos mais dedicados ao assunto e vários grupos de áreas que contem o mesmo número de artigos como o núcleo". (Dahal, 1998) 
0 segundo grupo, os indicadores de citação, mede o impacto das relações entre as publicações científicas por meio das medidas de fator de impacto, análise de citações, análises de co-citações, índice de impacto, índice de auto citação entre outros.

Do terceiro grupo, os indicadores relacionais mais importantes são as citações comuns ou co-citações, as análises de colaboração científica e a co-ocorrência de palavras, "coword analysis". Em atenção à data em que se começou a utilizar estes indicadores, os primeiros são denominados indicadores relacionais de primeira geração enquanto que os segundos se chamam de segunda geração.

\section{3. "CO-WORD ANALISYS"}

A "co-word analysis" estuda a co-ocorrência de palavras, ou seja, a aparição conjunta de duas ou mais palavras representativas em campos como títulos de artigos ou de patentes, resumos de artigos, descritores e identificadores - palavraschave ou "key words" - códigos de classificação, reivindicações de patentes ou diretamente no texto livre. Os Descritores, objeto deste estudo, são palavras ou expressões utilizadas em indexação e tesauro para representar, sem ambigüidade, um determinado conceito. Por sua vez "tesauro", vem do latim "thesaurus", é uma palavra latina e foi empregada, a partir de 1500, para indicar um acervo ordenado de informações e conhecimentos.

Uma das primeiras obras a incluir esta expressão no seu título foi o "Thesaurus linguae romanae et britannicae", publicada em 1565, de autoria de Cooper. Em 1852 foi publicado por Peter Mark Roget, um estudioso do léxico, o "English Thesaurus of Words and Phrases", o qual reunia palavras pela 
ordem alfabética, de acordo com as "idéias que exprimiam, pelo seu significado". (Cavalcanti, 1978)

Mais especificamente, um tesauro atualmente reúne palavras escolhidas, destinadas à indexação e recuperação de documentos e dados num determinado campo de saber. Não é dicionário, nem vocabulário controlado. Trata-se de um instrumento que garante aos documentalistas e pesquisadores a padronização da linguagem documentária. (Bruschini et al, 2001)

Um tesauro distingue-se de um simples vocabulário controlado por duas características. A primeira é que as palavras nele listadas não descrevem, mas antes significam: cada palavra é um conceito. Sendo assim, essas palavras que designam conceitos não são mais simples palavras, tornam-se "termos", ou ainda "descritores". A segunda característica é que todos os termos estão relacionados entre si; nenhum termo pode figurar no tesauro sem estar relacionado a algum outro, sendo essa relação determinada pelo seu significado. (Fundação Carlos Chagas)

Em co-ocorrência de palavras a repetição de duas palavras juntas, por exemplo, indica também uma relação de proximidade entre elas. Isto é, os conceitos que representam estão estreitamente associados, enquanto que se nunca aparecem juntos, significa que estas palavras não têm pontos de contato, ou seja, estão distantes uma das outras. A repetição de duas palavras juntas com fraca intensidade, pode indicar a aparição de uma nova tecnologia ou de um novo agrupamento ou "cluster". (Escorsa e Maspons, 2001)

Segundo Robredo e Cunha em 1998, em um artigo que pode ser considerado como um clássico na matéria, Whitaker definia, em 1989, a análise da co-ocorrência de palavras, a "co-word analysis", "...como a utilização do 'comportamento' das palavras como um meio para elucidar as estruturas das idéias e outros problemas representados em conjuntos adequados de documentos". 
Além de Whitaker, pode-se encontrar na obra de Callon, Law e Rip em 1986, uma descrição bastante completa do desenvolvimento dos métodos de análise das co-ocorrências entre pares de palavras. Dentre os numerosos autores que nos últimos anos aplicaram a análise de co-ocorrência de palavras-chave ao estudo da situação ou da evolução de diversas áreas da ciência, merecem destaque, além dos já citados, Jean King em 1987, Leydesdorff em 1991, Callon, Courtial e Laville em 1991.

A co-ocorrência de palavras consiste, primeiramente, na detecção das palavras que caracterizam o conteúdo de determinados trabalhos sobre um tema e a contagem das aparições das palavras. Posteriormente verifica-se a co-ocorrência dessas palavras, ou seja, que palavras aparecem juntas e com que freqüência. os conceitos de proximidade ou distância entre essas palavras podem ser representados graficamente e constituem a base para a laboração dos "mapas tecnológicos".

Os mapas tecnológicos representam graficamente estas proximidades ou distâncias, dando uma visão da estrutura de relações que existe em um âmbito dado. À distância no mapa entre duas palavras, referentes a tecnologias, produtos, autores, empresas, assinala a maior ou menor relação entre elas. Esta proximidade pode ser quantificada mediante diversos índices e medidas e, graças a isto, visualizá-las graficamente por meio dos mapas tecnológicos.

Estes mapas mostram um panorama detalhado das linhas de investigação em uma área considerada, através da análise do que se está publicando ou patenteando. Tratados dinamicamente, ou seja, comparando mapas de diferentes períodos, permitem seguir a evolução, no tempo, das tecnologias e das linhas de investigação.

Como afirma Van Raan em 1993, a "...representação visual de grandes volumes de dados proporciona em pouco tempo um panorama completo que se recorda facilmente. Além disso, há uma 
redução da informação, o que é muito importante. Atualmente encontramos uma enorme quantidade de "ruído" em uma enorme quantidade de dados disponíveis. É crucial filtrar os dados significativos." Os mapas agregam os dados de uma forma que nenhum perito é capaz de fazer, dada a impossibilidade de assimilar a quantidade de informação disponível.

\section{Mapas baseados na "co-word analysis" ou co-ocorrência de palavras}

Os mapas baseados nas citações permitem detectar as áreas, "clusters" ou programas de investigação em que se subdivide um campo do conhecimento, mas não nos permitem entrar no conteúdo dos documentos. Para consegui-lo é indispensável abordar a análise de palavras, já que estas explicam o conteúdo dos próprios documentos. Com a "co-word analysis" e os mapas podemos visualizar a estrutura do conhecimento que há por trás do documento e o que o tornou possível.

0 método "co-word analysis" começa surgir em meados dos anos oitenta, a partir de um projeto francês desenvolvido pelo "Centre de Sociologie de l'Innovation (CSI) de l'École des Mines de Paris" e l'Institut National d'information Scientifique et Technique "(INIST) com a finalidade de processar os termos de indexação de Pascal, uma base de dados científica e multidisciplinar que agrupa os trabalhos de autores europeus, principalmente como Callon, Courtial e Laville em 1991. Como parte deste projeto também se desenvolveu uma ferramenta informática, o Leximappe que permitia desenvolver este tipo de análise de uma forma automatizada e confiável.

A técnica "co-word" não se limita estudar a co-ocorrência entre palavras, presta-se também ao estudo da co-ocorrência entre palavras e empresas, palavras e datas, palavras e códigos de classificação, isto é, entre os diversos campos de informação de uma base de dados. 
Os constantes avanços da informática têm favorecido o desenvolvimento de ferramentas estatísticas úteis para a cienciometria. Estão disponíveis no mercado, programas que agilizam as tarefas de processamento de documentos e multiplicam as possibilidades de análises, combinando múltiplos indicadores. (Dousset, 1999) Entretanto, especificamente para análise cienciométrica, existem até o momento, escassos programas informáticos.

Dentre os programas mais conhecidos temos, o Leximappe, Dataview e o Tétralogie, do Institut de Recherche Informatique (IRIT) de Toulouse. Estes três programas têm facilitado o processamento da informação e apresentação dos resultados, tanto para a geração de listas e matrizes, contagem simples, como para a análise da co-ocorrência das palavras, chegando inclusive à elaboração de mapas tecnológicos. (Maspons, 1996)

Assim, o principal objetivo deste trabalho é estudar 0 campo da ciência da saúde, no Brasil por meio de métodos de análise, devidamente validados, em avaliação de C\&T.

Demonstrar as etapas de trabalho, a potencialidade da "co-word analysis" e verificar se esta técnica de análise incrementa os resultados observados, com as técnicas bibliométricas, já tradicionalmente utilizadas, de maneira a poder qualificar as instituições, as disciplinas e os profissionais produtores do conhecimento técnico e científico, nas diferentes áreas que compõe este campo.

Discutir uma nova abordagem para a área, ampliando as análises bibliométricas tradicionais e consolidar no nosso meio científico a utilização dessa área de estudos quantitativos. Explorar as bases de dados também como um instrumento para desenvolver atividades de análise, enfatizando as possibilidades que este tipo de avaliação tem, para elevar o nível das 
informações, assim como para explorar as técnicas bibliométricas no gerenciamento de políticas e de tomadas de decisão. 


\section{4 - OBJETIVOS}

\subsection{OBJETIVO GERAL}

0 objetivo deste trabalho é avaliar a produção científica brasileira no campo da saúde e sua repercussão internacional no período de 1990 a 2002 .

\subsection{OBJETIVOS ESPECÍfICOS}

Analisar a produção científica no campo da saúde brasileira utilizando-se de indicadores bibliométricos, bem como estudá-la através da co-ocorrência de palavras-chave, descritoras do campo, com a finalidade de:

1- Responder o que é o campo do conhecimento no campo da saúde atualmente no país: estudar os indicadores de produção e impacto no tempo; qual a complexidade da produção científica no campo da saúde brasileira; quais os processos de geração e divulgação dessa produção; mecanismos da investigação científica enquanto atividade social. Os autores serão estudados como padrões de comportamento.

2- Demonstrar a potencialidade da técnica de "co-word analysis" e verificar de que forma ela complementa os resultados observados, com as técnicas bibliométricas tradicionalmente, utilizadas. 


\section{5 - MATERIAL E MÉTODOS}

\subsection{UNIVERSO DO ESTUDO:}

A pesquisa das publicações, indexadas, de autores brasileiros, no período de 1990 a 2002, foi realizada utilizandose duas bases de dados: ISI-Science Citation Index Expanded (SCIEXPANDED) e ISI-Social Sciences Citation Index (SSCI) ambas da Web of Knowledge, do Institute for Scientific Information (USA). Essas bases contem publicações indexadas a partir de 1945 e de 1956 respectivamente.

0 Institute for Scientific Information, (ISI) mantêm, hoje, a maior base de dados bibliográfica, multidisciplinar de informação em pesquisa do mundo. Esta base inclui mais de $8 \mathrm{mil}$ jornais e revistas em 164 áreas do conhecimento, indexando dados bibliográficos completos, referências citadas pelo autor e resumo. Dentre esses estão 15 revistas brasileiras. 0 ISI foi criado em princípios da década de sessenta por Eugene Garfield, discípulo de De Solla Price, na Filadélfia.

Os produtos e serviços do ISI incluem além de dados atualizados constantemente, citações retrospectivas indexadas, serviços ao usuário, informações em produtos químicos.

Estas bases de dados foram escolhidas para garantir uma padronização das informações visando à construção do banco de dados compatível com os pacotes estatísticos que foram utilizados na análise, ou seja, a base garante a obtenção de resultados em estruturas padrões, especialmente projetados para dados bibliométricos.

Foi utilizada a totalidade das informações disponíveis no campo da saúde, no período de 1990 a 2002 e foram definidas, para busca do tema a ser estudado, todas as áreas relacionadas que 
contem as publicações do campo. Para tal foram selecionadas as revistas indexadas que se distribuem entre as 50 áreas relacionadas ao campo da saúde, de acordo com a classificação ISI - De Luxe.

As revistas selecionadas para busca de dados, pertencem ao campo saúde, cujas áreas estão relacionadas no Quadro 1.

Quadro 1 - Áreas do Conhecimento - ISI

\begin{tabular}{|c|c|}
\hline 1- Anaesthesia e Intensive Care & 26- Medical Research, Diagnosis and Treatment \\
\hline 2- Biochemistry e Biophysics & 27- Medical Research, Organs and Systems \\
\hline 3- Biology & 28- Medical Research General Topics \\
\hline 4- Biotechnology e Applied Microbiology & 29- Microbiology \\
\hline 5- Cardiovascular e Hematology research & 30- Molecular Biology and Genetics \\
\hline 6- Cardiovascular e Respiratory System & 31- Neurology \\
\hline 7- Cell e Developmental Biology & 32- Neuroscience and Behavior \\
\hline 8- Chemistry & 33- Oncogenesis and Cancer Research \\
\hline 9- Chemistry e Analysis & 34- Oncology \\
\hline 10- Clinical Immunology e Infectious Disease & 35- Ophthalmology \\
\hline 11- Clinical Psychology e Psychiatry & 36- Orthopedics, Rehabilitation and Sport Medicine \\
\hline 12- Dentistry Oral surgery medicine & 37- Otolaryngology \\
\hline 13- Dermatology & 38- Pediatrics \\
\hline 14- Endocrinology, Metabolism e Nutrition & 39- Pharmacology and Toxicology \\
\hline 15- Endocrinology, Nutrition e Metabolism & 40- Physiology \\
\hline 16- Entomology Pest Control & 41- Psychiatry \\
\hline 17- Environment Ecology & 42- Psychology \\
\hline 18- Environmental Medicine e Public Health & 43- Public Health and Health Care Science \\
\hline 19- Experimental Biology & 44- Radiology, Nuclear Medicine and Imaging \\
\hline 20- Food Science Nutrition & 45- Rehabilitation \\
\hline 21- Gastroenterology and Hepatology & 46- Reprodutive medicine \\
\hline 22- General and Internal Medicine & 47-Research Lab.Medicine and Medical Technology \\
\hline 23- Health Care Science and services & 48- Rheumatology \\
\hline 24- Hematology & 49- Surgery \\
\hline 25- Immunology & 50- Urology and Nephrology \\
\hline
\end{tabular}

Algumas revistas estão indexadas em mais de uma área relacionada ao campo da saúde. Por este motivo, o total de revistas selecionadas somaram 3.543. Após terem sido identificadas duplicações, 477 revistas foram subtraídas e o arquivo final para busca contou com 3.066 revistas.

\subsection{BUSCA DE DADOS:}


Para padronizar a pesquisa na base de dados ISI, utilizou-se o mecanismo de busca "GENERAL SEARCH" tendo sido pesquisadas as 3.066 revistas nos campos: SOURCE TITLE/Fonte. A seleção de publicação para o país foi feita utilizando-se o campo "ADRESS"/Endereço, colocando-se o nome do país, "BRAZIL or BRASIL" e o período dessa busca foi fixado de 1990 a 2002, no campo "TIME"/Tempo. Com este critério definido, foi realizada a pesquisa das publicações brasileiras, no campo da saúde, no período fixado.

Resumo de busca: Source Title $=$ total das 3.066 revistas do campo da saúde e áreas relacionadas. Address=Brazil or Brasil; DocType=All document types; Language=All languages; Databases=SCI -EXPANDED，SSCI; Publication data $=1990 ， 1991 ， 1992$, 1993, 1994, 1995, 1996, 1997, 1998,1999,2000,2001 e 2002. (sorted by latest date)

\subsection{ANÁLISES BIBLIOMÉTRICAS}

Os pacotes estatísticos utilizados para este tipo de análise exigiram padrões rígidos na construção dos bancos de dados, sem os quais tornar-se-ia inviável o processamento e análise de cada variável. Os registros oriundos das duas bases pesquisadas passaram por um processo de correção e recodificação para obtenção de uniformidade na sua apresentação.

\subsubsection{TRATAMENTO DOS DADOS:}

Os dados obtidos foram submetidos a um tratamento onde foi fixado em 6 o número máximo de autores por artigo, conforme recomendam os requisitos de Vancouver (1997), para a inclusão de autores nas referências bibliográficas, bem como os respectivos endereços para a identificação de parcerias. Foi acrescentado um 
campo para registro do total de autores, campo (TA), de forma a garantir essa informação para a análise de freqüência de autores por artigo. Todos os dados migrados em plataforma Access, uma vez corrigidos e codificados, foram exportados para planilhas de Microsoft Excel de forma padronizada, dando origem às variáveis necessárias para a análise.

0 total de 38.349 registros desse banco de dados foi analisado por meio do Statistical Package for Social Science SPSS. Para estudar os indicadores de publicação e de citação, ou seja, o número médio de publicações por autor, por cidade, por ano, por área, número médio de referências, taxas de crescimento para as publicações entre outros, foram utilizadas técnicas de extensão bibliométrica e técnicas de análise de citações. Aplicou-se a lei do quadrado inverso, Lei de Lotka, para verificar a contribuição dos autores. Para estudar a distribuição dos artigos pelas diferentes revistas, aplicou-se a lei de dispersão, de Bradford. Técnica de análise de "cluster" foram utilizadas para estudar os padrões da produção científica brasileira.

\section{4. "CO-WORD ANALYSIS"}

o software utilizado para as análises de "co-word" também exigiu padrões rígidos na construção de um arquivo a partir das informações obtidas. Para este grupo de análises foi utilizado o software "Tétralogie". Este software foi desenvolvido pelo Institut de Recherche Informatique (IRIT) de Toulouse, França. Seu idealizador foi o pesquisador Bernard Dousset.

\subsubsection{TRATAMENTO DOS DADOS PARA A "CO-WORD ANALYSIS"}


As informações obtidas das bases de dados, em formato html (Hyper Text Markup Language), foram migradas para um arquivo em formato texto (ASCII). Foram selecionados somente dados de interesse para o trabalho e como exemplo, um registro do arquivo em formato de texto (txt), é demonstrado na sua íntegra no quadro 2 abaixo, onde:

AU1...AU6- nome de autor da publicação; TA- total de autores por publicação; TI- título; so- fonte, revista; LAidioma; DT- tipo de arquivo; NR- número de referências; ISSNnúmero de identificação internacional da revista; PU- editor; C01...C06- endereço de autores; DE- descritores; IDidentificadores; TC- número de citações recebidas; BP- número da primeira página; EP- número da última página; P- páginas; PY-ano de publicação; PD- mês de publicação; VL- Volume; RV- dados da localização da publicação na revista; PI- informações da editora.

Quadro 2 - Exemplo de registro do arquivo em formato texto.

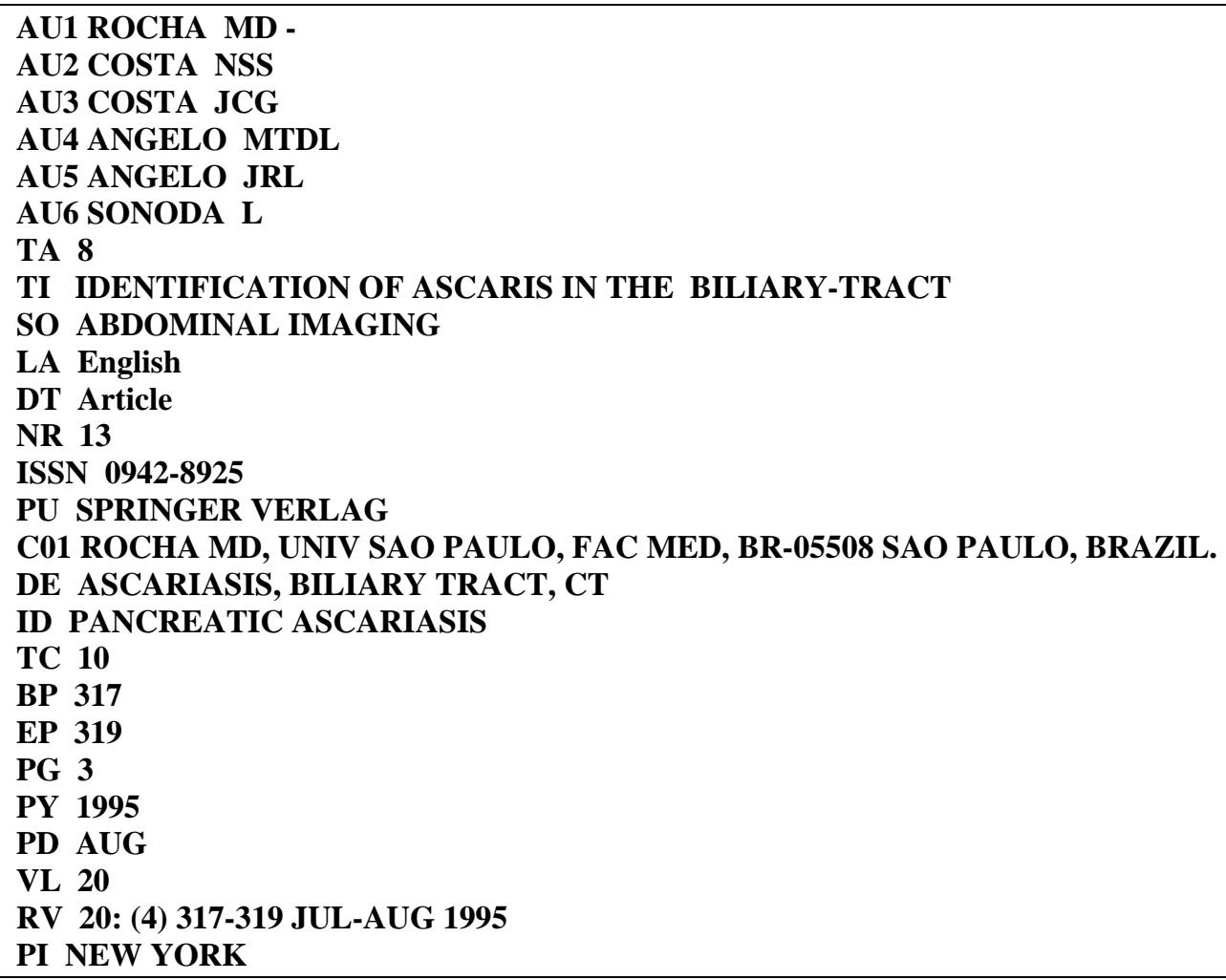


Para a contagem, identificação e análise de palavraschave - que se refere ao campo conceitual no qual a publicação se enquadra - foi utilizado o software "Tétralogie". Utilizou-se a metodologia de "Co-word Analysis" que permite observar a freqüência da ocorrência de palavras isoladamente e detectar palavras que aparecem juntas freqüentemente nas publicações, evidenciando uma proximidade.

A partir dessas análises é possível visualizar a informação em forma de mapas e agregá-la, utilizando técnicas de análise hierárquica. Com este software é possível, além de contar autores, instituições e publicações, analisar colaborações entre autores, entre autores e instituições, instituições e palavraschave, autores e palavras-chave, entre outras. Isto nos possibilita compreender com detalhe a estrutura da atividade científica.

o Tétralogie (mimeo 1997) supõe que a fase de obtenção de dados foi realizada, que os dados estejam disponíveis e que se investigará um tema. Supõe também que a fonte de informação é conhecida e que sua descrição está disponível. Quando os dados provêm de uma base de dados não estruturada e existe o interesse de estudar um campo texto completo, dentro de uma base de dados estruturada (Título, Abstract ou Descritores ou Identificadores) o pacote Tétralogie dispõe de uma fase de Pré-tratamento, com modelos Estatísticos e modelos Morfológicos. A versão utilizada neste trabalho ainda não incorpora modelos lingüísticos, semânticos (análises dos diferentes sentidos de uma palavra) e sintáticos (relações entre palavras por seu significado), os quais permitiriam um tratamento mais completo de documentos em formato texto, mas não foram objeto do presente estudo. No Tétralogie o processo de tratamento da informação se dá como no esquema 1. 
Esquema 1 - Metodologia de trabalho do Software TÉTRALOGIE

Fonte: (Dousset e Dkakis, 1997)

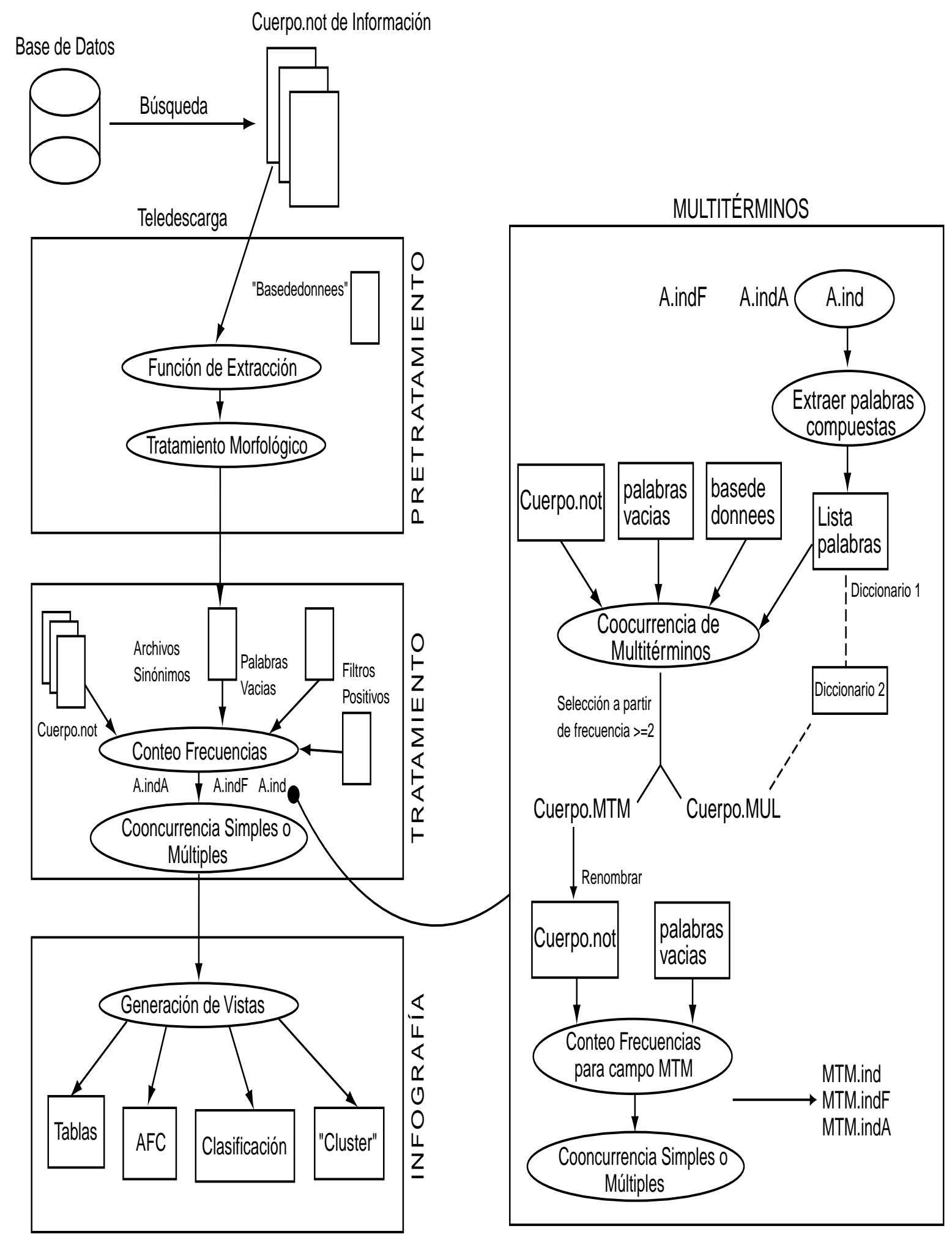




\subsection{PROCESSO DE TRATAMENTO DA INFORMAÇÃO}

\subsubsection{PRÉ-TRATAMENTO DOS DADOS}

Esta etapa compreende analisar dados a partir do corpo de informação oriunda do arquivo em formato texto, contando 38.349 registros, base do estudo cienciométrico em questão, elaborado a partir dos registros obtidos de uma ou de várias bases de dados.

Esses registros foram unificados, as duplicidades foram eliminadas e os campos foram renomeados entre outras operações. Este arquivo junto com uma nova estrutura da base de dados, a "basededonnées", permitirá iniciar o processo de tratamento da informação .

\subsubsection{ESTRUTURA DA "BASEDEDONNEES"}

Para que o programa lesse o arquivo texto, foi necessário alimentá-lo com uma espécie de roteiro das informações, denominado "Basededonnées". Trata-se de arquivo criado a partir das informações contidas no arquivo em formato texto, para descrever a estrutura dos campos da base de dados e isolar a informação pertinente aos campos de interesse para o estudo, mediante a identificação e uso dos separadores. A seguir observa-se um exemplo de alguns campos na "Basededonnées", utilizada para o processamento do banco de dados.

Basededonnées para o processamento do banco de dados.

\section{Exemplo:}




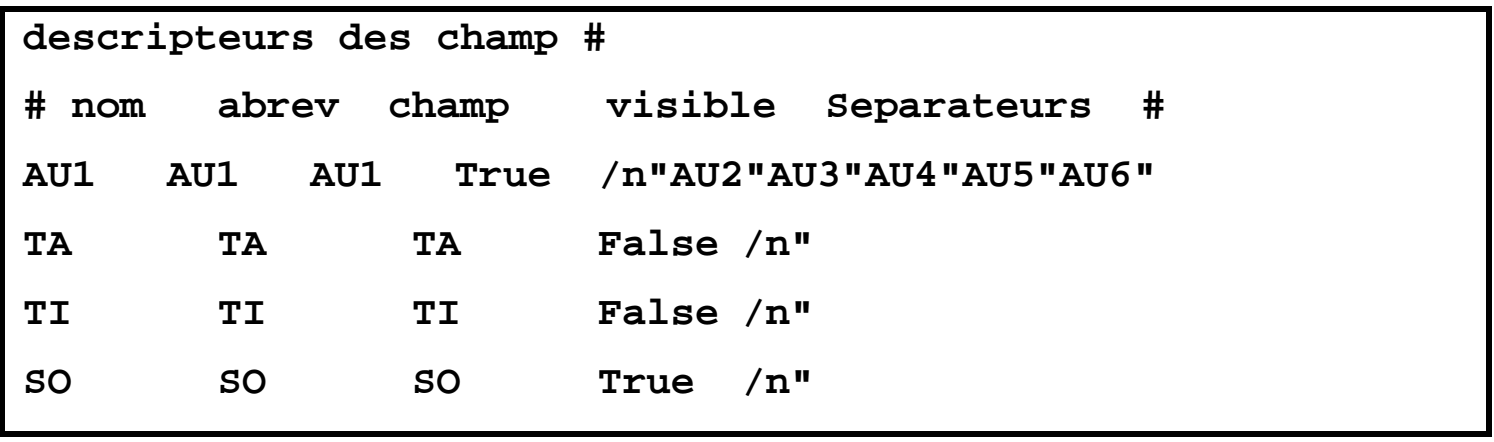

0 arquivo da "basededonnées" pode sofrer modificações sucessivas de acordo com as necessidades que surjam durante a etapa de tratamento e os objetivos da análise. Após a definição do corpo de informações a serem tratadas, a primeira etapa de análise ou de pré-tratamento foi a extração dos dados e a primeira contagem simples de freqüências de palavras, a partir da qual criaram-se os dicionários de sinônimos. Foram realizadas contagens simples para alguns campos como os que continham os descritores, identificadores, autores, instituições, fonte e ano de publicação os resultados foram expressos em arquivos que podem ser visualizados com um software editor de texto chamado UEDIT32 - UltraEdit-32 - Professional Text/Hex Editor (IDM Computer Solutions, Inc.)

Por meio das análises realizadas obtivemos, inicialmente, uma contagem de 42.233 diferentes descritores e 41.281 diferentes identificadores, distribuídos entre os 38.349 registros do banco de dados. Os arquivos gerados nessa contagem contem as palavras encontradas nos artigos e pode apresentar-se em ordem alfabética ou de freqüência de aparições, como mostra o exemplo a seguir, referente à freqüência de descritores onde, "BRAZIL" é a primeira palavra mais encontrada e "DAY-CARE SURGERY" finaliza a lista de 42.233 descritores, com uma ocorrência.

Exemplo de arquivo de descritores e sua respectiva freqüência 


\begin{tabular}{|ll|}
\hline FREQ. & DESCRITORES \\
\hline 721 & BRAZIL \\
\hline 360 & EPIDEMIOLOGY \\
\hline 202 & NITRIC OXIDE \\
\hline 201 & RAT \\
\hline 187 & TRYPANOSOMA CRUZI \\
\hline 121 & HYPERTENSION \\
\hline 114 & RATS \\
\hline 112 & RISK FACTORS \\
\hline 111 & ULTRASTRUCTURE \\
\hline 109 & CYTOKINES \\
\hline 108 & INFLAMMATION \\
\hline 103 & FISH \\
\hline 101 & DIAGNOSIS \\
\hline 101 & ANXIETY .. até... \\
\hline 1 & "DAY-CARE" SURGERY \\
\hline
\end{tabular}

Uma das fases, extremamente importante, desta etapa de pré-tratamento é a de Tratamento Morfológico. Esta é uma função que permite a equiparação de palavras ou a criação de sinônimos para as palavras. Depois de criado o dicionário de sinônimos, cria-se os demais arquivos que são os filtros. 0 software prevê uma forma automática de dicionários, porém insuficiente para os problemas encontrados. Desta forma, estes sempre devem ser revisados e ajustados, como no exemplo a seguir.

Tratamento Morfológico e Sinônimos para os Descritores

\begin{tabular}{|l|l|}
\hline DESCRITORES & SINÔNIMOS \\
\hline IMMUNODEFICIENCY VIRUS & HIV/AIDS \\
\hline BRAZIL & BRAZIL \\
\hline BR- & BRAZIL \\
\hline APOPTOSIS & APOPTOSIS \\
\hline T CELL APOPTOSIS & APOPTOSIS \\
\hline MACROPHAGE APOPTOSIS & APOPTOSIS \\
\hline IMMUNOMODULATION AND APOPTOSIS & APOPTOSIS \\
\hline INDUCED APOPTOSIS & APOPTOSIS \\
\hline AIDS & HIV/AIDS \\
\hline HIV/AIDS & HIV/AIDS \\
\hline IMPACT OF AIDS & HIV/AIDS \\
\hline
\end{tabular}




\begin{tabular}{|l|l|}
\hline RESPONSES TO AIDS & HIV/AIDS \\
\hline
\end{tabular}

Após tratamento com filtros de sinônimos, os novos arquivos apresentaram uma listagem por ordem de freqüência de todas as palavras presentes nos campos, a serem estudados, sem duplicações. 0 arquivo de descritores passou a contar com 39.455 palavras enquanto o de identificadores foi de 40.160. 0 produto inicial da contagem realizada para o campo de autores continha 148.971 registros, com os autores das publicações registrados no banco de dados, até o sexto autor. Neste caso, além das duplicações, em alguns registros as informações presentes no campo endereço, devido sua formatação original na base de dados, "invadiram" o campo de autores. Após a retirada de dados não pertinentes e tratamento morfológico este campo livre de duplicações e interferências somou 73.644 autores.

Desta forma foram realizadas as análises e os cruzamentos necessários para o estudo dos indicadores bibliométricos desejados. 0 mesmo procedimento foi realizado para todas as informações contidas nos diferentes campos de interesse para o estudo.

\subsubsection{TRATAMENTO DOS DADOS}

A simples contagem permitiu análises estatísticas dos diferentes campos objeto do estudo. Uma segunda contagem dos arquivos listados por freqüência, desta vez com os arquivos de filtros e sinônimos, geraram novos arquivos que foram utilizados na etapa das análises de "co-word".

Algumas das análises realizadas foram feitas por amostragem, a saber: dos descritores e dos identificadores foram selecionadas $1 \%$ das palavras de maior ocorrência respectivamente, 39.455 e 40.160 palavras. Para autores foi fixado um mínimo de 3 
publicações no período estudado; e as análises de "clusters", um mínimo de 10 publicações no período.

Para as etapas de Pré-tratamento e Tratamento é muito importante o critério dos peritos nas áreas do conhecimento, objeto do estudo. Da qualidade dos dicionários, filtros, sinônimos, palavras vazias, multitermos, dependerá a qualidade das análises e interpretações posteriores.

\subsection{MATRIZES E MAPAS TECNOLÓGICOS}

Nesta fase de elaboração dos mapas tecnológicos, foram utilizadas matrizes com os resultados da co-ocorrência de palavras, geradas do cruzamento das variáveis estudadas e com as devidas aplicações de dicionários, filtros e sinônimos.

\section{- Matrizes}

As matrizes oriundas das análises de cruzamentos das informações desejadas, permitiram organizar, transformar e refinar os dados, por meio das eliminações de duplicidades ou aplicando-se operações matemáticas nas linhas ou colunas quando a tabela original se apresentava muito dispersa. Os dados das tabelas são representados nas linhas, pelos indivíduos e nas colunas pelas variáveis relativas a cada indivíduo. As variáveis podem ser quantitativas (valores absolutos) ou qualitativas (valores relativos).

As tabelas podem receber diferentes formas de ordenação da informação de modo a conseguir melhores resultados das análises de cruzamento dos dados. As formas de ordenação utilizadas foram por afinidade bem como, por consistência de colunas e linhas. Outro recurso disponível no software, é a ordenação por ordem alfabética, dos indivíduos ou variáveis. A 
ferramenta de "Zoom" permite visualizar a qualidade da estrutura das ordenações obtidas e os "Histogramas" explicam a intensidade das relações entre linhas e colunas.

\section{- Mapas tecnológicos}

Os mapas tecnológicos são mapas fatoriais que resultaram das transformações matemáticas das tabelas ou da aplicação de métodos estatísticos integrados ao software conforme explicamos a seguir.

\subsubsection{MÉtOdOS ESTATÍSTICOS INTEGRAdOS AO SOFTWARE "TÉTRALOGIE" UTILIZADOS NAS ANÁLISES DE "CO-WORD"}

- Análise dos Componentes Principais (ACP)

É um método de análise de dados que permite identificar os eixos principais de uma nuvem de pontos. Quando os dados são da mesma natureza, cruzamento de autor-autor, por exemplo, foi utilizada a métrica euclidiana. Se dois indivíduos aparecem próximos no mapa, sua proximidade encontrará uma explicação no círculo de correlação, com a posição das variáveis no mesmo setor, correlação positiva ou no setor oposto, correlação negativa.

- Análise dos Componentes Principais Reduzida (ACPR)

Este método foi utilizado para normalizar os dados e equilibrar as variáveis analisadas. A redução dos dados permitiu considerar as variáveis de menor valor absoluto.

\section{- Análise Fatorial de Correspondência (AFC)}

Este método também permite identificar os eixos principais de uma nuvem de pontos, é realizado sobre os valores relativos dos dados, é recomendado para parâmetros qualitativos. No mesmo mapa podem ser visualizados tanto os indivíduos como as 
variáveis. À distância entre um indivíduo e uma variável é interpretada como uma relação de proximidade e de dependência. Aplica-se como método de análise tanto em tabelas de contingência como a matrizes de cruzamento.

\section{- Classificação Hierárquica Ascendente (CHA)}

Esta classificação gera uma árvore plana que se pode cortar a diferentes níveis para determinar as classes mais ou menos extensas e numerosas. Estas classes são obtidas mediante a agregação dos elementos mais próximos, distância mínima, considerados como uma mesma classe. A métrica utilizada também é a euclidiana.

\subsection{LIMITAÇÕES DO ESTUDO}

Não obstante a qualidade das informações pesquisadas nas bases do ISI e desta ser um dos mais importantes sistema de informações referente à produção bibliográfica em âmbito internacional, é necessário reconhecer que é limitada em sua abrangência geográfica, além de ter rígidos critérios de inclusão de revistas.

Para Garfield, criador da base de dados ISI, a seletiva cobertura oferecida pela base, não é devido tão somente a motivos econômicos, mas, ao fato de que, em algumas áreas do conhecimento, as revistas realmente importantes que são lidas e citadas, são relativamente pouco numerosas, refletindo os preceitos da Lei de Bradford.(Pellegrini Filho e Goldbaum, 1997) Grande parte das publicações brasileiras está registrada em periódicos não indexados na base ISI, especialmente em determinadas áreas do conhecimento mais direcionadas a temas do interesse nacional. 
Assim, a produtividade científica brasileira é, em parte, prejudicada, mas esta base foi escolhida porque apesar de representar um corte dessa produção, apresenta as publicações de grande impacto e maior repercussão. Também colabora para as limitações o fato de haver outras formas de produção científica e bibliográfica além da publicação de artigos em periódicos. As formas de divulgação dos resultados da produção científica variam segundo áreas do conhecimento, de modo que a contabilização destes resultados, limitada ao número de artigos publicados, introduz um viés em seu cálculo, privilegiando algumas destas áreas em detrimento de outras.

0 motivo de não termos utilizado os dados de fontes específicas para publicações da América Latina e Caribe, como a base LILACS em Ciências da Saúde bem como, bases de reconhecimento mundial neste campo como a Medline, deve-se ao fato destas não oferecerem as informações importantes para este estudo, como os indicadores de impacto das publicações, por exemplo o número de citações por artigo. Modelo semelhante ao sistema de informação da "web of Knowledge" é o SciELo que, no entanto, teve seu início em 1997.

Desta forma, fica registrado que não se estudou 0 universo da produção científica brasileira na área da saúde e que se admite algumas limitações no que tange à adequada mensuração dessa produção.

Em função dos objetivos deste trabalho, apresentaremos os resultados obtidos por meio das análises bibliométricas tradicionais, com o auxílio do software Statistical Package for Social Science - SPSS.

A "co-word analysis" será apresentada de forma a evidenciar o potencial de análises e resultados que este tipo de ferramenta pode oferecer, mostrando exemplos com as diferentes variáveis estudadas. 


\section{6 - RESULTADOS E DISCUSSÃO}

\subsection{ANÁLISES BIBLIOMÉTRICAS}

\subsubsection{INDICADORES DE PRODUÇÃO E IMPACTO NO TEMPO}

$\mathrm{Na}$ tabela 1 e gráfico 1, a produção intelectual na área da Saúde no Brasil, reflete o número de publicações distribuídas entre 3.066 revistas pesquisadas, de diversas áreas do conhecimento relacionados com o campo da saúde e de acordo com os registros da base de dados da ISI, "web of Knowledge", num período estudado de 13 anos, de 1990 a 2002.

Tabela 1 - Número de publicações brasileiras, registrados na base de dados da "web of Knowledge", no período de 1990 a 2002, no campo da saúde.

\begin{tabular}{c|ccc}
\hline Ano & Freqüência & Percentual & $\begin{array}{c}\text { Percentual } \\
\text { Cumulativo }\end{array}$ \\
\hline 1990 & 1111 & 2,9 & 2,9 \\
1991 & 1242 & 3,2 & 6,1 \\
1992 & 1334 & 3,5 & 9,6 \\
1993 & 1396 & 3,6 & 13,3 \\
1994 & 1638 & 4,3 & 17,5 \\
1995 & 2162 & 5,6 & 23,2 \\
1996 & 2772 & 7,2 & 30,4 \\
1997 & 3092 & 8,1 & 38,5 \\
1998 & 3718 & 9,7 & 48,1 \\
1999 & 4278 & 11,2 & 59,3 \\
$200 \odot$ & 5190 & 13,5 & 72,8 \\
2001 & 4607 & 12,0 & 84,9 \\
2002 & 5809 & 15,1 & $10 \odot$ \\
\hline & & & 100 \\
\hline
\end{tabular}

Os resultados encontrados evidenciam que a produção científica em saúde no Brasil cresceu a uma taxa anual média de 14,98\% nesse período. Em termos comparativos, no curto intervalo de duas décadas, entre 1981 e 2000, o Brasil passou da 28 ${ }^{\mathrm{a}}$ para $17^{\mathrm{a}}$ posição no ranking mundial de produção de ciência. Nesta 
posição, o Brasil está à frente da Bélgica, Escócia e Israel, entre outros, e bem próximo da coréia do Sul, Suíça, Suécia, Índia e Holanda. (IBICT 2004)

Gráfico 1 - Crescimento da produção científica brasileira, registrado na base de dados da "web of Knowledge", no período de 1990 a 2002, no campo da saúde.

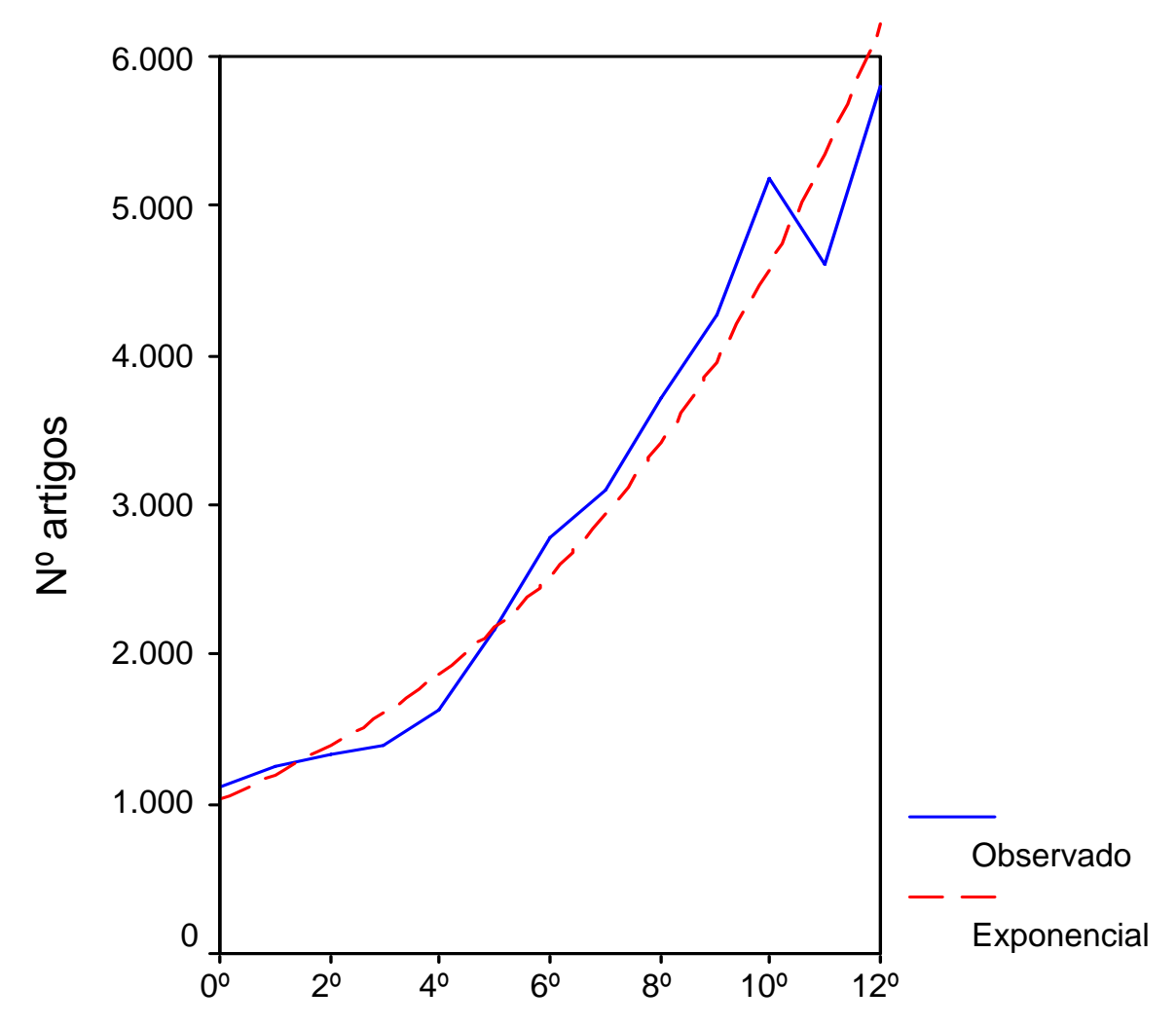

Ano

\subsubsection{Impacto das publicações no tempo - Citações por ano}

A busca do reconhecimento entre os pares na carreira de pesquisadores e cientistas é percebida com seriedade. A citação na ciência é um veículo de comunicação, onde os diálogos se dão de forma não presencial, podem ser considerados "a teia invisível ou virtual da ciência" a qual é responsável pela disseminação da ciência. 
Os diálogos entre cientistas e pesquisadores vêm sendo estudados desde os anos 50 através das chamadas redes de comunicação científica. No entanto, a proliferação destes estudos deu-se a partir da década de 60 com Derek de Solla Price, que pesquisou a mensuração da literatura científica através das análises de citações. Nessas análises percebe-se que a ciência é construída por meio de diálogos estabelecidos entre o autor citado e aquele que o cita; outro aspecto relevante abordado é o direcionamento evolutivo da ciência e tecnologia.(Pinto e Lima, 2002)

Tabela 2 - Número de citações em artigos brasileiros, no campo da saúde, registrados na base de dados da "web of Knowledge", no período de 1990 a 2002.

\begin{tabular}{c|ccc}
\hline Ano & $\begin{array}{c}\text { No. de } \\
\text { Citações }\end{array}$ & $\begin{array}{c}\text { No. de } \\
\text { Artigos }\end{array}$ & $\begin{array}{c}\text { Média de } \\
\text { citação por } \\
\text { artigo }\end{array}$ \\
\hline 1990 & 8524 & 1111 & 7,67 \\
1991 & 10759 & 1242 & 8,66 \\
1992 & 10395 & 1334 & 7,79 \\
1993 & 11813 & 1396 & 8,46 \\
1994 & 12302 & 1638 & 7,51 \\
1995 & 13177 & 2162 & 6,09 \\
1996 & 13541 & 2772 & 4,88 \\
1997 & 11376 & 3092 & 3,68 \\
1998 & 10788 & 3718 & 2,9 \\
1999 & 7445 & 4278 & 1,74 \\
2000 & 11135 & 5190 & 2,15 \\
2001 & 5848 & 4607 & 1,27 \\
2002 & 1560 & 5809 & 0,27 \\
\hline
\end{tabular}

De acordo com a tabela 2 e gráfico 2, a análise das citações para os artigos brasileiros, publicados no período, revela que enquanto o número de artigos aumenta, o número de citações é mais ou menos estável com valores que variam entre 8 e 13 mil citações por ano. Em conseqüência a taxa média de citação por artigo diminui.

Os valores encontrados para os anos de 2001 e 2002 necessitam um período maior de tempo para inferirmos algum 
julgamento, porque o número de citações das publicações mais recentes é menor, pois estas necessitam de tempo para serem citadas.

Gráfico 2 - Curva das publicações e citações no campo da saúde, registrados na base de dados da "web of Knowledge", no Brasil, no período de 1990 a 2002.

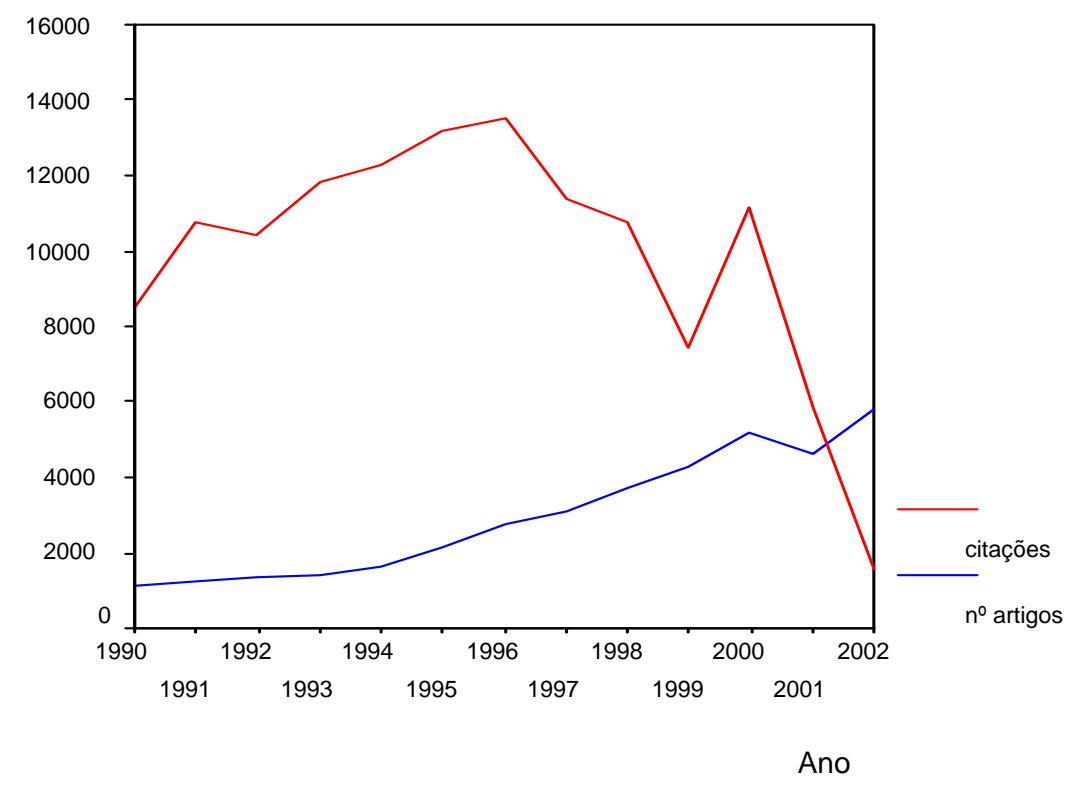


Gráfico 3 - Tendência de citações por ano, para publicações brasileiras, no campo da saúde, registrados na base de dados da "web of Knowledge", no período de 1990 a 2002.

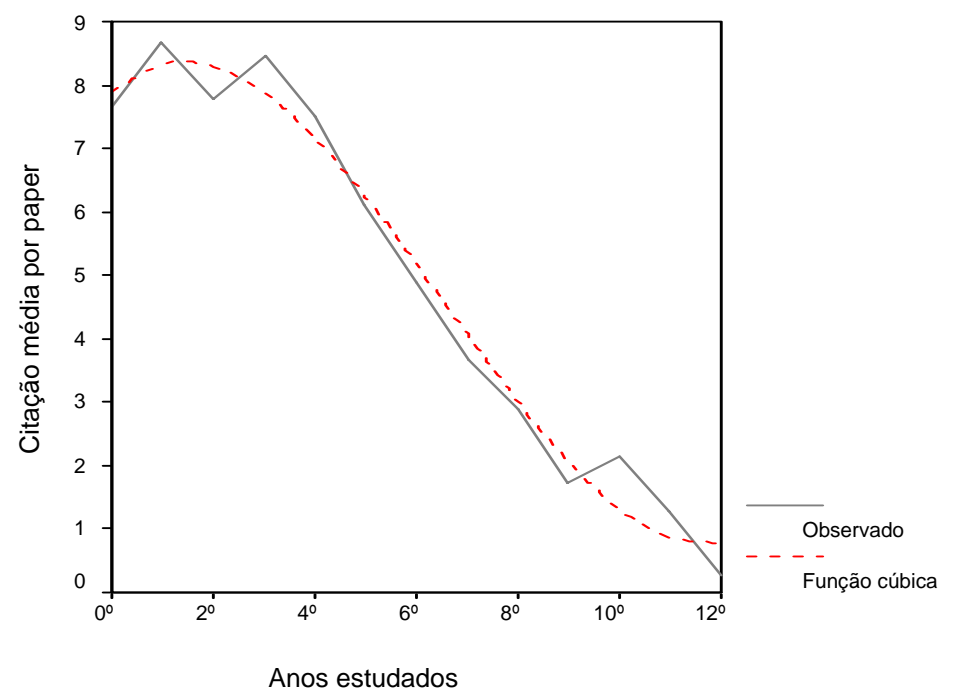

A taxa de citação, gráfico 3, para os artigos brasileiros publicados na área da saúde, mostra tendência de diminuição de ๑,56 citações por artigo a cada ano, para o período estudado. Ainda assim, embora a publicação de King em 2004, na revista "Nature", refira-se a todas as áreas do conhecimento, seu artigo mostra que apenas 31 países, incluindo 0 Brasil, estão representados no $1 \%$ dos mais importantes artigos científicos, ou seja, aqueles que foram os mais citados por outros cientistas. Isto significa o impacto ou a visibilidade das publicações dentro de uma comunidade científica.

Enquanto o aumento do número de artigos publicados num determinado período, significa o crescimento do campo da ciência, o envelhecimento dos campos científicos, podem ser observados segundo a vida média das referências de suas publicações. (Sancho, 1990)

Podemos inferir que a queda no número de citações pode significar o esgotamento de determinada área e ainda assim, é 
verificado um aumento de produção ou se a qualidade da produção científica em algumas áreas não corresponde ao desejado.

\subsubsection{COMPLEXIDADE: No MÉDIO DE AUTORES POR ARTIGO}

Gráfico 4 - Curva da média de autores, para publicações brasileiras, no campo da saúde, registrados na base de dados da "web of Knowledge", no período de 1990 a 2002.

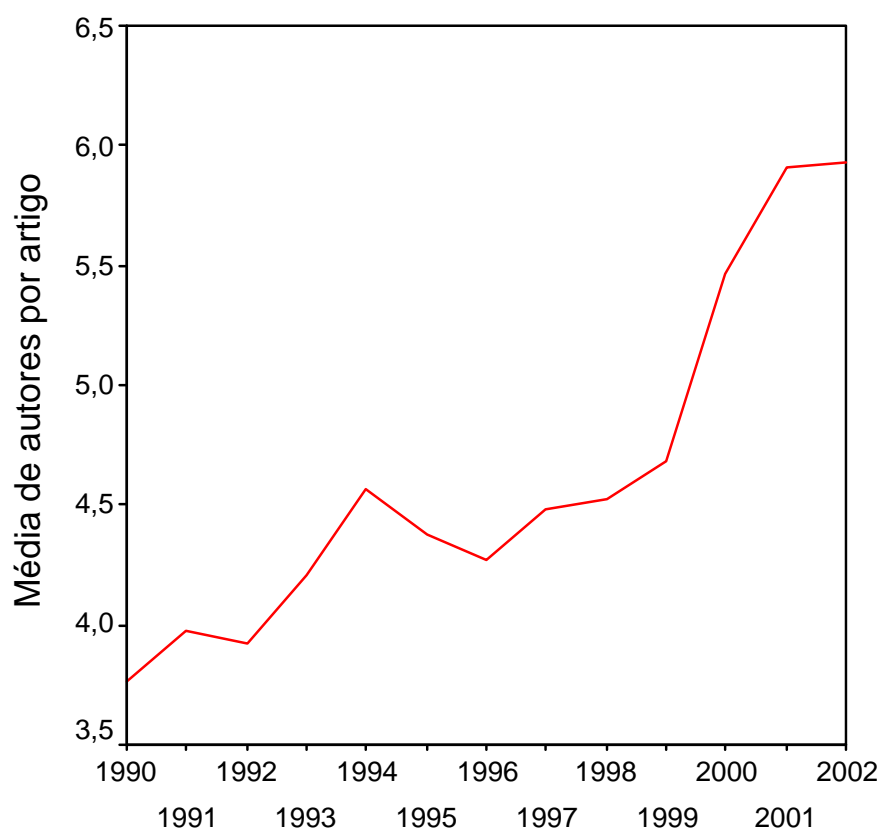

Ano Publicação

Segundo resultados apontados nos gráficos 4 e 5 e nas tabelas 3 e 4, se o número de autores necessários para um artigo pode indicar a complexidade de um estudo, podemos dizer, de acordo com os dados recuperados da base de dados da ISI, que a complexidade dos trabalhos científicos tem aumentado. 0 número médio de autores por artigo cresceu de 3,7 autores para 5, 9 aproximadamente, no período estudado. Este número também pode indicar a busca de melhor desempenho, ou seja, a necessidade de conjugar esforços financeiros e competência técnica e científica, conseqüentemente aumentando o grau de parcerias, rumo a maior 
produtividade e competitividade, que por sua vez facilitam a obtenção de recursos para o financiamento de pesquisas.

Gráfico 5 - Curva do Percentual de publicações com colaboração, no campo da saúde, no Brasil, registrados na base de dados da "web of Knowledge", no período de 1990 a 2002.

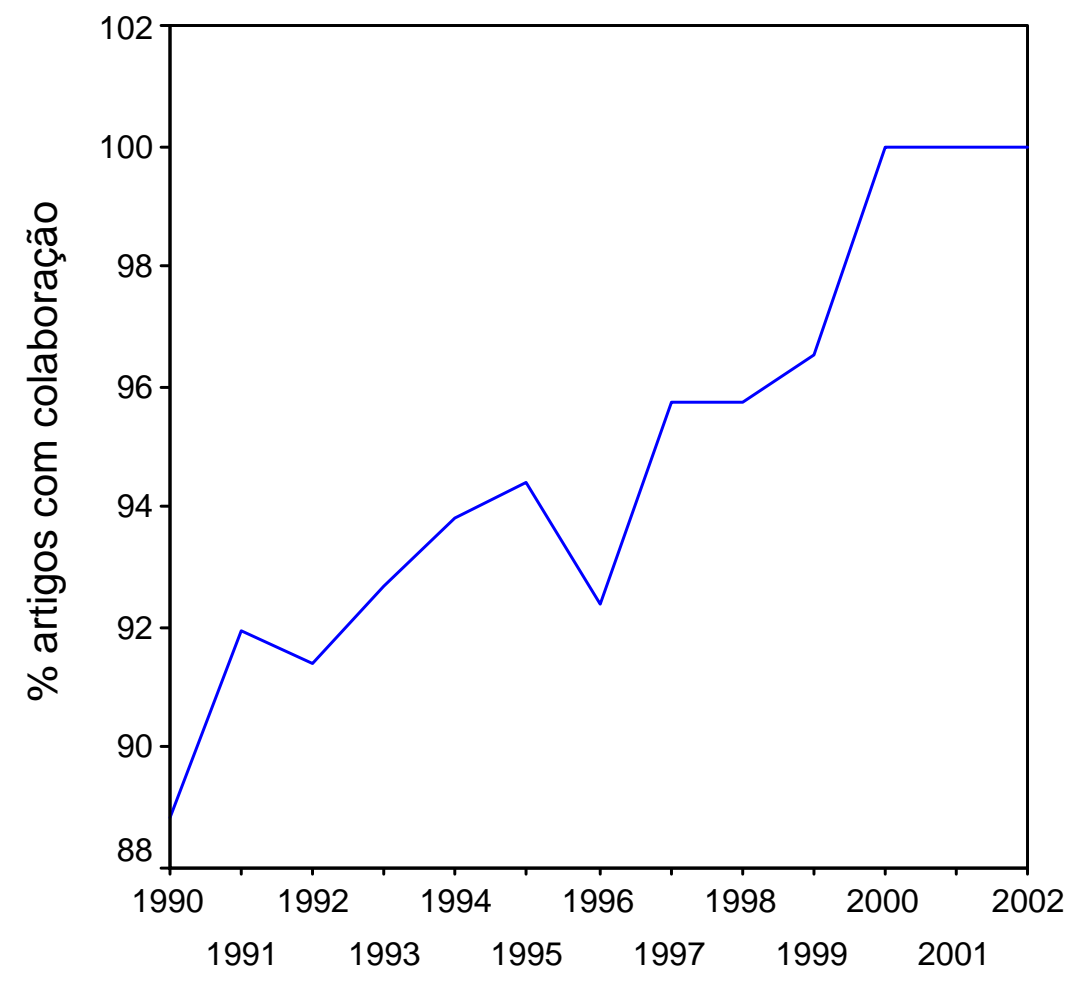

Ano Publicação

A tabela 3 mostra que a colaboração entre autores concentra, até 10 autores, um percentual de 96,75\% dos artigos publicados no período, sendo maior o número de artigos com 2 a 6 autores. Publicações com mais de 10 autores significam apenas 3,15\% dos artigos, com 1 autor, somente 3,4\% dos artigos foram realizados sem colaboração.

Tabela 3 - Número de autores por publicação, no Brasil, no campo da saúde, registrados na base de dados da "web of Knowledge", no período de 1990 a 2002. 


\begin{tabular}{c|cc}
\hline $\begin{array}{c}\text { No. de } \\
\text { Autores }\end{array}$ & $\begin{array}{c}\text { No. de } \\
\text { Publicações }\end{array}$ & $\begin{array}{c}\% \\
\text { Publicações }\end{array}$ \\
\hline 1 & 1310 & $3,4 \%$ \\
2 & 4230 & $11,0 \%$ \\
3 & 6538 & $17,0 \%$ \\
4 & 7170 & $18,7 \%$ \\
5 & 6103 & $15,9 \%$ \\
6 & 4694 & $12,2 \%$ \\
7 & 3264 & $8,5 \%$ \\
8 & 1885 & $4,9 \%$ \\
9 & 1164 & $3,2 \%$ \\
10 & 741 & $1,9 \%$ \\
Sub total & $\mathbf{3 7 . 0 9 9}$ & $\mathbf{9 6}, \mathbf{7 5} \%$ \\
$>10$ & 1208 & $3,15 \%$ \\
0 & 42 & $0,10 \%$ \\
\hline Total & $\mathbf{3 8 . 3 4 9}$ & $\mathbf{1 0 0 \%}$ \\
\hline
\end{tabular}

Tabela 4 - Distribuição anual das publicações brasileiras, com um autor e com colaboração, no campo da saúde, registrados na base de dados da "web of Knowledge", no período de 1990 a 2002.

\begin{tabular}{|c|c|c|c|c|c|}
\hline \multirow[b]{2}{*}{ Ano } & \multicolumn{2}{|c|}{ Um único autor } & \multicolumn{2}{|c|}{ Com colaboração } & \multirow{2}{*}{$\begin{array}{c}\text { Total } \\
\text { Publicações }\end{array}$} \\
\hline & Publicações & $\%$ & Publicações & $\%$ & \\
\hline 1990 & 124 & $11,20 \%$ & 986 & $88,80 \%$ & 1110 \\
\hline 1991 & 100 & $8,10 \%$ & 1140 & $91,90 \%$ & 1240 \\
\hline 1992 & 115 & $8,60 \%$ & 1219 & $91,40 \%$ & 1334 \\
\hline 1993 & 102 & $7,30 \%$ & 1292 & $92,70 \%$ & 1394 \\
\hline 1994 & 101 & $6,20 \%$ & 1536 & $93,80 \%$ & 1637 \\
\hline 1995 & 121 & $5,60 \%$ & 2037 & $94,40 \%$ & 2158 \\
\hline 1996 & 210 & $7,60 \%$ & 2557 & $92,40 \%$ & 2767 \\
\hline 1997 & 132 & $4,30 \%$ & 2953 & $95,70 \%$ & 3085 \\
\hline 1998 & 157 & $4,20 \%$ & 3546 & $95,80 \%$ & 3703 \\
\hline 1999 & 148 & $3,50 \%$ & 4125 & $96,50 \%$ & 4273 \\
\hline 2000 & $\odot$ & $\odot, \odot \odot \%$ & 5190 & $100,00 \%$ & 5190 \\
\hline 2001 & $\odot$ & $\odot, \odot \odot \%$ & 4607 & $100,00 \%$ & 4607 \\
\hline 2002 & $\odot$ & $\odot, \odot \odot \%$ & 5809 & $100,00 \%$ & 5809 \\
\hline
\end{tabular}


A tabela 4 evidencia a distribuição das publicações com e sem colaboração, por ano. Os artigos com colaboração são responsáveis por $88,80 \%$ das publicações no ano de 1990 e num crescimento constante chega a $100 \%$ de 2000 a 2002 . Vale lembrar que em $\odot, 1 \%$ do total das publicações no período não constam autores, o que pode ocorrer quando as publicações são institucionais.

\subsubsection{LEI DE LOTKA}

Tabela 5 - Distribuição do número de autores brasileiros, segundo número de publicações, no campo da saúde, registrados na base de dados da "web of Knowledge", no período de 1990 a 2002.

\begin{tabular}{c|rr}
\hline No. de Publicações & Autores & \multicolumn{1}{c}{$\%$} \\
\hline 1 & 45788 & 62,17 \\
$\geq 2$ & 27856 & 38,83 \\
& 73644 & 100 \\
\hline
\end{tabular}

Segundo Urbizagástegui (2002) para estabelecer a parte com que homens de diferentes qualidades contribuem ao progresso da ciência, Lotka em 1926 estabeleceu os fundamentos da lei do quadrado inverso, afirmando que o número de autores que fazem " $\boldsymbol{n}$ " contribuições em um determinado campo científico é proporcional a $1 / n^{2}$ daqueles que fazem uma só contribuição e que a proporção daqueles que fazem uma única contribuição é de $60 \%$.

Desde 1926, muitos estudos têm sido conduzidos para investigar a produtividade dos autores em distintas disciplinas. Até dezembro de 2000, mais de 200 trabalhos, entre artigos, monografias, capítulos de livro, comunicações em congressos e literatura gris, foram produzidas tentando criticar, replicar e/ou reformular esta Lei bibliométrica, ainda segundo Urbizagástegui (2002). Apesar das numerosas pesquisas realizadas 
sobre este assunto, os resultados parecem contraditórios e inconclusivos. No entanto no seu trabalho para avaliar o ajuste da distribuição teórica à distribuição observada, o autor conclui que, das dez literaturas revisadas, somente quatro se ajustaram ao modelo da Lei de Lotka, entre elas a da medicina.

$\mathrm{Na}$ tabela 5, onde $62,17 \%$ dos 73.644 autores, presentes na base de dados, publicaram um único artigo no campo estudado, fica comprovado o princípio da Lei de Lotka.

Gráfico 6 - Distribuição das publicações no campo da saúde, segundo localidade onde são editadas, registrados na base de dados da "web of Knowledge", no período de 1990 a 2002.

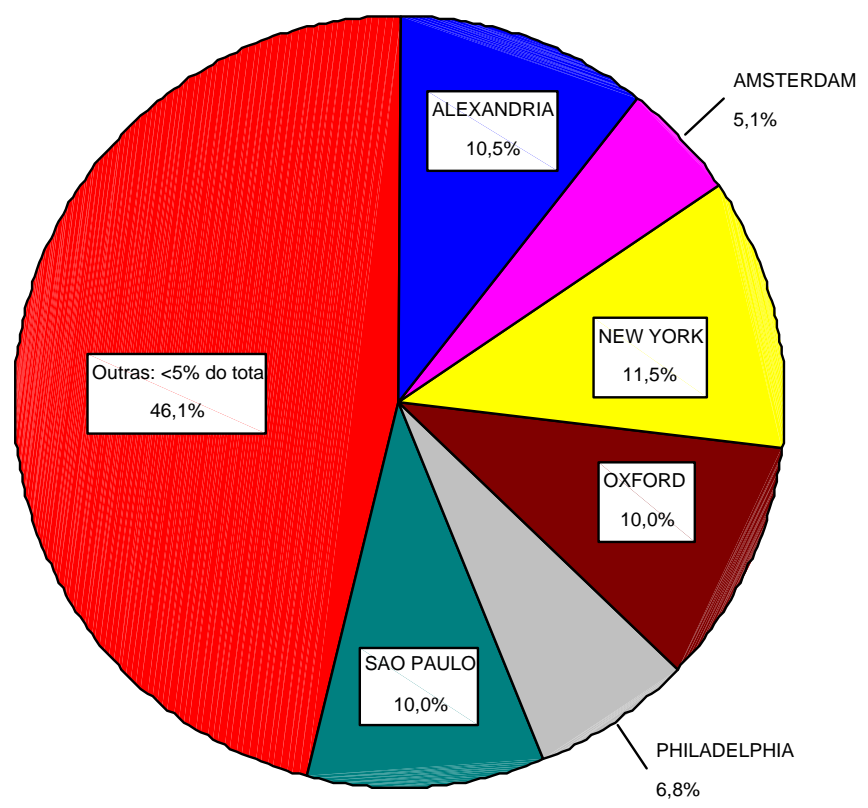

Tabela 6 - Distribuição das publicações no campo da saúde, segundo localidade onde são editadas, registrados na base de dados da "web of Knowledge", no período de 1990 a 2002.

\begin{tabular}{l|cc}
\hline $\begin{array}{c}\text { Local de } \\
\text { Publicação }\end{array}$ & $\begin{array}{c}\text { No. de } \\
\text { Publicações }\end{array}$ & \% de Publicações \\
\hline NEW YORK & 4410 & 11,5 \\
ALEXANDRIA & 4027 & 10,5 \\
SAO PAULO & 3834 & 10,0 \\
OXFORD & 3835 & 10,0 \\
PHILADELPHIA & 2608 & 6,8
\end{tabular}




\begin{tabular}{l|rr} 
AMSTERDAM & 1956 & 5,1 \\
\hline TOTAL & 20670 & 53,9 \\
\hline
\end{tabular}

As informações sobre as cidades onde se editam as revistas são oriundas do campo de informações dos publicadores. Mais de 300 cidades de vários países do mundo constam dessa listagem onde estão destacados no Brasil, além de São Paulo com $10 \%$ das publicações, gráfico 6 e tabela 6, as cidades do Rio de Janeiro, Curitiba e Ribeirão Preto que elevam para quatro 0 número de cidades brasileiras e para $13,41 \%$ o percentual de publicações no país. (anexo 1)

\subsubsection{REVISTAS SEGUNDO A "LEI DE BRADFORD"}

A "Lei de Bradford", ou Lei de Dispersão, permite, mediante a medição da produtividade das revistas, estabelecer o núcleo e as áreas de dispersão sobre um determinado assunto em um mesmo conjunto de revistas, portanto $1 / 3$ das publicações concentram-se em 1 grupo de revistas, outro $1 / 3$ em outro grupo com ' $n$ ' revistas, e o último terço em um grupo com $\mathbf{n}^{2}$ revistas, ou seja, Bradford expressou sua lei com a seguinte fórmula: 1:n: $n^{2}$.

Podemos observar estes resultados na tabela 7, onde no primeiro grupo, 24 revistas são responsáveis por $33,7 \%$ das publicações. Com 12.946 artigos em 209 revistas, ou seja, 33,8\% das publicações temos o segundo grupo e as restantes, 1813 revistas, com $32.5 \%$ das publicações formam o terceiro grupo, que representam 12.482 artigos.

Tabela 7 - Produção científica brasileira, de acordo com a "Lei de Bradford", registrada na base de dados da "web of Knowledge" no período de 1990 a 2002. 


\begin{tabular}{l|cccc}
\hline $\begin{array}{c}\text { Grupos } \\
\text { de }\end{array}$ & Média de \\
Bradford & Publicações & $\begin{array}{c}\text { \% de } \\
\text { Publicações }\end{array}$ & $\begin{array}{c}\text { No.de } \\
\text { Revistas }\end{array}$ & $\begin{array}{c}\text { Mublicações } \\
\text { Pubr Revista } \\
\text { por Re }\end{array}$ \\
\hline Grupo 1 & 12921 & 33,7 & 24 & 538,4 \\
Grupo 2 & 12946 & 33,8 & 209 & 61,94 \\
Grupo 3 & 12482 & 32,5 & 1813 & 6,8 \\
Total & $\mathbf{3 8 . 3 4 9}$ & $\mathbf{1 0 0}$ & $\mathbf{2 . 0 4 6}$ & \\
\hline
\end{tabular}


Tabela 8 - Núcleo das revistas mais produtivas, de acordo com o Grupo 1 de Bradford, relacionadas ao campo da saúde, pesquisadas na base de dados da "web of Knowledge", no período de 1990 a 2002.

\begin{tabular}{l|cc}
\hline \multicolumn{1}{c|}{ REVISTA } & Artigos & $\%$ \\
\hline JOURNAL OF DENTAL RESEARCH & 3953 & 0,1031 \\
BRAZILIAN JOURNAL OF MEDICAL AND BIOLOGICAL & 1721 & 0,0449 \\
RESEARCH & 995 & 0,0259 \\
REVISTA DE SAUDE PUBLICA & 611 & 0,0159 \\
JOURNAL OF THE BRAZILIAN CHEMICAL SOCIETY & 513 & 0,0134 \\
REVISTA DE MICROBIOLOGIA & 472 & 0,0123 \\
BRAZILIAN ARCHIVES OF BIOLOGY AND TECHNOLOGY & 440 & 0,0115 \\
MEMORIAS DO INSTITUTO OSWALDO CRUZ & 435 & 0,0113 \\
BLOOD & 426 & 0,0111 \\
FASEB JOURNAL & 397 & 0,0104 \\
GENETICS AND MOLECULAR BIOLOGY & 301 & 0,0078 \\
INTERNATIONAL JOURNAL OF PSYCHOLOGY & 275 & 0,0072 \\
HEPATOLOGY & 274 & 0,0071 \\
JOURNAL OF BIOLOGICAL CHEMISTRY & 236 & 0,0062 \\
TRANSPLANTATION PROCEEDINGS & 218 & 0,0057 \\
AMERICAN JOURNAL OF TROPICAL MEDICINE AND HYGIENE & 215 & 0,0056 \\
BIOPHYSICAL JOURNAL & 210 & 0,0055 \\
GASTROENTEROLOGY & 188 & 0,0049 \\
BRAIN RESEARCH & 188 & 0,0049 \\
TETRAHEDRON LETTERS & 186 & 0,0049 \\
AMERICAN JOURNAL OF MEDICAL GENETICS & 180 & 0,0047 \\
PEDIATRIC RESEARCH & 167 & 0,0044 \\
EUROPEAN JOURNAL OF PHARMACOLOGY & 160 & 0,0042 \\
TRANSFUSION & 160 & 0,0042 \\
WATER SCIENCE AND TECHNOLOGY & $\mathbf{1 2 9 2 1}$ & $\mathbf{0}, \mathbf{3 3 7 1}$ \\
\hline TOTAL & &
\end{tabular}

As 24 revistas do Grupo 1 de Bradford ou "hard core", da tabela 8, representam as que contêm o maior número de publicações no campo da saúde, (12.921) ou seja, 33,7\% do total das publicações analisadas e uma média de 538,7 publicações por revista. No anexo 2, encontram-se listadas as revistas do Grupo 2, "soft core" com 209 revistas e 12.946 publicações, que significam uma média de 61,94 publicações por revista e o Grupo 3, "periférico" com 12.482 publicações em 1.813 revistas com a média de 6,8 publicações por revista. As publicações brasileiras pertencem a 2.046 títulos de periódicos, embora tenham sido 
pesquisados 3.066 títulos o que significa que destas, 1.020 não contém nenhuma publicação brasileira, no período estudado.

Tabela 9 - Áreas do Conhecimento de maior produtividade, segundo revistas classificadas no Grupo 1 de Bradford, para publicações brasileiras, relacionadas ao campo da saúde, de acordo com as bases de dados da "web of Knowledge", no período de 1990 a 2002.

\begin{tabular}{|c|c|c|}
\hline Áreas do Conhecimento & Publicações & $\%$ \\
\hline $\begin{array}{l}\text { 1.Medical Research, Organs and } \\
\text { Systems }\end{array}$ & 4438 & $34,30 \%$ \\
\hline 2. Dentistry \& Oral Surgery Medicine & 3953 & $30,60 \%$ \\
\hline 3.Medical Research General Topics & 2559 & $19,80 \%$ \\
\hline 4.Public Health and Health Care & & \\
\hline $\begin{array}{l}\text { Science } \\
\text { 5.Biology }\end{array}$ & $\begin{array}{l}995 \\
985\end{array}$ & $\begin{array}{l}7,70 \% \\
7,6 \odot \%\end{array}$ \\
\hline 6. Chemistry & 611 & $4,70 \%$ \\
\hline $\begin{array}{l}\text { 7. Cardiovascular e Hematology } \\
\text { research }\end{array}$ & 595 & $4,60 \%$ \\
\hline 8. Hematology & 595 & $4,60 \%$ \\
\hline 9.Molecular Biology and Genetics & 583 & $4,50 \%$ \\
\hline 10.Biochemistry e Biophysics & 489 & $3,80 \%$ \\
\hline 11. Gastroenterology and Hepatology & 485 & $3,80 \%$ \\
\hline 12. Experimental Biology & 426 & $3,30 \%$ \\
\hline 13. Physiology & 301 & $2,30 \%$ \\
\hline $\begin{array}{l}\text { 14.Medical Research, Diagnosis and } \\
\text { Treatment }\end{array}$ & 236 & $1,80 \%$ \\
\hline 15. Surgery & 236 & $1,80 \%$ \\
\hline $\begin{array}{l}\text { 16.Environmental Medicine e Public } \\
\text { Health }\end{array}$ & 218 & $1,70 \%$ \\
\hline 17. Chemistry e Analysis & 188 & $1,50 \%$ \\
\hline 18. Neuroscience and Behavior & 188 & $1,50 \%$ \\
\hline 19.0tolaryngology & 180 & $1,40 \%$ \\
\hline 20.Pharmacology and Toxicology & 167 & $1,30 \%$ \\
\hline 21. Environment Ecology & 160 & $1,20 \%$ \\
\hline
\end{tabular}

0 prestígio das revistas onde se publicam os resultados das investigações científicas representa uma medida da influência que podem exercer os artigos nelas publicados.

Como cada revista pode corresponder de 1 a 3 áreas de conhecimento, pelos grupos de Bradford podemos conhecer as áreas de maior produtividade em ciências da saúde. 
De acordo com as tabelas 9 e 10, observa-se a relação entre diferentes áreas de especialização. Temos que as áreas de Pesquisa Médica em órgãos e Sistemas, Odontologia e Cirurgia Oral e Pesquisa Médica Geral somam o maior número de publicações da área. Juntos são responsáveis por 10.950 artigos, isto é, 28,55\% de toda a produção do campo, no período estudado.

$\mathrm{Na}$ tabela 9 estão relacionados os grupos de áreas com maior produtividade, ou seja, grupo "hard core". Na tabela 10 temos a distribuição da produção científica total, no período estudado, segundo a área do conhecimento ao qual está relacionada. No anexo 5, estão relacionados os grupos de áreas do conhecimento, que de acordo com a produtividade das revistas do campo da saúde, formam o que denominamos "soft core" e "periféricos". 
Tabela 10 - Produtividade por Áreas do Conhecimento, relacionados ao campo da saúde, publicadas em revistas classificadas nos Grupos 1, 2 e 3 de Bradford, pesquisadas na base de dados da "web of Knowledge", no Brasil, no período de 1990 a 2002.

\begin{tabular}{|c|c|c|}
\hline Área do Conhecimento & Artigos & $\%$ \\
\hline 1.Medical Research, Organs and Systems & 6117 & $16,00 \%$ \\
\hline 2.Dentistry Oral surgery Medicine & 4674 & $12,20 \%$ \\
\hline 3.Medical Research General Topics & 3508 & $9,10 \%$ \\
\hline 4.Biochemistry and Biophysics & 2203 & $5,70 \%$ \\
\hline 5. Neuroscience and Behavior & 2203 & $5,70 \%$ \\
\hline 6.Cardiovascular and Hematology research & 1901 & $5, \odot \odot \%$ \\
\hline 7. Biology & 1862 & $4,90 \%$ \\
\hline 8. Environment Ecology & 1707 & $4,50 \%$ \\
\hline 9.Pharmacology and Toxicology & 1655 & $4,30 \%$ \\
\hline 10. Microbiology & 1600 & $4,20 \%$ \\
\hline 11. Molecular Biology and Genetics & 1518 & $4, \odot \odot \%$ \\
\hline 12. Cardiovascular and Respiratory System & 1517 & $4, \odot \odot \%$ \\
\hline 13. Immunology & 1266 & $3,30 \%$ \\
\hline 14. Medical Research, Diagnosis and Treatment & 1255 & $3,30 \%$ \\
\hline 15.Public Health and Health Care Science & 1180 & $3,10 \%$ \\
\hline 16. Chemistry & 1090 & $2,80 \%$ \\
\hline 17. Chemistry and Analysis & 1020 & $2,70 \%$ \\
\hline 18. Gastroenterology and Hepatology & 861 & $2,20 \%$ \\
\hline 19. Entomology Pest Control & 803 & $2,10 \%$ \\
\hline 20. Hematology & 762 & $2, \odot \odot \%$ \\
\hline 21.Endocrinology, Nutrition and Metabolism & 690 & $1,80 \%$ \\
\hline 22. Food Science Nutrition & 686 & $1,80 \%$ \\
\hline 23. Biotechnology and Applied Microbiology & 682 & $1,80 \%$ \\
\hline 24. Surgery & 654 & $1,70 \%$ \\
\hline 25. Experimental Biology & 647 & $1,70 \%$ \\
\hline 26. Physiology & 592 & $1,50 \%$ \\
\hline 27.Cell and Developmental Biology & 581 & $1,50 \%$ \\
\hline 28. Environmental Medicine and Public Health & 579 & $1,50 \%$ \\
\hline 29. Research Laboratory Medicine and Medical Technology & 505 & $1,30 \%$ \\
\hline 30. Oncogenesis and Cancer Research & 467 & $1,20 \%$ \\
\hline 31. Endocrinology, Metabolism and Nutrition & 423 & $1,10 \%$ \\
\hline 32. Urology and Nephrology & 421 & $1,10 \%$ \\
\hline 33. Psychology & 412 & $1,10 \%$ \\
\hline 34.Clinical Immunology and Infectious Disease & 404 & $1,10 \%$ \\
\hline 35. Otolaryngology & 360 & $\odot, 9 \odot \%$ \\
\hline 36. Neurology & 343 & $0,90 \%$ \\
\hline 37. General and Internal Medicine & 342 & $\odot, 90 \%$ \\
\hline 38. Pediatrics & 280 & $\odot, 70 \%$ \\
\hline 39.Radiology, Nuclear Medicine and Imaging & 264 & $\odot, 70 \%$ \\
\hline 40. Anaesthesia and Intensive Care & 254 & $\odot, 70 \%$ \\
\hline 41. Oncology & 246 & $\odot, 60 \%$ \\
\hline 42. Psychiatry & 223 & $0,60 \%$ \\
\hline 43. Reprodutive Medicine & 220 & $0,60 \%$ \\
\hline
\end{tabular}


Tabela 10 - Produtividade por Áreas do Conhecimento, relacionados ao campo da saúde, publicadas em revistas classificadas nos Grupos 1, 2 e 3 de Bradford, pesquisadas na base de dados da "web of Knowledge", no Brasil, no período de 1990 a 2002. (continuação)

\begin{tabular}{l|ll}
\hline Áreas do Conhecimento & Artigos $\%$ \\
\hline 44.0phthalmology & 195 & $0,50 \%$ \\
45. Rheumatology & 173 & $0,50 \%$ \\
46. Dermatology & 152 & $0,40 \%$ \\
47. Orthopedics, Rehabilitation and Sport Medicine & 82 & $0,20 \%$ \\
48.Clinical Psychology and Psychiatry & 62 & $0,20 \%$ \\
49. Rehabilitation & 27 & $0,10 \%$ \\
50. Health Care Science and Services & 10 & $0,00 \%$ \\
\hline Total de Publicações & $\mathbf{3 8 3 4 9}$ & $\mathbf{1 0 0 , 0 0 \%}$ \\
\hline
\end{tabular}

\subsubsection{TIPO DE DOCUMENTOS}

Os resultados da maioria das investigações em ciência e tecnologia são transmitidos por meio de um processo de comunicação escrita, em artigos de revista, livros, revisões, anais de congressos, teses, patentes e cartas entre outros. Portanto, os trabalhos publicados compõem um dos produtos finais de toda a atividade científica e tecnológica e representam um indicador do volume da pesquisa produzida. 
Tabela 11 - Produção científica por Tipo de Documento, no campo da saúde, no Brasil, registrados na base de dados da "web of Knowledge", no período de 1990 a 2002.

\begin{tabular}{lrr}
\hline \multicolumn{1}{c}{ Tipo de Documento } & $\begin{array}{c}\text { Número de } \\
\text { Publicações }\end{array}$ \\
\hline Article & 26460 & $\% 9,0$ \\
Meeting Abstract & 9168 & 23,9 \\
Letter & 930 & 2,4 \\
Note & 725 & 1,9 \\
Review & 581 & 1,5 \\
Editorial Material & 327 & 0,9 \\
Book Review & 57 & 0,1 \\
Correction & 39 & 0,1 \\
Correction, Addition & 13 & 0 \\
Discussion & 13 & 0 \\
Biographical-Item & 12 & 0 \\
Item About an Individual & 8 & 0 \\
Reprint & 3 & 0 \\
News Item & 2 & 0 \\
Software Review & 1 & 0 \\
Sub-Total & $\mathbf{3 8 3 3 9}$ & $\mathbf{1 0 0}$ \\
**MISSING & 10 & \\
\hline TOTAL GERAL & $\mathbf{3 8 3 4 9}$ & \\
\hline
\end{tabular}

o crescimento observado para as publicações, de acordo com o tipo de documento, na tabela 11 e gráfico 7, é tanto para artigos quanto para participações em congressos. 
Gráfico 7 - Distribuição das publicações brasileiras, segundo tipo de documento, no campo da saúde, registrados na base de dados da "web of Knowledge", no período de 1990 a 2002.

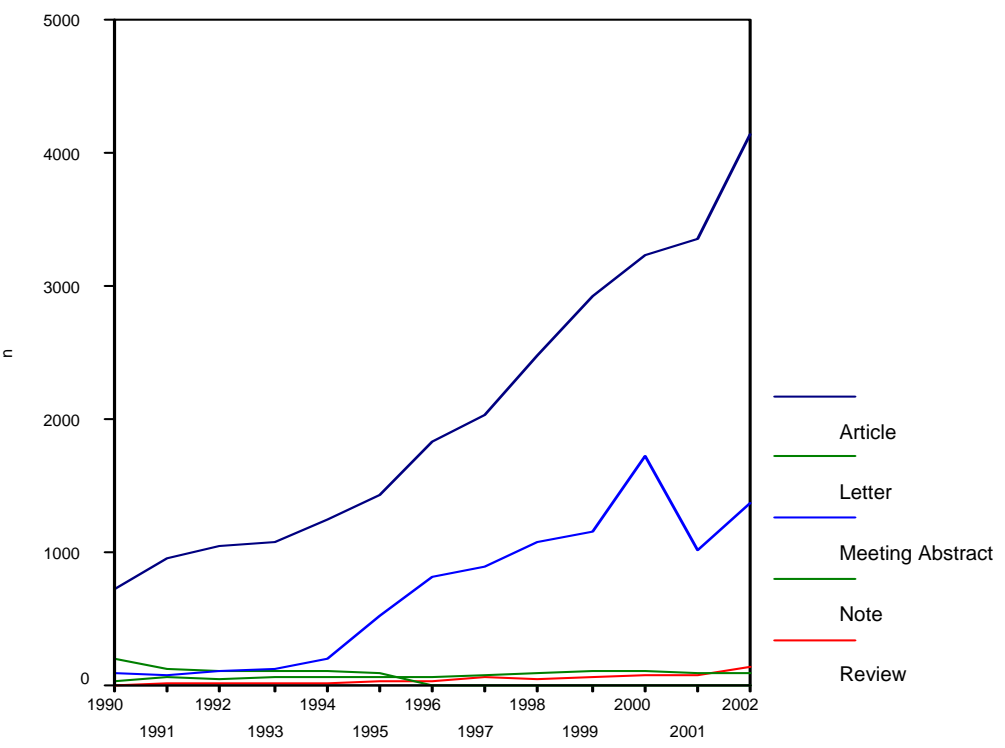

Tradicionalmente os artigos são o principal veículo de difusão da ciência e tem maior expressão numérica. Representaram 69\% de toda a produção estudada, seguidos de participações em congresso com 23,9\% no período, conforme mostram a tabela 11 e o gráfico 7 .

A tabela 12 apresenta o número médio de autores, de acordo com os tipos documentos científicos publicados. Os artigos e as participações em congresso apresentam uma média de 5 autores por publicação. 
Tabela 12 - Publicações científicas brasileiras, classificadas por Tipo de Documento, segundo número médio de autores, no campo da saúde, registrados na base de dados da "web of Knowledge", no período de 1990 a 2002.

\begin{tabular}{lc}
\hline \multicolumn{1}{c}{ Tipo de Documento } & $\begin{array}{c}\text { Número de Autores } \\
\text { Média }\end{array}$ \\
\hline Article & 5 \\
Biographical-Item & 3 \\
Book Review & 1 \\
Correction & 6 \\
Correction, Addition & 4 \\
Discussion & 9 \\
Editorial Material & 3 \\
Item About an & 2 \\
Individual & \\
Letter & 4 \\
Meeting Abstract & 5 \\
News Item & 11 \\
Note & 4 \\
Reprint & 12 \\
Review & 4 \\
Software Review & 1 \\
\hline
\end{tabular}

\subsubsection{IDIOMA E LOCAL DE PUBLICAÇÃO}

A tabela 13 e o gráfico 8 indicam o idioma que as publicações foram divulgadas e sua freqüência.

Tabela 13 - Número de artigos segundo o idioma de publicação, na área da saúde, no Brasil, registrados na base de dados da "web of Knowledge", no período de 1990 a 2002.

\begin{tabular}{l|rr}
\hline \multicolumn{1}{c|}{ Idioma } & Frequência & \multicolumn{1}{c}{$\%$} \\
\hline Inglês & 37037 & 96,6 \\
Português & $90 \odot$ & 2,3 \\
Espanhol & 252 & 0,7 \\
Francesa & 117 & 0,3 \\
Alemã & 28 & 0,1 \\
Russo & 3 & $\odot$ \\
Italiano & 2 & 0 \\
Checo & 1 & 0 \\
Sub Total & $\mathbf{3 8 3 4 0}$ & $\mathbf{1 0 0}$ \\
Sem Informação & 9 & \\
\hline Total & $\mathbf{3 8 3 4 9}$ & $\mathbf{1 0 0}$ \\
\hline
\end{tabular}


Gráfico 8 - Percentual de publicações brasileiras, segundo o idioma de publicação, no campo da saúde, registrados na base de dados da "web of Knowledge", no período de 1990 a 2002.

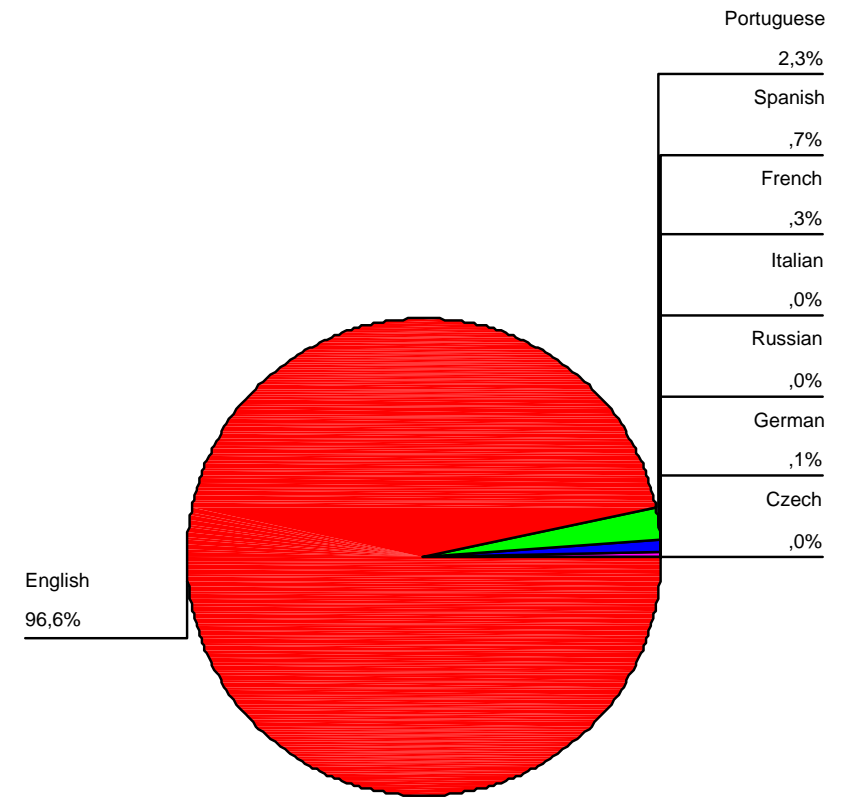

0 perfil das publicações brasileiras quanto ao idioma preferido para publicação evidencia a língua inglesa, que fica a frente, com a grande maioria das publicações, 96,6\%. Já as publicações em português aparecem com apenas 2,3\%. Publicações em língua espanhola representam $\odot, 7 \%$ do total de 38.340 publicações. Este é o resultado esperado, pois os autores têm preferência pelo idioma inglês para divulgar seus trabalhos em revistas estrangeiras.

A produção científica brasileira, no campo da saúde, segundo a filiação da editora, soma 33.191, ou seja, 87\% do total, no período, para as editoras estrangeiras, uma vez que as publicações em revistas internacionais são a maioria. 


\subsubsection{PADRÕES DA PRODUÇÃO CIENTÍfICA BRASILEIRA.}

Para conhecer os padrões da produção científica brasileira, foram realizadas análises de "cluster" das áreas do conhecimento, usando os como indicadores, o número total das publicações, a tendência de crescimento da produção científica, o número médio de autores por artigo, a proporção de artigos publicados em revistas no exterior, o número médio de referências de cada publicação e o número médio de citações. A análise de citações que se fazem a artigos e revistas, proporciona uma visão fundamental, quantitativa e objetiva do desenvolvimento da investigação científica e sua tendência, em um determinado campo do conhecimento.

0 objetivo primário da análise de "cluster" é buscar entender a estrutura dos dados, aglomerando observações similares em grupos. A sua aplicação é, portanto, bastante imediata e pode conferir um bom poder explanatório à pesquisa, supondo que decisões ponderadas sejam tomadas sobre formas alternativas para mensuração de similaridades, critérios para formação de grupos e número ideal de grupos a serem formados.

Estudos similares realizados por Pereira (1996 e 1999), demonstram a utilização de métodos de análise multivariada, como a análise de agrupamento, "cluster analysis", em avaliação de Ciência e Tecnologia, pois esta é uma área que lida com evento multidimensional e exige uma abordagem multivariada.

0 fator de impacto dos artigos e revistas, idealizado por Garfield, baseia-se na freqüência média de citações num determinado período.

É evidente que o fator de impacto indica a categoria de um artigo ou de uma revista. Daí a importância para os autores de 
publicarem em revistas com um elevado fator de impacto, já que conseguiram obter grande visibilidade.

$\mathrm{Na}$ atualidade, discute-se o valor das citações e existe um consenso sobre as citações nem sempre medirem a qualidade da pesquisa científica, mas o impacto das publicações.

Para visualizar os resultados, as tabelas 14, 15, 16 e 17, evidenciam a composição dos "clusters" em conjunto e separadamente. A tabela 14, mostra o resultado global das análises, e apresenta como forma de comparação os 4 "clusters".

Tabela 14 - Composição dos "clusters" de acordo com os padrões da produção científica brasileira, no campo da saúde, segundo registros contidos na base de dados da "web of Knowledge", no período de 1990 a 2002.

\begin{tabular}{|c|c|c|c|c|c|c|}
\hline cluster & $\begin{array}{c}\text { Média de } \\
\text { publicações }\end{array}$ & $\begin{array}{c}\text { Tendência de } \\
\text { crescimento }\end{array}$ & $\begin{array}{c}N^{\circ} \\
\text { médio } \\
\text { de } \\
\text { autores }\end{array}$ & $\begin{array}{c}N^{o} \\
\text { médio de } \\
\text { citações }\end{array}$ & $\begin{array}{c}\text { Proporção } \\
\text { artigos } \\
\text { publicados } \\
\text { no exterior }\end{array}$ & $\begin{array}{c}\text { No médio }^{\circ} \\
\text { de } \\
\text { referências }\end{array}$ \\
\hline 1 & 406,12 & 0,24 & 5,23 & 3,56 & 1 & 10,86 \\
\hline 2 & 1569,79 & 0,05 & 5,1 & 4,06 & 0,84 & 12,41 \\
\hline 3 & 4091 & 0,01 & 4,55 & 2,22 & 0,69 & 9,26 \\
\hline 4 & 6117 & $\odot, 07$ & 4,88 & $\odot, 93$ & 1 & 2,62 \\
\hline Média & 993,56 & 0,17 & 5,16 & 3,6 & 0,94 & 11,07 \\
\hline
\end{tabular}

Da análise dos indicadores bibliométricos estudados para a definição do comportamento da produção científica, em "clusters" ou agrupamentos, como o número total das publicações, a tendência de crescimento da produção científica, o número médio de autores, o número médio de citações, a proporção de artigos publicados no exterior e o número médio de referências de cada publicação, resultou a caracterização de 4 "clusters", distinguidos por diferenças significantes em número de publicações, taxa de crescimento da produção científica, citações e proporção de publicações no exterior. 
Desta forma, podemos caracterizar o campo da ciência da saúde em dois padrões distintos definidos pelos "clusters" 1 e 2, tabelas 15 e 16, que contemplam 33 e 14 áreas do conhecimento respectivamente. E, em 3 áreas de comportamentos característicos, de acordo com os "clusters" 3 e 4, tabela 17. 0 "cluster" 3, com apenas 2 áreas do conhecimento, fica melhor analisado como sendo áreas afastadas, com alguma relação entre si que permitiu seu agrupamento e o "cluster" 4 é representado por uma única área do conhecimento. Assim entendemos os "clusters" 3 e 4 como três áreas de comportamentos característicos.

0 "cluster" 1, representado na tabela 15, apresenta as áreas do conhecimento menos produtivos, com um total de 13.402 artigos publicados durante os treze anos estudados, distribuídos em 33 áreas, o que significa uma média de 406,12 publicações por área do conhecimento. No entanto, possui a maior tendência de crescimento, 0,24 por ano, de publicações integralmente no exterior. Como característica adicional, tende a ter maior complexidade, se tomarmos em conta o alto número de referências, uma média de 10,86 referências por artigo e maior número médio de autores por publicação. A alta taxa de citação desse "cluster", a média de 3,56 citações por artigo, pode significar a existência de áreas emergentes, bem como um impacto ou visibilidade de suas publicações para a comunidade científica internacional. 
Tabela 15 - Relação do "cluster" 1 das publicações brasileiras, com as áreas do conhecimento, no campo da saúde, registradas na base de dados da "web of Knowledge", no período de 1990 a 2002.

\begin{tabular}{|c|c|c|c|c|c|c|}
\hline $\begin{array}{c}\text { “cluster" } 1 \\
\text { Área } \\
\text { do Conhecimento }\end{array}$ & $\begin{array}{c}N^{o} \\
\text { Médio }\end{array}$ & $\begin{array}{c}\text { Tendência } \\
\text { de } \\
\text { crescimento }\end{array}$ & $\begin{array}{c}N^{o} \text { médio } \\
\text { de } \\
\text { autores }\end{array}$ & $\begin{array}{c}N^{o} \text { médio } \\
\text { de } \\
\text { citações }\end{array}$ & $\begin{array}{l}\text { Proporção } \\
\text { artigos } \\
\text { publicados } \\
\text { no exterior }\end{array}$ & $\begin{array}{c}\text { No médio } \\
\text { de } \\
\text { referências }\end{array}$ \\
\hline Anaesthesia and Intensive Care & 254 & 0,16 & 5,02 & 3,09 & 1 & 6 \\
\hline Biotechnology and Applied Microbiology & 682 & 0,13 & 4,3 & 3,52 & 1 & 15,5 \\
\hline $\begin{array}{l}\text { Cell e Developmental Biology } \\
\text { Clinical Immunology and Infectious }\end{array}$ & 581 & 0,11 & 4,51 & 3,92 & 1 & 15,9 \\
\hline Disease & 404 & 0,1 & 7,18 & 3,99 & 1 & 7,47 \\
\hline $\begin{array}{l}\text { Clinical Psychology and Psychiatry } \\
\text { Dermatology }\end{array}$ & $\begin{array}{c}62 \\
152\end{array}$ & $\begin{array}{l}0,78 \\
0,32\end{array}$ & $\begin{array}{l}4,68 \\
5,22\end{array}$ & $\begin{array}{l}2,27 \\
1,64\end{array}$ & $\begin{array}{l}1 \\
1\end{array}$ & $\begin{array}{c}13,84 \\
9,11\end{array}$ \\
\hline Endocrinology, Metabolism and Nutrition & 423 & 0,16 & 6,11 & 6,53 & 1 & 11,71 \\
\hline Endocrinology, Nutrition and Metabolism & 690 & 0,11 & 5,47 & 3,81 & 1 & 13,34 \\
\hline $\begin{array}{l}\text { Entomology Pest Control } \\
\text { Environmental Medicine and Public }\end{array}$ & 803 & 0,08 & 3,76 & 2,3 & 1 & 12,22 \\
\hline Health & 579 & 0,14 & 5,55 & 6,39 & 1 & 17,79 \\
\hline Experimental Biology & 647 & 0,09 & 4,41 & 2,22 & 1 & 8,84 \\
\hline Food Science Nutrition & 686 & 0,11 & 4,26 & 3,06 & 1 & 12,91 \\
\hline Gastroenterology and Hepatology & 861 & 0,08 & 6,51 & 1,3 & 1 & 3,77 \\
\hline General and Internal Medicine & 342 & 0,2 & 5,27 & 5,9 & 1 & 9,14 \\
\hline Health Care Science and Services & 10 & 1,2 & 4,5 & 1,9 & 1 & 10,4 \\
\hline Hematology & 762 & 0,07 & 6,75 & 1,48 & 1 & 3,93 \\
\hline Neurology & 343 & 0,2 & 5,41 & 5,36 & 1 & 13,39 \\
\hline Oncogenesis and Cancer Research & 467 & 0,17 & 6,85 & 7,26 & 1 & 15,29 \\
\hline Oncology & 246 & 0,25 & 6,89 & 9,93 & 1 & 13,2 \\
\hline $\begin{array}{l}\text { Ophthalmology } \\
\text { Orthopedics, Rehabilitation and Sport }\end{array}$ & 195 & 0,33 & 5,42 & 4,07 & 1 & 9 \\
\hline Medicine & 82 & 0,89 & 3,96 & 2,67 & 1 & 9,3 \\
\hline Otolaryngology & 360 & 0,11 & 5,41 & 1,17 & 0,99 & 5,84 \\
\hline Pediatrics & 280 & 0,18 & 5,2 & 2,99 & 0,99 & 14,24 \\
\hline Psychology & 412 & 0,23 & 4,62 & 3,85 & 1 & 18,62 \\
\hline Psychiatry & 223 & 0,03 & 4,81 & 3,47 & 1 & 14,62 \\
\hline Physiology & 592 & 0,23 & 3,1 & 1,63 & 1 & 6,31 \\
\hline $\begin{array}{l}\text { Radiology, Nuclear Medicine and } \\
\text { Imaging }\end{array}$ & 264 & 0,22 & 5,55 & 3,14 & 1 & 7,19 \\
\hline Rehabilitation & 27 & 0,39 & 3,78 & 1,07 & 1 & 10,07 \\
\hline Reprodutive medicine & 220 & 0,22 & 6,44 & 1,86 & 1 & 5,85 \\
\hline $\begin{array}{l}\text { Research Laboratory Medicine and } \\
\text { Medical Technology }\end{array}$ & 505 & 0,09 & 5,48 & 4,99 & 1 & 12,36 \\
\hline Rheumatology & 173 & 0,32 & 5,11 & 4,13 & 1 & 12,9 \\
\hline Surgery & 654 & 0,08 & 5,57 & 2,56 & 1 & 8,29 \\
\hline Urology and Nephrology & 421 & 0,1 & 5,39 & 4,1 & 1 & 10,12 \\
\hline No. Mé & \multicolumn{2}{|c|}{$406,120,24$} & 5,23 & 3,56 & 1 & 10,86 \\
\hline
\end{tabular}


Tabela 16 - Relação do "cluster" 2 das publicações brasileiras, com as áreas do conhecimento, no campo da saúde, registradas na base de dados da "web of Knowledge", no período de 1990 a 2002.

\begin{tabular}{|c|c|c|c|c|c|c|}
\hline Área do Conhecimento & $\begin{array}{c}N^{\circ} \\
\text { Médio }\end{array}$ & $\begin{array}{c}\text { Tendência } \\
\text { de } \\
\text { crescimento }\end{array}$ & $\begin{array}{c}N^{\circ} \\
\text { médio } \\
\text { de } \\
\text { autores }\end{array}$ & $\begin{array}{c}N^{\circ} \\
\text { médio } \\
\text { de } \\
\text { citações }\end{array}$ & $\begin{array}{c}\text { Proporção } \\
\text { artigos } \\
\text { publicados } \\
\text { no exterior }\end{array}$ & $\begin{array}{c}N^{\circ} \text { médio } \\
\text { de } \\
\text { referências }\end{array}$ \\
\hline Biology & 1862 & 0,04 & 3,94 & 2,02 & 0,47 & 8,25 \\
\hline Cardiovascular and Hematology research & 1901 & 0,03 & 6,61 & 2,82 & 1 & 6,43 \\
\hline Cardiovascular and Respiratory System & 1517 & 0,04 & 6,42 & 3,5 & 1 & 7,92 \\
\hline Chemistry & 1090 & 0,06 & 4,16 & 2,5 & 0,44 & 12,49 \\
\hline Chemistry and Analysis & 1020 & 0,08 & 4,44 & 4,96 & 1 & 12,65 \\
\hline Environment Ecology & 1707 & 0,05 & 3,92 & 3,69 & 1 & 13,64 \\
\hline $\begin{array}{l}\text { Immunology } \\
\text { Medical Research, Diagnosis and }\end{array}$ & 1266 & 0,05 & 6,44 & 6,4 & 1 & 14,33 \\
\hline Treatment & 1255 & 0,03 & 5,41 & 3,32 & 1 & 10,88 \\
\hline Microbiology & 1600 & 0,05 & 5,46 & 4,55 & 1 & 14,55 \\
\hline Molecular Biology and Genetics & 1518 & 0,05 & 5,21 & 5,57 & 0,74 & 12,39 \\
\hline Neuroscience and Behavior & 2203 & 0,03 & 5,34 & 5,79 & 1 & 16,15 \\
\hline Pharmacology and Toxicology & 1655 & 0,05 & 5,12 & 4,56 & 1 & 14,66 \\
\hline Public Health and Health Care Science & 1180 & 0,12 & 3,69 & 1,06 & 0,16 & 14,06 \\
\hline Número Médio & 1569,8 & 0,05 & 5,1 & 4,06 & 0,84 & 12,41 \\
\hline
\end{tabular}

0 "cluster" 2, representado na tabela 16, possui uma alta produção, com uma média de 1596,76 publicações distribuídas pelas 14 áreas do conhecimento, o que representa um total de 21.977 artigos publicados no período. Têm menor tendência de crescimento, 0,05, e menor expressão, em relação ao "cluster" 1, no que diz respeito às publicações no exterior, uma proporção de $\odot$,84. Tende a uma maior complexidade com o maior número de referências por artigo e um alto número médio de 5,10 autores, por trabalho publicado.

Este é o "cluster" mais citado, tem o maior número médio de 4,06 citações por artigo publicado e, portanto pode sugerir áreas emergentes, maior impacto e visibilidade das suas publicações, uma vez que atualmente é consenso que número de citações não se traduz, obrigatoriamente, em qualidade da 
investigação científica. Os "clusters" 1 e 2 são áreas estáveis que talvez melhor representem as ciências da saúde.

Tabela 17 - Relação dos "cluster" 3 e 4, das publicações brasileiras, com as áreas do conhecimento, no campo da saúde, registradas na base de dados da "web of Knowledge", no período de 1990 a 2002.

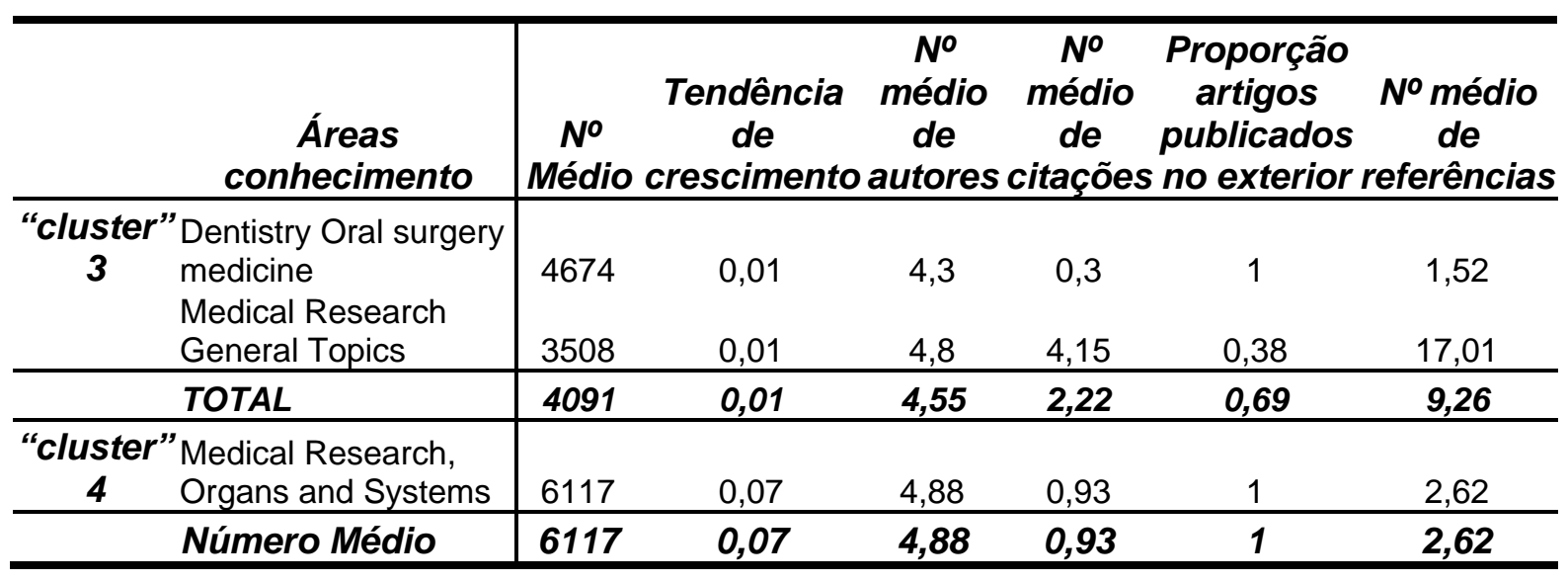

0s "clusters" 3 e 4 estão representados na tabela 17. As áreas que compõem os "clusters" 3 e 4 estão muito afastadas das demais devido sua alta produtividade. Apresentam uma produção média por área de 4091 e 6117 artigos, respectivamente, ao longo do período estudado. Diferenciam-se um do outro porque 0 "cluster" 3 recebe maior número de citações, uma média de 2, 22 citações por publicação. No entanto, se isolarmos a área "Dentistry oral Surgery Medicine", chama a atenção no "cluster" 3 pois é a área que menos citações recebe, uma média de $\odot, 3$ por artigo, dentre as 50 áreas estudadas no campo do conhecimento da saúde.

Enquanto o "cluster" 4 recebe o menor número de citações de todos os grupos, com uma média de apenas 0,93 citações por artigo, apresenta maior taxa de crescimento, ainda que modesta, de $\odot, 07$ ao ano, em relação ao "cluster" 3. Como são áreas de grande produção não se espera que tenham elevada tendência de crescimento. Estas, parecem ser áreas, do campo das ciências da saúde, já consolidadas. 


\section{2. "CO-WORD ANALYSIS"}

o grupo de análises que serão apresentadas nesta segunda parte trata de estudar a co-ocorrência de palavras. Esta consiste na detecção das palavras que caracterizam o conteúdo dos trabalhos sobre um determinado tema, na contagem da aparição destas e posterior estudo de sua proximidade e significância. Os conceitos de proximidade ou distância podem ser representados graficamente e constituem a base para a elaboração dos "mapas tecnológicos".

Os mapas tecnológicos representam graficamente estas proximidades ou distâncias, dando uma visão da estrutura de relações que existe em um âmbito dado. À distância no mapa entre duas palavras, referentes a tecnologias, produtos, autores, empresas, assinala a maior ou menor relação entre elas. Esta proximidade pode ser quantificada mediante diversos índices e métricas e, graças a isto, visualizá-las graficamente por meio dos mapas. "O fundamento metodológico da "co-word analysis" é a idéia que a co-ocorrência de palavras-chave descreve o conteúdo de um documento em um arquivo. Do ponto de vista metodológico, é portanto uma questão de usar um ou mais índices para medir a intensidade relativa dessas ocorrências e efetuar uma representação simplificada das redes as quais elas podem evidenciar". (Callon, 1991)

As palavras que foram estudadas estão contidas no campo descritores da base de dados e foram relacionadas com outras variáveis, da mesma base, como autores, identificadores, ano de publicação do artigo ou filiação da publicação.

Os descritores foram escolhidos porque representam o assunto do artigo, são chamados de descritores de assunto, mas 
estes termos também são conhecidos como palavras-chave. Com base no artigo ou documento propriamente dito, os profissionais que realizam indexações fazem uma análise temática e identificam os descritores que representam os assuntos enfocados no artigo.

Já os identificadores, que também representam os assuntos enfocados no artigo, são designados pelo próprio autor, de acordo com sua interpretação do que melhor identificará seu trabalho. Um identificador pode, ou não, pertencer ao dicionário ou ao vocabulário controlado de descritores de um determinado campo do conhecimento, pois, muitas vezes, são palavras novas ou que melhor representam novas descobertas.

0 fato de escolher trabalhar com descritores e identificadores está fundamentado no princípio, segundo Whitaker, de que "os autores dos artigos científicos escolhem com cuidado os termos técnicos que utilizam; quando diversos termos são utilizados no mesmo artigo, isso acontece, de fato, porque o autor reconhece ou supõe que existe algum tipo de relação não trivial entre seus referentes; se um número significativo de autores reconhece o mesmo tipo de relacionamento entre os termos, pode-se admitir que esse relacionamento possui algum significado dentro da área da ciência considerada; que as palavras-chave escolhidas, por indexadores competentes, como descritores do conteúdo dos artigos são de fato uma indicação confiável dos conceitos científicos a que se referem, o que torna possível o uso dessas palavras como o elemento base para a análise das coocorrências das palavras". (Robredo e Cunha, 1998)

Se os pressupostos acima fazem sentido, nada impede utilizar as freqüências com que ocorrem os possíveis pares de palavras relacionadas, em cada artigo integrante de um conjunto de artigos, como um meio para descrever a estrutura dos conceitos contidos nos artigos. 
$\mathrm{Na}$ impossibilidade de apresentar a totalidade dos agrupamentos de palavras e todas suas inter-relações, as análises de co-ocorrências de palavras foram centradas em alguns exemplos significativos, de forma a evidenciar as possibilidades e potencialidades desse método para "mapear" diferentes áreas do conhecimento, sem, necessariamente, caracterizar o estado da arte da produção científica brasileira, na área da saúde, no período estudado. 


\subsubsection{ANÁLISE DOS DESCRITORES}

Os descritores encontrados somaram 39.455 palavras diferentes, no total de 38.349 registros em todo o banco de dados. Para algumas análises dos descritores, como a realização de matrizes de co-ocorrência simples, foram selecionadas 395 palavras, que significam $1 \%$ do total de descritores, em ordem decrescente de freqüência de ocorrência. Um total de descritores e seu respectivo número de aparições, até 15 ocorrências, consta de uma lista e está apresentado na seção de anexos. (Anexo 3)

Polanco (1993) e (Basevi 1993), em suas análises de coocorrência de palavras, aplicaram critérios que consiste em eliminar termos e expressões com freqüência $(f)$ muito baixa, ( $f$ <2), e que são muito numerosos, e os de freqüência muito elevada quando são muito genéricos ou obviamente redundantes com o tema escolhido. Para o presente estudo foram eliminados alguns termos do grupo de palavras escolhido para análise, como "infection", "formation", "transmission", "brazil", pois estes são demasiado genéricos e, na grande maioria das vezes, são comuns a diferentes agrupamentos de palavras, sem nenhuma relação entre si.

A tabela 18 mostra o percentual dos descritores segundo sua freqüência, onde observamos que $72,03 \%$ deles aparecem uma única vez como descritor de assunto de um artigo. Apenas 27,97\% dos 39.455 descritores, têm freqüência maior que 1. No entanto, se tomarmos os descritores que se repetem até no mínimo 10 vezes, no período estudado, somente 1142 (2,89\%) ocorrem numa freqüência igual ou maior que 10 .

Tabela 18 - Percentual dos Descritores segundo sua freqüência de ocorrência, nas publicações brasileiras, registradas na base de dados da "web of Knowledge", no campo da saúde, no período de 1990 a 2002. 
Tabela 19 - Descritores e Identificadores, segundo as vinte primeiras maiores freqüências de ocorrência, nas publicações brasileiras, registradas na base de dados da "web of Knowledge", no campo da saúde, no período 2002.

\begin{tabular}{|c|c|c|c|}
\hline & & & \\
\hline & Freqüência & Descritores & $\%$ \\
\hline & 1 & & 72,03 \\
\hline & $>1$ & 11.037 & 27,97 \\
\hline & Total & 39.455 & 100 \\
\hline Descritores & Freqüência & Identificadores & Freqüência \\
\hline BRAZIL & 743 & PROTEIN & 835 \\
\hline EPIDEMIOLOGY & 407 & RAT & 765 \\
\hline RAT & 401 & EXPRESSION & 741 \\
\hline INSULIN/DIABETES & 359 & INFECTION & 631 \\
\hline TRYPANOSOMA & 327 & CELLS & 582 \\
\hline HIV/AIDS & 294 & MICE & 570 \\
\hline NITRIC OXIDE & 275 & DISEASE & 562 \\
\hline AMAZONIA & 249 & IDENTIFICATION & 547 \\
\hline SCHISTOSOMA & 217 & RECEPTOR & 468 \\
\hline LEISHMANIA & 192 & MUTATIONS & 438 \\
\hline CALCIUM & 189 & MECHANISM & 436 \\
\hline ANTIBODY & 188 & CHILDREN & 383 \\
\hline INFLAMMATION/INFLAMM & 178 & BINDING & 378 \\
\hline GLUTAMINE/GLUTAMATE & 167 & DNA & 374 \\
\hline HYPERTENSION & 160 & INHIBITION & 361 \\
\hline MORTALITY & 156 & BRAZIL & 361 \\
\hline DNA & 155 & BRAIN & 357 \\
\hline CHAGAS & 155 & GROWTH & 342 \\
\hline PCR & 146 & POPULATION & 336 \\
\hline STRESS & 134 & CANCER & 323 \\
\hline
\end{tabular}
de 1990 a

A tabela 19 é um exemplo do resultado de uma contagem simples de palavras. Esta, evidencia apenas os 20 descritores e identificadores mais freqüentes. A freqüência significa o número de ocorrência das palavras nos campos de descritor e identificador. Apenas com a contagem de palavras podemos obter 
informações interessantes, sobretudo se compararmos sua ocorrência no tempo para observarmos seu comportamento. Palavras referentes a tecnologias ou temas específicos que têm sua freqüência aumentada num período determinado, demonstram que estão captando a atenção, que se está patenteando sobre o assunto, enfim, que há um interesse de investigação sobre elas. Ao contrário, as que diminuem de freqüência ao longo do tempo, podem representar temas que estão chegando ao limite de seu interesse.

A palavra dengue, por exemplo, com 61 ocorrências, entre descritores e identificadores, conduz no tempo às ações sanitárias para erradicação do mosquito Aedes. Segundo Donalísio (1999), "...há noventa anos vem travando-se, nas Américas, uma luta contra o mosquito transmissor do dengue, da febre amarela e de outras viroses. Esforços de erradicação foram freqüentes, com grande mobilização de recursos, em extensas campanhas nacionais, em várias regiões do continente." Nas campanhas de erradicação do Aedes aegypti, o Brasil foi um dos melhores exemplos, tiveram êxito no país desde as primeiras décadas do século XX, em epidemias nos Estados de São Paulo, Rio de Janeiro e nas cidades de Salvador, Recife, entre outras. Em 1933 várias cidades costeiras do país estiveram novamente livres do Aedes aegypti, a custa de insistentes programas de eliminação de criadouros de larvas. No Brasil, o vetor foi considerado erradicado de 1955 a 1967 e de 1972 até 1976. Embora o dengue não se tenha constituído, de fato, em problema de saúde pública brasileira até a década de 80, o controle do vetor da febre amarela influenciou diretamente as possibilidades de ocorrência de epidemias. (Donalísio, 1999)

A re-introdução do Aedes no Brasil, na década de 80, elevou o risco de infecção pelas moléstias veiculadas por este 
vetor. Com isso, segundo dados da Fundação Nacional da Saúde do Ministério da Saúde, o dengue volta à região norte em 1982, em 1986-1987 na região nordeste e sudeste, envolvendo os estados do Ceará, Alagoas, Pernambuco e Rio de Janeiro, quando apresentaram mais de 130.000 casos, nos anos de 1990 e 1991, outros 140.000 casos e a partir de 1995 em todas as regiões do país.

Gráfico 9 - Ocorrência da palavra "Dengue", nas publicações brasileiras, registradas na base de dados da "web of science", no campo da saúde, no período de 1990 a 2002.

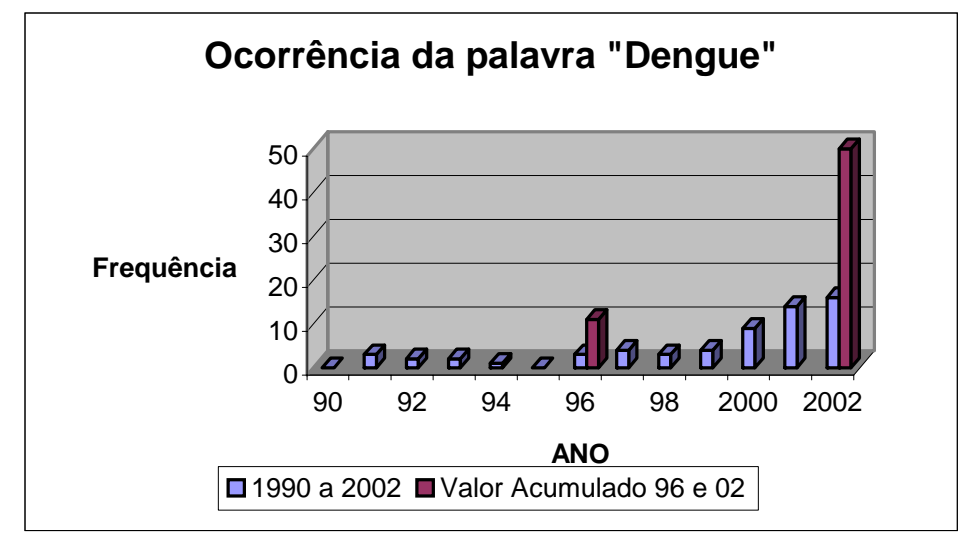

o gráfico 9 mostra a evolução dessa palavra, presente no campo de descritores e identificadores, ao longo do período estudado e em dois períodos delimitados. No primeiro momento, de 1990 a 1996, temos uma baixa ocorrência da palavra "dengue", 18,03\%. Já de 1997 a 2002 um visível aumento pode ser observado com $81,97 \%$ num total de 61 ocorrências, em todo o período estudado.

Estes dados coincidem com a história da evolução do dengue no país, na década de 90, quando os pesquisadores, motivados pelo recrudescimento dessa moléstia, impulsionaram as investigações e buscaram investimentos, para a produção de novos 
conhecimentos científicos e tecnológicos de modo a controlar a propagação da epidemia e eliminar a doença.

\subsubsection{ANÁLISE DO CRUZAMENTO ENTRE DESCRITORES}

As análises de co-ocorrência são as bases para a elaboração dos mapas tecnológicos e de possíveis definições de "clusters" ou associações. (Cruz, Escorsa e Maspons, 2003) Estas podem ser simples ou múltiplas, simétricas ou assimétricas. As simples permitem o cruzamento de duas informações de natureza similar como, autor-autor, autor-ano, autor-país. As coocorrências múltiplas requerem um terceiro campo de análises como autor-descritor-ano. As simétricas analisam dados de um mesmo campo, como autor-autor ou descritor-descritor. Já as assimétricas são as que se prestam a analisar campos diferentes como autor-descritor, descritor-identificador, por exemplo.

A análise, do cruzamento entre descritores, resultou primeiramente em uma matriz, com resultados das contagens que permitiram organizar, depurar e transformar os dados através de operações matemáticas. A ACP - Análise dos Componentes Principais é um método que se utiliza para dados quantitativos. É indicado quando se deseja trabalhar com valores absolutos das variáveis e permite destacar os valores de maior magnitude. Quando os dados originais das matrizes apresentam-se dispersos é necessário ordená-las por blocos absolutos, o que permite uma maior proximidade dos dados da tabela. Partimos, portanto, de uma matriz de co-ocorrência, onde nas linhas e colunas foram analisados os descritores. As linhas representam os indivíduos e as colunas as variáveis. Cada linha nos dá o valor de todas as variáveis para o indivíduo desta linha. 
os fragmentos da matriz simples e simétrica de coocorrência de descritores evidenciados a seguir, representam os "clusters" que aparecem melhor delimitados no "zoom" da matriz de ocorrência. A figura 1, por exemplo, mostra a palavra de maior freqüência dentre os descritores, que é "epidemiology" e seu respectivo "cluster". Originalmente os resultados podem vir acompanhados de zoom e da tabela de elementos que compõe o "cluster". 
Figura 1 - Fragmento da matriz de co-ocorrência de descritores, segundo $1 \%$ das palavras de maior freqüência, contidas no campo de descritores, das publicações brasileiras, registradas na base de dados da "web of Knowledge", no campo da saúde, no período de 1990 a 2002.

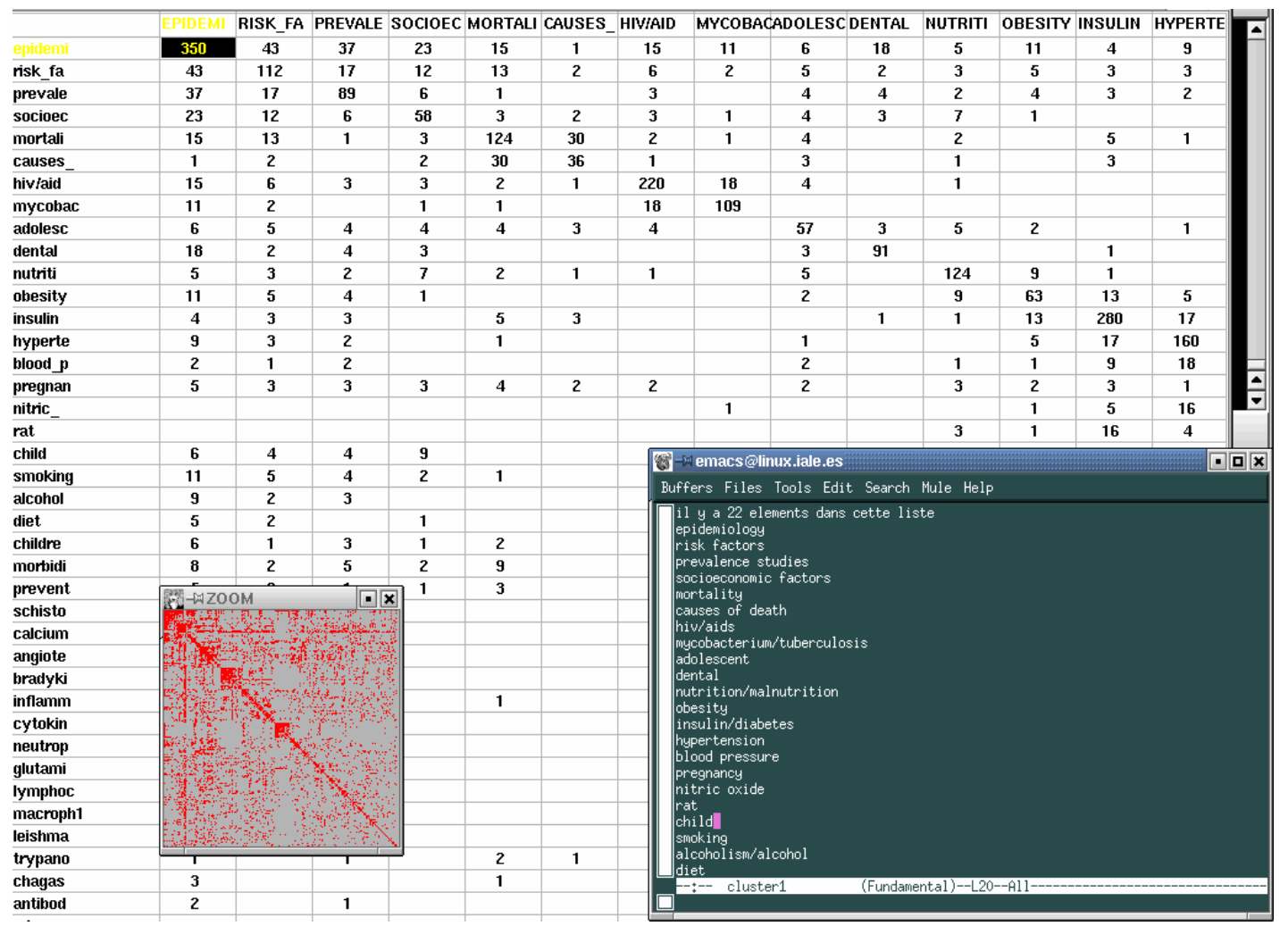

0 software "Tétralogie", utilizado para a realização destas análises, dispõe de uma função "zoom" que nos dá uma síntese gráfica de uma matriz de ocorrência. Nesta síntese se apresentam as magnitudes das ocorrências como pontos. Os "clusters" se concentram ao longo de uma diagonal e cada acumulação de pontos nesta diagonal representa um "cluster". Na informação gráfica do "zoom", as palavras com maiores freqüências aparecem, no inicio da diagonal. Pode se dar diferentes formas de ordenação à informação para conseguir melhores resultados nas análises de co-ocorrências. Entre estas formas está a ordenação por conexão ou ligação. A informação gráfica fornecida pelo "zoom" mostrará a qualidade e estrutura das ordenações conseguidas, conforme a figura 2 . 
Figura 2 - Zoom da matriz de co-ocorrência de Descritores

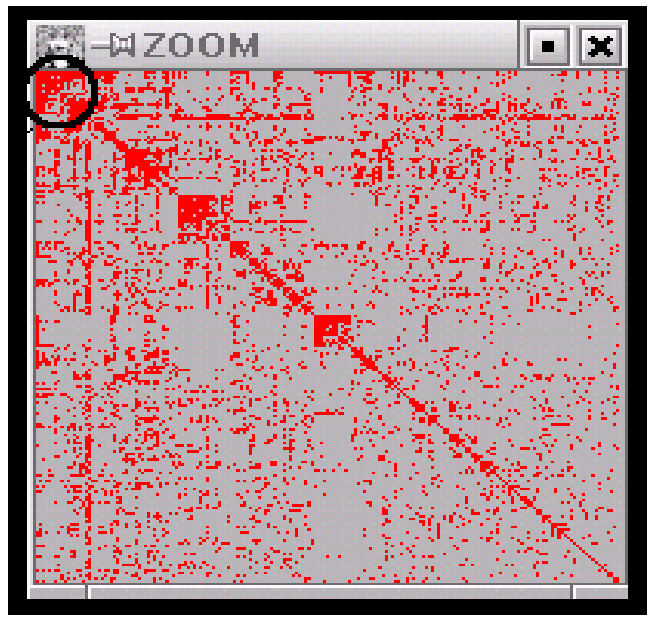

Figura 3 - Fragmento da matriz de co-ocorrência descritores, segundo 1\% das palavras de maior freqüência, das publicações brasileiras, registradas na base de dados da "web of Knowledge", no campo da saúde, no período de 1990 a 2002.

\begin{tabular}{|c|c|c|c|c|c|c|c|}
\hline & EPIDEMI & RISK FA & PREWALE & SOCIOEC & HORTALI & CAUSES & HWA \\
\hline apidemi & 350 & 43 & 37 & 23 & 15 & 1 & 15 \\
\hline isk fa & $49 \quad \$$ & 112 & 17 & 12 & 13 & 2 & 6 \\
\hline prevale & 37 & 17 & 69 & 6 & 1 & & 3 \\
\hline socioec: & 23 & 12 & 6 & 50 & 3 & 2 & 3 \\
\hline mortali & 15 & 13 & 1 & 3 & 124 & 30 & 2 \\
\hline causes & 1 & 2 & 8 & 2 & 30 & 36 & 1 \\
\hline iivfaid & 15 & 6 & 3 & 3 & 2 & 1 & 221 \\
\hline mycobac & 11 & 2 & 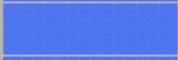 & 1 & 1 & & 18 \\
\hline adolesc & 6 & 5 & 4 & 4 & 4 & 3 & 4 \\
\hline iantal & 10 & 2 & 4 & 3 & & & \\
\hline nutriti & 5 & 3 & 2 & 7 & 2 & 1 & 1 \\
\hline abesity & 11 & 5 & 4 & 1 & & & \\
\hline insulin & 4 & 3 & 3 & & 5 & 3 & \\
\hline iyperte & 9 & 3 & 2 & & 1 & & \\
\hline Mond in & 2 & 1 & 2 & & & & \\
\hline Mreynal & 5 & 3 & 3 & 3 & 4 & 2 & 2 \\
\hline
\end{tabular}

figur

a 3 repre senta um fragm ento $\mathrm{da}$ matri $z$ de ocorrência de descritores e mostra algumas palavras do cluster e o grau de proximidade ou força de associação entre elas. Por exemplo, a palavra "epidemiology" co-ocorre com "risk factor" 43 vezes do total de sua aparição no campo de descritores. Na figura 4 descrevemos o total de palavras que compõe este grupo. Algumas 
palavras demonstram o campo de estudo como HIV/AIDS, mas quando associada a epidemiology ou "risk factor" ou "prevalence" podemos inferir com que finalidade. Sua forte relação com a palavra "mycobacterium" também sugere a importância da investigação e da pesquisa quando da associação dessas duas infecções, pois o advento da AIDS modificou o perfil epidemiológico da Tuberculose.

Figura 4 - Grupo de descritores, liderado pela palavra "epidemiology", das publicações brasileiras, registradas na base de dados da "web of Knowledge", no campo da saúde, no período de 1990 a 2002.

\begin{tabular}{|l|l|}
\hline epidemiology & obesity \\
risk factors & insulin/diabetes \\
prevalence studies & hypertension \\
socioeconomic factors & blood pressure \\
mortality & pregnancy \\
causes of death & nitric oxide \\
hiv/aids & rat \\
mycobacterium/tuberculosis & child \\
adolescent & smoking \\
dental & alcoholism/alcohol \\
nutrition/malnutrition & diet \\
\hline
\end{tabular}

Para construção dos mapas, foi utilizado método estatístico integrado, isto é, aplicou-se à matriz original, de números absolutos, a análise de componentes principais, para fazer emergir as palavras mais fortes. Esta análise permite identificar os eixos principais de uma nuvem de pontos e a melhor representação desta nuvem num triedro formado pelos primeiros eixos.

A figura 5 evidencia algumas das palavras mais freqüentes, lideradas por "epidemiology", porém as demais formam uma nuvem de pontos tornando impossível visualiza-las. 
Figura 5 - Mapa segundo matriz de co-ocorrência de descritores, das publicações brasileiras, registradas na base de dados da "web of Knowledge", no campo da saúde, no período de 1990 a 2002.

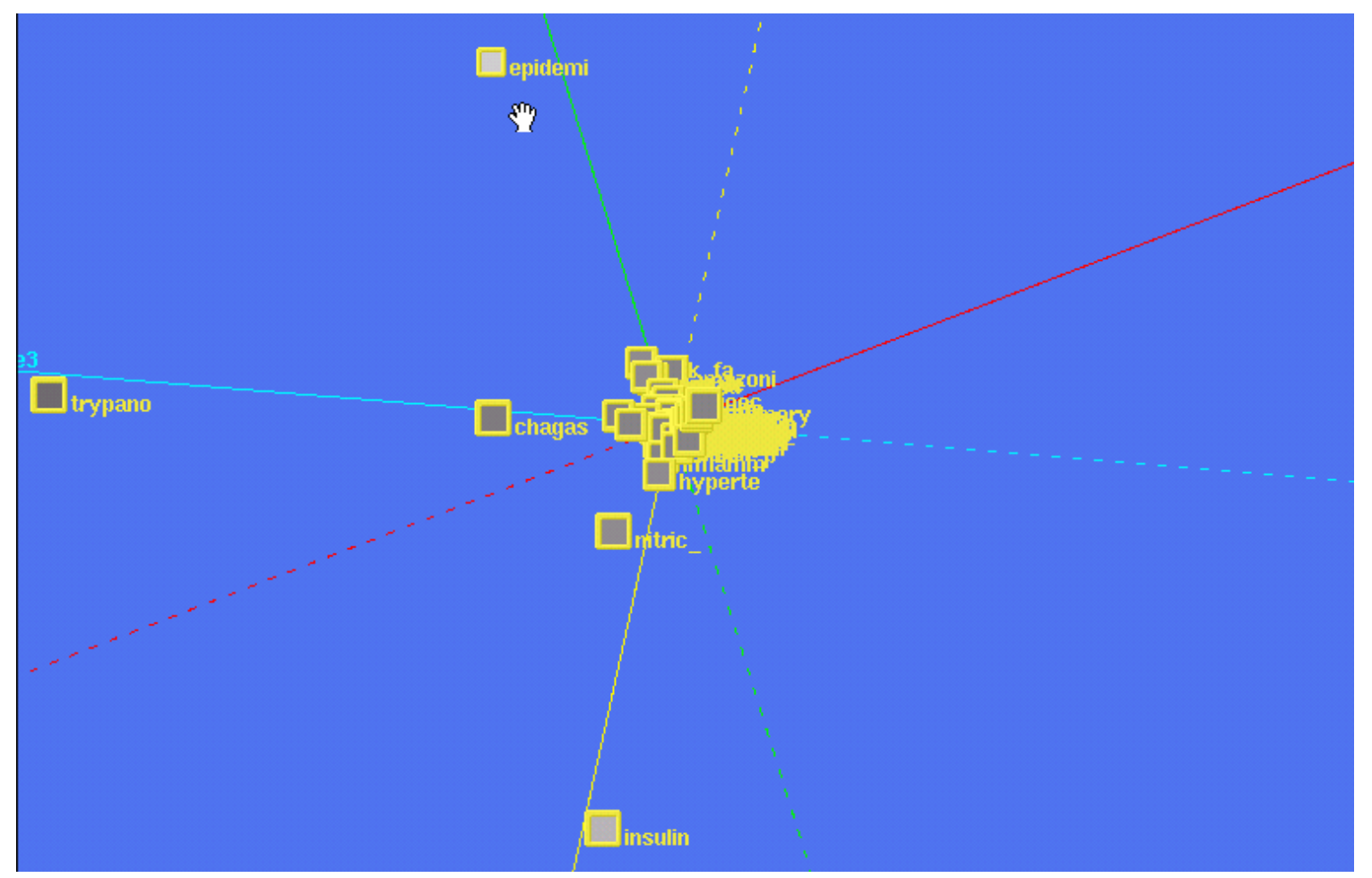

$\mathrm{Na}$ figura 6 temos outro fragmento da matriz de descritores, onde delimitamos novo "cluster", como evidencia o "zoom" no mesmo quadro. Este é composto por 14 palavras, lideradas pela palavra "anxiety", conforme descritas na figura 7 . 
Figura 6 - Fragmento da matriz de descritores, liderado pela palavra "anxiety", das publicações brasileiras, registradas na base de dados da "web of Knowledge", no campo da saúde, no período de 1990 a 2002.

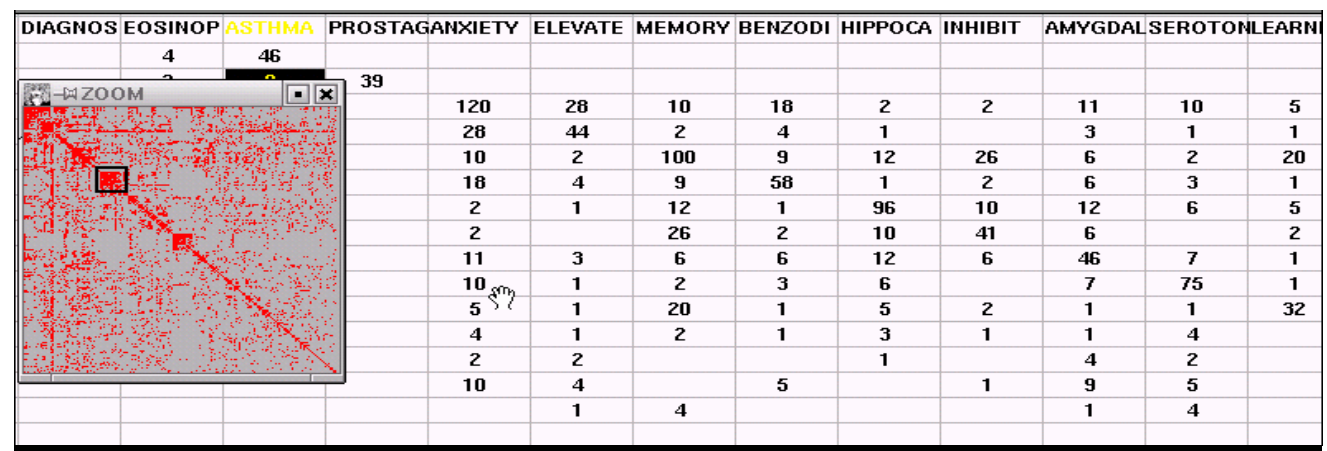

Figura 7 - Descritores liderados pela palavra "anxiety", das publicações brasileiras, registradas na base de dados da "web of Knowledge", no campo da saúde, no período de 1990 a 2002.

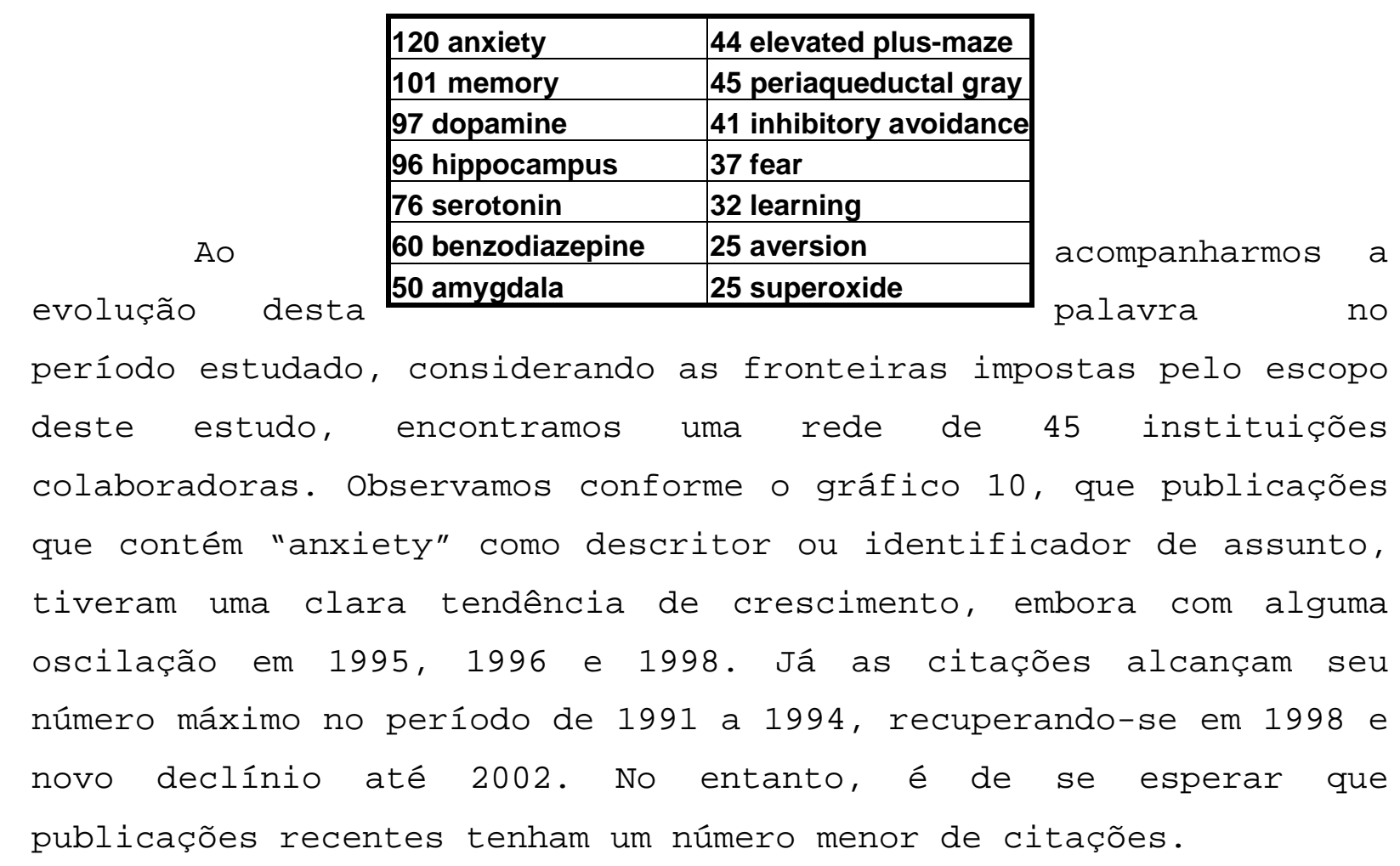


Gráfico 10 - Artigos e citações segundo a palavra "anxiety", registrado nos campos descritor e identificador, das publicações brasileiras, na base de dados da "web of Knowledge", no campo da saúde, no período de 1990 a 2002.

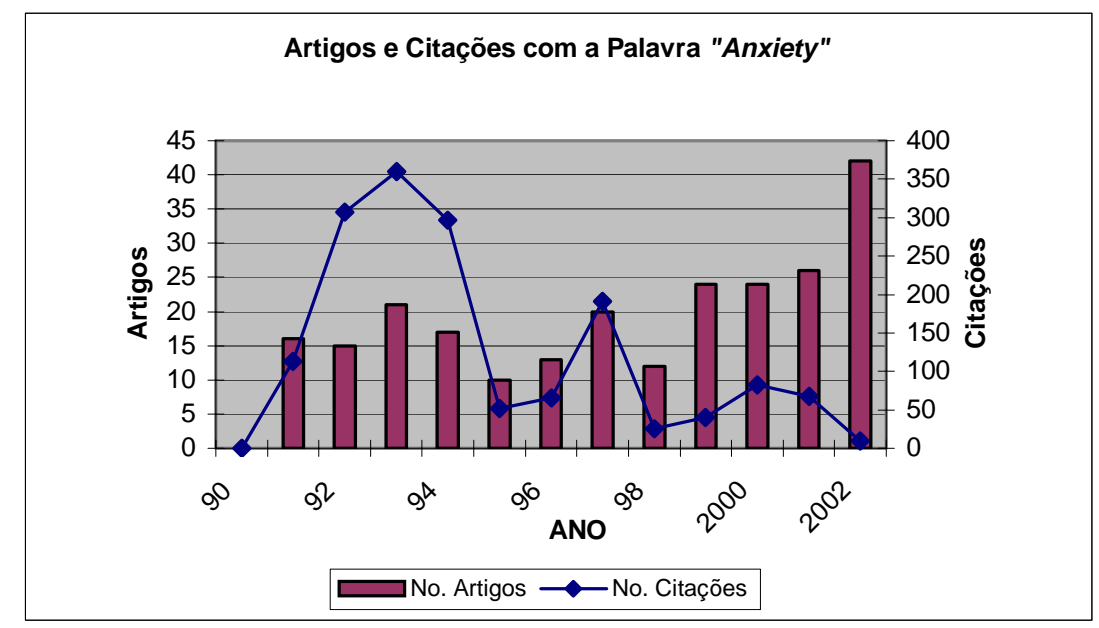

$\mathrm{Na}$ tabela 20, destacamos as instituições mais envolvidas com o termo "anxiety" e temos como líder a Universidade de São Paulo (USP) com 53,1\% do total de 177 publicações e 68,93\% do total das 1.926 citações no período. Optou-se por subdividir a USP em campi São Paulo e campi Ribeirão Preto devido à diferença de produção e número de citações da USP-Ribeirão Preto, que responde sozinha por $37,84 \%$ das publicações e $48,34 \%$ das citações. As colaborações internacionais com esta universidade se dão principalmente com as Universidades de Hull e Manchester e com o Guys Hospital na Inglaterra, com os laboratórios LNBC, CTR Neuroch. E SYTHELABO Recherche na França, as Universidades de Dusseldorf na Alemanha, de Mendoza na Argentina e a Hebraica de Jerusalém entre outras. 
Tabela 20 - Artigos e citações que contém a palavra "anxiety", segundo Universidades, das publicações brasileiras, na base de dados da "web of Knowledge", no campo da saúde, no período de 1990 a 2002.

\begin{tabular}{l|rrrr}
\hline Universidades & \multicolumn{1}{|c}{ Artigos } & \% Artigos & Citações & \% Citações \\
\hline USP-Ribeirão Preto & 67 & 37,84 & 931 & 48,34 \\
USP-São Paulo & 27 & 15,26 & 246 & 12,77 \\
UFSta.Catarina & 22 & 12,44 & 139 & 7,22 \\
UNIFESP & 20 & 11,3 & 47 & 2,44 \\
U.Maringá & 9 & 5,08 & 195 & 10,14 \\
UNESP & 8 & 4,52 & 49 & 2,54 \\
UFRSul & 8 & 4,52 & 142 & 7,37 \\
UNICAMP & 6 & 3,39 & 26 & 1,35 \\
U.F. Espírito Santo & 6 & 3,39 & 28 & 1,45 \\
UFRio Janeiro & 2 & 1,13 & 101 & 5,24 \\
UFParaná & 2 & 1,13 & 22 & 1,14 \\
\hline Total & 177 & 100 & 1926 & 100 \\
\hline
\end{tabular}

Outras instituições de destaque são a Universidade Federal de São Paulo e a Universidade Federal de Santa Catarina. Esta ultima têm como colaboradores a Universidade de "Leeds" na Inglaterra, mais recentemente a Universidade de Ferrara na Itália, mas sendo o "Institut National de la Santé et de la Recherche Médicale, -INSERM- da França, seu principal colaborador no exterior.

Pode-se dizer que tanto a USP quanto a UFSC, apresentam grupos de pesquisa consolidados nesse campo pois além da produtividade e impacto de seus trabalhos, ambas mantém uma atividade contínua ao longo do período. 
Figura 8 - Fragmento da matriz de co-ocorrência de descritores, das publicações brasileiras, registradas na base de dados da "web of Knowledge", no campo da saúde, no período de 1990 a 2002.

\begin{tabular}{|c|c|c|c|c|c|c|c|c|c|}
\hline ECOLOGY & YVECTORS & TRANSMI & AEDES & ANOPHEL & DENGUE & IRSECT_ & MOSQUIT & BIOMPHA & PARASIT \\
\hline & & & & & & & & & \\
\hline & & & & 2 & & & & 2 & \\
\hline & & sin & & 1 & & & & & \\
\hline & & & & & & & & & \\
\hline & & & & & & & & & \\
\hline 100 & 56 & 12 & 20 & 13 & 5 & 12 & 9 & 2 & 1 \\
\hline 56 & 62 & 10 & 17 & 11 & 5 & 8 & 8 & 2 & 1 \\
\hline 12 & 10 & 49 & 9 & 3 & 6 & 5 & 1 & 3 & 4 \\
\hline 20 & 17 & 9 & 52 & 1 & 13 & 8 & 7 & & \\
\hline 13 & 11 & 3 & 1 & 45 & & 3 & 6 & & 2 \\
\hline 5 & 5 & 6 & 13 & & 24 & 5 & 2 & & \\
\hline 12 & 8 & 5 & 8 & 3 & 5 & 21 & 1 & & 3 \\
\hline 9 & 8 & 1 & 7 & 6 & 2 & 1 & 31 & & \\
\hline 2 & 2 & 3 & 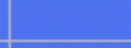 & & & & & 48 & 9 \\
\hline 1 & 1 & 4 & $=1$ & 2 & & 3 & & 9 & 48 \\
\hline 11 & 8 & 2 & 4 & & 1 & 9 & 2 & & 1 \\
\hline 2 & 2 & 1 & 2 & & 1 & & & 2 & \\
\hline 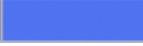 & . & 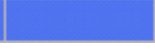 & 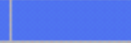 & & . & & & 1 & 1 \\
\hline
\end{tabular}

Figura 9 - Lista de descritores, das publicações brasileiras, registradas na base de dados da "web of Knowledge", no campo da saúde, no período de 1990 a 2002.

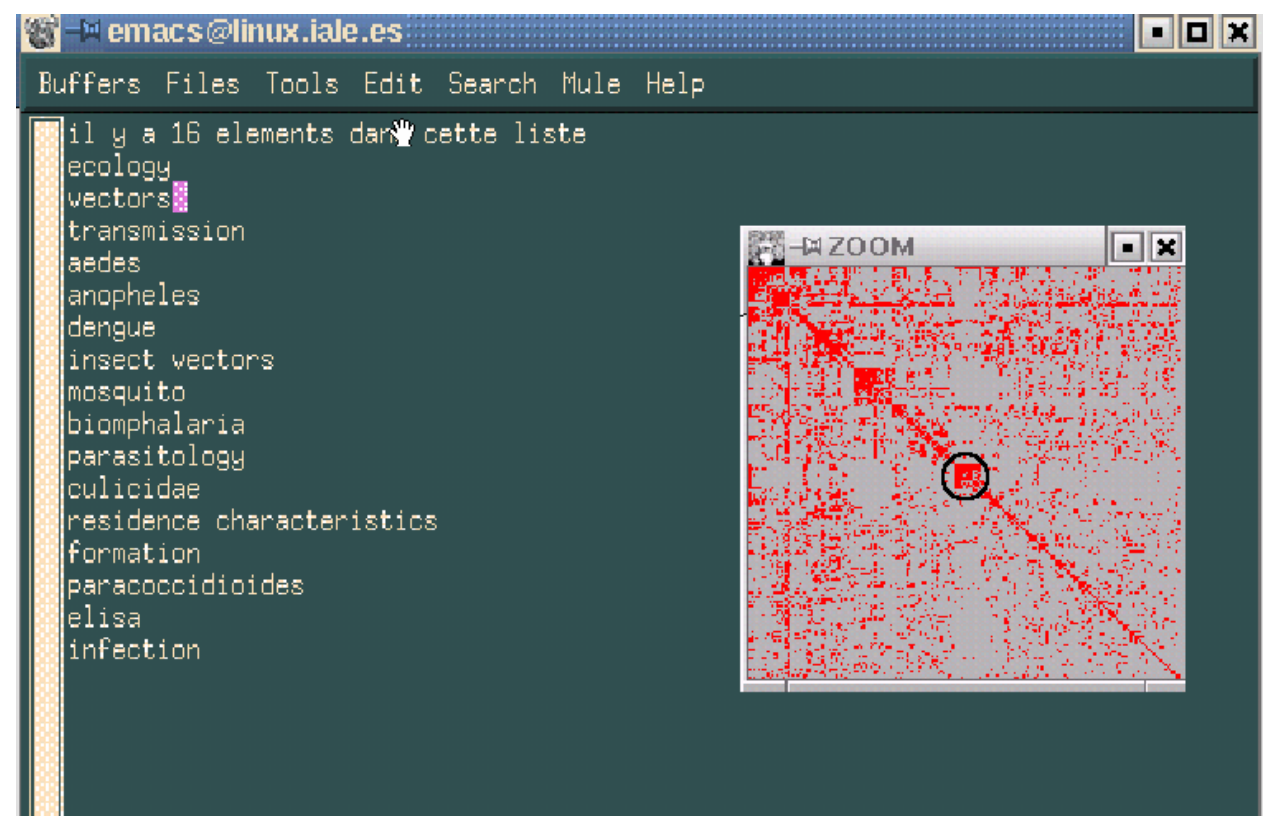


A figura 8 é um fragmento de uma matriz de co-ocorrência de descritores, simples e simétrica, onde está evidenciado o "cluster ecology" e a figura 9 é o resultado da decomposição dessa matriz na sua síntese gráfica, representado pelo "zoom" e na tábua que mostra as palavras do "cluster" bem delimitado e que está liderado pela palavra ecologia, contém 16 elementos, a saber: "Ecology, vectors, transmission, aedes, anopheles, dengue, insect, vectors, mosquito, biomphalaria, parasitology, culicidae, residence characteristics, formation, paracoccidioides, Elisa e infection". Este grupo de palavras foi escolhido para representar os exemplos de mapas tecnológicos e para evidenciar a potencialidade das análises de co-ocorrência com as demais variáveis que estão demonstradas a seguir.

Quando os dados são da mesma natureza, como o cruzamento de descritores com descritores, utiliza-se a métrica euclidiana. Nos mapas da figura 10 e 11, utilizou-se análise dos componentes principais reduzidos com a classificação por análise hierárquica com métrica euclidiana. A análise dos componentes principais reduzidos (ACPR) parte de normalizar os dados e equilibrar os caracteres analisados. A redução dos dados permite considerar as variáveis de menor valor absoluto. Nestes mapas, são evidenciados distintos grupos de palavras que possuem maior afinidade entre si e estão representados por cores ou apresentam a lista de palavras. A figura 10 mostra o mapa com 4 grupos diferenciados pela cor segundo a proximidade das palavras, o que permite diferenciar "clusters" bem definidos. 
Figura 10 - Mapa dos "clusters", segundo matriz de co-ocorrência de descritores, das publicações brasileiras, registradas na base de dados da "web of Knowledge", no campo da saúde, no período de 1990 a 2002.

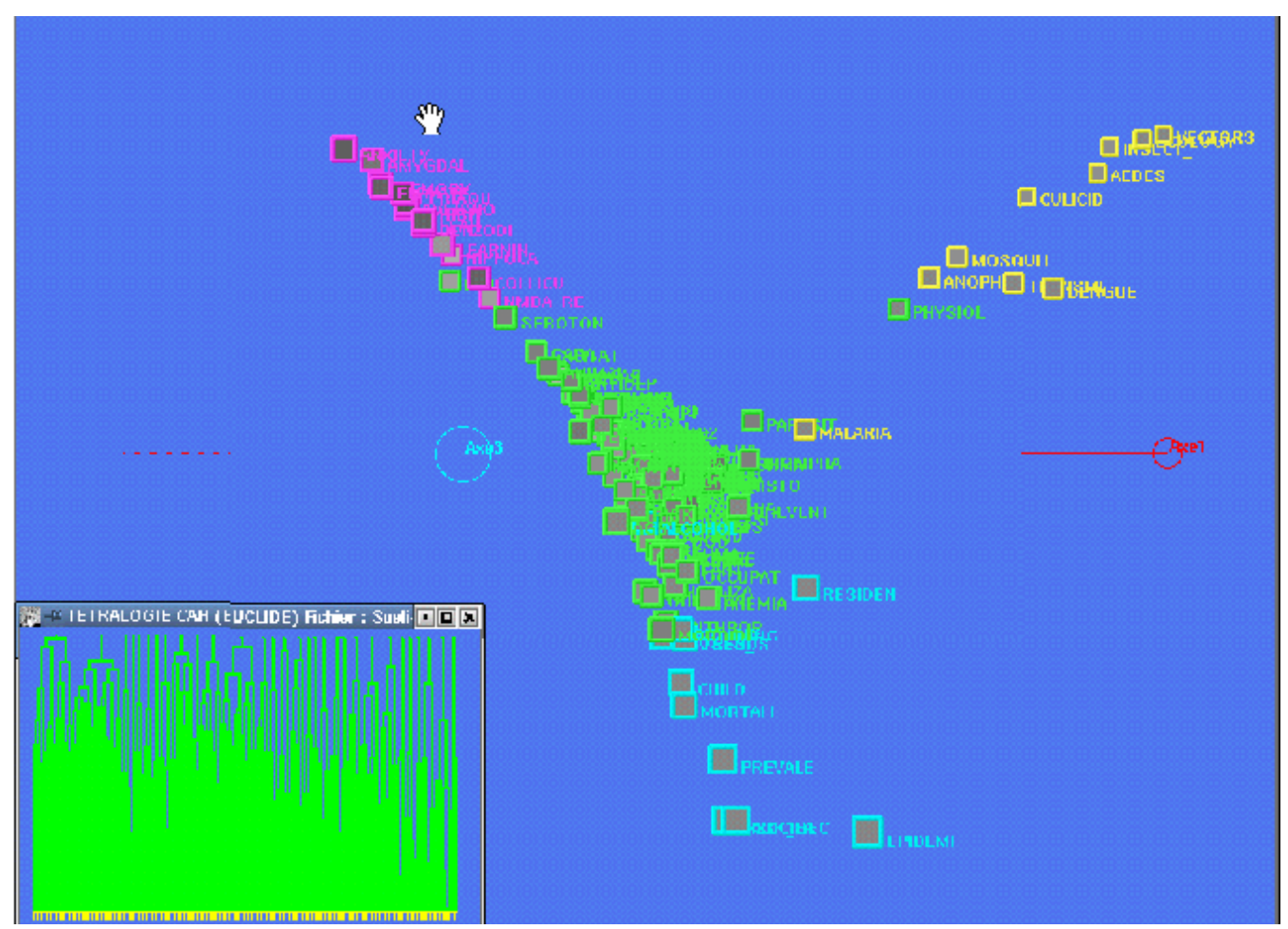

Figura 11 - Mapa segundo matriz de co-ocorrência de descritores, das publicações brasileiras, registradas na base de dados da "web of Knowledge", no campo da saúde, no período de 1990 a 2002.

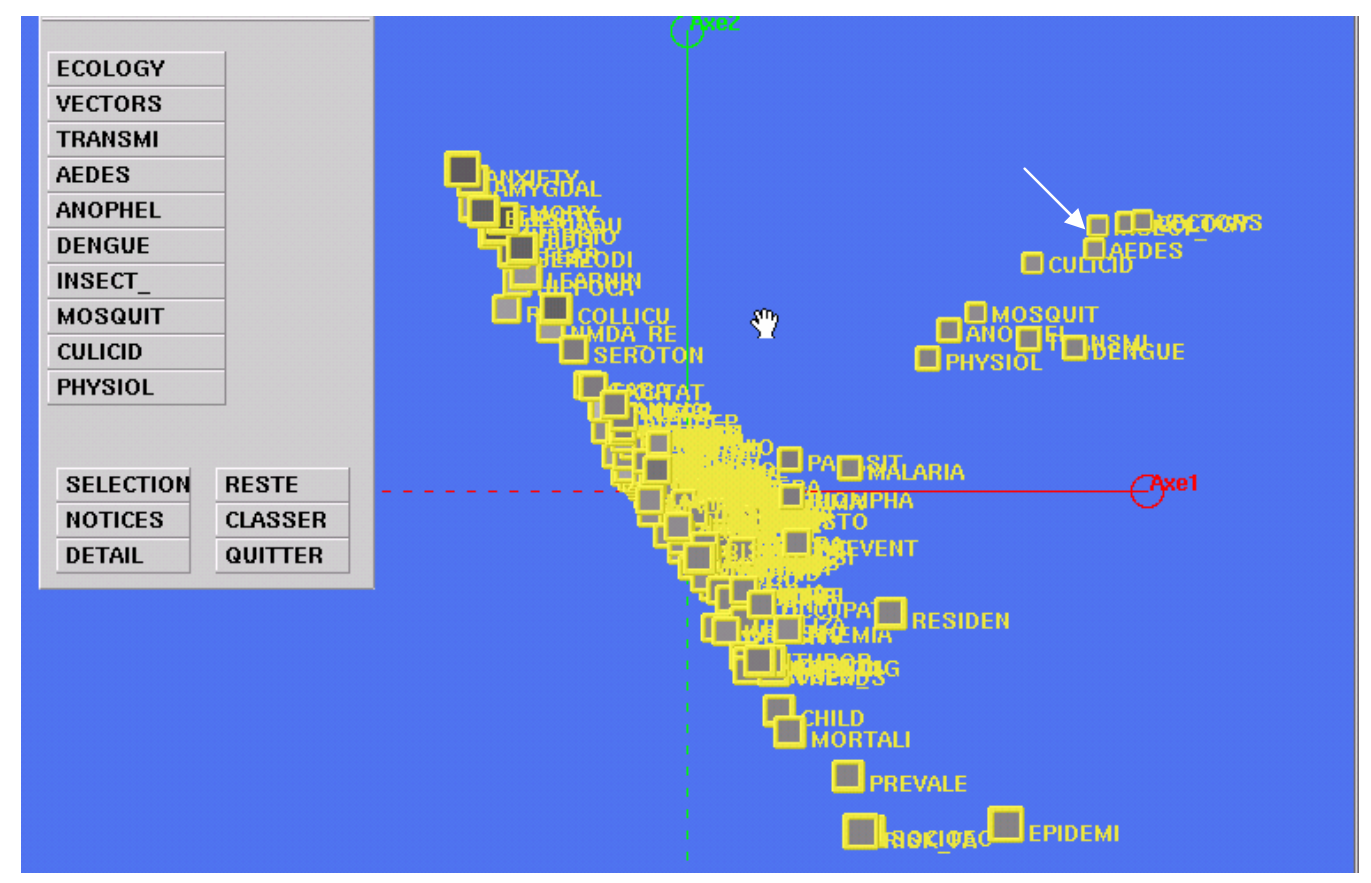


Já o mapa da figura 11, evidencia o grupo que aparece na matriz da figura 8 que será estudado quanto as suas relações com autores, identificadores e instituições.

\subsubsection{ANÁLISE DOS IDENTIFICADORES}

Os identificadores somaram 40.160 palavras diferentes no total de 38.349 registros em todo o banco de dados e correspondem às palavras-chave presentes no campo de identificadores de cada artigo. Abaixo, a tabela 21 apresenta os 20 primeiros identificadores por ordem decrescente de freqüência, antes e após o tratamento com o arquivo de sinônimos. Palavras como "protein" e "rats", por exemplo, tiveram sua freqüência praticamente duplicada após a correção pelos sinônimos. 
Tabela 21 - Identificadores, liderado pela palavra "expression" e "protein", das publicações brasileiras, registradas na base de dados da "web of Knowledge", no campo da saúde, no período de 1990 a 2002.

\begin{tabular}{|c|c|c|c|c|}
\hline & $\begin{array}{l}\text { FREQÜÊNCIA DE } \\
\text { IDENTIFICADORES }\end{array}$ & FRE & $\begin{array}{r}\text { QÜÊNCIA DE } \\
\text { APÓS SI }\end{array}$ & $\begin{array}{l}\text { NTIFICADORES } \\
\text { IIMOS }\end{array}$ \\
\hline 741 & EXPRESSION & 835 & PROTEIN & \\
\hline 581 & CELLS & 765 & RAT & \\
\hline 547 & IDENTIFICATION & 741 & EXPRESSION & \\
\hline 518 & DISEASE & 631 & INFECTION & \\
\hline 509 & INFEfrION & Desc & citors & $\%$ \\
\hline $\begin{array}{l}438 \\
433\end{array}$ & PROTEIN 1 & $562^{25}$ & D\$GE्ASE & 63,54 \\
\hline 413 & $R A T$ & $547_{14}$ & IBE $82^{T}$ IFICA & 36,46 \\
\hline 404 & MICE & 468 & RECEPTOR & \\
\hline 389 & PROTEIN'Sotal & 43840 & MEQPTIONS & 100 \\
\hline 374 & DNA & 438 & GENE & \\
\hline 366 & CHILDREN & 383 & CHILDREN & \\
\hline 360 & BINDING & 378 & BINDING & \\
\hline 358 & INHIBITION & 374 & DNA & \\
\hline 357 & BRAIN & 361 & INHIBITION & \\
\hline 342 & GROWTH & 357 & BRAIN & \\
\hline 340 & RATS & 342 & GROWTH & \\
\hline 315 & PURIFICATION & 336 & POPULATION & \\
\hline 297 & BRAZIL & 323 & CANCER & \\
\hline 282 & ACTIVATION & 315 & PURIFICATI & \\
\hline
\end{tabular}

A tabela 22 demonstra o percentual dos identificadores segundo sua freqüência e observamos que $63,54 \%$ destes aparecem apenas uma vez como identificador de assunto de um artigo, um percentual menor se comparado com os descritores. Somente 36,46\% dos 40.160 identificadores, têm freqüência >2. Ainda assim, apenas $2,96 \%$ das palavras têm uma freqüência de ocorrência de até 10 vezes, no período estudado.

Tabela 22 - Percentual dos Identificadores segundo sua freqüência de ocorrência, nas publicações brasileiras, registradas na base de dados da "web of Knowledge", no campo da saúde, no período de 1990 a 2002. 
Para avaliar as relações entre identificadores e descritores, foi realizado um cruzamento com o campo dos descritores e identificadores. Utilizamos o total de indicadores e apenas descritores constantes da figura 39 para fazer emergir a co-ocorrência de palavras entre eles. Ambos arquivos foram antes tratados com seus respectivos filtros de sinônimos.

A visualização dos resultados é dada primeiramente por uma matriz de co-ocorrência simples e assimétrica, pois trabalhamos campos diferentes, e em arquivos do editor de texto, "ultra edit".

A melhor maneira para visualizar os mesmos resultados de forma gráfica são os mapas tecnológicos. Na figura 12 podemos observar em cores diferentes os descritores e identificadores, formando 5 sub-grupos de palavras com maior afinidade entre si. Podemos selecionar os grupos para obtermos a lista de palavras correspondentes a cada grupo. Feita esta seleção, obtivemos os resultados que podem ser visualizados em editor de texto.

Figura 12 - Grupo 4 de descritores, das publicações brasileiras, liderado pela palavra ecologia, registradas na base de dados da "web of Knowledge", no campo da saúde, no período de 1990 a 2002. 


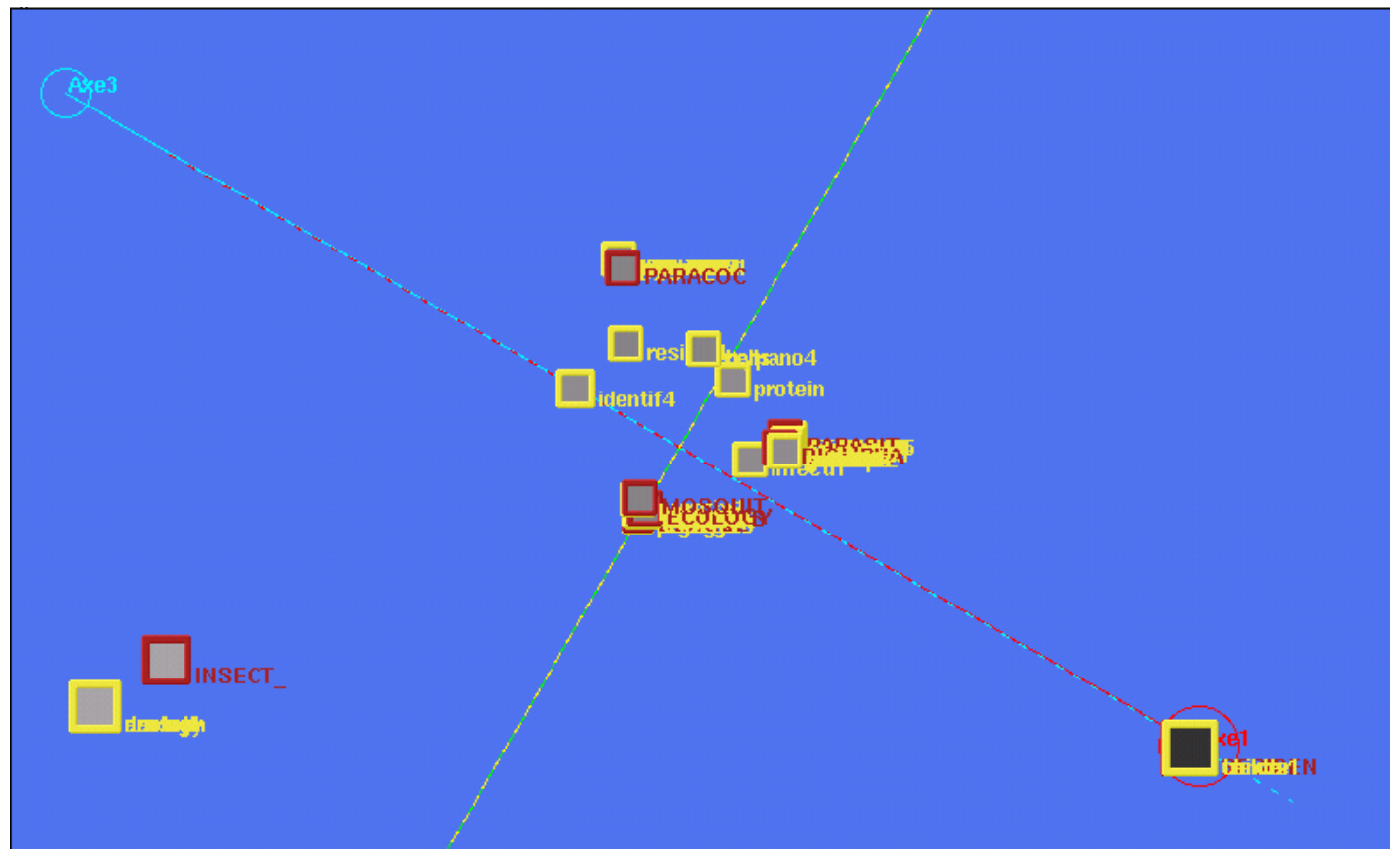

os resultados são emitidos por meio de uma lista de palavras em 2 colunas. A coluna a direita mostra os identificadores em letra minúscula. A coluna da esquerda, que aparecem em letras maiúsculas, evidencia os descritores, ou seja, a relação existente entre um ou mais descritores, neste caso apenas os relacionados na figura 8, com todos os identificadores que tem proximidades com essas palavras. Isto significa que o descritor em evidência co-ocorre com os diferentes identificadores apresentados, num mesmo artigo. Os 5 sub-grupos originados desta análise, com 1 ou mais descritores liderando cada grupo de palavras associadas, estão demonstrados nas figuras 13, 14, 15, 16 e 17. Um único descritor pode estar ligado a vários termos que estejam ocorrendo juntos em identificadores, o que pode significar que o âmbito do trabalho é maior, mais amplo do que fixou o "thesaurus". 
Figura 13 - Cruzamento de descritores e identificadores, das publicações brasileiras, registradas na base de dados da "web of Knowledge", no campo da saúde, no período de 1990 a 2002.

Figura 14 - Cruzamento de descritores e identificadores, das publicações brasileiras, registradas na base de dados da "web of Knowledge", no campo

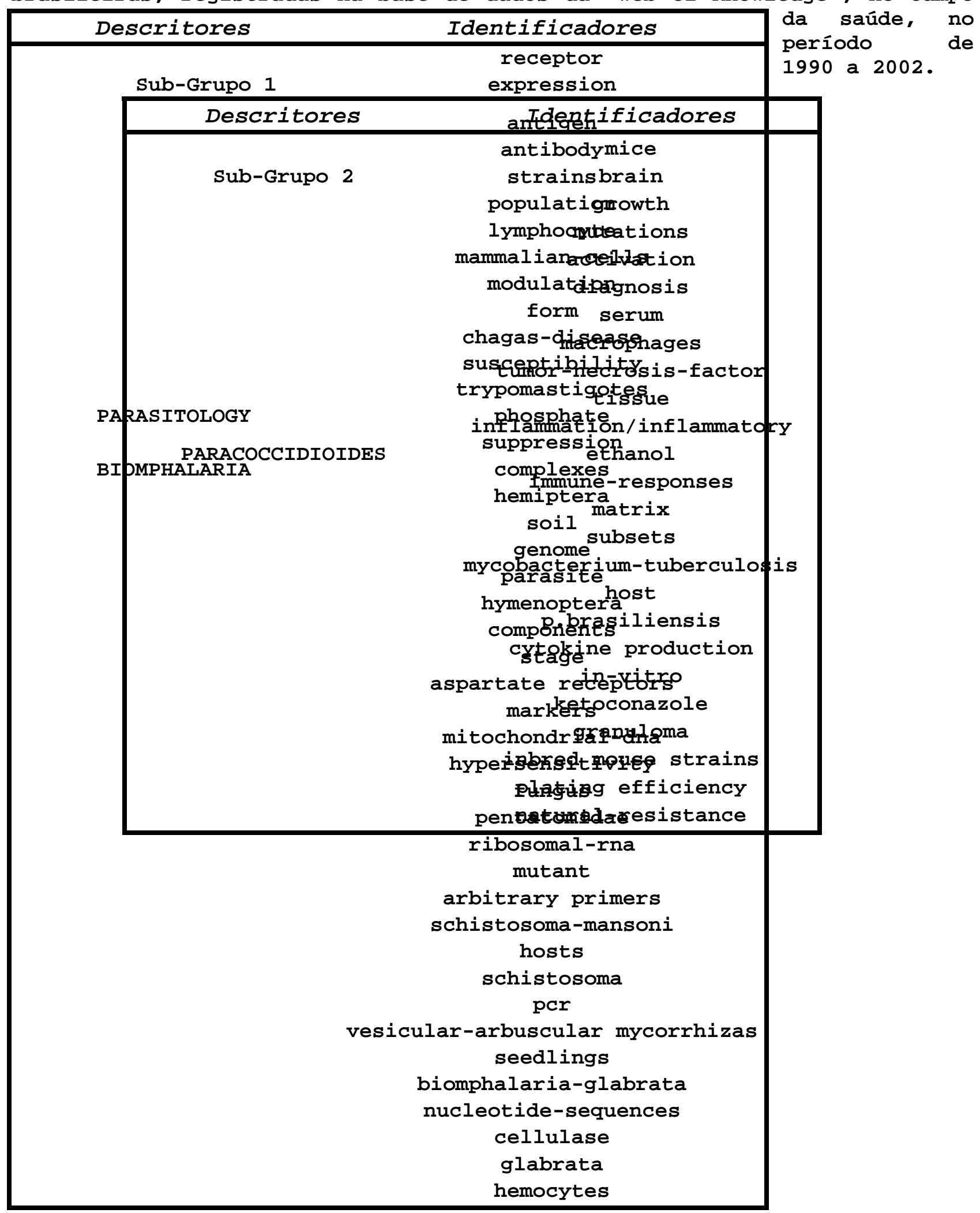


Figura 15 - Cruzamento de descritores e identificadores, das publicações brasileiras, registradas na base de dados da "web of Knowledge", no campo da saúde, no período de 1990 a 2002.

\begin{tabular}{|cc|}
\hline Descritores & Identificadores \\
\hline Sub-Grupo 3 & children \\
& cancer \\
& trends \\
RESIDENCE & helminth communities \\
CHARACTERISTICS & density \\
& model \\
& stability \\
& survival \\
& richness \\
& age \\
& vector \\
& income \\
& undernutrition \\
& population \\
& community \\
& health \\
& competition \\
& culicidae \\
& diptera \\
& america \\
& iron-deficiency \\
& supplementation \\
cancer mortality & \\
&
\end{tabular}


Figura 16 - Cruzamento de descritores e identificadores, das publicações brasileiras, registradas na base de dados da "web of Knowledge", no campo da saúde, no período de 1990 a 2002.

Ao estudarmos por exemplo, a figura 48, os resultados das

\begin{tabular}{|c|c|}
\hline Descritores & Identificadores \\
\hline $\begin{array}{c}\text { Sub-Grupo } 4 \\
\\
\\
\text { ECOLOGY } \\
\text { VECTORS } \\
\text { MOSQUITO } \\
\text { AEDES } \\
\text { ANOPHELES } \\
\text { DENGUE } \\
\text { CULICIDAE }\end{array}$ & $\begin{array}{c}\text { monoclonal-antibodies } \\
\text { brazil } \\
\text { virus } \\
\text { united-states } \\
\text { pathogenesis } \\
\text { diptera } \\
\text { transmission } \\
\text { sao-paulo state } \\
\text { organization } \\
\text { immunosorbent-assay } \\
\text { culicidae } \\
\text { biology } \\
\text { mosquito } \\
\text { psychodidae } \\
\text { vector } \\
\text { fixation } \\
\text { fever } \\
\text { ribeira valley } \\
\text { project } \\
\text { pyrethroids } \\
\text { field-evaluation } \\
\text { hemorrhagic-disease } \\
\text { irrigation }\end{array}$ \\
\hline
\end{tabular}

relações entre descritores e identificadores, temos que o grupo de palavras liderado por "ecology" co-ocorre com "ribeira valley, irrigation, mosquito, sao-paulo state, psychodidae, culicidae, hemorrhagic-disease, vector", entre outras e podemos concluir, por exemplo, que a linha de pesquisa está voltada para insetos vetores e que o grupo tem investigado algumas regiões do estado, ricas em material para seus estudos, onde as condições são favoráveis ao desenvolvimento desses insetos e à manutenção da transmissão das doenças por eles veiculados. 
Figura 17 - Cruzamento de descritores e identificadores, das publicações brasileiras, registradas na base de dados da "web of Knowledge", no campo da saúde, no período de 1990 a 2002.

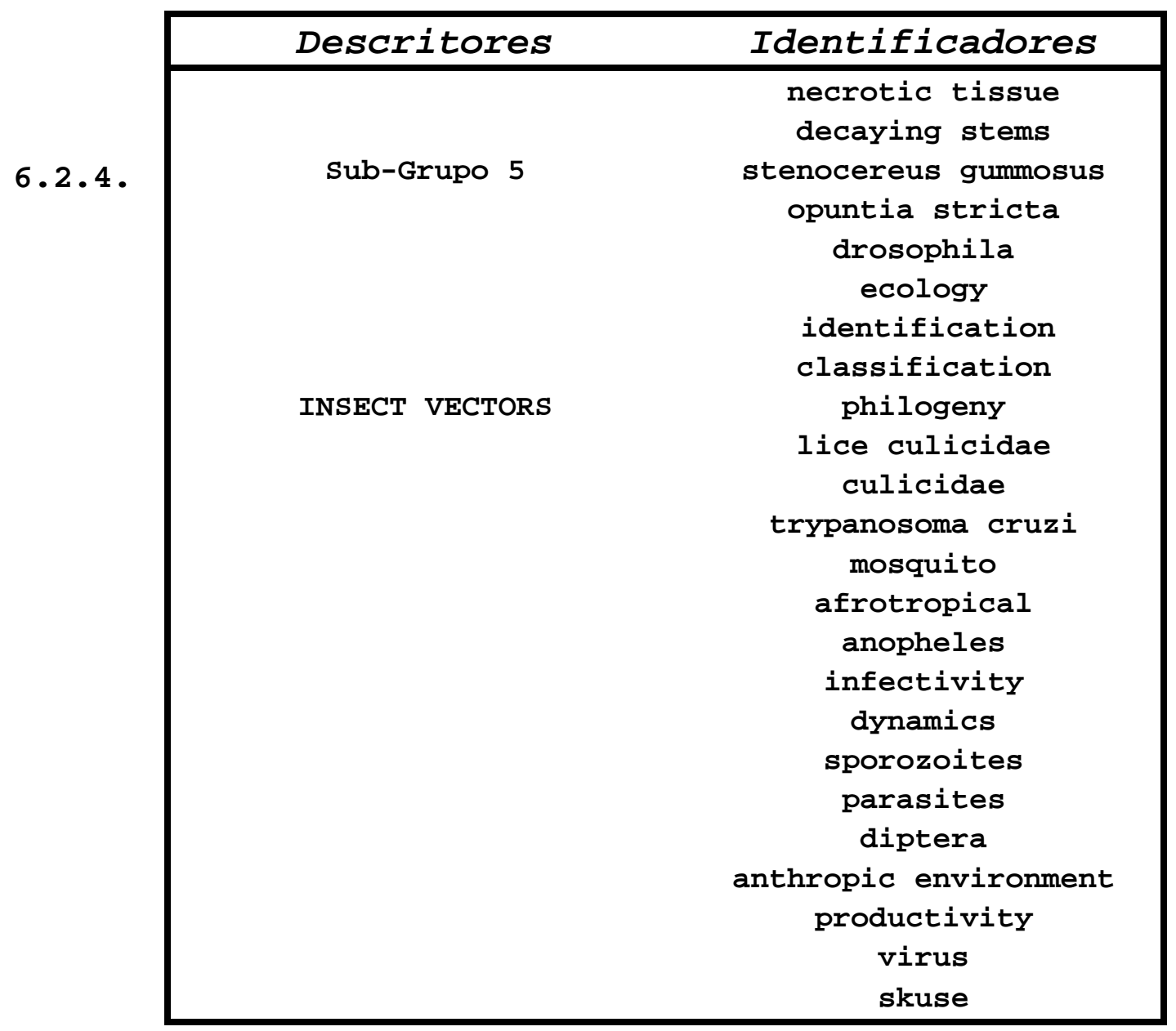

\section{ANÁLISE DOS AUTORES}

0 produto inicial da contagem realizada para o campo de autores continha 148.971 registros, contando a totalidade dos autores presentes no banco de dados e que estão registrados nos campos AU1, AU2, AU3... até AU6. Neste caso, além das duplicações, em alguns registros as informações presentes no 
campo endereço, devido sua formatação original na base de dados, "invadiram" o campo de autores. Após a retirada de dados não pertinentes e tratamento morfológico, este campo livre de duplicações e interferências conta com 73.644 autores, ou seja, a contagem inicial somava $49,43 \%$ registros indesejáveis.

Para exemplificar estudos com autores, tomamos por referência as palavras lideradas pelo grupo "ecology" que estão evidenciadas no fragmento de matriz da figura 8 e na figura 9. Foi realizada uma contagem de autores, com até 3 publicações no período, utilizando-se como filtro este grupo de palavras. Após selecionar os autores pertencentes a esse grupo, relacionados no anexo 4, o cruzamento entre autores resultou numa matriz, cujo fragmento está representado na figura 18. Neste, a função "zoom" evidencia a síntese gráfica da matriz, onde "clusters" aparecem bem delimitados. É possível consultar o conteúdo de cada "cluster" e dessa forma visualizar a que grupo se refere. Do "cluster" assinalado com a seta, figura 18, emerge um grupo de autores, doravante chamado "cluster ecology", aqui representado pelo autor "Forattini".

Figura 18 - Autores do "cluster ecology" segundo publicações brasileiras, no campo da saúde, registradas na base de dados da "web of Knowledge", no período de 1990 a 2002.

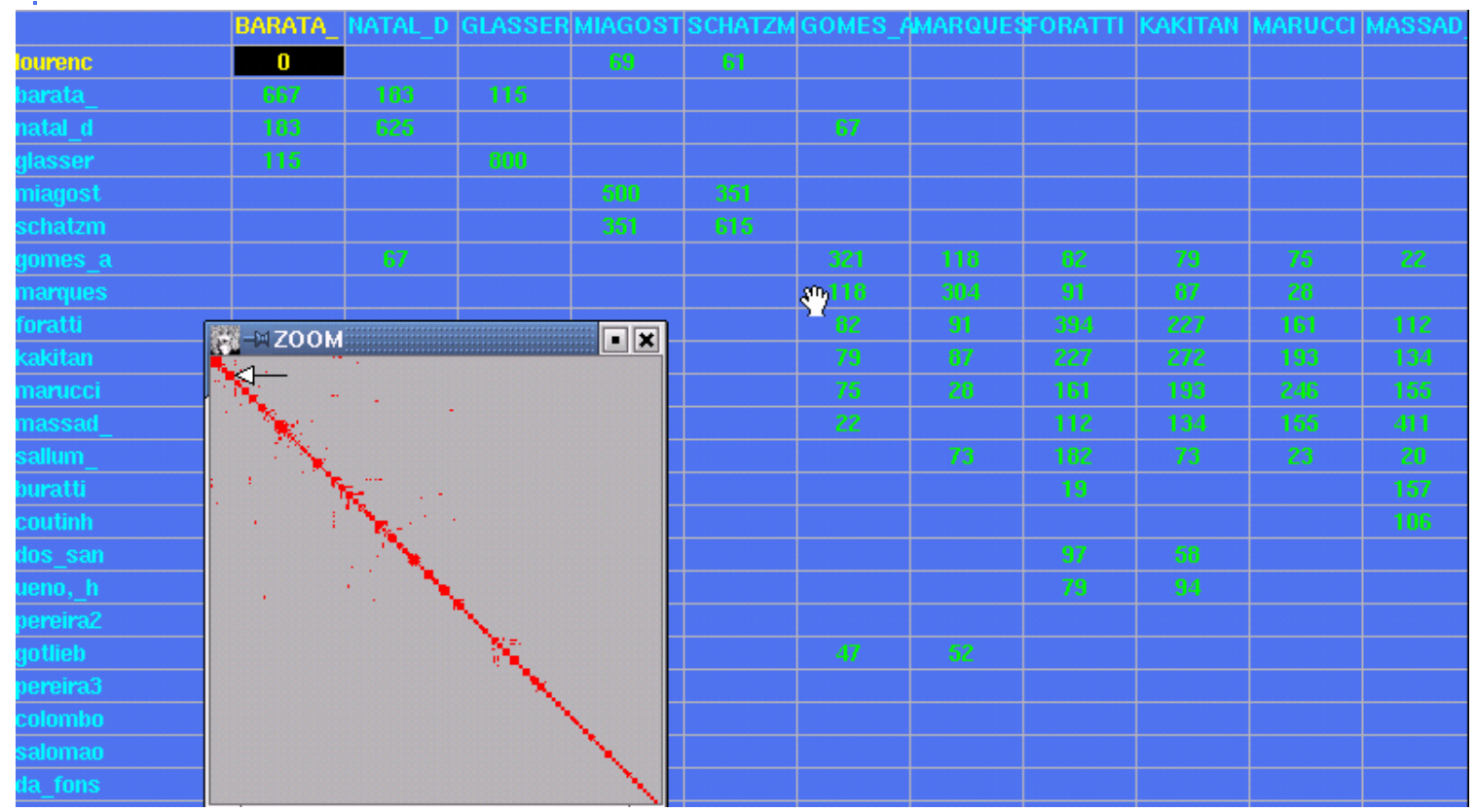


Figura 19 - Mapa de autores do "cluster" ecology, segundo descritores, registradas na base de dados da "web of Knowledge", no campo da saúde, no período de 1990 a 2002.

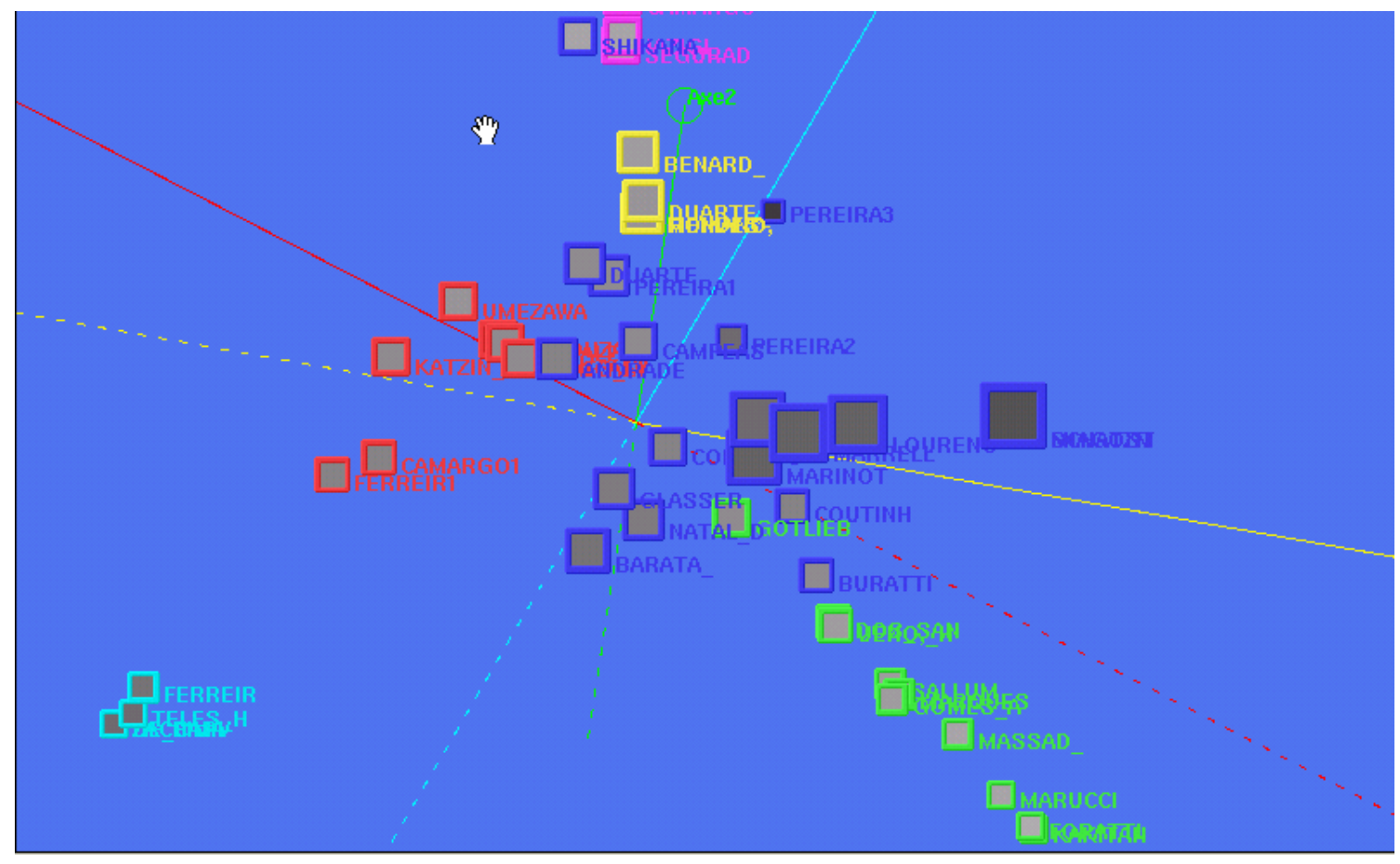

$\mathrm{Na}$ figura 19, podemos ver no mapa tecnológico, com identificação colorida, os grupos de autores que compõe o "cluster ecology". Nota-se no mapa uma interface entre os "clusters" liderados por "Forattini" e "Burattini", devido a eventuais colaborações e na figura 20 temos um mapa de autores onde distinguimos, no detalhe ao lado, a descrição do grupo liderado pelo autor "Forattini".

Figura 20 - Mapa de autores do "cluster" ecology, segundo descritores, registradas na base de dados da "web of Knowledge", no campo da saúde, no período de 1990 a 2002. 


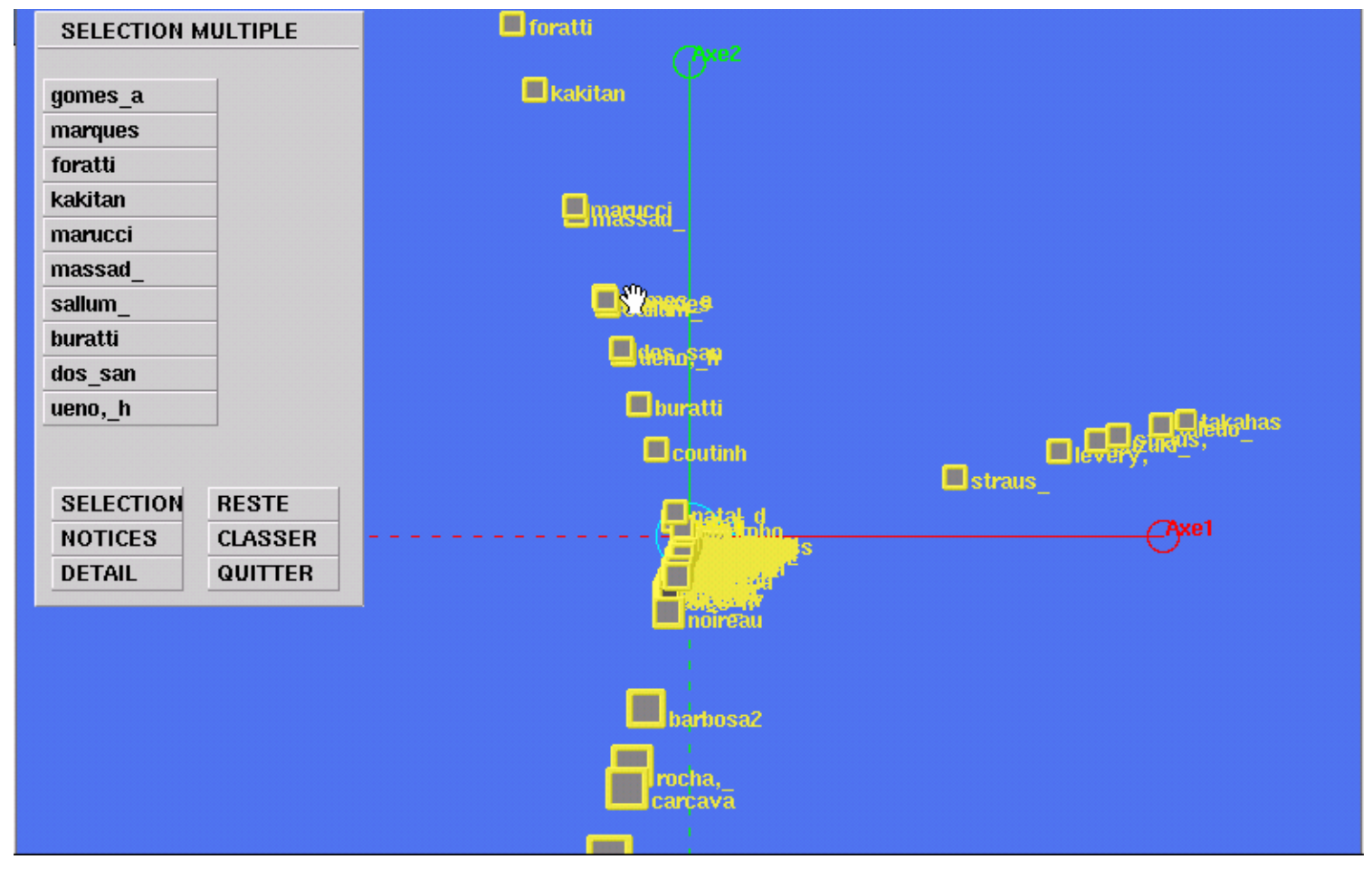


Figura 21 - Mapa tecnológico de autores e descritores do "cluster ecology", segundo publicações brasileiras, registradas na base de dados da "web of Knowledge", no campo da saúde, no período de 1990 a 2002.

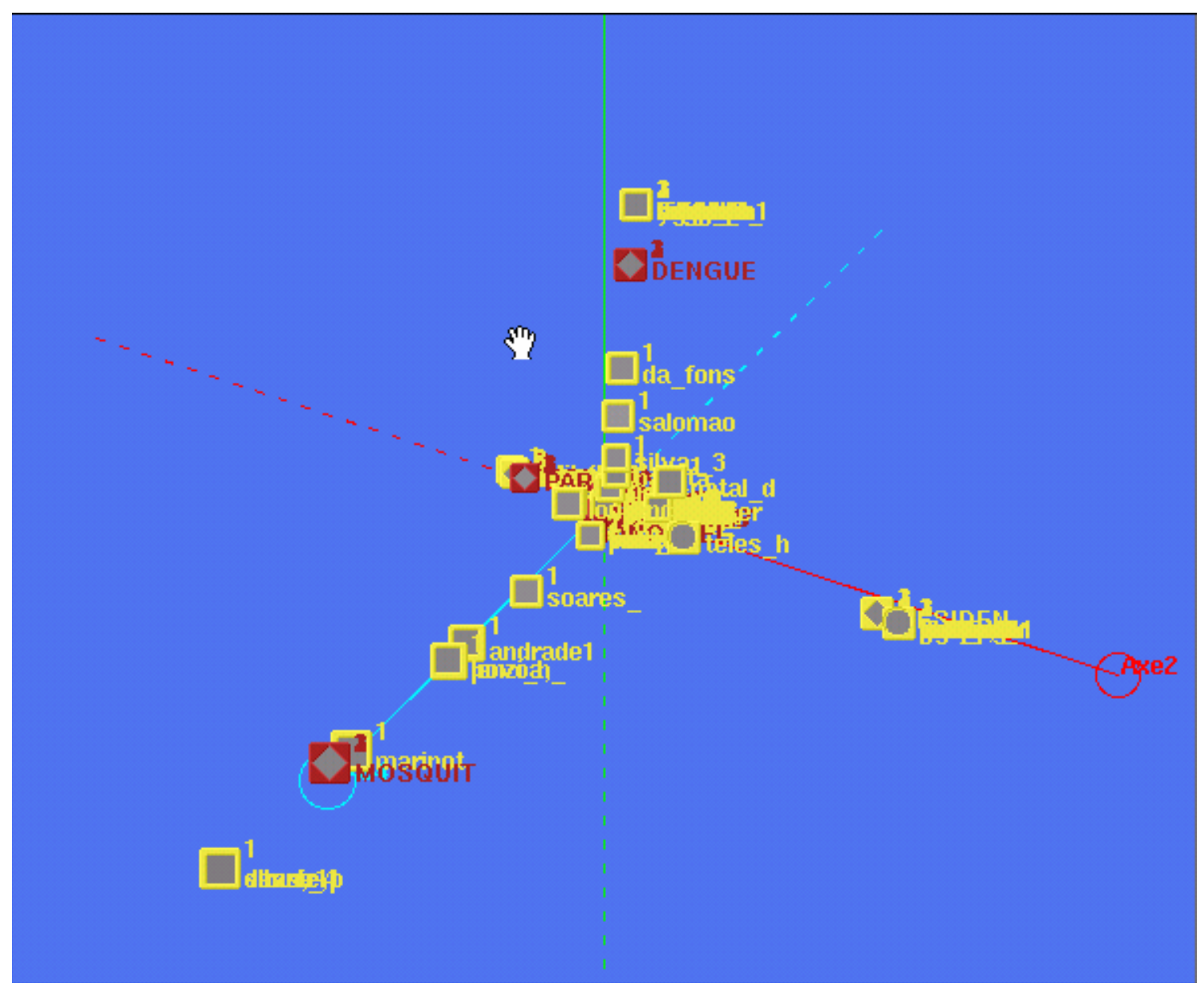

$\mathrm{Na}$ figura 21 e 22 os mapas tecnológicos representam uma matriz simples assimétrica de co-ocorrência dos campos descritores e autores, onde podemos verificar a proximidade de grupos de palavras descritoras de temas e seus respectivos autores, na figura 22 o detalhe indica autores que tem maior afinidade com palavra dengue.

Figura 22 - Mapa tecnológico de autores e descritores do "cluster ecology", segundo publicações brasileiras, registradas na base de dados da "web of Knowledge", no campo da saúde, no período de 1990 a 2002. 
Na figura 23 mostramos a evolução das colaborações entre

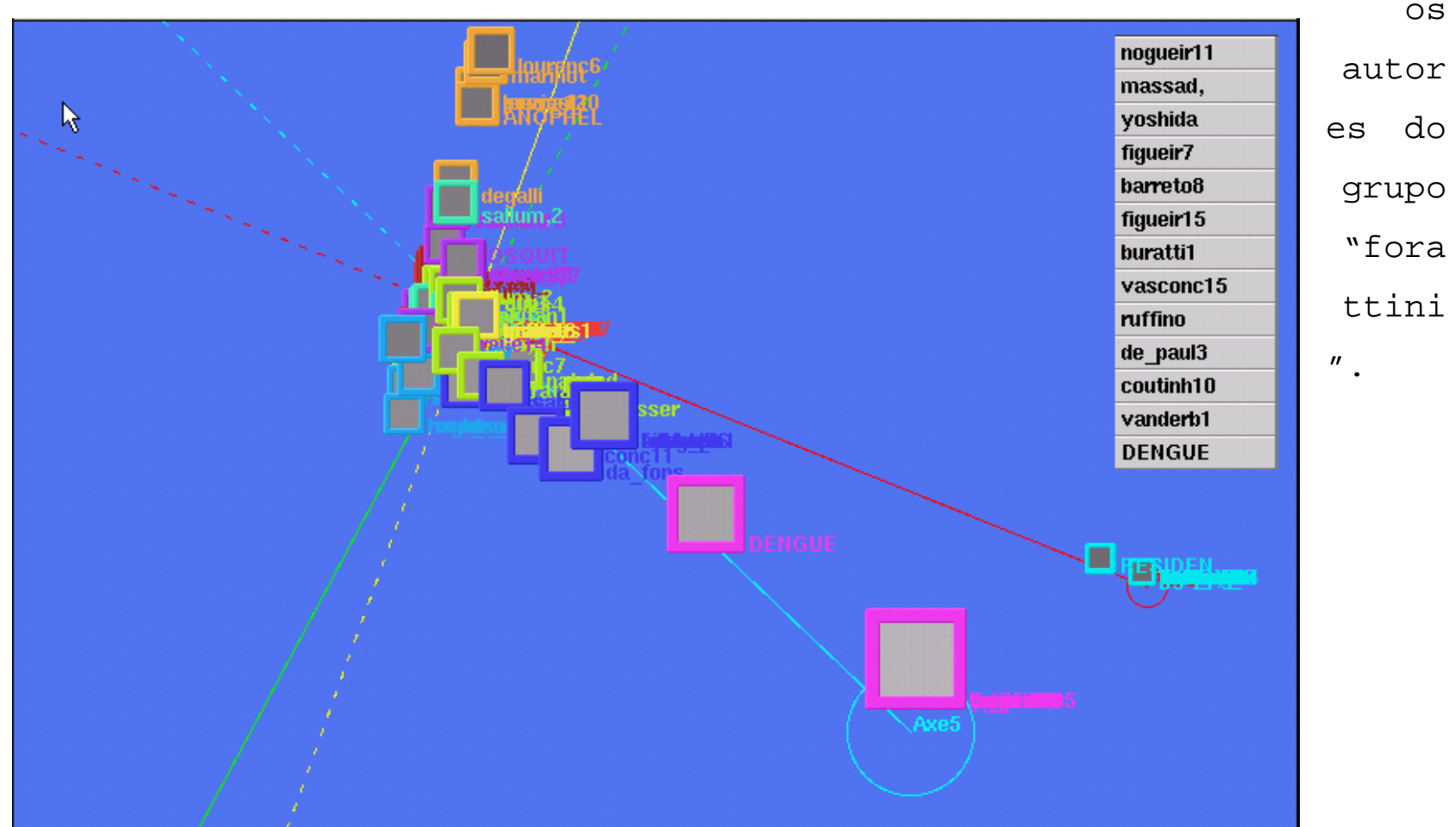

Figura 23 - Evolução do Grupo de autores relacionados ao autor "Forattini" nos períodos 1990-1994, 1995-1998 e 1999-2002, segundo publicações brasileiras, registradas na base de dados da "web of Knowledge", no campo da saúde.

\begin{tabular}{|c|c|c|}
\hline $1990-1994$ & $1995-1998$ & $1999-2002$ \\
\hline $\begin{array}{l}* * * * \text { Classe } \\
\text { numero } 12 \quad * * * *\end{array}$ & $\begin{array}{l}\star * * * \text { Classe numero } 11 \\
\star * * *\end{array}$ & 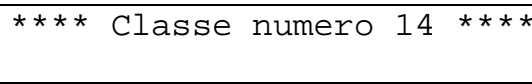 \\
\hline marques gram & zerbini caf & massad e \\
\hline kakitani i & jorge mhpd & forattini op \\
\hline forattini op & gotlieb sld & marques gram \\
\hline sallum mam & marques gram & kakitani i \\
\hline flores dc & gomes ad & marucci d \\
\hline marques ccd & sallum mam & santos jlf \\
\hline gomes ad & forattini op & gomes ad \\
\hline santos jlf & kakitani i & sallum mam \\
\hline marucci $d$ & marucci $d$ & galati eab \\
\hline massad e & massad e & de brito $\mathrm{m}$ \\
\hline
\end{tabular}




\begin{tabular}{|c|c|c|}
\hline & burattini $\mathrm{mn}$ & wilkerson $r c$ \\
\hline & saldiva phn & bergo es \\
\hline & martins ma & de Brito \\
\hline & vaz fac & ueno $\mathrm{hm}$ \\
\hline & paiva pso & kobayashi km \\
\hline & lichtenfels ajfc & dos santos $r l$ \\
\hline & schultz $r$ & fernandez z \\
\hline & zanetta dmt & flores dc \\
\hline & sakae rs & burattini $\mathrm{mn}$ \\
\hline & lorenzi g & \\
\hline & dolhnikoff $\mathrm{m}$ & \\
\hline & conceicao gms & \\
\hline & bohm gm & \\
\hline & duarte mis & \\
\hline & pereira pm & \\
\hline & shikanaiyasuda ma & \\
\hline & caramelli b & \\
\hline & santos rtm & \\
\hline & neto va & \\
\hline & alves vaf & \\
\hline & sartori amc & \\
\hline & benard $\mathrm{g}$ & \\
\hline & duarte ajs & \\
\hline & hong ma & \\
\hline & sato $\mathrm{mn}$ & \\
\hline & campeas ae & \\
\hline & barbosa ad & \\
\hline & wakamatsu a & \\
\hline & grumach as & \\
\hline & bellinatipires $r$ & \\
\hline & salgado $\mathrm{mm}$ & \\
\hline & ueda m & \\
\hline & flores dc & \\
\hline & de Rezende & \\
\hline
\end{tabular}

Figura 24 - Matriz de descritores e autores do "cluster ecology", segundo as publicações brasileiras, registradas na base de dados da "web of Knowledge", no campo da saúde, no período de 1990 a 2002. 


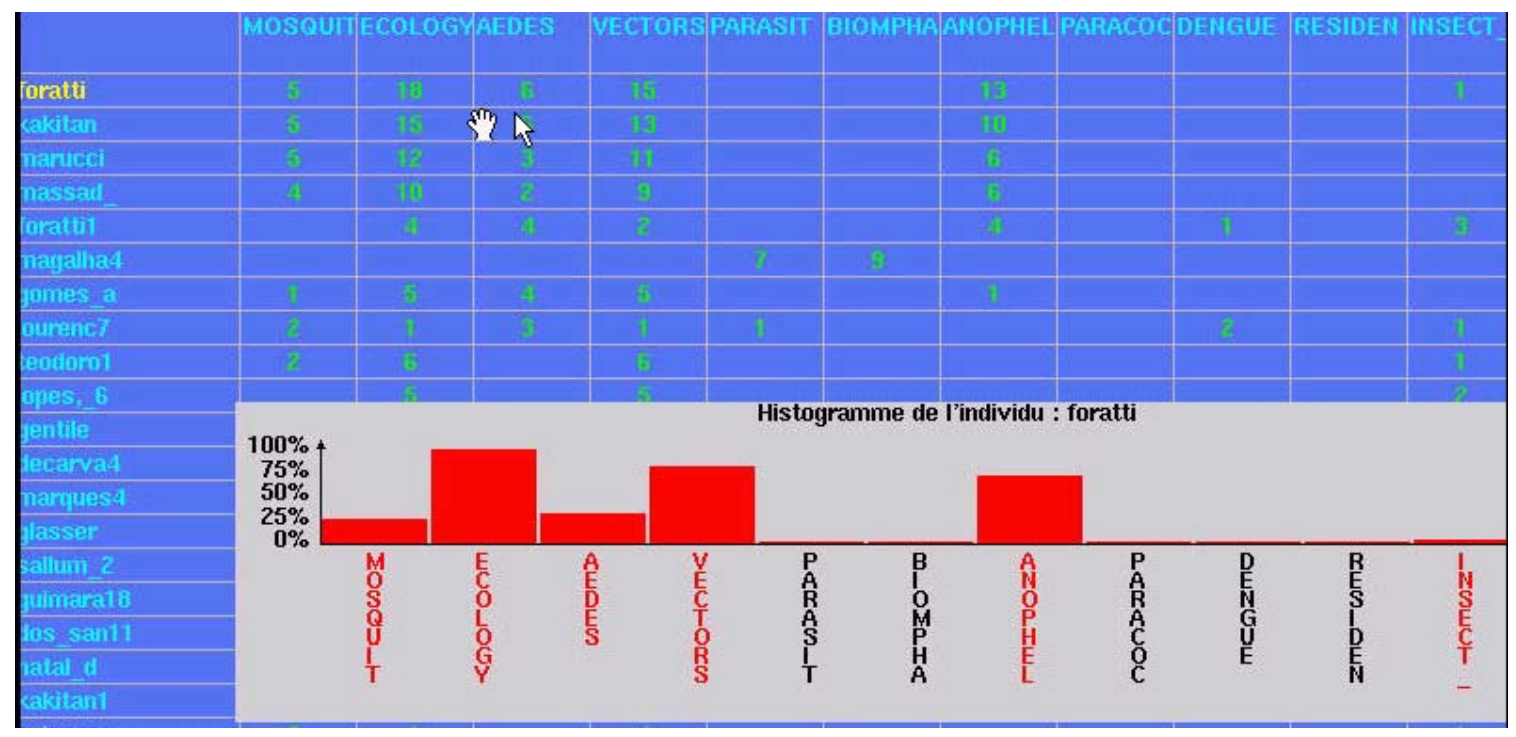

$\mathrm{Na}$ figura 24 temos a representação dessa matriz e um histograma com os resultados da relação dessas palavras com o autor "Forattini", que em 100\% de seus artigos publicados, no período estudado, utilizou a palavra "ecology", que evidencia a linha de pesquisa desse grupo de autores.

0 estudo das colaborações entre instituições, embora importantes, nem sempre é fácil de ser realizado, devido à qualidade da informação nas bases de dados. Para avaliar o campo de filiação do autor foi realizada uma curva de carga, assim designada porque reflete os registros de informação nova. Neste caso, figura 25, observamos uma curva ascendente que tende ao infinito, ou seja, o número de informações novas não se estabiliza. Esta curva, por exemplo, que expressa o que está registrado nos campos c01 até C06, que significam a filiação profissional do autor, demonstra a urgente necessidade de uniformização do registro de informações como nome de universidades, institutos de pesquisa e outras instituições. As diferentes formas de registrar uma mesma informação, assim como já demonstramos, inclusive com autores, chega a triplicar dados idênticos de um mesmo campo. 
Figura 25 - Curva de carga para a contagem do campo de endereços, segundo as publicações brasileiras, registradas na base de dados da "web of Knowledge", no campo da saúde, no período de 1990 a 2002.

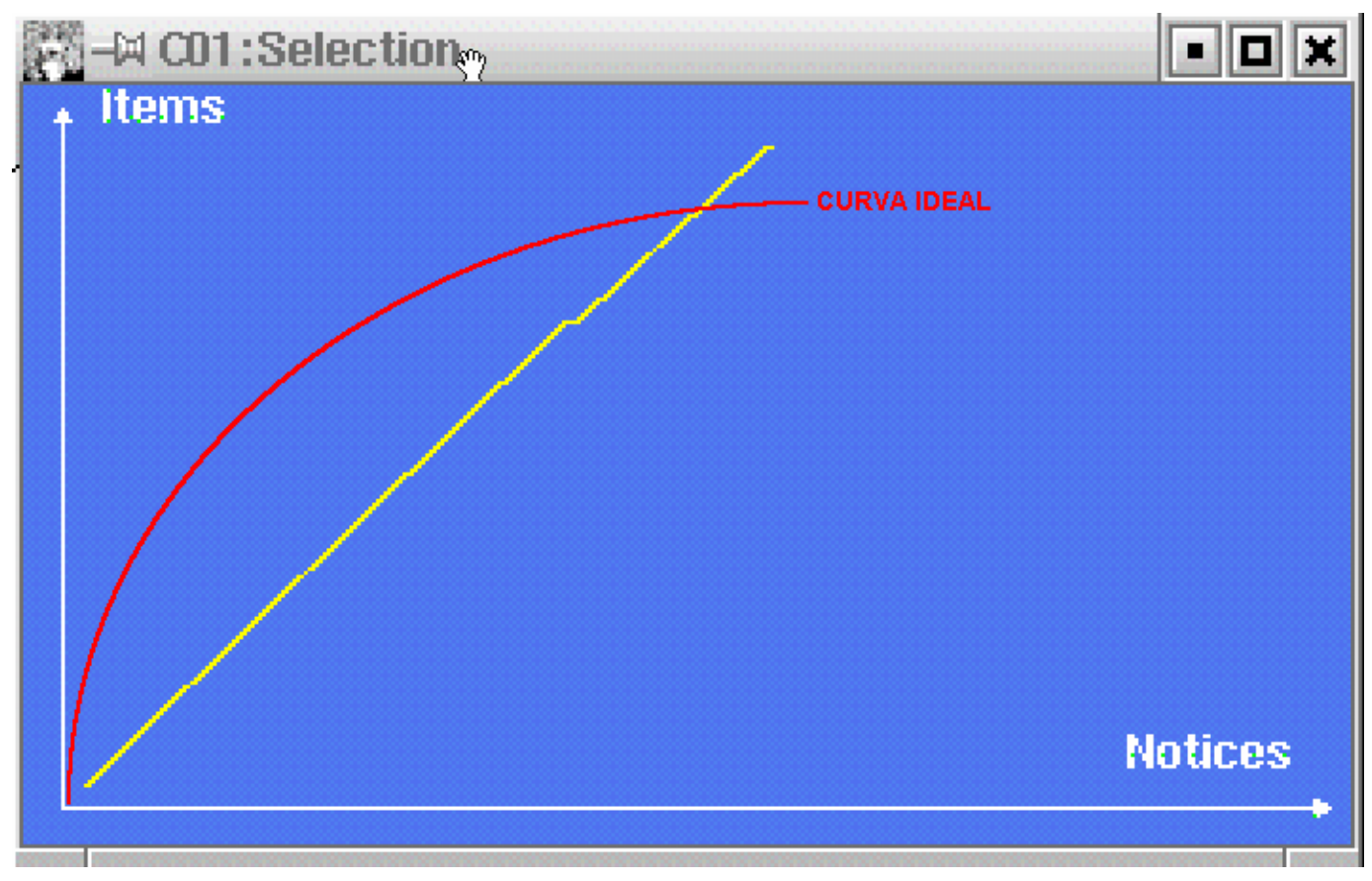


Figura 26 - Rede de colaboradores do "cluster ecology", segundo as publicações brasileiras, registradas na base de dados da "web of Knowledge", no campo da saúde, no período de 1990 a 2002.

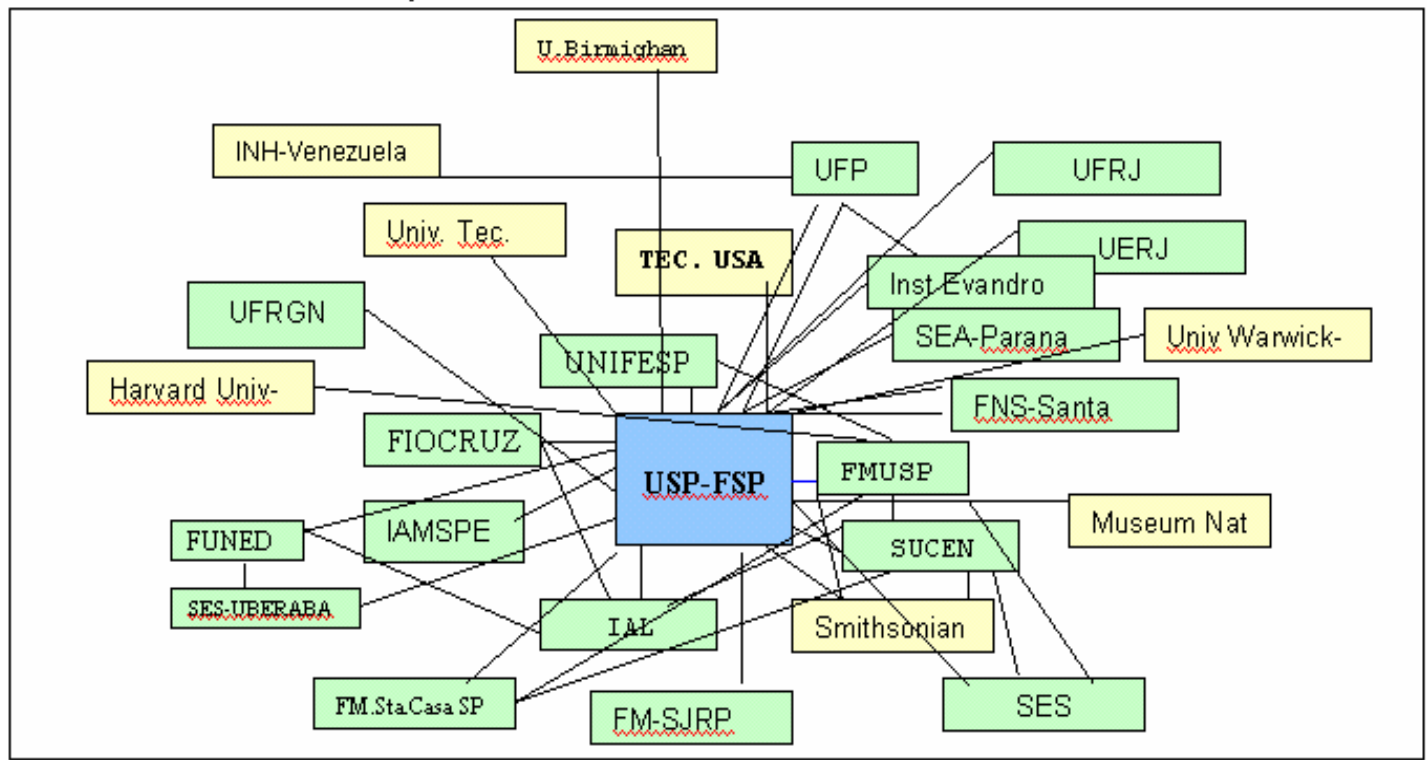

figura

mostra

a rede

de

instit uições parcei ras do autor "Forat tini" e seus principais colaboradores. A análise da dinâmica de colaboração do grupo, realizada em três períodos, 1990-1993, 1994-1997 e 1998-2002, mostra que 10 membros do grupo já no período inicial, cooperam em menor ou maior intensidade em todos os 3 períodos, figura 23. Este é um grupo consolidado, que está filiado principalmente à Faculdade de Saúde Pública, Faculdade de Medicina da USP e a SUCEN. Tomando-se o autor "Forattini" como líder do grupo, este publicou 52 artigos e recebeu 157 citações, uma média de 3,1 citações por artigo. Este grupo tem padrão de comportamento semelhante aos "clusters" 1 e 2, com alta média de citações por artigo publicado e, o que pode sugerir linhas de pesquisa emergentes, maior impacto e visibilidade das suas publicações, uma vez que atualmente é consenso que número de citações não se traduz, obrigatoriamente, em qualidade da investigação científica. Como os "clusters" 1 e 2, é um campo 
estável e consolidado que talvez represente o padrão no campo das ciências da saúde. 


\section{7 - CONSIDERAÇÕES FINAIS}

A necessidade de equacionar problemas sociais e impulsionar o crescimento econômico coloca a Ciência e Tecnologia (C\&T) no centro das estratégias e políticas de desenvolvimento sustentado em países em desenvolvimento, como o Brasil.

É necessário fomentar esta área nas esferas pública e privada, e mais, fazê-lo de forma ordenada e firme, orientada por uma visão de futuro, articulada com as necessidades e demandas dos cidadãos.

A idéia de que a pesquisa em saúde é uma ferramenta importante para a melhoria da situação de saúde das populações, bem como, para a tomada de decisões na definição de políticas e no planejamento em saúde, vem se fortalecendo desde 1980. Isso tem contribuído para a melhoria das ações de promoção, proteção, recuperação e reabilitação da saúde e a diminuição das desigualdades sociais. É do conhecimento também, que a exemplo do que ocorre em vários países, o setor saúde representa o maior componente de toda a produção científica e tecnológica.

É importante avaliar o rendimento da atividade científica, seu impacto e benefícios na sociedade, com a finalidade primordial de adequar a distribuição de recursos. Para esse fim tem-se utilizado indicadores de insumos destinados a medir recursos humanos e gastos; indicadores de inovação tecnológica; indicadores de impacto da ciência e tecnologia no desenvolvimento social e indicadores bibliométricos.

Indicadores bibliométricos são complementares, mas não substituem meios tradicionais de avaliação de pesquisa. As publicações não são o único tipo de produção que pode ser medido. 
$\mathrm{Na}$ verdade, documentos internos, publicações científicas em apresentações ou conferências são atividades expressivas da dinâmica da produção científica, entre todos os tipos de organizações que tem interesse no desenvolvimento científico e tecnológico de alguma área do conhecimento.

Tomando-se em conta que indicadores bibliométricos são de um lado pouco relevantes, se simplesmente praticarmos a contagem de artigos produzidos; e de outro, pouco objetivos, se realizarmos somente análises de avaliação por pares, figura entre estes dois extremos um grande número de técnicas bibliométricas capazes de avaliar a produção científica e tecnológica de diferentes campos do conhecimento de forma satisfatória. No entanto deve estar sempre presente nas avaliações deste tipo, um olhar crítico de que os indicadores devem ser empregados com cautela e preferencialmente para grupos homogêneos de pesquisadores e que trabalhem em áreas afins.

Ao proceder a avaliação da produção científica do campo da saúde, no Brasil, de 1990 a 2002, de acordo com as publicações registradas nas bases de dados do Institut for Scientific Information, Web of Knowledge, os resultados encontrados evidenciam que foram publicados 38.349 artigos e a produção científica em saúde no país, cresceu a uma taxa anual média de 14,98\% nesse período. Destes, 31.191, ou seja, 87\% foram publicados no exterior, o que dá maior visibilidade à ciência brasileira, na área da saúde. 0 número de autores envolvidos nessa produção somou 73.644, a colaboração entre autores concentra, até 10 autores.

0 número médio de autores por artigo cresceu de 3,7 autores para 5,9 aproximadamente, no período estudado, ou seja aumentou o engajamento entre os cientistas brasileiros, bem como a busca de melhor desempenho, ou seja, a necessidade de conjugar 
esforços financeiros e competência técnica e científica, conseqüentemente aumentando o grau de parcerias, rumo a maior produtividade e competitividade, que por sua vez facilitam a obtenção de recursos para o financiamento de pesquisas.

Ficou comprovado o princípio da Lei de Lotka, que afirma que a proporção daqueles que fazem uma única contribuição em um determinado campo científico, é de mais ou menos $60 \%$, pois encontramos um valor muito próximo dessa afirmação, 62,17\%.

Análises recentes mostraram que o número de artigos sobre pesquisa genômica publicados por brasileiros, em periódicos científicos internacionais indexados, cresceu 72,4\% entre 1998 e 2003 e que o número de citações também é crescente. Pode-se inferir, no caso brasileiro, que algumas áreas do conhecimento tiveram peso específico no desempenho em alta. A pesquisa genômica certamente é uma delas.

Os resultados observados no nosso trabalho vão ao encontro dessas afirmações, pois a área "Molecular Biology and Genetics" pertence ao "cluster" 2 do nosso estudo. Este "cluster" possui uma alta produção, com uma média de 1596,76 publicações e foi o grupo que mais citações recebeu. Tem um número médio de 5,57 citações por artigo publicado e, portanto pode sugerir campos emergentes ou campos de maior impacto das suas publicações. Atualmente é consenso que número de citações não se traduz, necessariamente, em qualidade da investigação científica, mas indica o impacto, maior visibilidade e reconhecimento pelos pares.

Do total das 3.066 revistas pesquisadas neste trabalho, 24 revistas representam as que contêm o maior número de artigos publicados, 12.921, ou seja 540 artigos por revista e são responsáveis por $33,7 \%$ do total das publicações. A este grupo 
chamamos "grupo hard core" de Bradford, que segundo sua "Lei de Dispersão", permite, mediante a medição da produtividade das revistas, estabelecer o núcleo e as áreas de dispersão sobre um determinado assunto em um mesmo conjunto de revistas, portanto $1 / 3$ das publicações concentram-se em um grupo de revistas. Revistas como "Medical Research, organs and Systems, Dentistry Oral surgery Medicine, Medical Research General Topics e Genetics and Molecular Biology", pertencem a este grupo. 0 prestígio das fontes bibliográficas, onde se publicam os resultados das investigações científicas, representa uma medida da influência que podem exercer os artigos nelas publicados.

Considerações críticas sobre o nosso bom desempenho também devem ser levadas em conta. É necessário lembrar que esses estudos foram realizados em bases de dados que, apesar da abrangência, utilizam critérios para indexar suas revistas que privilegiam os temas, prioridades e cultura de países e grupos líderes no desenvolvimento e na produção científica e tecnológica. Ao considerarmos o crescimento da ciência brasileira temos que incluir as publicações em congressos, livros e em revistas não indexadas. Não podemos excluir do computo dessa produção, temas prioritários de pesquisa que embora pertençam a temas científicos universais, estejam voltadas para problemas nacionais, tais como, as que dizem respeito as nossas doenças tropicais, endêmicas e nossa biodiversidade, mas que raramente encontram espaço nas revistas internacionais.

Há que se valorizar a bibliometria e seus indicadores, não só pelas possibilidades de análise e conhecimento do comportamento da ciência, mas por permitir a reflexão e a discussão induzidas por seus resultados.

Deve-se impedir, por meio dessas reflexões, que indicadores quando usados, por exemplo, para comparar diferentes países, possam induzir uma avaliação simplista de que a ciência 
no Brasil evolui bem e encontra-se bem assistida em suas políticas. A informação sobre o crescimento da produção científica brasileira e as comparações com outros países devem vir acompanhadas de outros indicadores de competência, no uso do conhecimento para gerar inovações, que é o crescimento do número de patentes.

Quando se trata de responder sobre o papel que a ciência e a tecnologia assumem no desenvolvimento de uma sociedade, os indicadores bibliométricos são importantes ferramentas de análise. No entanto, as suas características e os critérios para sua construção, devem ser contemplados por diferentes olhares.

Um segundo grupo de análises foram realizados neste trabalho e trata da co-ocorrência de palavras ou "co-word analysis". Assim foram detectadas palavras que caracterizam o conteúdo dos trabalhos sobre um determinado tema, procedeu-se à contagem da aparição destas e posterior estudo de sua proximidade e significância. Os conceitos de proximidade ou distância foram representados graficamente e constituíram a base para a elaboração dos "mapas tecnológicos".

$\mathrm{Na}$ impossibilidade de apresentar a totalidade dos agrupamentos de palavras e todas suas inter-relações, as análises de co-ocorrências de palavras foram centradas em alguns exemplos significativos, de forma a evidenciar as possibilidades e potencialidades desse método para "mapear" diferentes áreas do conhecimento, sem, necessariamente, caracterizar o estado da arte da produção científica brasileira, na área da saúde, no período estudado.

As palavras que foram estudadas estão contidas no campo descritores da base de dados e foram relacionadas com outras variáveis como autores, identificadores, ano de publicação do 
artigo ou filiação da publicação. Os descritores encontrados somaram 39.455 diferentes palavras, que correspondem às palavraschave presentes publicações registradas. Um ponto crítico para a qualidade dessas análises é a etapa de "Tratamento Morfológico". Esta é uma função que permite a equiparação de palavras ou a criação de sinônimos para as palavras. Nesta etapa não puderam ser incorporados, ao software de análise, modelos lingüísticos, semânticos, que prevêem análises dos diferentes sentidos de uma palavra e sintáticos que relacionam as palavras por seu significado. Portanto, o tratamento dado aos descritores imprimiu um certo grau de subjetividade à criação dos sinônimos.

Definitivamente, a fase preparatória para proceder as análises de co-word, deve contar com um "thesaurus" que garanta aos documentalistas e pesquisadores a padronização da linguagem documentária, bem como, a análise de peritos da área objeto de estudo. Considero estes dois procedimentos complementares e a ausência de um ou outro prejudica a qualidade do estudo, principalmente em grandes volumes de informações.

Observamos que $72,03 \%$ dos descritores, aparecem uma única vez como descritor de assunto de um artigo. Apenas $27,97 \%$ dos 39.455 descritores, têm freqüência $>2$. No entanto, se tomarmos as palavras que se repetem até o mínimo 10 vezes, somente 1142 $(2,89 \%)$ ocorrem numa freqüência igual ou maior que 10 . (Lei de Zipf)

Apenas com a contagem de palavras pudemos obter informações interessantes, sobretudo se compararmos sua ocorrência no tempo para observarmos seu comportamento. Palavras referentes a tecnologias ou temas específicos que têm sua freqüência aumentada num período determinado demonstram que estão captando a atenção, que se está patenteando sobre o assunto, 
enfim, que há um interesse de investigação sobre elas. Ao contrário, as que diminuem de freqüência ao longo do tempo, podem representar temas que estão chegando ao limite de seu interesse. Por outro lado dependendo do enfoque dado ao estudo, patentes, por exemplo, as palavras de menor freqüência e que apareceram nos últimos anos podem ser as mais importantes para as análises por estarem apontando para tecnologias ou produto novos.

As análises de co-ocorrência são as bases para a elaboração dos mapas tecnológicos e de possíveis definições de "clusters" ou associações. A análise, do cruzamento entre descritores e identificadores, por exemplo, resultou primeiramente em uma matriz, com resultados das contagens que permitiram organizar, depurar e transformar os dados através de operações matemáticas. São inúmeras as possibilidades de análises e uma vasta gama de resultados puderam ser obtidos com essas análises.

Em que pese os critérios e as limitações impostas a este estudo e as possíveis divergências entre uma ou outra métrica, que melhor se adequaria a este tipo de análise, a utilização da métrica euclidiana utilizada para estas análises privilegiou as palavras mais fortes e as co-ocorrências de maior afinidade.

Ao estudarmos os resultados das relações entre Descritores e Identificadores, temos que a palavra "ecology" coocorre com "ribeira valley, irrigation, mosquito, sao-paulo state, psychodidae, culicidae, hemorrhagic-disease, vector", entre outras e podemos concluir, por exemplo, que esta linha de pesquisa está voltada para insetos vetores e que o grupo tem investigado algumas regiões do estado, ricas em material para seus estudos, onde as condições são favoráveis ao desenvolvimento desses insetos e à manutenção da transmissão das doenças por eles veiculados. 
Para exemplificar estudos com autores, tomamos por referência as palavras lideradas pelo grupo "ecology". Foi realizada uma contagem de autores, com até 3 publicações no período, utilizando-se como filtro este grupo de palavras.

Após selecionar os autores pertencentes a esse grupo, o cruzamento entre autores resultou numa matriz que evidencia "clusters" bem delimitados. É possível consultar o conteúdo de cada "cluster" e dessa forma visualizar a que grupo se refere. Do "cluster" assinalado emergiu um grupo de autores, liderado pelo autor "Forattini".

Nos mapas tecnológicos, elaborados a partir dessas matrizes surgiram os autores que compõe o "cluster ecology". Ficou evidenciada nos mapas a interface entre os "clusters", como, por exemplo, os liderados por "Forattini" e Burattini, devido a eventuais colaborações.

$\mathrm{Na}$ análise de co-ocorrência dos campos de descritores e autores, pudemos verificar a proximidade de grupos de palavras descritoras de temas e seus respectivos autores. Resultados da relação dessas palavras com o autor "Forattini", por exemplo, mostra que em $100 \%$ de seus artigos publicados, no período estudado, utilizou a palavra "ecology", que evidencia a linha de pesquisa desse grupo de autores.

A análise da dinâmica de colaboração do grupo, realizada em três períodos, 1990-1993, 1994-1997 e 1998-2002, mostra a rede de instituições parceiras do autor "Forattini" e que 10 membros do grupo já no período inicial, cooperam em menor ou maior intensidade em todos os 3 períodos. Este é um grupo consolidado, que está filiado, principalmente, à Faculdade de Saúde Pública, 
Faculdade de Medicina da USP e a SUCEN, mas que tem colaboração com diversas instituições nacionais e internacionais.

Tomando-se o autor "Forattini" como referência, o grupo publicou 52 artigos e recebeu 157 citações, uma média de 3,1 citações por artigo. Este grupo tem padrão de comportamento que revela alta média de citações por artigo publicado, impacto e visibilidade das suas publicações. Como é um campo estável e consolidado que talvez represente o padrão no campo das ciências da saúde.

As técnicas de "co-word analysis" demonstraram incrementar os resultados observados, com as técnicas bibliométricas, já tradicionalmente utilizadas, de maneira a poder qualificar as instituições, as disciplinas e os profissionais produtores do conhecimento técnico e científico, nas diferentes áreas que compõe este campo.

A representação visual de grandes volumes de dados proporciona em pouco tempo um panorama completo que se recorda facilmente. Além disso, há uma redução da informação, o que é muito importante. Atualmente encontramos uma grande quantidade de "ruídos" na enorme quantidade de dados disponíveis. É crucial filtrar os dados significativos. Os mapas agregam os dados de uma forma que nenhum especialista é capaz de fazer, dada a impossibilidade de assimilar a quantidade de informação disponível.

Esta abordagem para a área de avaliação em Ciência e Tecnologia amplia as análises bibliométricas tradicionais e poderia incrementar as atividades de planejamento e definição de ações estratégicas indicando, para onde e como se poderiam dirigir esforços para desenvolvimento do campo estudado. Constitui uma importante ferramenta de gestão de ciência e 
Tecnologia, no planejamento científico de qualquer instituição, instância de governo ou pais, para conseguir uma rentabilidade máxima nos investimentos neste campo.

Consolidar no meio científico a utilização dessa qualidade de estudos quantitativos e qualitativos, pode apontar para a utilização das bases de dados, também como um instrumento para desenvolver atividades de análise, enfatizando as possibilidades que este tipo de avaliação pode possibilitar, para elevar o nível das informações, assim como para explorar as técnicas bibliométricas no gerenciamento de políticas e de tomadas de decisão. 


\section{8 - BIBLIOGRAFIA}

Almeida PIR, Klein L, Henrique JSJ. Ciência e Tecnologia no Brasil. Ministério das Relações Exteriores.

http://www.mre.gov.br/portugues/politica_externa/temas_agenda/ciência_tecnologia/ciência_tecbra.asp (acesso 7/12/04)

Almind $T$, Ingwersen $P$. Informetric analyses on the World Wide Web: methodological approaches to webmetrics. Journal of Documentation 1997;53: 404-26.

Arlington, VA. National Science Board, Science \& Engineering Indicators - 1998, National Science Foundation.

Basevi THMM. Tendências na aplicação de formatos, sistemas cooperativos e redes de intercâmbio: uma visão infométrica. Departamento de Ciência da Informação e Documentação 1993. Universidade de Brasília DF(Dissertação de Mestrado).

Black N. A National Strategy for research and development:

lessons from England. Annu. Rev. Public Health 1997;18:485-505.

Bonalume Neto R. Desigualdade afeta produção científica. Folha de São Paulo, Ciência 15/07/2004.

Bordons, M.; Zulueta M. A. Evaluación de la actividad científica através de indicadores bibliométricos. Revista Española de Cardiología, - Madri, v. 52, n. 10, p. 790-800, out. 1999. Disponível em:

http://www.revespcardiol.org/cgibin/wdbcgi.exe/cardio/cardioeng.mrevista_cardio.fulltext?pident=190 . (acesso 7 jun. 2004).

Bruschini C, Ardaillon D, Ubehaum SG. Tesauro para estudos de gênero e sobre mulheres. Fundação Carlos Chagas São Paulo 2001.

Callon M, Courtial JP et al. La Scientométrie, que sais-je?, Presses Universitaires de France 1993; París.

Callon M, Courtial JP., Laville F. et al??. Co-word analysis as a tool for describing a network interactions between basic and technological research: the case of polymer chemistry. Scientometrics 1991; 22:155-205, 1991.

Callon M, Law J, Rip A. Mapping the dynamics of science and technology: sociology of science in the real world. Eds Basingstoke Hants: MacMillan 1986.

Características del Software Tétralogie Ver. 7, Herramientas para la Inteligencia Tecnológica, (mimeo), 1997. 
Carneiro DM. C\&T em prol da cidadania http://revista.fapemig.br/15/opiniao.html (acesso 20/07/04)

Cavalcanti CR. Indexação \& tesauro metodologia \& técnicas. ABDF 1978; Brasília.

Cavalcanti, Cordelia R. Indexação \& Tesauro Metodologia \& Técnicas. Brasília, ABDF, 1978.

CNPq - Introdução ao Plano Institucional do CNPq, novembro de 1998. http://www.cnpq.br (acesso 15/12/03)

Cole FJ, Eales NB. Part I: a Statistical Analysis of the Literature, Science Progress.In: The History of Comparative Anatomy. 1917.

Cruz E, Escorsa P, Maspons R, Guixé J et al. La Vigilância Tecnológica en el Sector de los Nuevos Materiales. Publicación del CYTED, Ed. IALE Tecnologia, España 2003.

Documento Base da $2^{a}$ Conferência Nacional de Ciência, Tecnologia e Inovação em Saúde. Situação Atual de Ciência e Tecnologia no Brasil 2004; Brasília.

Donalísio MR. O Dengue no Espaço Habitado. FUNCRAF - HUCITEC 1999 São Paulo.

Dousset B. Tetralogie http://atlas.irit.fr (acesso 15/12/04)

El Estado de la Ciência 2003 - http://www.ricyt.edu.ar - (acesso $15 / 01 / 05$ ).

Escorsa P, Maspons R. La Ciencimetria y sus Aplicaciones. In: eds? Da vigilancia tecnológica a inteligencia competitiva. Prentice Hall, Pearson Education, S.A; 2001.

Fundação Carlos Chagas - 0 que é um Tesauro? http://www.fcc.org.br/pesquisa/rgenero/teg/tesauro.html (acesso 10/08/04)

Gross PL, Gross EM. College Libraries and Chemical Education. Science $1927 ; 66$.

Guimarães R. Pesquisa no Brasil: A Reforma Tardia. São Paulo Perspec 2002; 16(4):41-47.

Gusmão, R. -Indicadores FAPESP de CT\&I: um diagnóstico atualizado dos esforços de Ciência, Tecnologia e Inovação no Estado de São Paulo, apresentado em RICYT VI Taller de Indicadores de Ciencia y Tecnologia Iberoamericano e Interamericano Medir el conocimiento para la transformación social. Buenos Aires, 15-17 septiembre de 2004 
Holm-Nielsen L, Crawford M, Saliba MA. Institutional and entrepreneurial leadership in the brazilian science and technology sector. Setting a new agenda, World Bank Discussion Papers 325.

Indicateurs de sciences et de technologies, http://www.obsost.fr/fr/accueil.php - (Acesso 15/01/05).

King D. The scientific impact of nations. Nature 2004; 430: . http://www.nature.com/nature .

King J. A review of bibliometric and other science indicators and the role in research evaluation. Journal of Information Science 1987; 13: 261-276.

Kostoff RN. Research impact quantification. R\&D Management 1994; 24(3): 207-218.

Leta J, De Meeis L. A Profile of science in Brazil", Scientometrics 1996; 25(1): 33-44.

Leydesdorff L. The search of epistemic networks. Social studies in Science 1991; 21(1): 75-110.

Luukkonen-Gronow $\mathrm{T}$. Scientific research evaluation: a review of methods and various contexts of their application. R\&D Management $1987 ; 17(3): 207-214$.

Marcovitch J et al. Política e gestão em ciência e tecnologia, Livraria Pioneira ed., São Paulo, 1986.

Marques F. Indicadores: uma prova de qualidade. Boletim FAPESP Ed. $10 ; 08 / 04$.

Maspons R. La cienciometria como instrumento de evaluación, utilidade práctica de los indicadores. VIII Seminário de Avaliação em C\&T. Núcleo de Política e Gestão de Ciência e Tecnologia, FEA/USP 22 a 26 de abril de 1996; 1-9.

Mugnaini, R. , Jannuzzi, P.M. , Quoniam, L. M. - Indicadores bibliométricos da produção científica brasileira: uma análise a partir da base Pascal. - Ci. Inf., Brasília, v. 33, n. 2, p. 123-131, maio/ago. 2004.

NORMAS de VANCOUVER - Comissão Internacional de Editores de Revistas Médicas. Normas para apresentação de artigos propostos para publicação em revistas médicas. Rev Port Clin Geral 1997;14:159-74 - Tradução de "Uniform requirements for manuscripts submitted to biomedical journals". 
Pellegrini Filho, A. e Goldbaum, M. - Production of scientific articles on health in six Latin American countries, 1973-1992.

Rev. Panam. Salud Publica v.2 n.2 Washington Ago. 1997.

Pereira, J R C - Análise de Dados Qualitativos - Estratégias Metodológicas para as Ciências da Saúde, Humanas e Sociais. São Paulo, EDUSP -1999.

Pereira, J R C; Baião, M S; Fisher, A L Avaliação de Projetos em Institutos de Pesquisa - Revista de Administração - USP - 1996 Vol 31 No. 04, Pag. 77 a 92 .

Pinto VB, Lima MC. Diálogos com os professores da UFC através das citaçõe. In: Encontros Universitários, Anais 2002. Fortaleza, 04 a 06 de dezembro de 2002. (Anais Eletrônicos) http://www.decigi.ufpr.br/anais_enebd/documentos/oral/ENEBDMIRIAN.doc .

Polanco $X$. Scientometrics análisis of the cognitive sciences in Pascal". Inisit Info 1993:7.

Pritchard A. Statistical bibliography or bibliometrics? Journal of Publication 1969; 25.

Quoniam L. Inteligência obtida pela aplicação de data mining em base de teses francesas sobre o Brasil. Ci. Inf. Brasília, 2001; $30: 2$.

Robredo, J e da Cunha, MB - Aplicação de Técnicas Infométricas para identificar a abrangência do léxico básico que caracteriza os processos de indexação e recuperação da informação. Ci. Inf., Brasília, v.27, n.1, p.11-27, jan/abr 1998.

Rodrigues, T. Quando os Indicadores de C\&T deixam de indicar e passam a determinar. http://www.comciencia.br/reportagens/2004/11/11.shtml (acesso $15 / 01 / 05$ ).

Rostaing $H$. La bibliométrie et ses techniques. Sciences de la Societé. Toulouse y Centre de Recherche Rétrospective de Marseille (CRRM) 1995.

Rousseau, R. Timeline of Bibliometrics.

http://users.pandora.be/ronald.rousseau/html/timeline_of_bibliometrics.html (acesso 24/03/03).

Sancho R. Indicadores bibliométricos utilizados em la evaluaciónde la ciência y la tecnología. Revisión Bibliográfica. Revista Española de Documentación Científica 1990; 13.

SPINAK, E. Indicadores Cienciométricos. Seminário de Avaliação da Produção Científica. Projeto SciELo, BIREME - São Paulo - 4 a 6 de março de 1998. 
Tundisi JG. Ciência no Brasil.

http://www.mre.gov.br/portugues/politica_externa/temas_agenda/ciência_tecnologia/ciência_tec_bra.asp (acesso 10/08/04).

Turnock BJ. From measuring to improving public health practice. Annu. Rev. Public Health 1997; 18:261-82.

IBICT, Uma Radiografia da Ciência Brasileira - Scientific

American Brasil (on-line) http://listas.ibict.br/pipermail/bib_virtual/2004-May/000159.html (acesso $07 / 07 / 04$ ).

UNESCO - Setor de Ciências e Meio Ambiente da UNESCO

http://www.unesco.org.br/programas/meioamb/desenv_inst.asp (acesso 07/07/04).

Urbizagástegui R. A Lei de Lotka na bibliometria brasileira. Ci Inf Brasília 2002; 31(2): 14-20.

Van Raan AFJ. Advanced bibliometric methods to assess research performance and scientific development: basic principles and recent practical applications.ed;1993.

Vogt, C. e Gusmão, R. - FAPESP lança busca de informações científicas, www.fapesp.br/indicadores - (acesso 15/01/05).

Whitaker J. Creativity and conformity in science: titles, keywords and co-word analysis. Social Studies in Science;V.19, $1989: 473-496$. 
ANEXOS 
ANEXO 1 - Publicações Brasileiras, segundo localidade de Publicação

\begin{tabular}{|c|c|c|c|}
\hline Cidades & Publicações & Cidades & Publicações \\
\hline NEW YORK & 4407 & CARY & 80 \\
\hline ALEXANDRIA & 4035 & PARIS & 72 \\
\hline SAO PAULO & 3880 & RESTON & 70 \\
\hline OXFORD & 3845 & WOBURN & 66 \\
\hline PHILADELPHIA & 2567 & NOISY-LE-GRAND & 63 \\
\hline AMSTERDAM & 1938 & TOKYO & 63 \\
\hline BETHESDA & 1743 & LISSE & 62 \\
\hline LONDON & 1470 & ATHENS & 62 \\
\hline WASHINGTON & 1072 & CARLTON & 61 \\
\hline CLARE & 624 & BOLOGNA & 57 \\
\hline SAN DIEGO & 621 & PARIS & 56 \\
\hline DORDRECHT & 610 & WIESBADEN & 54 \\
\hline CHICAGO & 503 & TURIN & 53 \\
\hline ST LOUIS & 483 & DALLAS & 53 \\
\hline CURITIBA-PARANA & 476 & DETROIT & 49 \\
\hline BASEL & 459 & VIENNA & 47 \\
\hline RIO DE JANEIRO, RJ & 440 & BOSTON & 48 \\
\hline BALTIMORE & 437 & PLON & 46 \\
\hline RIBEIRAO PRET & 397 & LAUSANNE & 46 \\
\hline BASINGSTOKE & 355 & INC, BALTIMORE & 45 \\
\hline HOVE & 304 & ARMONK & 44 \\
\hline STUTTGART & 283 & LANDSKRONA & 43 \\
\hline COPENHAGEN & 292 & TRUMBULL & 41 \\
\hline CAMBRIDGE & 241 & BRISTOL & 41 \\
\hline LAWRENCE & 227 & BATON ROUGE & 41 \\
\hline BERLIN & 213 & WALLINGFORD & 40 \\
\hline MCLEAN & 210 & RES TRIANGLE PK & 39 \\
\hline TOTOWA & 200 & DEERFIELD BEACH & 38 \\
\hline OTTAWA & 190 & MUNCHEN - DEISENHOFEN & 37 \\
\hline W SUSSEX & 181 & GENEVA & 36 \\
\hline LARCHMONT & 170 & E NORWALK & 36 \\
\hline MALDEN & 140 & ATLANTA & 35 \\
\hline OSLO & 135 & CONCEPCION & 34 \\
\hline JENA & 137 & ROME & 31 \\
\hline TORONTO & 126 & PISA & 31 \\
\hline MADISON & 125 & MAHWAH & 30 \\
\hline EDINBURGH & 118 & MILAN & 29 \\
\hline THOROFARE & 116 & INDIANAPOLIS & 29 \\
\hline CARACAS & 111 & PAVIA & 27 \\
\hline CAROL STREAM & 108 & MENDOZA & 27 \\
\hline ABINGDON & 107 & BIRMINGHAM & 27 \\
\hline TUBINGEN & 100 & MONTROUGE & 26 \\
\hline SAN JOSE & 97 & GLEN HEAD & 26 \\
\hline LANHAM & 93 & COLCHESTER & 26 \\
\hline PARIS & 92 & INC, DES MOINES & 25 \\
\hline NORTHBROOK & 87 & INC, SAN ANTONIO & 24 \\
\hline FLORENCE & 85 & AUCKLAND & 24 \\
\hline ROCHESTER & 83 & PLAINVIEW & 23 \\
\hline READING & 81 & HAMILTON & 23 \\
\hline CARY & 80 & MISSOULA & 22 \\
\hline LOS ANGELES & 22 & WAYNE & 9 \\
\hline GREENVILLE & 22 & TALLAHASSEE & 9 \\
\hline DARMSTADT & 22 & SILVER SPRING & 9 \\
\hline BILTHOVEN & 22 & PRAGUE & 9 \\
\hline ESCHBORN & 20 & OAK BROOK & 9 \\
\hline BARCELONA & 20 & MYSORE & 9 \\
\hline WALTHAM & 19 & FAIRFAX & 9 \\
\hline PORT CHESTER & 19 & CESKE BUDEJOVICE & 9 \\
\hline ISSY MOULINEAUX & 19 & CARNFORTH LANCASHIRE & 9 \\
\hline STOCKHOLM & 18 & BOULDER & 9 \\
\hline SAVOY & 18 & WARSAW & 8 \\
\hline MURCIA & 18 & SANTIAGO & 8 \\
\hline LAKE CHARLES & 18 & PELLENBERG & 8 \\
\hline
\end{tabular}




\begin{tabular}{|c|c|c|c|}
\hline Cidades & Publicações & Cidades & Publicações \\
\hline BRATISLAVA & 18 & PALO ALTO & 8 \\
\hline WEINHEIM & 17 & MEMPHIS & 8 \\
\hline GODALMING & 17 & MADRID & 8 \\
\hline CHATTANOOGA & 17 & LAUREL & 8 \\
\hline CHARLOTTESVILLE & 17 & ELK GROVE VILLAGE & 8 \\
\hline NATICK & 16 & EASTON & 8 \\
\hline NATCHEZ & 16 & BUREN & 8 \\
\hline LEIDEN & 16 & BANGLADESH, DHAKA & 8 \\
\hline KAMIKYOKU KYOTO & 16 & WOODBURY & 7 \\
\hline GENEVA 27 & 16 & SANTA FE SPRINGS & 7 \\
\hline BRUSSELS & 15 & OBERHACHING & 7 \\
\hline NORTHWOOD & 14 & GENEVA AEROPORT & 7 \\
\hline NIIGATA & 14 & FREISING -WEIHENSTEPHAN & 7 \\
\hline CHAMPAIGN & 14 & AMITYVILLE & 7 \\
\hline AUGUSTA & 14 & STITTGART & 6 \\
\hline PITTSBURGH & 13 & SANTIAGO 9 & 6 \\
\hline MELVILLE & 13 & PROVIDENCE & 6 \\
\hline W CONSHOHOCKEN & 12 & PRETORIA & 6 \\
\hline SHEFFIELD & 12 & PRAGUE 4 & 6 \\
\hline SEATTLE & 12 & PARIS 5 & 6 \\
\hline PENSACOLA & 12 & LITTLE ROCK & 6 \\
\hline PARIS 06 & 12 & HILVERSUM & 6 \\
\hline LUTZ & 12 & HEIDELBERG & 6 \\
\hline KYOTO & 12 & E LANSING & 6 \\
\hline DES MOINES & 12 & CUERNAVACA & 6 \\
\hline COLLINGWOOD & 12 & AULENDORF & 6 \\
\hline BUENOS AIRES & 12 & APPLETON & 6 \\
\hline ANN ARBOR & 12 & WOODS HOLE & 5 \\
\hline THOUSAND OAKS & 11 & TUCSON & 5 \\
\hline REHOVOT & 11 & SURREY & 5 \\
\hline PINEROLO & 11 & SHANGHAI & 5 \\
\hline HOBOKEN & 11 & SAN FRANCISCO & 5 \\
\hline CARDIFF & 11 & LUND & 5 \\
\hline BOCA RATON & 11 & DIJON & 5 \\
\hline ZAGREB & 10 & BOWIE & 5 \\
\hline ZAGREB & 10 & BOWIE & 5 \\
\hline NILES & 10 & BOGOTA D C & 5 \\
\hline BUDAPEST & 10 & BINGHAMTON & 5 \\
\hline AUSTIN & 10 & ZEIST & 4 \\
\hline WESTERVILLE & 4 & LES ULIS & 2 \\
\hline WEST GLAMORGAN & 4 & LEEDS & 2 \\
\hline ROCKVILLE & 4 & LA MIRADA & 2 \\
\hline PORT WASHINGTON & 4 & KENT & 2 \\
\hline OAKVILLE & 4 & HONGO TOKYO & 2 \\
\hline LANDSBERG & 4 & GRANADA & 2 \\
\hline HVIDOVRE & 4 & FREDERICK & 2 \\
\hline HOUSTON & 4 & ELMSFORD & 2 \\
\hline HERNDON & 4 & EDGECLIFF & 2 \\
\hline GAMBIER & 4 & EATONTOWN & 2 \\
\hline DHAKA & 4 & DENVER & 2 \\
\hline CHAPEL HILL & 4 & CINCINNATI & 2 \\
\hline CALCUTTA & 4 & CHATHAM & 2 \\
\hline BERN 9 & 4 & BUSSUM & 2 \\
\hline ANKENY & 4 & BUFFALO & 2 \\
\hline WILTON & 3 & BANGALORE & 2 \\
\hline TRINITY & 3 & AUCKLAND 4 & 2 \\
\hline TLALPAN & 3 & WORTHING & 1 \\
\hline TIFTON & 3 & WHEATON & 1 \\
\hline STORRS & 3 & WELLINGTON & 1 \\
\hline SANTA ANA & 3 & WARWICK & 1 \\
\hline PORTLAND & 3 & TAIPEI & 1 \\
\hline OSAKA & 3 & SYRACUSE & 1 \\
\hline NEEDHAM & 3 & STAR CITY & 1 \\
\hline
\end{tabular}




\begin{tabular}{|c|c|c|c|}
\hline Cidades & Publicações & Cidades & Publicações \\
\hline MUNICH & 3 & SHIZUOKA & 1 \\
\hline MT VERNON & 3 & SECOND DEPT OF INTERNAL MED, TOKYO & 1 \\
\hline MT ROYAL & 3 & SARAG00SE & 1 \\
\hline MOSCOW & 3 & ROMA & 1 \\
\hline MONTREAL & 3 & PULSUS GROUP INC, OAKVILLE & 1 \\
\hline MEXICO CITY & 3 & PUBLICATIONS DIV, LONDON & 1 \\
\hline LARGO & 3 & PUBL OFFICE, TOYONAKA & 1 \\
\hline INST HYDROLOGY, WALLINGFORD & 3 & PISCATAWAY & 1 \\
\hline BOGOTA D.E. & 3 & PALM BEACH & 1 \\
\hline BERN & 3 & NURNBERG & 1 \\
\hline BERGEN & 3 & NORWOOD & 1 \\
\hline BELLE MEAD & 3 & NORTHAMPTON & 1 \\
\hline BANYULS-SUR-MER CEDEX & 3 & MUTTENZ & 1 \\
\hline AURORA & 3 & MEXICO D F & 1 \\
\hline VILLEJUIF & 2 & METUCHEN & 1 \\
\hline SURREY HILLS & 2 & LISBOA & 1 \\
\hline SUDBURY & 2 & LEICESTER & 1 \\
\hline ST FOY & 2 & LA LOLLA & 1 \\
\hline PRAGUE 6 & 2 & JOHANNESBURG & 1 \\
\hline PARIS & 2 & INST ENTOMOLOGY, CESKE BUDEJOVICE & 1 \\
\hline OVIEDO & 2 & INC, LAWRENCE & 1 \\
\hline OSPEDALETTO PISA & 2 & INC, EMMAUS & 1 \\
\hline NEW BRUNSWICK & 2 & HILLSDALE & 1 \\
\hline NAIROBI & 2 & HELSINKI & 1 \\
\hline MUNICH 70 & 2 & GUILDERLAND & 1 \\
\hline MIDDLEBURG & 2 & GREENWICH & 1 \\
\hline MARSEILLE CEDEX & 2 & GOTTINGEN & 1 \\
\hline GAITHERSBURG & 1 & BUCHAREST & 1 \\
\hline EVRY & 1 & BRIARCLIFF MANOR & 1 \\
\hline EMMAUS & 1 & BERLIN 38 & 1 \\
\hline DURHAM & 1 & BEACONSFIELD & 1 \\
\hline DUNEDIN & 1 & BALGOWLAH & 1 \\
\hline CORTE MADERA & 1 & AURORAR & 1 \\
\hline CHESTNUT HILL & 1 & ASSEN & 1 \\
\hline CHESTER & 1 & ASHFORD & 1 \\
\hline CALGARY & 1 & TOTAL & 35816 \\
\hline
\end{tabular}


ANEXO 2

Revistas-Grupo 1 (hard core: 12.921 papers em 24 journals -540 papers/revista)

\begin{tabular}{|c|c|c|c|c|}
\hline Revista & N. & $\%$ & $\begin{array}{l}\text { Acumulado } \\
\%\end{array}$ & Ordem \\
\hline JOURNAL OF DENTAL RESEARCH & 3953 & 0,1031 & 0,10 & 1 \\
\hline BRAZILIAN JOURNAL OF MEDICAL AND BIOLOGICAL RESEARCH & 1721 & 0,0449 & 0,15 & 2 \\
\hline REVISTA DE SAUDE PUBLICA & 995 & 0,0259 & 0,17 & 3 \\
\hline JOURNAL OF THE BRAZILIAN CHEMICAL SOCIETY & 611 & 0,0159 & 0,19 & 4 \\
\hline REVISTA DE MICROBIOLOGIA & 513 & 0,0134 & 0,20 & 5 \\
\hline BRAZILIAN ARCHIVES OF BIOLOGY AND TECHNOLOGY & 472 & 0,0123 & 0,22 & 6 \\
\hline MEMORIAS DO INSTITUTO OSWALDO CRUZ & 440 & 0,0115 & 0,23 & 7 \\
\hline BLOOD & 435 & 0,0113 & 0,24 & 8 \\
\hline FASEB JOURNAL & 426 & 0,0111 & 0,25 & 9 \\
\hline GENETICS AND MOLECULAR BIOLOGY & 397 & 0,0104 & 0,26 & 10 \\
\hline INTERNATIONAL JOURNAL OF PSYCHOLOGY & 301 & 0,0078 & 0,27 & 11 \\
\hline HEPATOLOGY & 275 & 0,0072 & 0,27 & 12 \\
\hline JOURNAL OF BIOLOGICAL CHEMISTRY & 274 & 0,0071 & 0,28 & 13 \\
\hline TRANSPLANTATION PROCEEDINGS & 236 & 0,0062 & 0,29 & 14 \\
\hline AMERICAN JOURNAL OF TROPICAL MEDICINE AND HYGIENE & 218 & 0,0057 & 0,29 & 15 \\
\hline BIOPHYSICAL JOURNAL & 215 & 0,0056 & 0,30 & 16 \\
\hline GASTROENTEROLOGY & 210 & 0,0055 & 0,30 & 17 \\
\hline BRAIN RESEARCH & 188 & 0,0049 & 0,31 & 18 \\
\hline TETRAHEDRON LETTERS & 188 & 0,0049 & 0,31 & 19 \\
\hline AMERICAN JOURNAL OF MEDICAL GENETICS & 186 & 0,0049 & 0,32 & 20 \\
\hline PEDIATRIC RESEARCH & 180 & 0,0047 & 0,32 & 21 \\
\hline EUROPEAN JOURNAL OF PHARMACOLOGY & 167 & 0,0044 & 0,33 & 22 \\
\hline TRANSFUSION & 160 & 0,0042 & 0,33 & 23 \\
\hline WATER SCIENCE AND TECHNOLOGY & 160 & 0,0042 & 0,34 & 24 \\
\hline Total & 12921 & & & \\
\hline
\end{tabular}


Revistas (Grupo 2, soft core: 12.946 papers em 209 journals -61,94 papers/revista).

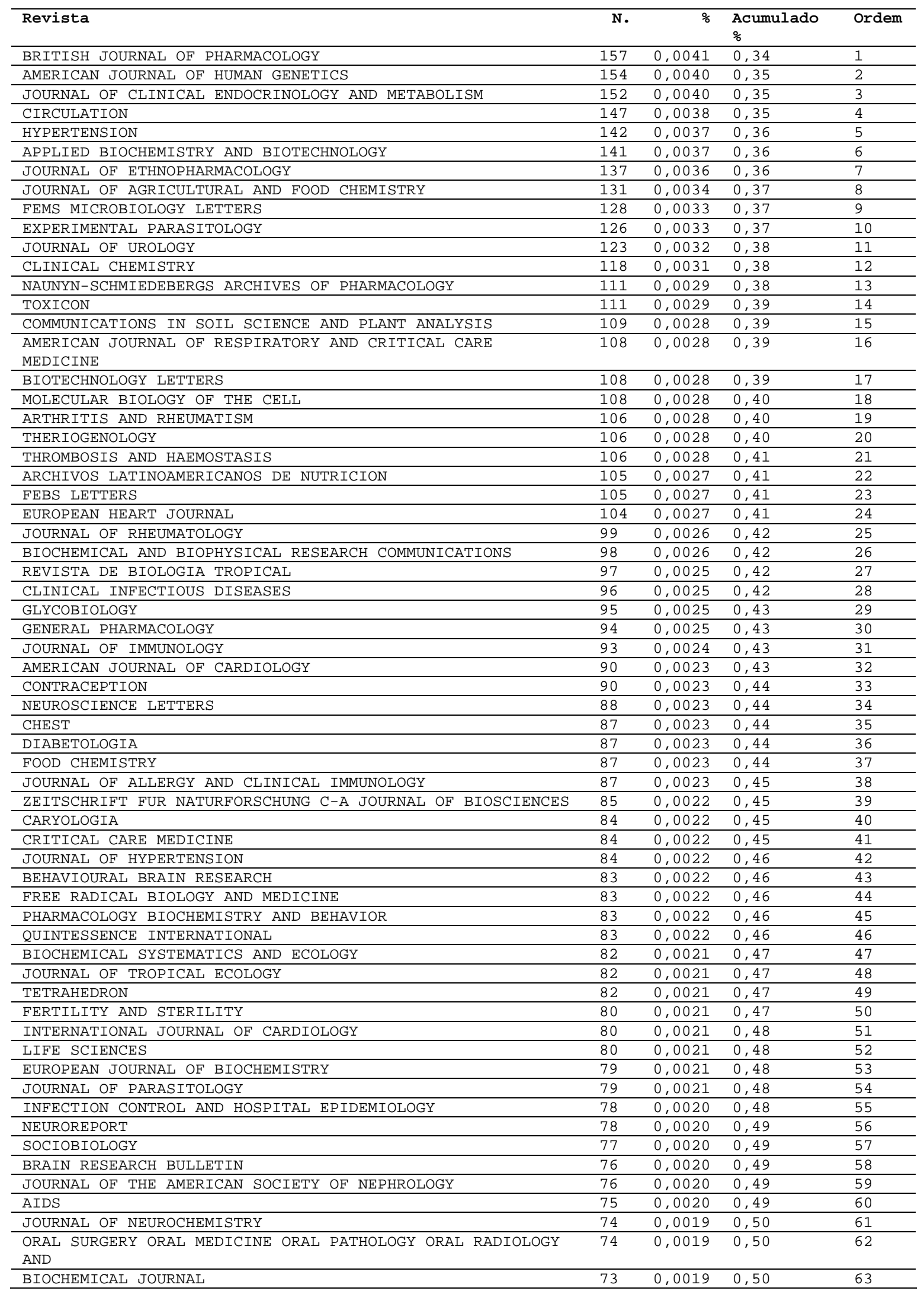




\begin{tabular}{|c|c|c|c|c|}
\hline Revista & $\mathbf{N}$. & $\%$ & $\begin{array}{l}\text { Acumulado } \\
\%\end{array}$ & Ordem \\
\hline BIOTROPICA & 72 & 0,0019 & $\odot, 5 \odot$ & 64 \\
\hline CYTOGENETICS AND CELL GENETICS & 71 & 0,0019 & 0,50 & 65 \\
\hline ACTA TROPICA & 70 & 0,0018 & 0,50 & 66 \\
\hline SCIENCE OF THE TOTAL ENVIRONMENT & 70 & 0,0018 & 0,51 & 67 \\
\hline JOURNAL OF THE AMERICAN COLLEGE OF CARDIOLOGY & 69 & 0,0018 & 0,51 & 68 \\
\hline ANALYST & 68 & 0,0018 & 0,51 & 69 \\
\hline BIOLOGY OF REPRODUCTION & 67 & 0,0017 & 0,51 & 70 \\
\hline JOURNAL OF INORGANIC BIOCHEMISTRY & 67 & 0,0017 & 0,51 & 71 \\
\hline PSYCHOPHARMACOLOGY & 67 & 0,0017 & 0,52 & 72 \\
\hline BRITISH JOURNAL OF HAEMATOLOGY & 65 & 0,0017 & 0,52 & 73 \\
\hline INTERNATIONAL JOURNAL OF CANCER & 65 & 0,0017 & 0,52 & 74 \\
\hline $\begin{array}{l}\text { JOURNAL OF APPLIED ENTOMOLOGY-ZEITSCHRIFT FUR ANGEWANDTE } \\
\text { ENT }\end{array}$ & 65 & 0,0017 & 0,52 & 75 \\
\hline MEDICAL MYCOLOGY & 65 & 0,0017 & 0,52 & 76 \\
\hline PLANT AND SOIL & 65 & 0,0017 & 0,52 & 77 \\
\hline NEUROCHEMICAL RESEARCH & 64 & 0,0017 & 0,53 & 78 \\
\hline CELLULAR AND MOLECULAR BIOLOGY & 63 & 0,0016 & 0,53 & 79 \\
\hline INFECTION AND IMMUNITY & 63 & 0,0016 & 0,53 & 80 \\
\hline $\begin{array}{l}\text { INTERNATIONAL JOURNAL OF LEPROSY AND OTHER MYCOBACTERIAL } \\
\text { DISEASE }\end{array}$ & 63 & 0,0016 & 0,53 & 81 \\
\hline VACCINE & 63 & 0,0016 & $\odot, 53$ & 82 \\
\hline BIOCHIMICA ET BIOPHYSICA ACTA-BIOMEMBRANES & 62 & 0,0016 & 0,53 & 83 \\
\hline CANADIAN JOURNAL OF MICROBIOLOGY & 62 & 0,0016 & 0,54 & 84 \\
\hline NUTRITION RESEARCH & 62 & 0,0016 & 0,54 & 85 \\
\hline ANALYTICAL LETTERS & 61 & 0,0016 & 0,54 & 86 \\
\hline JOURNAL OF TROPICAL PEDIATRICS & 61 & 0,0016 & 0,54 & 87 \\
\hline JOURNAL OF SUBMICROSCOPIC CYTOLOGY AND PATHOLOGY & 60 & 0,0016 & 0,54 & 88 \\
\hline JOURNAL OF PERIODONTOLOGY & 59 & 0,0015 & 0,54 & 89 \\
\hline INSECT BIOCHEMISTRY AND MOLECULAR BIOLOGY & 58 & 0,0015 & $\odot, 54$ & 90 \\
\hline INTERNATIONAL JOURNAL OF EPIDEMIOLOGY & 58 & 0,0015 & 0,55 & 91 \\
\hline BULLETIN OF ENVIRONMENTAL CONTAMINATION AND TOXICOLOGY & 57 & 0,0015 & 0,55 & 92 \\
\hline JOURNAL OF MEDICAL ENTOMOLOGY & 57 & 0,0015 & 0,55 & 93 \\
\hline JOURNAL OF NUCLEAR MEDICINE & 57 & 0,0015 & 0,55 & 94 \\
\hline SCHIZOPHRENIA RESEARCH & 57 & 0,0015 & $\odot, 55$ & 95 \\
\hline ATHEROSCLEROSIS & 56 & 0,0015 & 0,55 & 96 \\
\hline JOURNAL OF PHARMACOLOGY AND EXPERIMENTAL THERAPEUTICS & 56 & 0,0015 & 0,56 & 97 \\
\hline ARCHIVES OF BIOCHEMISTRY AND BIOPHYSICS & 55 & 0,0014 & 0,56 & 98 \\
\hline JOURNAL OF ENDODONTICS & 55 & 0,0014 & 0,56 & 99 \\
\hline JOURNAL OF MEDICAL MICROBIOLOGY & 55 & 0,0014 & 0,56 & 100 \\
\hline SLEEP & 55 & 0,0014 & 0,56 & 101 \\
\hline CHROMATOGRAPHIA & 54 & 0,0014 & 0,56 & 102 \\
\hline GASTROINTESTINAL ENDOSCOPY & 54 & 0,0014 & 0,56 & 103 \\
\hline MEDICAL SCIENCE RESEARCH & 54 & 0,0014 & 0,57 & 104 \\
\hline INTERNATIONAL ENDODONTIC JOURNAL & 53 & 0,0014 & 0,57 & 105 \\
\hline INTERNATIONAL JOURNAL FOR PARASITOLOGY & 52 & 0,0014 & 0,57 & 106 \\
\hline JOURNAL OF CLINICAL LASER MEDICINE \& SURGERY & 52 & 0,0014 & 0,57 & 107 \\
\hline JOURNAL OF CLINICAL MICROBIOLOGY & 52 & 0,0014 & 0,57 & 108 \\
\hline BIOLOGICAL RHYTHM RESEARCH & 51 & 0,0013 & 0,57 & 109 \\
\hline CEPHALALGIA & 51 & 0,0013 & 0,57 & 110 \\
\hline VETERINARY MICROBIOLOGY & 51 & 0,0013 & 0,57 & 111 \\
\hline JOURNAL OF MEDICAL VIROLOGY & 50 & 0,0013 & 0,58 & 112 \\
\hline SOIL SCIENCE SOCIETY OF AMERICA JOURNAL & 50 & 0,0013 & 0,58 & 113 \\
\hline CANCER GENETICS AND CYTOGENETICS & 49 & 0,0013 & 0,58 & 114 \\
\hline HUMAN BIOLOGY & 49 & 0,0013 & 0,58 & 115 \\
\hline JOURNAL OF MEDICAL GENETICS & 49 & 0,0013 & 0,58 & 116 \\
\hline ANNALS OF THORACIC SURGERY & 48 & 0,0013 & 0,58 & 117 \\
\hline CARBOHYDRATE POLYMERS & 48 & 0,0013 & 0,58 & 118 \\
\hline $\begin{array}{l}\text { TRANSACTIONS OF THE ROYAL SOCIETY OF TROPICAL MEDICINE } \\
\text { AND } \mathrm{H}\end{array}$ & 48 & 0,0013 & 0,58 & 119 \\
\hline BIOCHEMICAL PHARMACOLOGY & 47 & 0,0012 & 0,59 & 120 \\
\hline BULLETIN OF THE WORLD HEALTH ORGANIZATION & 47 & 0,0012 & 0,59 & 121 \\
\hline JOURNAL OF INFECTIOUS DISEASES & 47 & 0,0012 & 0,59 & 122 \\
\hline LETTERS IN APPLIED MICROBIOLOGY & 47 & 0,0012 & 0,59 & 123 \\
\hline MEDIATORS OF INFLAMMATION & 47 & 0,0012 & 0,59 & 124 \\
\hline $\begin{array}{l}\text { AMAZONIANA-LIMNOLOGIA ET OECOLOGIA REGIONALIS } \\
\text { SYSTEMAEFLUMIN }\end{array}$ & 46 & 0,0012 & 0,59 & 125 \\
\hline DIABETES CARE & 46 & 0,0012 & $\odot, 59$ & 126 \\
\hline EUROPEAN JOURNAL OF NEUROSCIENCE & 46 & 0,0012 & 0,59 & 127 \\
\hline
\end{tabular}




\begin{tabular}{|c|c|c|c|c|}
\hline Revista & $\mathbf{N}$. & $\%$ & $\begin{array}{l}\text { Acumulado } \\
\%\end{array}$ & Ordem \\
\hline HORMONE AND METABOLIC RESEARCH & 46 & 0,0012 & 0,60 & 128 \\
\hline DIAGNOSTIC MICROBIOLOGY AND INFECTIOUS DISEASE & 45 & 0,0012 & 0,60 & 129 \\
\hline GENETICA & 45 & 0,0012 & 0,60 & 130 \\
\hline HEREDITAS & 45 & 0,0012 & 0,60 & 131 \\
\hline JOURNAL OF NUTRITION & 45 & 0,0012 & 0,60 & 132 \\
\hline CHEMOSPHERE & 44 & 0,0011 & 0,60 & 133 \\
\hline FOOD ADDITIVES AND CONTAMINANTS & 44 & 0,0011 & 0,60 & 134 \\
\hline HUMAN IMMUNOLOGY & 44 & 0,0011 & 0,60 & 135 \\
\hline NEW ENGLAND JOURNAL OF MEDICINE & 44 & 0,0011 & 0,60 & 136 \\
\hline BIOTECHNOLOGY TECHNIQUES & 43 & 0,0011 & 0,61 & 137 \\
\hline INTERNATIONAL SURGERY & 43 & 0,0011 & 0,61 & 138 \\
\hline JOURNAL OF HEPATOLOGY & 43 & 0,0011 & 0,61 & 139 \\
\hline JOURNAL OF LEUKOCYTE BIOLOGY & 43 & 0,0011 & 0,61 & 140 \\
\hline INTENSIVE CARE MEDICINE & 42 & 0,0011 & 0,61 & 141 \\
\hline JOURNAL OF CARDIOVASCULAR PHARMACOLOGY & 42 & 0,0011 & 0,61 & 142 \\
\hline MOLECULAR AND CELLULAR BIOCHEMISTRY & 42 & 0,0011 & 0,61 & 143 \\
\hline PARASITOLOGY & 42 & 0,0011 & 0,61 & 144 \\
\hline CANADIAN JOURNAL OF PHYSIOLOGY AND PHARMACOLOGY & 41 & 0,0011 & 0,61 & 145 \\
\hline JOURNAL OF BASIC MICROBIOLOGY & 41 & 0,0011 & 0,62 & 146 \\
\hline JOURNAL OF PROTEIN CHEMISTRY & 41 & 0,0011 & 0,62 & 147 \\
\hline ANNALS OF ANATOMY-ANATOMISCHER ANZEIGER & 40 & 0,0010 & 0,62 & 148 \\
\hline $\begin{array}{l}\text { COMPARATIVE BIOCHEMISTRY AND PHYSIOLOGY A-MOLECULAR AND } \\
\text { INTE }\end{array}$ & 40 & 0,0010 & 0,62 & 149 \\
\hline CURRENT MICROBIOLOGY & 40 & 0,0010 & 0,62 & 150 \\
\hline GENOME & 40 & 0,0010 & 0,62 & 151 \\
\hline HUMAN REPRODUCTION & 40 & 0,0010 & 0,62 & 152 \\
\hline ACTA CYTOLOGICA & 39 & 0,0010 & 0,62 & 153 \\
\hline BIOLOGICAL CONSERVATION & 39 & 0,0010 & 0,62 & 154 \\
\hline BIOLOGY AND FERTILITY OF SOILS & 39 & 0,0010 & 0,63 & 155 \\
\hline BRITISH MEDICAL JOURNAL & 39 & 0,0010 & 0,63 & 156 \\
\hline ENTOMOLOGIA EXPERIMENTALIS ET APPLICATA & 39 & 0,0010 & 0,63 & 157 \\
\hline ENVIRONMENTAL RESEARCH & 39 & 0,0010 & 0,63 & 158 \\
\hline HUMAN GENETICS & 39 & 0,0010 & 0,63 & 159 \\
\hline JOURNAL OF INSECT PHYSIOLOGY & 39 & 0,0010 & 0,63 & 160 \\
\hline MEDICAL AND PEDIATRIC ONCOLOGY & 39 & 0,0010 & 0,63 & 161 \\
\hline PROCEEDINGS OF THE BIOLOGICAL SOCIETY OF WASHINGTON & 39 & 0,0010 & 0,63 & 162 \\
\hline JOURNAL OF CHEMICAL EDUCATION & 38 & 0,0010 & 0,63 & 163 \\
\hline JOURNAL OF COMPARATIVE NEUROLOGY & 38 & 0,0010 & 0,63 & 164 \\
\hline JOURNAL OF PEDIATRIC GASTROENTEROLOGY AND NUTRITION & 38 & 0,0010 & 0,64 & 165 \\
\hline AMERICAN JOURNAL OF GASTROENTEROLOGY & 37 & 0,0010 & 0,64 & 166 \\
\hline BEHAVIOURAL PHARMACOLOGY & 37 & 0,0010 & 0,64 & 167 \\
\hline BIORESOURCE TECHNOLOGY & 37 & 0,0010 & 0,64 & 168 \\
\hline JOURNAL OF FOOD PROTECTION & 37 & 0,0010 & 0,64 & 169 \\
\hline LANCET & 37 & 0,0010 & 0,64 & 170 \\
\hline NUTRITION & 37 & 0,0010 & 0,64 & 171 \\
\hline ANNALS OF TROPICAL MEDICINE AND PARASITOLOGY & 36 & 0,0009 & 0,64 & 172 \\
\hline CELL BIOCHEMISTRY AND FUNCTION & 36 & 0,0009 & 0,64 & 173 \\
\hline CLINICAL AND EXPERIMENTAL IMMUNOLOGY & 36 & 0,0009 & 0,64 & 174 \\
\hline EPILEPSY RESEARCH & 36 & 0,0009 & 0,64 & 175 \\
\hline EUROPEAN JOURNAL OF CELL BIOLOGY & 36 & 0,0009 & 0,65 & 176 \\
\hline JOURNAL OF BIOTECHNOLOGY & 36 & 0,0009 & 0,65 & 177 \\
\hline RENAL FAILURE & 36 & 0,0009 & 0,65 & 178 \\
\hline SURGICAL AND RADIOLOGIC ANATOMY & 36 & 0,0009 & 0,65 & 179 \\
\hline BIOCHIMICA ET BIOPHYSICA ACTA-GENERAL SUBJECTS & 35 & 0,0009 & 0,65 & 180 \\
\hline CONSERVATION BIOLOGY & 35 & 0,0009 & 0,65 & 181 \\
\hline EUROPEAN JOURNAL OF IMMUNOLOGY & 35 & 0,0009 & 0,65 & 182 \\
\hline INTERNATIONAL JOURNAL OF EXPERIMENTAL PATHOLOGY & 35 & 0,0009 & 0,65 & 183 \\
\hline OPERATIVE DENTISTRY & 35 & 0,0009 & 0,65 & 184 \\
\hline BOLETIN DE LA SOCIEDAD CHILENA DE QUIMICA & 34 & 0,0009 & 0,65 & 185 \\
\hline EUROPEAN RESPIRATORY JOURNAL & 34 & 0,0009 & 0,66 & 186 \\
\hline GUT & 34 & 0,0009 & 0,66 & 187 \\
\hline HUMAN MOLECULAR GENETICS & 34 & 0,0009 & 0,66 & 188 \\
\hline IMMUNOPHARMACOLOGY & 34 & 0,0009 & 0,66 & 189 \\
\hline TISSUE \& CELL & 34 & $\odot, 0 \odot \odot 9$ & 0,66 & 190 \\
\hline AIDS RESEARCH AND HUMAN RETROVIRUSES & 33 & 0,0009 & 0,66 & 191 \\
\hline APIDOLOGIE & 33 & 0,0009 & 0,66 & 192 \\
\hline BIOCHEMICAL GENETICS & 33 & 0,0009 & 0,66 & 193 \\
\hline
\end{tabular}




\begin{tabular}{|c|c|c|c|c|}
\hline Revista & $\mathbf{N}$ & $\%$ & $\begin{array}{l}\text { Acumulado } \\
\%\end{array}$ & $\begin{array}{l}\text { Orde } \\
\mathrm{m}\end{array}$ \\
\hline ENDOSCOPY & 33 & 0,0009 & 0,66 & 194 \\
\hline IMMUNOLOGY LETTERS & 33 & 0,0009 & 0,66 & 195 \\
\hline JOURNAL OF CHEMICAL RESEARCH-S & 33 & 0,0009 & 0,66 & 196 \\
\hline JOURNAL OF CHROMATOGRAPHY A & 33 & 0,0009 & 0,66 & 197 \\
\hline JOURNAL OF PHARMACEUTICAL AND BIOMEDICAL ANALYSIS & 33 & 0,0009 & 0,67 & 198 \\
\hline NEPHROLOGY DIALYSIS TRANSPLANTATION & 33 & 0,0009 & 0,67 & 199 \\
\hline HUMAN HEREDITY & 32 & 0,0008 & 0,67 & 200 \\
\hline JOURNAL OF FOOD SCIENCE & 32 & 0,0008 & 0,67 & 201 \\
\hline JOURNAL OF ORAL AND MAXILLOFACIAL SURGERY & 32 & 0,0008 & 0,67 & 202 \\
\hline ACTA HAEMATOLOGICA & 31 & 0,0008 & 0,67 & 203 \\
\hline BIOLOGICAL TRACE ELEMENT RESEARCH & 31 & 0,0008 & 0,67 & 204 \\
\hline CARBOHYDRATE RESEARCH & 31 & 0,0008 & 0,67 & 205 \\
\hline CLINICAL IMMUNOLOGY & 31 & 0,0008 & 0,67 & 206 \\
\hline JOURNAL OF MORPHOLOGY & 31 & 0,0008 & 0,67 & 207 \\
\hline JOURNAL OF THE NEUROLOGICAL SCIENCES & 31 & 0,0008 & 0,67 & 208 \\
\hline NEUROMUSCULAR DISORDERS & 31 & 0,0008 & 0,67 & 209 \\
\hline Total & 12946 & & & \\
\hline
\end{tabular}


Revistas (Grupo 3, periféricos: 12.482 papers em 1.813 journals $-6,8$ papers/revista).

\begin{tabular}{|c|c|c|c|c|}
\hline Revista & $\mathbf{N}$. & $\%$ & $\begin{array}{l}\text { Acumulado } \\
\%\end{array}$ & Ordem \\
\hline AMERICAN JOURNAL OF HYPERTENSION & 30 & 0,0008 & 0,68 & 1 \\
\hline ANESTHESIOLOGY & 30 & 0,0008 & 0,68 & 2 \\
\hline APPLIED AND ENVIRONMENTAL MICROBIOLOGY & 30 & 0,0008 & 0,68 & 3 \\
\hline CLINICAL AND EXPERIMENTAL RHEUMATOLOGY & 30 & 0,0008 & 0,68 & 4 \\
\hline EMERGING INFECTIOUS DISEASES & 30 & 0,0008 & 0,68 & 5 \\
\hline EUROPEAN JOURNAL OF CARDIO-THORACIC SURGERY & 30 & 0,0008 & 0,68 & 6 \\
\hline JOURNAL OF CHEMICAL AND ENGINEERING DATA & 30 & 0,0008 & 0,68 & 7 \\
\hline JOURNAL OF PHYSIOLOGY-LONDON & 30 & 0,0008 & 0,68 & 8 \\
\hline JOURNAL OF PROSTHETIC DENTISTRY & 30 & 0,0008 & 0,68 & 9 \\
\hline JOURNAL OF VIROLOGICAL METHODS & 30 & 0,0008 & 0,68 & 10 \\
\hline ORAL ONCOLOGY & 30 & 0,0008 & 0,68 & 11 \\
\hline PURE AND APPLIED CHEMISTRY & 30 & 0,0008 & 0,68 & 12 \\
\hline ADDICTION & 29 & 0,0008 & 0,68 & 13 \\
\hline AESTHETIC PLASTIC SURGERY & 29 & 0,0008 & 0,69 & 14 \\
\hline ANTIMICROBIAL AGENTS AND CHEMOTHERAPY & 29 & 0,0008 & 0,69 & 15 \\
\hline BIOPHYSICAL CHEMISTRY & 29 & 0,0008 & 0,69 & 16 \\
\hline HAEMATOLOGICA & 29 & 0,0008 & 0,69 & 17 \\
\hline JOURNAL OF ARACHNOLOGY & 29 & 0,0008 & 0,69 & 18 \\
\hline JOURNAL OF GENERAL VIROLOGY & 29 & 0,0008 & 0,69 & 19 \\
\hline MEDICAL AND VETERINARY ENTOMOLOGY & 29 & 0,0008 & 0,69 & 20 \\
\hline OBESITY RESEARCH & 29 & 0,0008 & 0,69 & 21 \\
\hline TOXICOLOGY & 29 & 0,0008 & 0,69 & 22 \\
\hline AMERICAN JOURNAL OF PHYSICAL ANTHROPOLOGY & 28 & 0,0007 & 0,69 & 23 \\
\hline AMERICAN JOURNAL OF PHYSIOLOGY-REGULATORY INTEGRATIVE AND CO & 28 & 0,0007 & 0,69 & 24 \\
\hline ARCHIVES OF VIROLOGY & 28 & 0,0007 & 0,69 & 25 \\
\hline BIOCHIMICA ET BIOPHYSICA ACTA-PROTEIN STRUCTURE AND MOLECULA & 28 & 0,0007 & 0,69 & 26 \\
\hline BIOTECHNOLOGY AND BIOENGINEERING & 28 & 0,0007 & 0,70 & 27 \\
\hline CELLULAR AND MOLECULAR NEUROBIOLOGY & 28 & 0,0007 & 0,70 & 28 \\
\hline CLINICAL AND DIAGNOSTIC LABORATORY IMMUNOLOGY & 28 & 0,0007 & 0,70 & 29 \\
\hline EPILEPSIA & 28 & 0,0007 & 0,70 & 30 \\
\hline EUROPEAN JOURNAL OF CANCER & 28 & 0,0007 & 0,70 & 31 \\
\hline JOURNAL OF APPLIED PHYSIOLOGY & 28 & 0,0007 & $\odot, 70$ & 32 \\
\hline JOURNAL OF EXPERIMENTAL BIOLOGY & 28 & 0,0007 & 0,70 & 33 \\
\hline MODERN PATHOLOGY & 28 & 0,0007 & 0,70 & 34 \\
\hline MYCOPATHOLOGIA & 28 & 0,0007 & 0,70 & 35 \\
\hline NUCLEIC ACIDS RESEARCH & 28 & 0,0007 & 0,70 & 36 \\
\hline SCANDINAVIAN JOURNAL OF IMMUNOLOGY & 28 & 0,0007 & 0,70 & 37 \\
\hline VIRUS RESEARCH & 28 & $\odot, 0 \odot \odot 7$ & $\odot, 7 \odot$ & 38 \\
\hline ACTA PAEDIATRICA & 27 & 0,0007 & 0,70 & 39 \\
\hline BIOCELL & 27 & 0,0007 & 0,70 & 40 \\
\hline BIODIVERSITY AND CONSERVATION & 27 & 0,0007 & 0,71 & 41 \\
\hline DIABETES & 27 & 0,0007 & 0,71 & 42 \\
\hline ENDOCRINOLOGY & 27 & 0,0007 & 0,71 & 43 \\
\hline EUROPEAN NEUROPSYCHOPHARMACOLOGY & 27 & 0,0007 & 0,71 & 44 \\
\hline HEREDITY & 27 & 0,0007 & 0,71 & 45 \\
\hline INTERNATIONAL JOURNAL OF GYNECOLOGY \& OBSTETRICS & 27 & 0,0007 & 0,71 & 46 \\
\hline JOURNAL OF BONE AND MINERAL RESEARCH & 27 & 0,0007 & 0,71 & 47 \\
\hline JOURNAL OF DENTISTRY FOR CHILDREN & 27 & $\odot, 0 \odot \odot 7$ & 0,71 & 48 \\
\hline JOURNAL OF PSYCHOPHARMACOLOGY & 27 & 0,0007 & 0,71 & 49 \\
\hline METABOLISM-CLINICAL AND EXPERIMENTAL & 27 & 0,0007 & 0,71 & 50 \\
\hline WATER AIR AND SOIL POLLUTION & 27 & 0,0007 & 0,71 & 51 \\
\hline ARTIFICIAL ORGANS & 26 & 0,0007 & 0,71 & 52 \\
\hline ENZYME AND MICROBIAL TECHNOLOGY & 26 & 0,0007 & 0,71 & 53 \\
\hline EPIDEMIOLOGY & 26 & 0,0007 & 0,71 & 54 \\
\hline FEMS IMMUNOLOGY AND MEDICAL MICROBIOLOGY & 26 & 0,0007 & 0,72 & 55 \\
\hline HISTOPATHOLOGY & 26 & 0,0007 & 0,72 & 56 \\
\hline JOURNAL OF FOOD ENGINEERING & 26 & 0,0007 & 0,72 & 57 \\
\hline JOURNAL OF THE AMERICAN MEDICAL INFORMATICS ASSOCIATION & 26 & 0,0007 & 0,72 & 58 \\
\hline LARYNGOSCOPE & 26 & 0,0007 & 0,72 & 59 \\
\hline MICROBES AND INFECTION & 26 & 0,0007 & 0,72 & 60 \\
\hline NEUROSURGERY & 26 & 0,0007 & 0,72 & 61 \\
\hline TERATOGENESIS CARCINOGENESIS AND MUTAGENESIS & 26 & 0,0007 & 0,72 & 62 \\
\hline AMERICAN HEART JOURNAL & 25 & 0,0007 & 0,72 & 63 \\
\hline BIOCHEMISTRY & 25 & 0,0007 & 0,72 & 64 \\
\hline CANCER & 25 & 0,0007 & 0,72 & 65 \\
\hline CANCER LETTERS & 25 & 0,0007 & 0,72 & 66 \\
\hline ENVIRONMENTAL CONSERVATION & 25 & 0,0007 & 0,72 & 67 \\
\hline HEART & 25 & 0,0007 & 0,72 & 68 \\
\hline
\end{tabular}




\begin{tabular}{|c|c|c|c|c|}
\hline INTERNATIONAL ARCHIVES OF ALLERGY AND IMMUNOLOGY & 25 & $0,0 \odot \odot 7$ & 0,72 & 69 \\
\hline JOURNAL OF APPLIED MICROBIOLOGY & 25 & 0,0007 & 0,72 & 70 \\
\hline JOURNAL OF CHEMICAL ECOLOGY & 25 & 0,0007 & 0,73 & 71 \\
\hline JOURNAL OF ENVIRONMENTAL RADIOACTIVITY & 25 & 0,0007 & 0,73 & 72 \\
\hline LASERS IN SURGERY AND MEDICINE & 25 & 0,0007 & 0,73 & 73 \\
\hline LUPUS & 25 & 0,0007 & 0,73 & 74 \\
\hline VISION RESEARCH & 25 & 0,0007 & 0,73 & 75 \\
\hline AMERICAN JOURNAL OF DENTISTRY & 24 & 0,0006 & 0,73 & 76 \\
\hline AMERICAN JOURNAL OF SURGERY & 24 & 0,0006 & 0,73 & 77 \\
\hline ANESTHESIA AND ANALGESIA & 24 & 0,0006 & 0,73 & 78 \\
\hline BRITISH JOURNAL OF PSYCHIATRY & 24 & 0,0006 & 0,73 & 79 \\
\hline DEVELOPMENTAL BRAIN RESEARCH & 24 & 0,0006 & 0,73 & 80 \\
\hline JOURNAL OF CLINICAL LABORATORY ANALYSIS & 24 & 0,0006 & 0,73 & 81 \\
\hline JOURNAL OF CLINICAL ONCOLOGY & 24 & 0,0006 & 0,73 & 82 \\
\hline JOURNAL OF MASS SPECTROMETRY & 24 & 0,0006 & 0,73 & 83 \\
\hline LEPROSY REVIEW & 24 & 0,0006 & 0,73 & 84 \\
\hline SYNTHESIS-STUTTGART & 24 & 0,0006 & 0,73 & 85 \\
\hline SYSTEMATIC PARASITOLOGY & 24 & 0,0006 & 0,74 & 86 \\
\hline THROMBOSIS RESEARCH & 24 & 0,0006 & 0,74 & 87 \\
\hline BIOLOGICAL PSYCHIATRY & 23 & 0,0006 & 0,74 & 88 \\
\hline BIOTECHNOLOGY AND APPLIED BIOCHEMISTRY & 23 & 0,0006 & 0,74 & 89 \\
\hline CARDIOLOGY IN THE YOUNG & 23 & 0,0006 & 0,74 & 90 \\
\hline ENVIRONMENTAL POLLUTION & 23 & 0,0006 & 0,74 & 91 \\
\hline EXPERIMENTAL AND TOXICOLOGIC PATHOLOGY & 23 & 0,0006 & 0,74 & 92 \\
\hline FLAVOUR AND FRAGRANCE JOURNAL & 23 & 0,0006 & 0,74 & 93 \\
\hline JOURNAL OF CLINICAL GASTROENTEROLOGY & 23 & 0,0006 & 0,74 & 94 \\
\hline JOURNAL OF CLINICAL INVESTIGATION & 23 & 0,0006 & 0,74 & 95 \\
\hline JOURNAL OF DAIRY SCIENCE & 23 & 0,0006 & 0,74 & 96 \\
\hline JOURNAL OF THE AMERICAN CHEMICAL SOCIETY & 23 & 0,0006 & 0,74 & 97 \\
\hline JOURNAL OF THE AMERICAN GERIATRICS SOCIETY & 23 & 0,0006 & 0,74 & 98 \\
\hline JOURNAL OF TRAUMA-INJURY INFECTION AND CRITICAL CARE & 23 & 0,0006 & 0,74 & 99 \\
\hline NEUROPHARMACOLOGY & 23 & 0,0006 & 0,74 & 100 \\
\hline SURGICAL LAPAROSCOPY \& ENDOSCOPY & 23 & 0,0006 & 0,74 & 101 \\
\hline AMERICAN JOURNAL OF CLINICAL NUTRITION & 22 & 0,0006 & 0,74 & 102 \\
\hline CLINICAL NUCLEAR MEDICINE & 22 & 0,0006 & 0,75 & 103 \\
\hline CORNEA & 22 & 0,0006 & 0,75 & 104 \\
\hline CURRENT THERAPEUTIC RESEARCH-CLINICAL AND EXPERIMENTAL & 22 & 0,0006 & 0,75 & 105 \\
\hline DIAGNOSTIC CYTOPATHOLOGY & 22 & 0,0006 & 0,75 & 106 \\
\hline DRUG DEVELOPMENT AND INDUSTRIAL PHARMACY & 22 & 0,0006 & 0,75 & 107 \\
\hline ECOTOXICOLOGY AND ENVIRONMENTAL SAFETY & 22 & 0,0006 & 0,75 & 108 \\
\hline ELECTROPHORESIS & 22 & 0,0006 & 0,75 & 109 \\
\hline INTERNATIONAL JOURNAL OF DERMATOLOGY & 22 & 0,0006 & 0,75 & 110 \\
\hline JOURNAL OF NEUROSCIENCE & 22 & 0,0006 & 0,75 & 111 \\
\hline JOURNAL OF ORGANIC CHEMISTRY & 22 & 0,0006 & 0,75 & 112 \\
\hline JOURNAL OF PEDIATRICS & 22 & 0,0006 & 0,75 & 113 \\
\hline JOURNAL OF THE AMERICAN MOSQUITO CONTROL ASSOCIATION & 22 & 0,0006 & 0,75 & 114 \\
\hline NEUROBIOLOGY OF LEARNING AND MEMORY & 22 & 0,0006 & 0,75 & 115 \\
\hline ODONATOLOGICA & 22 & 0,0006 & 0,75 & 116 \\
\hline AMERICAN JOURNAL OF EPIDEMIOLOGY & 21 & 0,0005 & 0,75 & 117 \\
\hline AMERICAN JOURNAL OF OPHTHALMOLOGY & 21 & 0,0005 & 0,75 & 118 \\
\hline CANADIAN JOURNAL OF CHEMISTRY-REVUE CANADIENNE DE CHIMIE & 21 & 0,0005 & 0,75 & 119 \\
\hline GENOMICS & 21 & 0,0005 & 0,75 & 120 \\
\hline INTERNATIONAL JOURNAL OF DEVELOPMENTAL NEUROSCIENCE & 21 & 0,0005 & 0,76 & 121 \\
\hline INTERNATIONAL JOURNAL OF TUBERCULOSIS AND LUNG DISEASE & 21 & 0,0005 & 0,76 & 122 \\
\hline INVESTIGATIVE OPHTHALMOLOGY \& VISUAL SCIENCE & 21 & 0,0005 & 0,76 & 123 \\
\hline JOURNAL OF FOOD BIOCHEMISTRY & 21 & 0,0005 & 0,76 & 124 \\
\hline JOURNAL OF NATURAL PRODUCTS & 21 & 0,0005 & 0,76 & 125 \\
\hline MOLECULAR ECOLOGY & 21 & 0,0005 & 0,76 & 126 \\
\hline PEDIATRIC INFECTIOUS DISEASE JOURNAL & 21 & 0,0005 & 0,76 & 127 \\
\hline AMERICAN JOURNAL OF PATHOLOGY & 20 & 0,0005 & 0,76 & 128 \\
\hline ANALYTICAL CHEMISTRY & 20 & 0,0005 & 0,76 & 129 \\
\hline ANNALS OF PLASTIC SURGERY & 20 & 0,0005 & 0,76 & 130 \\
\hline BIOLOGY OF THE CELL & 20 & 0,0005 & 0,76 & 131 \\
\hline BONE MARROW TRANSPLANTATION & 20 & 0,0005 & 0,76 & 132 \\
\hline CLINICAL ENDOCRINOLOGY & 20 & 0,0005 & 0,76 & 133 \\
\hline CLINICAL NEPHROLOGY & 20 & 0,0005 & 0,76 & 134 \\
\hline DENTOMAXILLOFACIAL RADIOLOGY & 20 & 0,0005 & 0,76 & 135 \\
\hline DISEASES OF THE ESOPHAGUS & 20 & 0,0005 & 0,76 & 136 \\
\hline INSECTES SOCIAUX & 20 & 0,0005 & 0,76 & 137 \\
\hline INTERNATIONAL JOURNAL OF IMMUNOPHARMACOLOGY & 20 & 0,0005 & 0,76 & 138 \\
\hline JOURNAL OF INVESTIGATIVE DERMATOLOGY & 20 & 0,0005 & 0,77 & 139 \\
\hline JOURNAL OF NUTRITIONAL BIOCHEMISTRY & 20 & 0,0005 & 0,77 & 140 \\
\hline MUTATION RESEARCH-GENETIC TOXICOLOGY AND ENVIRONMENTAL MUTAG & 20 & 0,0005 & 0,77 & 141 \\
\hline
\end{tabular}




\begin{tabular}{|c|c|c|c|c|}
\hline PHARMAZIE & 20 & 0,0005 & 0,77 & 142 \\
\hline SPINAL CORD & 20 & 0,0005 & 0,77 & 143 \\
\hline AMERICAN JOURNAL OF HUMAN BIOLOGY & 19 & 0,0005 & 0,77 & 144 \\
\hline BRITISH JOURNAL OF OPHTHALMOLOGY & 19 & 0,0005 & 0,77 & 145 \\
\hline BURNS & 19 & 0,0005 & 0,77 & 146 \\
\hline CLINICAL DYSMORPHOLOGY & 19 & 0,0005 & 0,77 & 147 \\
\hline ENVIRONMENTAL TECHNOLOGY & 19 & 0,0005 & 0,77 & 148 \\
\hline EUROPEAN JOURNAL OF ENDOCRINOLOGY & 19 & 0,0005 & 0,77 & 149 \\
\hline FARMACO & 19 & 0,0005 & 0,77 & 150 \\
\hline GENETICS & 19 & 0,0005 & 0,77 & 151 \\
\hline GLYCOCONJUGATE JOURNAL & 19 & $0,0 \odot \odot 5$ & 0,77 & 152 \\
\hline HEPATO - GASTROENTEROLOGY & 19 & 0,0005 & 0,77 & 153 \\
\hline INFLAMMATION RESEARCH & 19 & 0,0005 & 0,77 & 154 \\
\hline INTERNATIONAL JOURNAL OF PEDIATRIC OTORHINOLARYNGOLOGY & 19 & 0,0005 & 0,77 & 155 \\
\hline JOURNAL OF EUKARYOTIC MICROBIOLOGY & 19 & $0,0 \odot \odot 5$ & 0,77 & 156 \\
\hline JOURNAL OF PEDIATRIC SURGERY & 19 & 0,0005 & 0,77 & 157 \\
\hline JOURNAL OF THE AMERICAN ACADEMY OF DERMATOLOGY & 19 & 0,0005 & 0,77 & 158 \\
\hline LEUKEMIA & 19 & 0,0005 & 0,78 & 159 \\
\hline MEDICAL PHYSICS & 19 & 0,0005 & 0,78 & 160 \\
\hline MOLECULAR IMMUNOLOGY & 19 & 0,0005 & 0,78 & 161 \\
\hline MUTATION RESEARCH-FUNDAMENTAL AND MOLECULAR MECHANISMSOF MUT & 19 & 0,0005 & 0,78 & 162 \\
\hline NEPHRON & 19 & 0,0005 & 0,78 & 163 \\
\hline PARASITE-JOURNAL DE LA SOCIETE FRANCAISE DE PARASITOLOGIE & 19 & 0,0005 & 0,78 & 164 \\
\hline PATHOLOGY RESEARCH AND PRACTICE & 19 & 0,0005 & 0,78 & 165 \\
\hline PEDIATRIC RADIOLOGY & 19 & 0,0005 & 0,78 & 166 \\
\hline PHARMACOLOGICAL RESEARCH & 19 & 0,0005 & 0,78 & 167 \\
\hline REVISTA INTERAMERICANA DE PSICOLOGIA & 19 & 0,0005 & 0,78 & 168 \\
\hline AMBIO & 18 & 0,0005 & 0,78 & 169 \\
\hline ANALYTICAL BIOCHEMISTRY & 18 & 0,0005 & 0,78 & 170 \\
\hline BRITISH JOURNAL OF PLASTIC SURGERY & 18 & 0,0005 & 0,78 & 171 \\
\hline CANCER RESEARCH & 18 & 0,0005 & 0,78 & 172 \\
\hline CELLULAR IMMUNOLOGY & 18 & 0,0005 & 0,78 & 173 \\
\hline CLINICAL RHEUMATOLOGY & 18 & 0,0005 & 0,78 & 174 \\
\hline HISTOLOGY AND HISTOPATHOLOGY & 18 & 0,0005 & 0,78 & 175 \\
\hline HUMAN MUTATION & 18 & 0,0005 & 0,78 & 176 \\
\hline INTERNATIONAL JOURNAL OF ENVIRONMENTAL ANALYTICAL CHEMISTRY & 18 & 0,0005 & 0,78 & 177 \\
\hline JAMA-JOURNAL OF THE AMERICAN MEDICAL ASSOCIATION & 18 & 0,0005 & 0,78 & 178 \\
\hline JOURNAL OF ORAL REHABILITATION & 18 & 0,0005 & 0,78 & 179 \\
\hline JOURNAL OF PEDIATRIC ENDOCRINOLOGY \& METABOLISM & 18 & $0,0 \odot \odot 5$ & 0,79 & 180 \\
\hline JOURNAL OF REFRACTIVE SURGERY & 18 & 0,0005 & 0,79 & 181 \\
\hline LABORATORY INVESTIGATION & 18 & 0,0005 & 0,79 & 182 \\
\hline MICROSURGERY & 18 & 0,0005 & 0,79 & 183 \\
\hline PERCEPTUAL AND MOTOR SKILLS & 18 & 0,0005 & 0,79 & 184 \\
\hline PROCESS BIOCHEMISTRY & 18 & 0,0005 & 0,79 & 185 \\
\hline ACTA CRYSTALLOGRAPHICA SECTION D-BIOLOGICAL CRYSTALLOGRAPHY & 17 & 0,0004 & 0,79 & 186 \\
\hline AMERICAN JOURNAL OF ORTHODONTICS AND DENTOFACIAL ORTHOPEDICS & 17 & 0,0004 & 0,79 & 187 \\
\hline BIOCHIMIE & 17 & 0,0004 & 0,79 & 188 \\
\hline BIOGEOCHEMISTRY & 17 & 0,0004 & 0,79 & 189 \\
\hline CARDIOVASCULAR PATHOLOGY & 17 & 0,0004 & 0,79 & 190 \\
\hline CHROMOSOMA & 17 & $0,00 \odot 4$ & 0,79 & 191 \\
\hline COMMUNITY DENTISTRY AND ORAL EPIDEMIOLOGY & 17 & 0,0004 & 0,79 & 192 \\
\hline CRANIO-THE JOURNAL OF CRANIOMANDIBULAR PRACTICE & 17 & 0,0004 & 0,79 & 193 \\
\hline ENDOCRINE PATHOLOGY & 17 & 0,0004 & 0,79 & 194 \\
\hline ENVIRONMENTAL HEALTH PERSPECTIVES & 17 & 0,0004 & 0,79 & 195 \\
\hline EUROPEAN JOURNAL OF CLINICAL NUTRITION & 17 & $0,0 \odot \odot 4$ & 0,79 & 196 \\
\hline JOURNAL OF ACQUIRED IMMUNE DEFICIENCY SYNDROMES & 17 & 0,0004 & 0,79 & 197 \\
\hline JOURNAL OF ENDOUROLOGY & 17 & 0,0004 & 0,79 & 198 \\
\hline JOURNAL OF LIQUID CHROMATOGRAPHY \& RELATED TECHNOLOGIES & 17 & 0,0004 & 0,79 & 199 \\
\hline JOURNAL OF MEMBRANE SCIENCE & 17 & 0,0004 & 0,79 & 200 \\
\hline JOURNAL OF THE KANSAS ENTOMOLOGICAL SOCIETY & 17 & 0,0004 & 0,79 & 201 \\
\hline PROGRESS IN NEURO-PSYCHOPHARMACOLOGY \& BIOLOGICAL PSYCHIATRY & 17 & 0,0004 & 0,80 & 202 \\
\hline STRUCTURAL CHEMISTRY & 17 & $0,0 \odot \odot 4$ & 0,80 & 203 \\
\hline TRANSPLANTATION & 17 & 0,0004 & 0,80 & 204 \\
\hline TROPICAL MEDICINE \& INTERNATIONAL HEALTH & 17 & 0,0004 & 0,80 & 205 \\
\hline ACTA NEUROLOGICA SCANDINAVICA & 16 & 0,0004 & 0,80 & 206 \\
\hline AMERICAN JOURNAL OF HEMATOLOGY & 16 & 0,0004 & 0,80 & 207 \\
\hline AMERICAN JOURNAL OF PHYSIOLOGY-HEART AND CIRCULATORY PHYSIOL & 16 & 0,0004 & 0,80 & 208 \\
\hline ANNALS OF ONCOLOGY & 16 & $0,0 \odot \odot 4$ & 0,80 & 209 \\
\hline ANNALS OF THE ENTOMOLOGICAL SOCIETY OF AMERICA & 16 & 0,0004 & 0,80 & 210 \\
\hline BEHAVIOUR & 16 & 0,0004 & 0,80 & 211 \\
\hline BIOLOGICAL CONTROL & 16 & $0,0 \odot \odot 4$ & 0,80 & 212 \\
\hline BIOPROCESS ENGINEERING & 16 & $0,0 \odot \odot 4$ & 0,80 & 213 \\
\hline BIOTECHNIQUES & 16 & 0,0004 & 0,80 & 214 \\
\hline
\end{tabular}




\begin{tabular}{|c|c|c|c|c|}
\hline BREAST CANCER RESEARCH AND TREATMENT & 16 & 0,0004 & 0,80 & 215 \\
\hline BRITISH JOURNAL OF CANCER & 16 & 0,0004 & 0,80 & 216 \\
\hline BRITISH JOURNAL OF DERMATOLOGY & 16 & 0,0004 & 0,80 & 217 \\
\hline CARCINOGENESIS & 16 & 0,0004 & 0,80 & 218 \\
\hline CELL STRUCTURE AND FUNCTION & 16 & 0,0004 & 0,80 & 219 \\
\hline CHEMISTRY AND PHYSICS OF LIPIDS & 16 & 0,0004 & 0,80 & 220 \\
\hline CLINICAL CARDIOLOGY & 16 & 0,0004 & 0,80 & 221 \\
\hline COLEOPTERISTS BULLETIN & 16 & 0,0004 & 0,80 & 222 \\
\hline DIABETES RESEARCH AND CLINICAL PRACTICE & 16 & 0,0004 & 0,80 & 223 \\
\hline ECHOCARDIOGRAPHY-A JOURNAL OF CARDIOVASCULAR ULTRASOUND AND & 16 & 0,0004 & 0,80 & 224 \\
\hline EVOLUTION & 16 & 0,0004 & 0,80 & 225 \\
\hline GERONTOLOGY & 16 & 0,0004 & 0,81 & 226 \\
\hline INTERNATIONAL JOURNAL OF PSYCHOPHYSIOLOGY & 16 & 0,0004 & 0,81 & 227 \\
\hline INTERNATIONAL JOURNAL OF SYSTEMATIC BACTERIOLOGY & 16 & 0,0004 & 0,81 & 228 \\
\hline JOURNAL OF ADOLESCENT HEALTH & 16 & 0,0004 & 0,81 & 229 \\
\hline JOURNAL OF ASSISTED REPRODUCTION AND GENETICS & 16 & 0,0004 & 0,81 & 230 \\
\hline JOURNAL OF INHERITED METABOLIC DISEASE & 16 & 0,0004 & 0,81 & 231 \\
\hline JOURNAL OF NATURAL HISTORY & 16 & 0,0004 & 0,81 & 232 \\
\hline MAIN GROUP METAL CHEMISTRY & 16 & 0,0004 & 0,81 & 233 \\
\hline NATURE GENETICS & 16 & 0,0004 & 0,81 & 234 \\
\hline OPHTHALMIC PLASTIC AND RECONSTRUCTIVE SURGERY & 16 & 0,0004 & 0,81 & 235 \\
\hline OTOLARYNGOLOGY-HEAD AND NECK SURGERY & 16 & 0,0004 & 0,81 & 236 \\
\hline PROCEEDINGS OF THE ENTOMOLOGICAL SOCIETY OF WASHINGTON & 16 & 0,0004 & 0,81 & 237 \\
\hline ANNALS OF INTERNAL MEDICINE & 15 & 0,0004 & 0,81 & 238 \\
\hline BIOCHEMICAL SOCIETY TRANSACTIONS & 15 & 0,0004 & 0,81 & 239 \\
\hline BIOCONTROL SCIENCE AND TECHNOLOGY & 15 & 0,0004 & 0,81 & 240 \\
\hline BRITISH JOURNAL OF NUTRITION & 15 & 0,0004 & 0,81 & 241 \\
\hline BULLETIN OF ENTOMOLOGICAL RESEARCH & 15 & 0,0004 & 0,81 & 242 \\
\hline CHROMOSOME RESEARCH & 15 & 0,0004 & 0,81 & 243 \\
\hline CLINICA CHIMICA ACTA & 15 & 0,0004 & 0,81 & 244 \\
\hline CURRENT GENETICS & 15 & 0,0004 & 0,81 & 245 \\
\hline EUROPEAN JOURNAL OF NUCLEAR MEDICINE & 15 & 0,0004 & 0,81 & 246 \\
\hline FORENSIC SCIENCE INTERNATIONAL & 15 & 0,0004 & 0,81 & 247 \\
\hline INTERNATIONAL IMMUNOLOGY & 15 & 0,0004 & 0,81 & 248 \\
\hline INTERNATIONAL JOURNAL OF RADIATION ONCOLOGY BIOLOGY PHYSICS & 15 & 0,0004 & 0,81 & 249 \\
\hline JOURNAL OF PHARMACY AND PHARMACOLOGY & 15 & 0,0004 & 0,81 & 250 \\
\hline MEDICINE AND SCIENCE IN SPORTS AND EXERCISE & 15 & 0,0004 & 0,82 & 251 \\
\hline METABOLIC BRAIN DISEASE & 15 & 0,0004 & 0,82 & 252 \\
\hline NEUROLOGY & 15 & 0,0004 & 0,82 & 253 \\
\hline PERITONEAL DIALYSIS INTERNATIONAL & 15 & 0,0004 & 0,82 & 254 \\
\hline PSYCHIATRIC CLINICS OF NORTH AMERICA & 15 & 0,0004 & 0,82 & 255 \\
\hline STROKE & 15 & 0,0004 & 0,82 & 256 \\
\hline TISSUE ANTIGENS & 15 & 0,0004 & 0,82 & 257 \\
\hline TUMORI & 15 & 0,0004 & 0,82 & 258 \\
\hline VIROLOGY & 15 & 0,0004 & 0,82 & 259 \\
\hline ZENTRALBLATT FUR BAKTERIOLOGIE-INTERNATIONAL JOURNAL OF MEDI & 15 & 0,0004 & 0,82 & 260 \\
\hline ACTA OTO-LARYNGOLOGICA & 14 & 0,0004 & 0,82 & 261 \\
\hline ANATOMICAL RECORD & 14 & 0,0004 & 0,82 & 262 \\
\hline ANGIOLOGY & 14 & 0,0004 & 0,82 & 263 \\
\hline ARCHIVES OF HISTOLOGY AND CYTOLOGY & 14 & 0,0004 & 0,82 & 264 \\
\hline ATMOSPHERIC ENVIRONMENT & 14 & 0,0004 & 0,82 & 265 \\
\hline BIOLOGICAL CHEMISTRY & 14 & 0,0004 & 0,82 & 266 \\
\hline BONE & 14 & 0,0004 & 0,82 & 267 \\
\hline BRAIN RESEARCH REVIEWS & 14 & 0,0004 & 0,82 & 268 \\
\hline CARIES RESEARCH & 14 & 0,0004 & 0,82 & 269 \\
\hline CHEMICAL RESEARCH IN TOXICOLOGY & 14 & 0,0004 & 0,82 & 270 \\
\hline CLEFT PALATE-CRANIOFACIAL JOURNAL & 14 & 0,0004 & 0,82 & 271 \\
\hline ENVIRONMENTAL ENTOMOLOGY & 14 & 0,0004 & 0,82 & 272 \\
\hline FOOD AND CHEMICAL TOXICOLOGY & 14 & 0,0004 & 0,82 & 273 \\
\hline FRESENIUS ENVIRONMENTAL BULLETIN & 14 & 0,0004 & 0,82 & 274 \\
\hline GLIA & 14 & 0,0004 & 0,82 & 275 \\
\hline IMMUNOLOGY TODAY & 14 & 0,0004 & 0,82 & 276 \\
\hline INTERNATIONAL JOURNAL OF CLINICAL PHARMACOLOGY AND THERAPEUT & 14 & 0,0004 & 0,82 & 277 \\
\hline INTERNATIONAL JOURNAL OF MOLECULAR MEDICINE & 14 & 0,0004 & 0,83 & 278 \\
\hline JOURNAL OF ANTIMICROBIAL CHEMOTHERAPY & 14 & 0,0004 & 0,83 & 279 \\
\hline JOURNAL OF CARDIOVASCULAR ELECTROPHYSIOLOGY & 14 & 0,0004 & 0,83 & 280 \\
\hline JOURNAL OF CATARACT AND REFRACTIVE SURGERY & 14 & 0,0004 & 0,83 & 281 \\
\hline JOURNAL OF COMPUTATIONAL CHEMISTRY & 14 & 0,0004 & 0,83 & 282 \\
\hline JOURNAL OF MEMBRANE BIOLOGY & 14 & 0,0004 & 0,83 & 283 \\
\hline MOLECULAR PHYLOGENETICS AND EVOLUTION & 14 & 0,0004 & 0,83 & 284 \\
\hline NEUROSCIENCE & 14 & 0,0004 & 0,83 & 285 \\
\hline PEDIATRIC PULMONOLOGY & 14 & 0,0004 & 0,83 & 286 \\
\hline PHARMACOLOGY & 14 & 0,0004 & 0,83 & 287 \\
\hline
\end{tabular}




\begin{tabular}{|c|c|c|c|c|}
\hline TOXICOLOGY LETTERS & 14 & 0,0004 & 0,83 & 288 \\
\hline ULTRASOUND IN OBSTETRICS \& GYNECOLOGY & 14 & 0,0004 & 0,83 & 289 \\
\hline YEAST & 14 & 0,0004 & 0,83 & 290 \\
\hline ANTONIE VAN LEEUWENHOEK INTERNATIONAL JOURNAL OF GENERAL AND & 13 & 0,0003 & 0,83 & 291 \\
\hline CLAYS AND CLAY MINERALS & 13 & 0,0003 & 0,83 & 292 \\
\hline CLINICAL AND EXPERIMENTAL PHARMACOLOGY AND PHYSIOLOGY & 13 & 0,0003 & 0,83 & 293 \\
\hline DEVELOPMENTAL BIOLOGY & 13 & 0,0003 & 0,83 & 294 \\
\hline DIGESTIVE DISEASES AND SCIENCES & 13 & 0,0003 & 0,83 & 295 \\
\hline DYNAMISCHE PSYCHIATRIE & 13 & 0,0003 & 0,83 & 296 \\
\hline ENVIRONMENTAL SCIENCE \& TECHNOLOGY & 13 & 0,0003 & 0,83 & 297 \\
\hline EXPERIMENTAL AND APPLIED ACAROLOGY & 13 & 0,0003 & 0,83 & 298 \\
\hline EXPERIMENTAL EYE RESEARCH & 13 & 0,0003 & 0,83 & 299 \\
\hline HEADACHE & 13 & 0,0003 & 0,83 & 300 \\
\hline INTERNATIONAL JOURNAL OF ONCOLOGY & 13 & 0,0003 & 0,83 & 301 \\
\hline INTERNATIONAL JOURNAL OF PEST MANAGEMENT & 13 & 0,0003 & 0,83 & 302 \\
\hline INTERNATIONAL JOURNAL OF PHARMACEUTICS & 13 & 0,0003 & 0,83 & 303 \\
\hline JOURNAL OF APPLIED ECOLOGY & 13 & 0,0003 & 0,83 & 304 \\
\hline JOURNAL OF CLINICAL PERIODONTOLOGY & 13 & 0,0003 & 0,83 & 305 \\
\hline JOURNAL OF HEREDITY & 13 & 0,0003 & 0,84 & 306 \\
\hline JOURNAL OF HOSPITAL INFECTION & 13 & 0,0003 & 0,84 & 307 \\
\hline JOURNAL OF HUMAN HYPERTENSION & 13 & 0,0003 & 0,84 & 308 \\
\hline JOURNAL OF INTELLECTUAL DISABILITY RESEARCH & 13 & 0,0003 & 0,84 & 309 \\
\hline JOURNAL OF NEUROSURGERY & 13 & 0,0003 & 0,84 & 310 \\
\hline JOURNAL OF PATHOLOGY & 13 & 0,0003 & 0,84 & 311 \\
\hline JOURNAL OF VASCULAR RESEARCH & 13 & 0,0003 & 0,84 & 312 \\
\hline KIDNEY INTERNATIONAL & 13 & 0,0003 & 0,84 & 313 \\
\hline LEUKEMIA RESEARCH & 13 & 0,0003 & 0,84 & 314 \\
\hline MECHANISMS OF AGEING AND DEVELOPMENT & 13 & 0,0003 & 0,84 & 315 \\
\hline MEDICAL HYPOTHESES & 13 & 0,0003 & 0,84 & 316 \\
\hline MICROBIOLOGY AND IMMUNOLOGY & 13 & 0,0003 & 0,84 & 317 \\
\hline MOLECULAR PSYCHIATRY & 13 & 0,0003 & 0,84 & 318 \\
\hline MYCOSES & 13 & 0,0003 & 0,84 & 319 \\
\hline ORAL DISEASES & 13 & 0,0003 & $\odot, 84$ & 320 \\
\hline OSTEOPOROSIS INTERNATIONAL & 13 & 0,0003 & 0,84 & 321 \\
\hline PEPTIDES & 13 & 0,0003 & 0,84 & 322 \\
\hline PFLUGERS ARCHIV-EUROPEAN JOURNAL OF PHYSIOLOGY & 13 & 0,0003 & 0,84 & 323 \\
\hline SCANDINAVIAN JOURNAL OF RHEUMATOLOGY & 13 & 0,0003 & 0,84 & 324 \\
\hline SOCIAL SCIENCE \& MEDICINE & 13 & 0,0003 & 0,84 & 325 \\
\hline SURGICAL ENDOSCOPY-ULTRASOUND AND INTERVENTIONAL TECHNIQUES & 13 & 0,0003 & 0,84 & 326 \\
\hline SURGICAL NEUROLOGY & 13 & 0,0003 & 0,84 & 327 \\
\hline ACTA HISTOCHEMICA & 12 & 0,0003 & 0,84 & 328 \\
\hline ACTA VIROLOGICA & 12 & 0,0003 & 0,84 & 329 \\
\hline ADVANCES IN CONTRACEPTION & 12 & 0,0003 & 0,84 & 330 \\
\hline AMERICAN JOURNAL OF PHYSIOLOGY-CELL PHYSIOLOGY & 12 & 0,0003 & 0,84 & 331 \\
\hline ANNALS OF NUTRITION AND METABOLISM & 12 & 0,0003 & 0,84 & 332 \\
\hline BEHAVIOURAL PROCESSES & 12 & 0,0003 & 0,84 & 333 \\
\hline BIOCHIMICA ET BIOPHYSICA ACTA-BIOENERGETICS & 12 & 0,0003 & 0,84 & 334 \\
\hline BIOELECTROCHEMISTRY AND BIOENERGETICS & 12 & 0,0003 & 0,84 & 335 \\
\hline CARDIOLOGY & 12 & 0,0003 & 0,85 & 336 \\
\hline CLIMATIC CHANGE & 12 & 0,0003 & 0,85 & 337 \\
\hline CLINICAL SCIENCE & 12 & 0,0003 & 0,85 & 338 \\
\hline CLINICS IN DERMATOLOGY & 12 & 0,0003 & 0,85 & 339 \\
\hline COMPTES RENDUS DE L ACADEMIE DES SCIENCES SERIE III-SCIENCES & 12 & 0,0003 & 0,85 & 340 \\
\hline DERMATOLOGIC SURGERY & 12 & 0,0003 & 0,85 & 341 \\
\hline ECOLOGICAL ECONOMICS & 12 & 0,0003 & 0,85 & 342 \\
\hline ENTOMOLOGICAL NEWS & 12 & 0,0003 & 0,85 & 343 \\
\hline ENVIRONMENTAL GEOLOGY & 12 & 0,0003 & 0,85 & 344 \\
\hline ENVIRONMENTAL TOXICOLOGY AND CHEMISTRY & 12 & 0,0003 & 0,85 & 345 \\
\hline EUROPEAN JOURNAL OF ORAL SCIENCES & 12 & 0,0003 & 0,85 & 346 \\
\hline FLORIDA ENTOMOLOGIST & 12 & 0,0003 & 0,85 & 347 \\
\hline GENOME RESEARCH & 12 & 0,0003 & 0,85 & 348 \\
\hline HYBRIDOMA & 12 & 0,0003 & 0,85 & 349 \\
\hline IEEE ENGINEERING IN MEDICINE AND BIOLOGY MAGAZINE & 12 & 0,0003 & 0,85 & 350 \\
\hline INTERNATIONAL JOURNAL OF ORAL AND MAXILLOFACIAL SURGERY & 12 & 0,0003 & 0,85 & 351 \\
\hline INTERNATIONAL JOURNAL OF PSYCHOANALYSIS & 12 & 0,0003 & 0,85 & 352 \\
\hline JOURNAL OF CARBOHYDRATE CHEMISTRY & 12 & 0,0003 & 0,85 & 353 \\
\hline JOURNAL OF CARDIAC SURGERY & 12 & 0,0003 & 0,85 & 354 \\
\hline JOURNAL OF CLINICAL VIROLOGY & 12 & 0,0003 & 0,85 & 355 \\
\hline JOURNAL OF DIARRHOEAL DISEASES RESEARCH & 12 & 0,0003 & 0,85 & 356 \\
\hline JOURNAL OF ENDOCRINOLOGY & 12 & 0,0003 & 0,85 & 357 \\
\hline JOURNAL OF FORENSIC SCIENCES & 12 & 0,0003 & 0,85 & 358 \\
\hline JOURNAL OF INDUSTRIAL MICROBIOLOGY \& BIOTECHNOLOGY & 12 & 0,0003 & 0,85 & 359 \\
\hline JOURNAL OF MOLECULAR BIOLOGY & 12 & 0,0003 & 0,85 & 360 \\
\hline
\end{tabular}




\begin{tabular}{|c|c|c|c|c|}
\hline JOURNAL OF NEUROCYTOLOGY & 12 & 0,0003 & 0,85 & 361 \\
\hline JOURNAL OF PHOTOCHEMISTRY AND PHOTOBIOLOGY B-BIOLOGY & 12 & 0,0003 & 0,85 & 362 \\
\hline MOLECULAR AND BIOCHEMICAL PARASITOLOGY & 12 & 0,0003 & 0,85 & 363 \\
\hline MOLECULAR PHARMACOLOGY & 12 & 0,0003 & 0,85 & 364 \\
\hline PSYCHIATRY RESEARCH & 12 & 0,0003 & 0,85 & 365 \\
\hline REGULATORY PEPTIDES & 12 & 0,0003 & 0,85 & 366 \\
\hline THYROID & 12 & 0,0003 & 0,85 & 367 \\
\hline UROLOGY & 12 & 0,0003 & 0,86 & 368 \\
\hline ZEITSCHRIFT FUR NATURFORSCHUNG SECTION B-A JOURNAL OF CHEMIC & 12 & 0,0003 & 0,86 & 369 \\
\hline AMERICAN JOURNAL OF PUBLIC HEALTH & 11 & 0,0003 & 0,86 & 370 \\
\hline ANNALS OF HUMAN BIOLOGY & 11 & 0,0003 & 0,86 & 371 \\
\hline BIOCHIMICA ET BIOPHYSICA ACTA-MOLECULAR BASIS OF DISEASE & 11 & 0,0003 & 0,86 & 372 \\
\hline BIOLOGICAL \& PHARMACEUTICAL BULLETIN & 11 & 0,0003 & 0,86 & 373 \\
\hline BJU INTERNATIONAL & 11 & 0,0003 & 0,86 & 374 \\
\hline BRITISH JOURNAL OF CLINICAL PHARMACOLOGY & 11 & 0,0003 & 0,86 & 375 \\
\hline CHEMICO-BIOLOGICAL INTERACTIONS & 11 & 0,0003 & 0,86 & 376 \\
\hline CHRONOBIOLOGY INTERNATIONAL & 11 & 0,0003 & 0,86 & 377 \\
\hline CLINICAL AND EXPERIMENTAL ALLERGY & 11 & 0,0003 & 0,86 & 378 \\
\hline EUROPEAN JOURNAL OF PLASTIC SURGERY & 11 & 0,0003 & 0,86 & 379 \\
\hline IMMUNOLOGY & 11 & 0,0003 & 0,86 & 380 \\
\hline INTERNATIONAL JOURNAL OF FOOD MICROBIOLOGY & 11 & 0,0003 & 0,86 & 381 \\
\hline INTERNATIONAL JOURNAL OF ORAL \& MAXILLOFACIAL IMPLANTS & 11 & 0,0003 & 0,86 & 382 \\
\hline JOURNAL OF ANATOMY & 11 & 0,0003 & 0,86 & 383 \\
\hline JOURNAL OF APPLIED TOXICOLOGY & 11 & 0,0003 & 0,86 & 384 \\
\hline JOURNAL OF CHEMICAL TECHNOLOGY AND BIOTECHNOLOGY & 11 & 0,0003 & 0,86 & 385 \\
\hline JOURNAL OF CLINICAL EPIDEMIOLOGY & 11 & 0,0003 & 0,86 & 386 \\
\hline JOURNAL OF ENVIRONMENTAL MONITORING & 11 & 0,0003 & 0,86 & 387 \\
\hline JOURNAL OF HAND SURGERY-BRITISH AND EUROPEAN VOLUME & 11 & 0,0003 & 0,86 & 388 \\
\hline JOURNAL OF INVESTIGATIONAL ALLERGOLOGY \& CLINICAL IMMUNOLOGY & 11 & 0,0003 & 0,86 & 389 \\
\hline JOURNAL OF MOLECULAR AND CELLULAR CARDIOLOGY & 11 & 0,0003 & 0,86 & 390 \\
\hline JOURNAL OF PERINATAL MEDICINE & 11 & 0,0003 & 0,86 & 391 \\
\hline JOURNAL OF PERIODONTAL RESEARCH & 11 & 0,0003 & 0,86 & 392 \\
\hline MICROBIAL DRUG RESISTANCE-MECHANISMS EPIDEMIOLOGY AND DISEAS & 11 & 0,0003 & $\odot, 86$ & 393 \\
\hline NEUROCHEMISTRY INTERNATIONAL & 11 & 0,0003 & 0,86 & 394 \\
\hline NUCLEAR MEDICINE COMMUNICATIONS & 11 & 0,0003 & 0,86 & 395 \\
\hline OPHTHALMIC SURGERY AND LASERS & 11 & 0,0003 & 0,86 & 396 \\
\hline PROTEIN EXPRESSION AND PURIFICATION & 11 & 0,0003 & 0,86 & 397 \\
\hline RESPIRATION PHYSIOLOGY & 11 & 0,0003 & 0,86 & 398 \\
\hline SYMBIOSIS & 11 & 0,0003 & 0,86 & 399 \\
\hline AMERICAN JOURNAL OF CLINICAL PATHOLOGY & 10 & 0,0003 & 0,86 & 400 \\
\hline AMERICAN JOURNAL OF ROENTGENOLOGY & 10 & 0,0003 & 0,86 & 401 \\
\hline ANALES DE LA ASOCIACION QUIMICA ARGENTINA & 10 & 0,0003 & 0,86 & 402 \\
\hline ARCHIVES OF DISEASE IN CHILDHOOD & 10 & 0,0003 & 0,86 & 403 \\
\hline ARCHIVES OF OPHTHALMOLOGY & 10 & 0,0003 & 0,87 & 404 \\
\hline BIOLOGICAL JOURNAL OF THE LINNEAN SOCIETY & 10 & 0,0003 & 0,87 & 405 \\
\hline BIOMETRICS & 10 & 0,0003 & 0,87 & 406 \\
\hline BRAIN PATHOLOGY & 10 & 0,0003 & 0,87 & 407 \\
\hline BRITISH JOURNAL OF SURGERY & 10 & 0,0003 & 0,87 & 408 \\
\hline CLINICAL CANCER RESEARCH & 10 & 0,0003 & 0,87 & 409 \\
\hline CYTOMETRY & 10 & 0,0003 & 0,87 & 410 \\
\hline CYTOPATHOLOGY & 10 & 0,0003 & 0,87 & 411 \\
\hline DRUG AND ALCOHOL DEPENDENCE & 10 & 0,0003 & 0,87 & 412 \\
\hline ECOLOGY & 10 & 0,0003 & 0,87 & 413 \\
\hline ENDOCRINE & 10 & 0,0003 & 0,87 & 414 \\
\hline ENDOCRINOLOGIST & 10 & 0,0003 & 0,87 & 415 \\
\hline EUROPEAN JOURNAL OF PROTISTOLOGY & 10 & 0,0003 & 0,87 & 416 \\
\hline FREE RADICAL RESEARCH & 10 & 0,0003 & 0,87 & 417 \\
\hline GENE & 10 & 0,0003 & 0,87 & 418 \\
\hline HEAD AND NECK-JOURNAL FOR THE SCIENCES AND SPECIALTIESOF THE & 10 & 0,0003 & 0,87 & 419 \\
\hline HISTOCHEMISTRY AND CELL BIOLOGY & 10 & 0,0003 & 0,87 & 420 \\
\hline INSECT MOLECULAR BIOLOGY & 10 & 0,0003 & 0,87 & 421 \\
\hline INTERNATIONAL JOURNAL OF BIOCHEMISTRY \& CELL BIOLOGY & 10 & 0,0003 & 0,87 & 422 \\
\hline INTERNATIONAL JOURNAL OF IMPOTENCE RESEARCH & 10 & 0,0003 & 0,87 & 423 \\
\hline JOURNAL OF CHROMATOGRAPHY B & 10 & 0,0003 & 0,87 & 424 \\
\hline JOURNAL OF CLINICAL IMMUNOLOGY & 10 & 0,0003 & 0,87 & 425 \\
\hline JOURNAL OF CLINICAL PATHOLOGY & 10 & 0,0003 & 0,87 & 426 \\
\hline JOURNAL OF ENDOCRINOLOGICAL INVESTIGATION & 10 & 0,0003 & 0,87 & 427 \\
\hline JOURNAL OF HEART VALVE DISEASE & 10 & 0,0003 & 0,87 & 428 \\
\hline JOURNAL OF INCLUSION PHENOMENA AND MACROCYCLIC CHEMISTRY & 10 & 0,0003 & 0,87 & 429 \\
\hline JOURNAL OF MICROENCAPSULATION & 10 & 0,0003 & $\odot, 87$ & 430 \\
\hline JOURNAL OF NEUROIMMUNOLOGY & 10 & 0,0003 & 0,87 & 431 \\
\hline MUSCLE \& NERVE & 10 & 0,0003 & 0,87 & 432 \\
\hline MUTATION RESEARCH-FUNDAMENTAL AND MOLECULAR MECHANISMS OF MU & 10 & 0,0003 & 0,87 & 433 \\
\hline
\end{tabular}




\begin{tabular}{|c|c|c|c|c|}
\hline NEW JOURNAL OF CHEMISTRY & 10 & 0,0003 & 0,87 & 434 \\
\hline OECOLOGIA & 10 & 0,0003 & 0,87 & 435 \\
\hline OPHTHALMOLOGY & 10 & 0,0003 & 0,87 & 436 \\
\hline PESTICIDE SCIENCE & 10 & 0,0003 & 0,87 & 437 \\
\hline SEPARATION SCIENCE AND TECHNOLOGY & 10 & 0,0003 & 0,87 & 438 \\
\hline SHOCK & 10 & 0,0003 & 0,87 & 439 \\
\hline TRENDS IN PHARMACOLOGICAL SCIENCES & 10 & 0,0003 & 0,87 & 440 \\
\hline VETERINARY PATHOLOGY & 10 & 0,0003 & 0,87 & 441 \\
\hline VOX SANGUINIS & 10 & 0,0003 & 0,88 & 442 \\
\hline ACTA ALIMENTARIA & 9 & 0,0002 & 0,88 & 443 \\
\hline ALCOHOLISM-CLINICAL AND EXPERIMENTAL RESEARCH & 9 & 0,0002 & 0,88 & 444 \\
\hline AMERICAN JOURNAL OF INFECTION CONTROL & 9 & 0,0002 & 0,88 & 445 \\
\hline AMERICAN JOURNAL OF OBSTETRICS AND GYNECOLOGY & 9 & 0,0002 & 0,88 & 446 \\
\hline ANNALS OF OTOLOGY RHINOLOGY AND LARYNGOLOGY & 9 & 0,0002 & 0,88 & 447 \\
\hline ARCHIVES OF ORAL BIOLOGY & 9 & 0,0002 & 0,88 & 448 \\
\hline BIOCONTROL & 9 & 0,0002 & 0,88 & 449 \\
\hline BIOLOGICAL CYBERNETICS & 9 & 0,0002 & 0,88 & 450 \\
\hline BIOMETRIKA & 9 & 0,0002 & 0,88 & 451 \\
\hline BIOSCIENCE REPORTS & 9 & 0,0002 & 0,88 & 452 \\
\hline BRAIN BEHAVIOR AND EVOLUTION & 9 & 0,0002 & 0,88 & 453 \\
\hline CANADIAN JOURNAL OF SOIL SCIENCE & 9 & 0,0002 & 0,88 & 454 \\
\hline CELL AND TISSUE RESEARCH & 9 & $\odot, 0 \odot \odot 2$ & 0,88 & 455 \\
\hline CHILDS NERVOUS SYSTEM & 9 & 0,0002 & 0,88 & 456 \\
\hline CLINICAL NEUROPATHOLOGY & 9 & 0,0002 & 0,88 & 457 \\
\hline CLINICAL TRANSPLANTATION & 9 & 0,0002 & 0,88 & 458 \\
\hline COLLECTION OF CZECHOSLOVAK CHEMICAL COMMUNICATIONS & 9 & 0,0002 & 0,88 & 459 \\
\hline CRYOBIOLOGY & 9 & 0,0002 & 0,88 & 460 \\
\hline EPIDEMIOLOGY AND INFECTION & 9 & 0,0002 & 0,88 & 461 \\
\hline EUROPEAN BIOPHYSICS JOURNAL WITH BIOPHYSICS LETTERS & 9 & 0,0002 & 0,88 & 462 \\
\hline EUROPEAN JOURNAL OF MEDICINAL CHEMISTRY & 9 & 0,0002 & 0,88 & 463 \\
\hline EUROPEAN JOURNAL OF SURGERY & 9 & 0,0002 & 0,88 & 464 \\
\hline EUROPEAN UROLOGY & 9 & 0,0002 & 0,88 & 465 \\
\hline IMMUNOPHARMACOLOGY AND IMMUNOTOXICOLOGY & 9 & 0,0002 & 0,88 & 466 \\
\hline INTERNATIONAL ANGIOLOGY & 9 & 0,0002 & 0,88 & 467 \\
\hline INTERNATIONAL JOURNAL OF INDUSTRIAL ERGONOMICS & 9 & 0,0002 & 0,88 & 468 \\
\hline INTERNATIONAL JOURNAL OF OBESITY & 9 & 0,0002 & 0,88 & 469 \\
\hline JOURNAL OF AFFECTIVE DISORDERS & 9 & 0,0002 & 0,88 & 470 \\
\hline JOURNAL OF BIOENERGETICS AND BIOMEMBRANES & 9 & 0,0002 & 0,88 & 471 \\
\hline JOURNAL OF CLINICAL PSYCHOPHARMACOLOGY & 9 & 0,0002 & 0,88 & 472 \\
\hline JOURNAL OF CLINICAL ULTRASOUND & 9 & 0,0002 & 0,88 & 473 \\
\hline JOURNAL OF DRUG ISSUES & 9 & 0,0002 & 0,88 & 474 \\
\hline JOURNAL OF EPIDEMIOLOGY AND COMMUNITY HEALTH & 9 & 0,0002 & 0,88 & 475 \\
\hline JOURNAL OF FOOD SCIENCE AND TECHNOLOGY-MYSORE & 9 & 0,0002 & 0,88 & 476 \\
\hline JOURNAL OF GLAUCOMA & 9 & 0,0002 & 0,88 & 477 \\
\hline JOURNAL OF HEART AND LUNG TRANSPLANTATION & 9 & 0,0002 & 0,88 & 478 \\
\hline JOURNAL OF INVASIVE CARDIOLOGY & 9 & 0,0002 & 0,88 & 479 \\
\hline JOURNAL OF LIPID RESEARCH & 9 & 0,0002 & 0,88 & 480 \\
\hline JOURNAL OF MEDICINAL CHEMISTRY & 9 & 0,0002 & 0,88 & 481 \\
\hline JOURNAL OF THE AMERICAN ACADEMY OF CHILD AND ADOLESCENT PSYC & 9 & 0,0002 & 0,88 & 482 \\
\hline JOURNAL OF THE AMERICAN COLLEGE OF NUTRITION & 9 & 0,0002 & 0,88 & 483 \\
\hline JOURNAL OF THORACIC AND CARDIOVASCULAR SURGERY & 9 & 0,0002 & 0,89 & 484 \\
\hline MICROBIOLOGICAL RESEARCH & 9 & 0,0002 & 0,89 & 485 \\
\hline NEUROSCIENCE AND BIOBEHAVIORAL REVIEWS & 9 & 0,0002 & 0,89 & 486 \\
\hline NUTRITION AND CANCER-AN INTERNATIONAL JOURNAL & 9 & 0,0002 & 0,89 & 487 \\
\hline ORAL MICROBIOLOGY AND IMMUNOLOGY & 9 & 0,0002 & 0,89 & 488 \\
\hline PEDIATRIC SURGERY INTERNATIONAL & 9 & 0,0002 & 0,89 & 489 \\
\hline POSTGRADUATE MEDICAL JOURNAL & 9 & 0,0002 & 0,89 & 490 \\
\hline PROTEIN SCIENCE & 9 & 0,0002 & 0,89 & 491 \\
\hline PSYCHO-ONCOLOGY & 9 & 0,0002 & 0,89 & 492 \\
\hline RESEARCH IN MICROBIOLOGY & 9 & 0,0002 & 0,89 & 493 \\
\hline REVISTA MEDICA DE CHILE & 9 & 0,0002 & 0,89 & 494 \\
\hline SURGICAL LAPAROSCOPY ENDOSCOPY \& PERCUTANEOUS TECHNIQUES & 9 & 0,0002 & 0,89 & 495 \\
\hline THEORY IN BIOSCIENCES & 9 & 0,0002 & 0,89 & 496 \\
\hline VIRCHOWS ARCHIV-AN INTERNATIONAL JOURNAL OF PATHOLOGY & 9 & 0,0002 & 0,89 & 497 \\
\hline WATER RESOURCES RESEARCH & 9 & 0,0002 & 0,89 & 498 \\
\hline ACTA PSYCHIATRICA SCANDINAVICA & 8 & 0,0002 & 0,89 & 499 \\
\hline ANIMAL GENETICS & 8 & 0,0002 & 0,89 & 500 \\
\hline ANNALS OF HEMATOLOGY & 8 & 0,0002 & 0,89 & 501 \\
\hline ANTICANCER RESEARCH & 8 & 0,0002 & 0,89 & 502 \\
\hline ARCHIVES OF ENVIRONMENTAL CONTAMINATION AND TOXICOLOGY & 8 & 0,0002 & 0,89 & 503 \\
\hline AUSTRALIAN JOURNAL OF SOIL RESEARCH & 8 & 0,0002 & 0,89 & 504 \\
\hline BIOCHEMISTRY AND CELL BIOLOGY-BIOCHIMIE ET BIOLOGIE CELLULAI & 8 & 0,0002 & 0,89 & 505 \\
\hline BIOCHIMICA ET BIOPHYSICA ACTA-GENE STRUCTURE AND EXPRESSION & 8 & 0,0002 & 0,89 & 506 \\
\hline
\end{tabular}




\begin{tabular}{|c|c|c|c|c|}
\hline BIOORGANIC \& MEDICINAL CHEMISTRY LETTERS & 8 & 0,0002 & 0,89 & 507 \\
\hline CANADIAN JOURNAL OF ANAESTHESIA-JOURNAL CANADIEN D ANESTHESI & 8 & 0,0002 & 0,89 & 508 \\
\hline CHEMICAL COMMUNICATIONS & 8 & 0,0002 & 0,89 & 509 \\
\hline CHEMISTRY-A EUROPEAN JOURNAL & 8 & 0,0002 & 0,89 & 510 \\
\hline CLINICAL GENETICS & 8 & 0,0002 & 0,89 & 511 \\
\hline CLINICS IN PLASTIC SURGERY & 8 & 0,0002 & 0,89 & 512 \\
\hline ENTOMOLOGIA GENERALIS & 8 & 0,0002 & 0,89 & 513 \\
\hline ENVIRONMENT INTERNATIONAL & 8 & 0,0002 & 0,89 & 514 \\
\hline EUROPEAN JOURNAL OF DERMATOLOGY & 8 & 0,0002 & 0,89 & 515 \\
\hline FEMS MICROBIOLOGY ECOLOGY & 8 & 0,0002 & 0,89 & 516 \\
\hline FOLIA PARASITOLOGICA & 8 & 0,0002 & 0,89 & 517 \\
\hline FOOD HYDROCOLLOIDS & 8 & 0,0002 & 0,89 & 518 \\
\hline FOOD MICROBIOLOGY & 8 & 0,0002 & 0,89 & 519 \\
\hline FUEL & 8 & 0,0002 & 0,89 & 520 \\
\hline FUNCTIONAL ECOLOGY & 8 & 0,0002 & 0,89 & 521 \\
\hline GENETIC EPIDEMIOLOGY & 8 & 0,0002 & 0,89 & 522 \\
\hline GLOBAL CHANGE BIOLOGY & 8 & 0,0002 & 0,89 & 523 \\
\hline GREEN CHEMISTRY & 8 & 0,0002 & 0,89 & 524 \\
\hline HAEMOPHILIA & 8 & 0,0002 & 0,89 & 525 \\
\hline HEALTH POLICY AND PLANNING & 8 & 0,0002 & 0,89 & 526 \\
\hline HISTOCHEMICAL JOURNAL & 8 & 0,0002 & 0,89 & 527 \\
\hline HYDROLOGICAL SCIENCES JOURNAL-JOURNAL DES SCIENCES HYDROLOGI & 8 & 0,0002 & 0,89 & 528 \\
\hline INJURY-INTERNATIONAL JOURNAL OF THE CARE OF THE INJURED & 8 & 0,0002 & 0,89 & 529 \\
\hline INTERNATIONAL JOURNAL OF ANTIMICROBIAL AGENTS & 8 & 0,0002 & 0,89 & 530 \\
\hline INTERNATIONAL JOURNAL OF GYNECOLOGICAL CANCER & 8 & 0,0002 & 0,90 & 531 \\
\hline INTERNATIONAL JOURNAL OF PROSTHODONTICS & 8 & 0,0002 & 0,90 & 532 \\
\hline INTERNATIONAL JOURNAL OF STD \& AIDS & 8 & 0,0002 & 0,90 & 533 \\
\hline ITALIAN JOURNAL OF FOOD SCIENCE & 8 & 0,0002 & 0,90 & 534 \\
\hline JOURNAL DE MYCOLOGIE MEDICALE & 8 & 0,0002 & 0,90 & 535 \\
\hline JOURNAL OF ASTHMA & 8 & 0,0002 & 0,90 & 536 \\
\hline JOURNAL OF CELL SCIENCE & 8 & 0,0002 & 0,90 & 537 \\
\hline JOURNAL OF CELLULAR BIOCHEMISTRY & 8 & 0,0002 & 0,90 & 538 \\
\hline JOURNAL OF CLINICAL PSYCHIATRY & 8 & 0,0002 & 0,90 & 539 \\
\hline JOURNAL OF COASTAL RESEARCH & 8 & 0,0002 & 0,90 & 540 \\
\hline JOURNAL OF COGNITIVE NEUROSCIENCE & 8 & 0,0002 & 0,90 & 541 \\
\hline JOURNAL OF COMPARATIVE PHYSIOLOGY B-BIOCHEMICAL SYSTEMIC AND & 8 & 0,0002 & 0,90 & 542 \\
\hline JOURNAL OF ENVIRONMENTAL QUALITY & 8 & 0,0002 & 0,90 & 543 \\
\hline JOURNAL OF INVESTIGATIVE MEDICINE & 8 & 0,0002 & 0,90 & 544 \\
\hline JOURNAL OF MICROBIOLOGICAL METHODS & 8 & 0,0002 & 0,90 & 545 \\
\hline JOURNAL OF NEUROLOGY & 8 & 0,0002 & 0,90 & 546 \\
\hline JOURNAL OF ORAL PATHOLOGY \& MEDICINE & 8 & 0,0002 & 0,90 & 547 \\
\hline JOURNAL OF PORPHYRINS AND PHTHALOCYANINES & 8 & 0,0002 & 0,90 & 548 \\
\hline JOURNAL OF REPRODUCTION AND FERTILITY & 8 & 0,0002 & 0,90 & 549 \\
\hline JOURNAL OF REPRODUCTIVE MEDICINE & 8 & 0,0002 & 0,90 & 550 \\
\hline JOURNAL OF SURGICAL ONCOLOGY & 8 & 0,0002 & 0,90 & 551 \\
\hline JOURNAL OF THE NATIONAL CANCER INSTITUTE & 8 & 0,0002 & 0,90 & 552 \\
\hline JOURNAL OF THERMAL BIOLOGY & 8 & 0,0002 & 0,90 & 553 \\
\hline JOURNAL OF ULTRASOUND IN MEDICINE & 8 & 0,0002 & 0,90 & 554 \\
\hline JOURNAL OF VASCULAR SURGERY & 8 & 0,0002 & 0,90 & 555 \\
\hline LIPIDS & 8 & 0,0002 & 0,90 & 556 \\
\hline MEAT SCIENCE & 8 & 0,0002 & 0,90 & 557 \\
\hline MICROBIAL PATHOGENESIS & 8 & 0,0002 & 0,90 & 558 \\
\hline MOLECULAR MICROBIOLOGY & 8 & 0,0002 & 0,90 & 559 \\
\hline MUTATION RESEARCH-GENETIC TOXICOLOGY AND ENVIRONMENTALMUTAGE & 8 & 0,0002 & 0,90 & 560 \\
\hline NEFROLOGIA & 8 & 0,0002 & 0,90 & 561 \\
\hline OBSTETRICS AND GYNECOLOGY & 8 & 0,0002 & 0,90 & 562 \\
\hline ORIGINS OF LIFE AND EVOLUTION OF THE BIOSPHERE & 8 & 0,0002 & 0,90 & 563 \\
\hline PEDIATRICS & 8 & 0,0002 & 0,90 & 564 \\
\hline QUANTITATIVE STRUCTURE-ACTIVITY RELATIONSHIPS & 8 & 0,0002 & 0,90 & 565 \\
\hline RADIOLOGY & 8 & 0,0002 & 0,90 & 566 \\
\hline REVISTA ESPANOLA DE CARDIOLOGIA & 8 & 0,0002 & 0,90 & 567 \\
\hline REVISTA LATINOAMERICANA DE PSICOLOGIA & 8 & 0,0002 & 0,90 & 568 \\
\hline SCANDINAVIAN JOURNAL OF INFECTIOUS DISEASES & 8 & 0,0002 & 0,90 & 569 \\
\hline SEXUALLY TRANSMITTED DISEASES & 8 & 0,0002 & 0,90 & 570 \\
\hline SOIL BIOLOGY \& BIOCHEMISTRY & 8 & 0,0002 & 0,90 & 571 \\
\hline SOIL SCIENCE & 8 & 0,0002 & 0,90 & 572 \\
\hline ULTRASTRUCTURAL PATHOLOGY & 8 & 0,0002 & 0,90 & 573 \\
\hline WORLD JOURNAL OF MICROBIOLOGY \& BIOTECHNOLOGY & 8 & 0,0002 & 0,90 & 574 \\
\hline XENOBIOTICA & 8 & 0,0002 & 0,90 & 575 \\
\hline ACTA HISTOCHEMICA ET CYTOCHEMICA & 7 & 0,0002 & 0,90 & 576 \\
\hline ACTA PHYSIOLOGICA SCANDINAVICA & 7 & 0,0002 & 0,90 & 577 \\
\hline ADDICTION BIOLOGY & 7 & 0,0002 & 0,90 & 578 \\
\hline ALCOHOL AND ALCOHOLISM & 7 & 0,0002 & 0,91 & 579 \\
\hline
\end{tabular}




\begin{tabular}{|c|c|c|c|c|}
\hline AMERICAN BEE JOURNAL & 7 & 0,0002 & 0,91 & 580 \\
\hline AMERICAN JOURNAL OF CLINICAL ONCOLOGY-CANCER CLINICAL TRIALS & 7 & 0,0002 & 0,91 & 581 \\
\hline AMERICAN JOURNAL OF PHYSIOLOGY-ENDOCRINOLOGY AND METABOLISM & 7 & 0,0002 & 0,91 & 582 \\
\hline ANATOMY AND EMBRYOLOGY & 7 & 0,0002 & 0,91 & 583 \\
\hline ANIMAL BEHAVIOUR & 7 & 0,0002 & 0,91 & 584 \\
\hline ANNALS OF TROPICAL PAEDIATRICS & 7 & 0,0002 & 0,91 & 585 \\
\hline APPLIED IMMUNOHISTOCHEMISTRY & 7 & 0,0002 & 0,91 & 586 \\
\hline ARCHIVES OF PHYSIOLOGY AND BIOCHEMISTRY & 7 & 0,0002 & 0,91 & 587 \\
\hline BIOLOGICALS & 7 & 0,0002 & 0,91 & 588 \\
\hline BIOMETALS & 7 & 0,0002 & 0,91 & 589 \\
\hline BIOORGANIC \& MEDICINAL CHEMISTRY & 7 & $0,0 \odot \odot 2$ & 0,91 & 590 \\
\hline BIOSCIENCE & 7 & 0,0002 & 0,91 & 591 \\
\hline BIOTECHNOLOGY PROGRESS & 7 & 0,0002 & 0,91 & 592 \\
\hline BULLETIN DE LA SOCIETE DE PATHOLOGIE EXOTIQUE & 7 & 0,0002 & 0,91 & 593 \\
\hline CATENA & 7 & 0,0002 & 0,91 & 594 \\
\hline CELL MOTILITY AND THE CYTOSKELETON & 7 & 0,0002 & 0,91 & 595 \\
\hline CLINICAL CHEMISTRY AND LABORATORY MEDICINE & 7 & 0,0002 & 0,91 & 596 \\
\hline CLINICAL NEUROPHYSIOLOGY & 7 & 0,0002 & 0,91 & 597 \\
\hline CLINICAL ORTHOPAEDICS AND RELATED RESEARCH & 7 & 0,0002 & 0,91 & 598 \\
\hline CYTOKINE & 7 & 0,0002 & 0,91 & 599 \\
\hline EARLY HUMAN DEVELOPMENT & 7 & 0,0002 & 0,91 & 600 \\
\hline EMBO JOURNAL & 7 & 0,0002 & 0,91 & 601 \\
\hline ENDOCRINE RESEARCH & 7 & 0,0002 & 0,91 & 602 \\
\hline ENVIRONMENTAL AND MOLECULAR MUTAGENESIS & 7 & 0,0002 & 0,91 & 603 \\
\hline EUROPEAN ARCHIVES OF OTO-RHINO-LARYNGOLOGY & 7 & 0,0002 & 0,91 & 604 \\
\hline EUROPEAN JOURNAL OF APPLIED PHYSIOLOGY AND OCCUPATIONAL PHYS & 7 & 0,0002 & 0,91 & 605 \\
\hline EUROPEAN JOURNAL OF HAEMATOLOGY & 7 & 0,0002 & 0,91 & 606 \\
\hline EUROPEAN JOURNAL OF HUMAN GENETICS & 7 & 0,0002 & 0,91 & 607 \\
\hline EXPERIMENTAL NEPHROLOGY & 7 & 0,0002 & 0,91 & 608 \\
\hline INTERNATIONAL JOURNAL OF ENVIRONMENT AND POLLUTION & 7 & 0,0002 & 0,91 & 609 \\
\hline JOURNAL OF ADVANCED NURSING & 7 & 0,0002 & 0,91 & 610 \\
\hline JOURNAL OF ECOLOGY & 7 & 0,0002 & $\odot, 91$ & 611 \\
\hline JOURNAL OF ENVIRONMENTAL ENGINEERING-ASCE & 7 & 0,0002 & 0,91 & 612 \\
\hline JOURNAL OF ENVIRONMENTAL SCIENCE AND HEALTH PART B-PESTICIDE & 7 & 0,0002 & 0,91 & 613 \\
\hline JOURNAL OF EXPERIMENTAL MEDICINE & 7 & 0,0002 & 0,91 & 614 \\
\hline JOURNAL OF GENERAL AND APPLIED MICROBIOLOGY & 7 & 0,0002 & 0,91 & 615 \\
\hline JOURNAL OF HAND SURGERY-AMERICAN VOLUME & 7 & 0,0002 & 0,91 & 616 \\
\hline JOURNAL OF HYDROLOGY & 7 & 0,0002 & 0,91 & 617 \\
\hline JOURNAL OF INSECT BEHAVIOR & 7 & 0,0002 & 0,91 & 618 \\
\hline JOURNAL OF INTERFERON AND CYTOKINE RESEARCH & 7 & 0,0002 & 0,91 & 619 \\
\hline JOURNAL OF MAGNETIC RESONANCE & 7 & 0,0002 & 0,91 & 620 \\
\hline JOURNAL OF MUSCLE RESEARCH AND CELL MOTILITY & 7 & 0,0002 & 0,91 & 621 \\
\hline JOURNAL OF NEURAL TRANSMISSION & 7 & 0,0002 & 0,91 & 622 \\
\hline JOURNAL OF OCCUPATIONAL AND ENVIRONMENTAL MEDICINE & 7 & 0,0002 & 0,91 & 623 \\
\hline JOURNAL OF PARENTERAL AND ENTERAL NUTRITION & 7 & 0,0002 & 0,91 & 624 \\
\hline JOURNAL OF PEDIATRIC HEMATOLOGY ONCOLOGY & 7 & 0,0002 & 0,91 & 625 \\
\hline JOURNAL OF PHARMACOLOGICAL AND TOXICOLOGICAL METHODS & 7 & 0,0002 & 0,91 & 626 \\
\hline JOURNAL OF RECONSTRUCTIVE MICROSURGERY & 7 & 0,0002 & 0,91 & 627 \\
\hline JOURNAL OF THE AMERICAN ASSOCIATION OF GYNECOLOGIC LAPAROSCO & 7 & 0,0002 & 0,91 & 628 \\
\hline JOURNAL OF THE EUROPEAN ACADEMY OF DERMATOLOGY AND VENEREOLO & 7 & 0,0002 & 0,91 & 629 \\
\hline MICROBIAL ECOLOGY & 7 & 0,0002 & 0,91 & 630 \\
\hline MOLECULAR BRAIN RESEARCH & 7 & 0,0002 & 0,91 & 631 \\
\hline MOLECULAR GENETICS AND METABOLISM & 7 & 0,0002 & 0,91 & 632 \\
\hline MOVEMENT DISORDERS & 7 & 0,0002 & 0,91 & 633 \\
\hline NEUROPEPTIDES & 7 & 0,0002 & 0,92 & 634 \\
\hline NEUROPSYCHOBIOLOGY & 7 & 0,0002 & 0,92 & 635 \\
\hline ONCOLOGY REPORTS & 7 & 0,0002 & 0,92 & 636 \\
\hline PARASITE IMMUNOLOGY & 7 & 0,0002 & 0,92 & 637 \\
\hline PEDIATRIC DERMATOLOGY & 7 & 0,0002 & 0,92 & 638 \\
\hline PERCEPTION & 7 & 0,0002 & 0,92 & 639 \\
\hline REGIONAL ANESTHESIA AND PAIN MEDICINE & 7 & 0,0002 & 0,92 & 640 \\
\hline REVUE D ECOLOGIE-LA TERRE ET LA VIE & 7 & 0,0002 & 0,92 & 641 \\
\hline SOCIAL PSYCHIATRY AND PSYCHIATRIC EPIDEMIOLOGY & 7 & 0,0002 & 0,92 & 642 \\
\hline SOIL USE AND MANAGEMENT & 7 & 0,0002 & 0,92 & 643 \\
\hline SUBSTANCE USE \& MISUSE & 7 & 0,0002 & 0,92 & 644 \\
\hline THORAX & 7 & 0,0002 & 0,92 & 645 \\
\hline TRENDS IN BIOTECHNOLOGY & 7 & 0,0002 & 0,92 & 646 \\
\hline TROPICAL DOCTOR & 7 & 0,0002 & 0,92 & 647 \\
\hline ULTRASOUND IN MEDICINE AND BIOLOGY & 7 & 0,0002 & 0,92 & 648 \\
\hline ACTA BIOTHEORETICA & 6 & 0,0002 & 0,92 & 649 \\
\hline ACTA PHARMACOLOGICA SINICA & 6 & 0,0002 & 0,92 & 650 \\
\hline ALCOHOL & 6 & 0,0002 & 0,92 & 651 \\
\hline ANALYTICAL AND QUANTITATIVE CYTOLOGY AND HISTOLOGY & 6 & 0,0002 & 0,92 & 652 \\
\hline
\end{tabular}




\begin{tabular}{|c|c|c|c|c|}
\hline ANALYTICAL CELLULAR PATHOLOGY & 6 & 0,0002 & 0,92 & 653 \\
\hline ANGLE ORTHODONTIST & 6 & 0,0002 & 0,92 & 654 \\
\hline ANNALES DE LA SOCIETE ENTOMOLOGIQUE DE FRANCE & 6 & 0,0002 & 0,92 & 655 \\
\hline ANNALS OF NEUROLOGY & 6 & 0,0002 & 0,92 & 656 \\
\hline ARCHIVES OF GENERAL PSYCHIATRY & 6 & 0,0002 & 0,92 & 657 \\
\hline ARCHIVES OF MICROBIOLOGY & 6 & 0,0002 & 0,92 & 658 \\
\hline ARCHIVES OF NEUROLOGY & 6 & 0,0002 & 0,92 & 659 \\
\hline AVIATION SPACE AND ENVIRONMENTAL MEDICINE & 6 & 0,0002 & 0,92 & 660 \\
\hline BEE WORLD & 6 & 0,0002 & 0,92 & 661 \\
\hline BIOCHEMICAL ENGINEERING JOURNAL & 6 & 0,0002 & 0,92 & 662 \\
\hline BRITISH JOURNAL OF ANAESTHESIA & 6 & $0,0 \odot \odot 2$ & 0,92 & 663 \\
\hline BULLETIN OF THE CHEMICAL SOCIETY OF JAPAN & 6 & 0,0002 & 0,92 & 664 \\
\hline CALCIFIED TISSUE INTERNATIONAL & 6 & 0,0002 & 0,92 & 665 \\
\hline CARDIOVASCULAR SURGERY & 6 & 0,0002 & 0,92 & 666 \\
\hline CHEMICAL \& PHARMACEUTICAL BULLETIN & 6 & 0,0002 & 0,92 & 667 \\
\hline CLINICAL AND EXPERIMENTAL HYPERTENSION & 6 & 0,0002 & 0,92 & 668 \\
\hline CLINICAL NUTRITION & 6 & 0,0002 & 0,92 & 669 \\
\hline CURRENT OPINION IN GASTROENTEROLOGY & 6 & 0,0002 & 0,92 & 670 \\
\hline CURRENT OPINION IN INFECTIOUS DISEASES & 6 & 0,0002 & 0,92 & 671 \\
\hline DEVELOPMENTAL AND COMPARATIVE IMMUNOLOGY & 6 & 0,0002 & 0,92 & 672 \\
\hline DISEASES OF THE COLON \& RECTUM & 6 & 0,0002 & 0,92 & 673 \\
\hline DNA AND CELL BIOLOGY & 6 & 0,0002 & 0,92 & 674 \\
\hline DRUG DEVELOPMENT RESEARCH & 6 & 0,0002 & 0,92 & 675 \\
\hline ECOLOGICAL ENTOMOLOGY & 6 & 0,0002 & 0,92 & 676 \\
\hline ERGONOMICS & 6 & 0,0002 & 0,92 & 677 \\
\hline EUROPEAN CYTOKINE NETWORK & 6 & 0,0002 & 0,92 & 678 \\
\hline EUROPEAN JOURNAL OF CLINICAL MICROBIOLOGY \& INFECTIOUS DISEA & 6 & 0,0002 & 0,92 & 679 \\
\hline EUROPEAN JOURNAL OF CLINICAL PHARMACOLOGY & 6 & 0,0002 & 0,92 & 680 \\
\hline EUROPEAN JOURNAL OF EPIDEMIOLOGY & 6 & 0,0002 & 0,92 & 681 \\
\hline EUROPEAN JOURNAL OF IMMUNOGENETICS & 6 & 0,0002 & 0,92 & 682 \\
\hline EUROPEAN JOURNAL OF OBSTETRICS GYNECOLOGY AND REPRODUCTIVE B & 6 & 0,0002 & 0,92 & 683 \\
\hline FETAL DIAGNOSIS AND THERAPY & 6 & 0,0002 & $\odot, 92$ & 684 \\
\hline FOLIA MICROBIOLOGICA & 6 & 0,0002 & $\odot, 92$ & 685 \\
\hline FOOD CONTROL & 6 & 0,0002 & 0,92 & 686 \\
\hline HELVETICA CHIMICA ACTA & 6 & 0,0002 & 0,92 & 687 \\
\hline HEMOGLOBIN & 6 & 0,0002 & 0,92 & 688 \\
\hline IEEE TRANSACTIONS ON MEDICAL IMAGING & 6 & 0,0002 & 0,92 & 689 \\
\hline INFANT MENTAL HEALTH JOURNAL & 6 & 0,0002 & 0,92 & 690 \\
\hline INTERNATIONAL ARCHIVES OF OCCUPATIONAL AND ENVIRONMENTAL HEA & 6 & 0,0002 & 0,92 & 691 \\
\hline INTERNATIONAL JOURNAL FOR VITAMIN AND NUTRITION RESEARCH & 6 & 0,0002 & 0,92 & 692 \\
\hline INTERNATIONAL JOURNAL OF ARTIFICIAL ORGANS & 6 & 0,0002 & 0,92 & 693 \\
\hline INTERNATIONAL JOURNAL OF BIOLOGICAL MACROMOLECULES & 6 & 0,0002 & 0,92 & 694 \\
\hline INTERNATIONAL JOURNAL OF FOOD SCIENCE AND TECHNOLOGY & 6 & 0,0002 & 0,93 & 695 \\
\hline INTERVIROLOGY & 6 & 0,0002 & 0,93 & 696 \\
\hline IUBMB LIFE & 6 & 0,0002 & 0,93 & 697 \\
\hline JAPANESE JOURNAL OF CANCER RESEARCH & 6 & 0,0002 & 0,93 & 698 \\
\hline JOURNAL OF BACTERIOLOGY & 6 & 0,0002 & 0,93 & 699 \\
\hline JOURNAL OF BIOGEOGRAPHY & 6 & 0,0002 & 0,93 & 700 \\
\hline JOURNAL OF CARDIOVASCULAR SURGERY & 6 & 0,0002 & 0,93 & 701 \\
\hline JOURNAL OF CHROMATOGRAPHIC SCIENCE & 6 & 0,0002 & 0,93 & 702 \\
\hline JOURNAL OF COMPARATIVE PATHOLOGY & 6 & 0,0002 & 0,93 & 703 \\
\hline JOURNAL OF ECONOMIC ENTOMOLOGY & 6 & 0,0002 & 0,93 & 704 \\
\hline JOURNAL OF FOOD PROCESS ENGINEERING & 6 & 0,0002 & 0,93 & 705 \\
\hline JOURNAL OF FOOD PROCESSING AND PRESERVATION & 6 & 0,0002 & 0,93 & 706 \\
\hline JOURNAL OF IMMUNOLOGICAL METHODS & 6 & 0,0002 & 0,93 & 707 \\
\hline JOURNAL OF NERVOUS AND MENTAL DISEASE & 6 & 0,0002 & 0,93 & 708 \\
\hline JOURNAL OF NEUROLOGY NEUROSURGERY AND PSYCHIATRY & 6 & 0,0002 & 0,93 & 709 \\
\hline JOURNAL OF NEUROPATHOLOGY AND EXPERIMENTAL NEUROLOGY & 6 & 0,0002 & 0,93 & 710 \\
\hline JOURNAL OF NEUROPHYSIOLOGY & 6 & 0,0002 & 0,93 & 711 \\
\hline JOURNAL OF NEUROSCIENCE METHODS & 6 & 0,0002 & $\odot, 93$ & 712 \\
\hline JOURNAL OF PEPTIDE RESEARCH & 6 & 0,0002 & 0,93 & 713 \\
\hline JOURNAL OF PHARMACEUTICAL SCIENCES & 6 & 0,0002 & 0,93 & 714 \\
\hline JOURNAL OF STORED PRODUCTS RESEARCH & 6 & 0,0002 & 0,93 & 715 \\
\hline JOURNAL OF STRUCTURAL BIOLOGY & 6 & 0,0002 & 0,93 & 716 \\
\hline JOURNAL OF THE AMERICAN COLLEGE OF SURGEONS & 6 & 0,0002 & 0,93 & 717 \\
\hline JOURNAL OF THE AMERICAN WATER RESOURCES ASSOCIATION & 6 & 0,0002 & 0,93 & 718 \\
\hline JOURNAL OF THE CHEMICAL SOCIETY-PERKIN TRANSACTIONS 1 & 6 & 0,0002 & 0,93 & 719 \\
\hline JOURNAL OF TRACE ELEMENTS IN MEDICINE AND BIOLOGY & 6 & 0,0002 & 0,93 & 720 \\
\hline LIVER & 6 & 0,0002 & 0,93 & 721 \\
\hline MATURITAS & 6 & 0,0002 & 0,93 & 722 \\
\hline MEDICINE & 6 & 0,0002 & 0,93 & 723 \\
\hline MOLECULAR AND CELLULAR PROBES & 6 & 0,0002 & 0,93 & 724 \\
\hline MUTATION RESEARCH-DNA REPAIR & 6 & 0,0002 & 0,93 & 725 \\
\hline
\end{tabular}




\begin{tabular}{|c|c|c|c|c|}
\hline NATURAL HISTORY & 6 & 0,0002 & 0,93 & 726 \\
\hline NEPHROLOGY & 6 & 0,0002 & 0,93 & 727 \\
\hline NEUROENDOCRINOLOGY & 6 & 0,0002 & 0,93 & 728 \\
\hline NEUROIMAGE & 6 & 0,0002 & 0,93 & 729 \\
\hline NEUROPEDIATRICS & 6 & 0,0002 & 0,93 & 730 \\
\hline NEURORADIOLOGY & 6 & 0,0002 & 0,93 & 731 \\
\hline NEUROTOXICOLOGY & 6 & 0,0002 & 0,93 & 732 \\
\hline NEUROTOXICOLOGY AND TERATOLOGY & 6 & 0,0002 & 0,93 & 733 \\
\hline OBESITY SURGERY & 6 & 0,0002 & 0,93 & 734 \\
\hline OCCUPATIONAL AND ENVIRONMENTAL MEDICINE & 6 & 0,0002 & 0,93 & 735 \\
\hline OCULAR IMMUNOLOGY AND INFLAMMATION & 6 & 0,0002 & 0,93 & 736 \\
\hline PHARMACEUTICAL RESEARCH & 6 & 0,0002 & 0,93 & 737 \\
\hline PHOTOCHEMISTRY AND PHOTOBIOLOGY & 6 & 0,0002 & 0,93 & 738 \\
\hline PSYCHOBIOLOGY & 6 & 0,0002 & 0,93 & 739 \\
\hline PSYCHOPATHOLOGY & 6 & 0,0002 & 0,93 & 740 \\
\hline RHEUMATOLOGY & 6 & 0,0002 & 0,93 & 741 \\
\hline SALUD PUBLICA DE MEXICO & 6 & 0,0002 & 0,93 & 742 \\
\hline SCANDINAVIAN JOURNAL OF GASTROENTEROLOGY & 6 & 0,0002 & 0,93 & 743 \\
\hline STATISTICS IN MEDICINE & 6 & 0,0002 & 0,93 & 744 \\
\hline SURGERY & 6 & 0,0002 & 0,93 & 745 \\
\hline SURGICAL CLINICS OF NORTH AMERICA & 6 & 0,0002 & 0,93 & 746 \\
\hline TERATOLOGY & 6 & $\odot, 0 \odot \odot 2$ & 0,93 & 747 \\
\hline VETERINARY IMMUNOLOGY AND IMMUNOPATHOLOGY & 6 & 0,0002 & 0,93 & 748 \\
\hline VIRUS GENES & 6 & 0,0002 & 0,93 & 749 \\
\hline WATER SA & 6 & 0,0002 & 0,93 & 750 \\
\hline WORLD JOURNAL OF SURGERY & 6 & 0,0002 & 0,93 & 751 \\
\hline ACTA CARDIOLOGICA & 5 & 0,0001 & 0,93 & 752 \\
\hline ACTA ODONTOLOGICA SCANDINAVICA & 5 & 0,0001 & 0,93 & 753 \\
\hline ACTA OPHTHALMOLOGICA SCANDINAVICA & 5 & 0,0001 & 0,93 & 754 \\
\hline ACTA PROTOZOOLOGICA & 5 & 0,0001 & 0,93 & 755 \\
\hline AMERICAN JOURNAL OF KIDNEY DISEASES & 5 & 0,0001 & 0,93 & 756 \\
\hline AMERICAN JOURNAL OF PHYSIOLOGY-RENAL PHYSIOLOGY & 5 & 0,0001 & 0,93 & 757 \\
\hline AMERICAN JOURNAL OF RHINOLOGY & 5 & 0,0001 & 0,93 & 758 \\
\hline AMERICAN SURGEON & 5 & 0,0001 & 0,93 & 759 \\
\hline ANAESTHESIA & 5 & 0,0001 & 0,93 & 760 \\
\hline ANNALS OF HUMAN GENETICS & 5 & 0,0001 & 0,94 & 761 \\
\hline ANNUAL REVIEW OF ENTOMOLOGY & 5 & 0,0001 & 0,94 & 762 \\
\hline APMIS & 5 & 0,0001 & 0,94 & 763 \\
\hline APPLIED PSYCHOLINGUISTICS & 5 & 0,0001 & 0,94 & 764 \\
\hline ARCHIVES OF MEDICAL RESEARCH & 5 & 0,0001 & 0,94 & 765 \\
\hline ARCHIVES OF ORTHOPAEDIC AND TRAUMA SURGERY & 5 & 0,0001 & 0,94 & 766 \\
\hline BEHAVIORAL AND BRAIN SCIENCES & 5 & 0,0001 & 0,94 & 767 \\
\hline BEHAVIORAL NEUROSCIENCE & 5 & 0,0001 & 0,94 & 768 \\
\hline BIOLOGICAL BULLETIN & 5 & 0,0001 & 0,94 & 769 \\
\hline BIOLOGY OF THE NEONATE & 5 & 0,0001 & 0,94 & 770 \\
\hline BIOMASS \& BIOENERGY & 5 & 0,0001 & 0,94 & 771 \\
\hline BIOPOLYMERS & 5 & 0,0001 & 0,94 & 772 \\
\hline BLOOD CELLS MOLECULES AND DISEASES & 5 & 0,0001 & 0,94 & 773 \\
\hline BRITISH JOURNAL OF OBSTETRICS AND GYNAECOLOGY & 5 & 0,0001 & 0,94 & 774 \\
\hline CANADIAN MEDICAL ASSOCIATION JOURNAL & 5 & 0,0001 & 0,94 & 775 \\
\hline CARDIOVASCULAR RESEARCH & 5 & 0,0001 & 0,94 & 776 \\
\hline CELL CALCIUM & 5 & 0,0001 & 0,94 & 777 \\
\hline CELLS TISSUES ORGANS & 5 & 0,0001 & 0,94 & 778 \\
\hline CLINICAL AND APPLIED THROMBOSIS-HEMOSTASIS & 5 & 0,0001 & 0,94 & 779 \\
\hline CLINICAL AUTONOMIC RESEARCH & 5 & 0,0001 & 0,94 & 780 \\
\hline CLINICAL DRUG INVESTIGATION & 5 & 0,0001 & 0,94 & 781 \\
\hline CONSCIOUSNESS AND COGNITION & 5 & 0,0001 & 0,94 & 782 \\
\hline CULTURE \& PSYCHOLOGY & 5 & 0,0001 & 0,94 & 783 \\
\hline CUTIS & 5 & 0,0001 & 0,94 & 784 \\
\hline DEVELOPMENTAL MEDICINE AND CHILD NEUROLOGY & 5 & 0,0001 & 0,94 & 785 \\
\hline DEVELOPMENTAL NEUROSCIENCE & 5 & 0,0001 & 0,94 & 786 \\
\hline DIABETES \& METABOLISM & 5 & 0,0001 & 0,94 & 787 \\
\hline DIGESTION & 5 & 0,0001 & 0,94 & 788 \\
\hline DRUGS-EDUCATION PREVENTION AND POLICY & 5 & 0,0001 & 0,94 & 789 \\
\hline DRUGS & 5 & 0,0001 & 0,94 & 790 \\
\hline ECOLOGICAL APPLICATIONS & 5 & 0,0001 & 0,94 & 791 \\
\hline ECOSYSTEMS & 5 & 0,0001 & 0,94 & 792 \\
\hline ENDOCRINE REVIEWS & 5 & 0,0001 & 0,94 & 793 \\
\hline ENTOMOLOGICA SCANDINAVICA & 5 & 0,0001 & 0,94 & 794 \\
\hline ENVIRONMENTAL MONITORING AND ASSESSMENT & 5 & 0,0001 & 0,94 & 795 \\
\hline ETHOLOGY & 5 & 0,0001 & 0,94 & 796 \\
\hline EUROPEAN JOURNAL OF SURGICAL ONCOLOGY & 5 & 0,0001 & 0,94 & 797 \\
\hline EXPERIMENTAL HEMATOLOGY & 5 & 0,0001 & 0,94 & 798 \\
\hline
\end{tabular}




\begin{tabular}{|c|c|c|c|c|}
\hline EXPERIMENTAL LUNG RESEARCH & 5 & 0,0001 & 0,94 & 799 \\
\hline EXPERIMENTAL NEUROLOGY & 5 & 0,0001 & 0,94 & 800 \\
\hline FOOD RESEARCH INTERNATIONAL & 5 & 0,0001 & 0,94 & 801 \\
\hline FOOT \& ANKLE INTERNATIONAL & 5 & 0,0001 & 0,94 & 802 \\
\hline GRAEFES ARCHIVE FOR CLINICAL AND EXPERIMENTAL OPHTHALMOLOGY & 5 & 0,0001 & 0,94 & 803 \\
\hline GYNAECOLOGICAL ENDOSCOPY & 5 & 0,0001 & 0,94 & 804 \\
\hline HAUTARZT & 5 & 0,0001 & 0,94 & 805 \\
\hline HORMONES AND BEHAVIOR & 5 & 0,0001 & 0,94 & 806 \\
\hline HUMAN PATHOLOGY & 5 & 0,0001 & 0,94 & 807 \\
\hline HYDROLOGICAL PROCESSES & 5 & 0,0001 & 0,94 & 808 \\
\hline IMMUNOLOGICAL INVESTIGATIONS & 5 & $0,0 \odot \odot 1$ & 0,94 & 809 \\
\hline INFECTIOUS DISEASE CLINICS OF NORTH AMERICA & 5 & 0,0001 & 0,94 & 810 \\
\hline INFLAMMATION & 5 & 0,0001 & 0,94 & 811 \\
\hline INTERNATIONAL BIODETERIORATION \& BIODEGRADATION & 5 & 0,0001 & 0,94 & 812 \\
\hline INTERNATIONAL JOURNAL OF CLINICAL PRACTICE & 5 & 0,0001 & 0,94 & 813 \\
\hline INTERNATIONAL JOURNAL OF ENVIRONMENTAL HEALTH RESEARCH & 5 & 0,0001 & 0,94 & 814 \\
\hline INTERNATIONAL JOURNAL OF HEALTH SERVICES & 5 & 0,0001 & 0,94 & 815 \\
\hline INTERNATIONAL JOURNAL OF INSECT MORPHOLOGY \& EMBRYOLOGY & 5 & 0,0001 & 0,94 & 816 \\
\hline INTERNATIONAL JOURNAL OF PERIODONTICS \& RESTORATIVE DENTISTR & 5 & 0,0001 & 0,94 & 817 \\
\hline INTERNATIONAL JOURNAL OF SURGICAL PATHOLOGY & 5 & 0,0001 & 0,94 & 818 \\
\hline INTERNATIONAL SUGAR JOURNAL & 5 & 0,0001 & 0,94 & 819 \\
\hline JOURNAL OF APICULTURAL RESEARCH & 5 & 0,0001 & 0,94 & 820 \\
\hline JOURNAL OF AUTOIMMUNITY & 5 & 0,0001 & 0,94 & 821 \\
\hline JOURNAL OF CLINICAL DENSITOMETRY & 5 & 0,0001 & 0,94 & 822 \\
\hline JOURNAL OF DENTISTRY & 5 & 0,0001 & 0,94 & 823 \\
\hline JOURNAL OF DERMATOLOGICAL TREATMENT & 5 & 0,0001 & 0,94 & 824 \\
\hline JOURNAL OF GASTROENTEROLOGY & 5 & 0,0001 & 0,94 & 825 \\
\hline JOURNAL OF GENERAL PHYSIOLOGY & 5 & 0,0001 & 0,94 & 826 \\
\hline JOURNAL OF HISTOTECHNOLOGY & 5 & 0,0001 & 0,94 & 827 \\
\hline JOURNAL OF INFECTION & 5 & 0,0001 & 0,94 & 828 \\
\hline JOURNAL OF MOLECULAR EVOLUTION & 5 & 0,0001 & 0,94 & 829 \\
\hline JOURNAL OF NEUROBIOLOGY & 5 & 0,0001 & 0,94 & 830 \\
\hline JOURNAL OF NEUROIMAGING & 5 & 0,0001 & 0,94 & 831 \\
\hline JOURNAL OF NEUROPSYCHIATRY AND CLINICAL NEUROSCIENCES & 5 & 0,0001 & 0,94 & 832 \\
\hline JOURNAL OF PAIN AND SYMPTOM MANAGEMENT & 5 & 0,0001 & 0,94 & 833 \\
\hline JOURNAL OF PINEAL RESEARCH & 5 & 0,0001 & 0,94 & 834 \\
\hline JOURNAL OF SOCIAL PSYCHOLOGY & 5 & 0,0001 & 0,94 & 835 \\
\hline JOURNAL OF THE AMERICAN SOCIETY OF ECHOCARDIOGRAPHY & 5 & 0,0001 & 0,94 & 836 \\
\hline JOURNAL OF THE AUTONOMIC NERVOUS SYSTEM & 5 & 0,0001 & 0,95 & 837 \\
\hline JOURNAL OF THE NEW YORK ENTOMOLOGICAL SOCIETY & 5 & 0,0001 & 0,95 & 838 \\
\hline JOURNAL OF VIROLOGY & 5 & 0,0001 & 0,95 & 839 \\
\hline JOURNAL OF VOICE & 5 & 0,0001 & 0,95 & 840 \\
\hline LEUKEMIA \& LYMPHOMA & 5 & 0,0001 & 0,95 & 841 \\
\hline LUNG & 5 & 0,0001 & 0,95 & 842 \\
\hline LYMPHOLOGY & 5 & 0,0001 & 0,95 & 843 \\
\hline MEDICAL MICROBIOLOGY AND IMMUNOLOGY & 5 & 0,0001 & 0,95 & 844 \\
\hline MOLECULAR AND CELLULAR ENDOCRINOLOGY & 5 & 0,0001 & 0,95 & 845 \\
\hline MOLECULAR ENDOCRINOLOGY & 5 & 0,0001 & 0,95 & 846 \\
\hline NEUROSCIENCE RESEARCH & 5 & 0,0001 & 0,95 & 847 \\
\hline OCCUPATIONAL MEDICINE-OXFORD & 5 & 0,0001 & 0,95 & 848 \\
\hline PANCREAS & 5 & 0,0001 & 0,95 & 849 \\
\hline PESTICIDE BIOCHEMISTRY AND PHYSIOLOGY & 5 & 0,0001 & 0,95 & 850 \\
\hline PHYSIOLOGICAL AND BIOCHEMICAL ZOOLOGY & 5 & 0,0001 & 0,95 & 851 \\
\hline PHYSIOLOGICAL ENTOMOLOGY & 5 & 0,0001 & 0,95 & 852 \\
\hline PLANT ECOLOGY & 5 & 0,0001 & 0,95 & 853 \\
\hline POLAR BIOLOGY & 5 & 0,0001 & 0,95 & 854 \\
\hline PROCEEDINGS OF THE ROYAL SOCIETY OF LONDON SERIES B-BIOLOGIC & 5 & 0,0001 & 0,95 & 855 \\
\hline PROSTATE & 5 & 0,0001 & 0,95 & 856 \\
\hline PROSTHETICS AND ORTHOTICS INTERNATIONAL & 5 & 0,0001 & 0,95 & 857 \\
\hline PROTEIN ENGINEERING & 5 & 0,0001 & 0,95 & 858 \\
\hline PROTEINS-STRUCTURE FUNCTION AND GENETICS & 5 & 0,0001 & 0,95 & 859 \\
\hline PROTOPLASMA & 5 & 0,0001 & 0,95 & 860 \\
\hline RADIATION RESEARCH & 5 & 0,0001 & 0,95 & 861 \\
\hline REVISTA CHILENA DE HISTORIA NATURAL & 5 & 0,0001 & 0,95 & 862 \\
\hline SCANDINAVIAN AUDIOLOGY & 5 & 0,0001 & 0,95 & 863 \\
\hline SCANDINAVIAN JOURNAL OF UROLOGY AND NEPHROLOGY & 5 & 0,0001 & 0,95 & 864 \\
\hline SKELETAL RADIOLOGY & 5 & 0,0001 & 0,95 & 865 \\
\hline SPINE & 5 & 0,0001 & 0,95 & 866 \\
\hline SYSTEMATIC BIOLOGY & 5 & 0,0001 & 0,95 & 867 \\
\hline TRENDS IN GENETICS & 5 & 0,0001 & 0,95 & 868 \\
\hline TRENDS IN NEUROSCIENCES & 5 & 0,0001 & 0,95 & 869 \\
\hline TUMOR BIOLOGY & 5 & 0,0001 & 0,95 & 870 \\
\hline WATER ENVIRONMENT RESEARCH & 5 & 0,0001 & 0,95 & 871 \\
\hline
\end{tabular}




\begin{tabular}{|c|c|c|c|c|}
\hline ACADEMIC MEDICINE & 4 & 0,0001 & 0,95 & 872 \\
\hline ACCIDENT ANALYSIS AND PREVENTION & 4 & 0,0001 & 0,95 & 873 \\
\hline ACP-APPLIED CARDIOPULMONARY PATHOPHYSIOLOGY & 4 & 0,0001 & 0,95 & 874 \\
\hline ACTA BIOTECHNOLOGICA & 4 & 0,0001 & 0,95 & 875 \\
\hline ACTA DERMATO-VENEREOLOGICA & 4 & 0,0001 & 0,95 & 876 \\
\hline ACTA DIABETOLOGICA & 4 & 0,0001 & 0,95 & 877 \\
\hline ACTA NEUROCHIRURGICA & 4 & 0,0001 & 0,95 & 878 \\
\hline ACTA NEUROPATHOLOGICA & 4 & 0,0001 & 0,95 & 879 \\
\hline ACTA OECOLOGICA-INTERNATIONAL JOURNAL OF ECOLOGY & 4 & 0,0001 & 0,95 & 880 \\
\hline AIDS EDUCATION AND PREVENTION & 4 & 0,0001 & 0,95 & 881 \\
\hline AIDS PATIENT CARE AND STDS & 4 & 0,0001 & 0,95 & 882 \\
\hline ALLERGY & 4 & 0,0001 & 0,95 & 883 \\
\hline AMERICAN JOURNAL OF INDUSTRIAL MEDICINE & 4 & 0,0001 & 0,95 & 884 \\
\hline AMERICAN JOURNAL OF MEDICINE & 4 & 0,0001 & 0,95 & 885 \\
\hline AMERICAN JOURNAL OF NEURORADIOLOGY & 4 & 0,0001 & 0,95 & 886 \\
\hline AMERICAN JOURNAL OF SURGICAL PATHOLOGY & 4 & 0,0001 & 0,95 & 887 \\
\hline ANNALES DE GENETIQUE & 4 & 0,0001 & 0,95 & 888 \\
\hline ANNALS OF THE RHEUMATIC DISEASES & 4 & 0,0001 & 0,95 & 889 \\
\hline ARCHIVES OF PHYSICAL MEDICINE AND REHABILITATION & 4 & 0,0001 & 0,95 & 890 \\
\hline ARTHROSCOPY & 4 & 0,0001 & 0,95 & 891 \\
\hline AUSTRALIAN JOURNAL OF CHEMISTRY & 4 & 0,0001 & 0,95 & 892 \\
\hline BASIC RESEARCH IN CARDIOLOGY & 4 & $0,0 \odot \odot 1$ & 0,95 & 893 \\
\hline BEHAVIOR GENETICS & 4 & 0,0001 & 0,95 & 894 \\
\hline BIOCHIMICA ET BIOPHYSICA ACTA-MOLECULAR AND CELL BIOLOGY OF & 4 & 0,0001 & 0,95 & 895 \\
\hline BIOCHIMICA ET BIOPHYSICA ACTA-MOLECULAR CELL RESEARCH & 4 & 0,0001 & 0,95 & 896 \\
\hline BIOLOGIA & 4 & 0,0001 & 0,95 & 897 \\
\hline BIOSCIENCE BIOTECHNOLOGY AND BIOCHEMISTRY & 4 & 0,0001 & 0,95 & 898 \\
\hline BRAIN AND COGNITION & 4 & 0,0001 & 0,95 & 899 \\
\hline BRAIN BEHAVIOR AND IMMUNITY & 4 & 0,0001 & 0,95 & 900 \\
\hline BREAST & 4 & 0,0001 & 0,95 & 901 \\
\hline BRITISH DENTAL JOURNAL & 4 & 0,0001 & 0,95 & 902 \\
\hline CANCER EPIDEMIOLOGY BIOMARKERS \& PREVENTION & 4 & 0,0001 & 0,95 & 903 \\
\hline CELL PROLIFERATION & 4 & 0,0001 & 0,95 & 904 \\
\hline CEREBRAL CORTEX & 4 & 0,0001 & 0,95 & 905 \\
\hline CHEMICAL SPECIATION AND BIOAVAILABILITY & 4 & 0,0001 & 0,95 & 906 \\
\hline CHILD DEVELOPMENT & 4 & 0,0001 & 0,95 & 907 \\
\hline CHIRALITY & 4 & 0,0001 & 0,95 & 908 \\
\hline CLINICAL AND LABORATORY HAEMATOLOGY & 4 & 0,0001 & 0,95 & 909 \\
\hline COMPARATIVE HAEMATOLOGY INTERNATIONAL & 4 & 0,0001 & 0,95 & 910 \\
\hline COMPUTERS \& CHEMISTRY & 4 & 0,0001 & 0,95 & 911 \\
\hline CONNECTIVE TISSUE RESEARCH & 4 & 0,0001 & 0,95 & 912 \\
\hline CONTACT DERMATITIS & 4 & 0,0001 & 0,95 & 913 \\
\hline CRITICAL REVIEWS IN MICROBIOLOGY & 4 & 0,0001 & 0,95 & 914 \\
\hline CROATICA CHEMICA ACTA & 4 & 0,0001 & 0,95 & 915 \\
\hline CURRENT EYE RESEARCH & 4 & 0,0001 & 0,95 & 916 \\
\hline CURRENT PHARMACEUTICAL DESIGN & 4 & 0,0001 & 0,95 & 917 \\
\hline DERMATOLOGY & 4 & 0,0001 & 0,95 & 918 \\
\hline DEVELOPMENTAL DYNAMICS & 4 & 0,0001 & 0,95 & 919 \\
\hline DIGESTIVE SURGERY & 4 & 0,0001 & 0,95 & 920 \\
\hline ENVIRONMENTAL MANAGEMENT & 4 & 0,0001 & 0,95 & 921 \\
\hline ENVIRONMENTAL SCIENCE AND POLLUTION RESEARCH & 4 & 0,0001 & 0,95 & 922 \\
\hline EUROPEAN FOOD RESEARCH AND TECHNOLOGY & 4 & 0,0001 & 0,95 & 923 \\
\hline EUROPEAN JOURNAL OF ANAESTHESIOLOGY & 4 & 0,0001 & 0,95 & 924 \\
\hline EUROPEAN JOURNAL OF DRUG METABOLISM AND PHARMACOKINETICS & 4 & 0,0001 & 0,96 & 925 \\
\hline EUROPEAN JOURNAL OF ORTHODONTICS & 4 & 0,0001 & 0,96 & 926 \\
\hline EUROPEAN SPINE JOURNAL & 4 & 0,0001 & 0,96 & 927 \\
\hline EYE & 4 & 0,0001 & 0,96 & 928 \\
\hline FLUORIDE & 4 & 0,0001 & 0,96 & 929 \\
\hline FOOD QUALITY AND PREFERENCE & 4 & 0,0001 & 0,96 & 930 \\
\hline FOOD TECHNOLOGY AND BIOTECHNOLOGY & 4 & 0,0001 & 0,96 & 931 \\
\hline GENERAL HOSPITAL PSYCHIATRY & 4 & 0,0001 & 0,96 & 932 \\
\hline GERONTOLOGIST & 4 & 0,0001 & 0,96 & 933 \\
\hline GLOBAL ECOLOGY AND BIOGEOGRAPHY & 4 & 0,0001 & 0,96 & 934 \\
\hline GROUND WATER & 4 & 0,0001 & 0,96 & 935 \\
\hline HAEMATOLOGIA & 4 & 0,0001 & 0,96 & 936 \\
\hline HEARING RESEARCH & 4 & 0,0001 & 0,96 & 937 \\
\hline HELICOBACTER & 4 & 0,0001 & 0,96 & 938 \\
\hline HIPPOCAMPUS & 4 & 0,0001 & 0,96 & 939 \\
\hline HUMAN \& EXPERIMENTAL TOXICOLOGY & 4 & 0,0001 & 0,96 & 940 \\
\hline INTERNATIONAL CLINICAL PSYCHOPHARMACOLOGY & 4 & 0,0001 & 0,96 & 941 \\
\hline INTERNATIONAL DAIRY JOURNAL & 4 & 0,0001 & 0,96 & 942 \\
\hline INTERNATIONAL JOURNAL OF COLORECTAL DISEASE & 4 & 0,0001 & 0,96 & 943 \\
\hline INTERNATIONAL JOURNAL OF FERTILITY AND WOMENS MEDICINE & 4 & 0,0001 & 0,96 & 944 \\
\hline
\end{tabular}




\begin{tabular}{|c|c|c|c|c|}
\hline INTERNATIONAL JOURNAL OF RADIATION BIOLOGY & 4 & 0,0001 & 0,96 & 945 \\
\hline INTERNATIONAL ORTHOPAEDICS & 4 & 0,0001 & 0,96 & 946 \\
\hline JAPANESE JOURNAL OF CLINICAL ONCOLOGY & 4 & 0,0001 & 0,96 & 947 \\
\hline JAPANESE JOURNAL OF PHARMACOLOGY & 4 & 0,0001 & 0,96 & 948 \\
\hline JOURNAL DE CHIRURGIE & 4 & 0,0001 & 0,96 & 949 \\
\hline JOURNAL DE RADIOLOGIE & 4 & 0,0001 & 0,96 & 950 \\
\hline JOURNAL OF ANALYTICAL TOXICOLOGY & 4 & 0,0001 & 0,96 & 951 \\
\hline JOURNAL OF AUTONOMIC PHARMACOLOGY & 4 & 0,0001 & 0,96 & 952 \\
\hline JOURNAL OF BIOCHEMICAL AND BIOPHYSICAL METHODS & 4 & 0,0001 & 0,96 & 953 \\
\hline JOURNAL OF CELL BIOLOGY & 4 & 0,0001 & 0,96 & 954 \\
\hline JOURNAL OF CONTROLLED RELEASE & 4 & 0,0001 & 0,96 & 955 \\
\hline JOURNAL OF CROSS-CULTURAL PSYCHOLOGY & 4 & 0,0001 & 0,96 & 956 \\
\hline JOURNAL OF DIABETES AND ITS COMPLICATIONS & 4 & 0,0001 & 0,96 & 957 \\
\hline JOURNAL OF ELECTROCARDIOLOGY & 4 & 0,0001 & 0,96 & 958 \\
\hline JOURNAL OF ELECTROMYOGRAPHY AND KINESIOLOGY & 4 & 0,0001 & 0,96 & 959 \\
\hline JOURNAL OF ENVIRONMENTAL SCIENCE AND HEALTH PART A- TOXIC/HA & 4 & 0,0001 & 0,96 & 960 \\
\hline JOURNAL OF GASTROENTEROLOGY AND HEPATOLOGY & 4 & 0,0001 & 0,96 & 961 \\
\hline JOURNAL OF LIQUID CHROMATOGRAPHY & 4 & 0,0001 & 0,96 & 962 \\
\hline JOURNAL OF MOLECULAR NEUROSCIENCE & 4 & 0,0001 & 0,96 & 963 \\
\hline JOURNAL OF MOTOR BEHAVIOR & 4 & 0,0001 & 0,96 & 964 \\
\hline JOURNAL OF NEUROSCIENCE RESEARCH & 4 & 0,0001 & 0,96 & 965 \\
\hline JOURNAL OF PSYCHOACTIVE DRUGS & 4 & 0,0001 & 0,96 & 966 \\
\hline JOURNAL OF SENSORY STUDIES & 4 & 0,0001 & 0,96 & 967 \\
\hline JOURNAL OF SOIL AND WATER CONSERVATION & 4 & 0,0001 & 0,96 & 968 \\
\hline JOURNAL OF THE INDIAN CHEMICAL SOCIETY & 4 & 0,0001 & 0,96 & 969 \\
\hline JOURNAL OF TOXICOLOGY-TOXIN REVIEWS & 4 & 0,0001 & 0,96 & 970 \\
\hline LANDSCAPE AND URBAN PLANNING & 4 & 0,0001 & 0,96 & 971 \\
\hline LEARNING \& MEMORY & 4 & 0,0001 & 0,96 & 972 \\
\hline MEDICAL EDUCATION & 4 & 0,0001 & 0,96 & 973 \\
\hline MEDICAL TEACHER & 4 & 0,0001 & 0,96 & 974 \\
\hline METHODS OF INFORMATION IN MEDICINE & 4 & 0,0001 & 0,96 & 975 \\
\hline MOLECULAR BIOLOGY AND EVOLUTION & 4 & 0,0001 & 0,96 & 976 \\
\hline MONATSHEFTE FUR CHEMIE & 4 & 0,0001 & 0,96 & 977 \\
\hline MUTAGENESIS & 4 & 0,0001 & 0,96 & 978 \\
\hline NEUROBIOLOGY OF AGING & 4 & 0,0001 & 0,96 & 979 \\
\hline NEUROPSYCHOLOGIA & 4 & 0,0001 & 0,96 & 980 \\
\hline NEUROSURGICAL REVIEW & 4 & 0,0001 & 0,96 & 981 \\
\hline NUCLEAR MEDICINE AND BIOLOGY & 4 & 0,0001 & 0,96 & 982 \\
\hline NUTRITION REVIEWS & 4 & 0,0001 & 0,96 & 983 \\
\hline OIKOS & 4 & 0,0001 & 0,96 & 984 \\
\hline ONCOGENE & 4 & 0,0001 & 0,96 & 985 \\
\hline OPHTHALMIC AND PHYSIOLOGICAL OPTICS & 4 & 0,0001 & 0,96 & 986 \\
\hline OTOLARYNGOLOGIC CLINICS OF NORTH AMERICA & 4 & 0,0001 & 0,96 & 987 \\
\hline PATHOLOGIE BIOLOGIE & 4 & 0,0001 & 0,96 & 988 \\
\hline PEDIATRIC AND DEVELOPMENTAL PATHOLOGY & 4 & 0,0001 & 0,96 & 989 \\
\hline PLATELETS & 4 & 0,0001 & 0,96 & 990 \\
\hline PROGRESS IN NEUROBIOLOGY & 4 & 0,0001 & 0,96 & 991 \\
\hline PSYCHOLOGICAL RECORD & 4 & 0,0001 & 0,96 & 992 \\
\hline PSYCHOLOGICAL REPORTS & 4 & 0,0001 & 0,96 & 993 \\
\hline PUBLIC HEALTH & 4 & 0,0001 & 0,96 & 994 \\
\hline RADIOLOGIC CLINICS OF NORTH AMERICA & 4 & 0,0001 & 0,96 & 995 \\
\hline RESPIRATORY MEDICINE & 4 & 0,0001 & 0,96 & 996 \\
\hline RESTORATIVE NEUROLOGY AND NEUROSCIENCE & 4 & 0,0001 & 0,96 & 997 \\
\hline RETINA-THE JOURNAL OF RETINAL AND VITREOUS DISEASES & 4 & 0,0001 & 0,96 & 998 \\
\hline REVUE NEUROLOGIQUE & 4 & 0,0001 & 0,96 & 999 \\
\hline SEMINARS IN ONCOLOGY & 4 & 0,0001 & 0,96 & 1000 \\
\hline SYSTEMATIC AND APPLIED MICROBIOLOGY & 4 & 0,0001 & 0,96 & 1001 \\
\hline TEXAS HEART INSTITUTE JOURNAL & 4 & 0,0001 & 0,96 & 1002 \\
\hline THERAPEUTIC DRUG MONITORING & 4 & 0,0001 & 0,96 & 1003 \\
\hline TOXICOLOGY AND APPLIED PHARMACOLOGY & 4 & 0,0001 & 0,96 & 1004 \\
\hline TRENDS IN BIOCHEMICAL SCIENCES & 4 & 0,0001 & 0,96 & 1005 \\
\hline TRENDS IN ECOLOGY \& EVOLUTION & 4 & 0,0001 & 0,96 & 1006 \\
\hline ULTRASONICS SONOCHEMISTRY & 4 & 0,0001 & 0,96 & 1007 \\
\hline WATER RESEARCH & 4 & 0,0001 & 0,96 & 1008 \\
\hline ACCOUNTS OF CHEMICAL RESEARCH & 3 & 0,0001 & 0,96 & 1009 \\
\hline ACTA OBSTETRICIA ET GYNECOLOGICA SCANDINAVICA & 3 & 0,0001 & 0,96 & 1010 \\
\hline ACTA ONCOLOGICA & 3 & 0,0001 & 0,96 & 1011 \\
\hline AGRICULTURE ECOSYSTEMS \& ENVIRONMENT & 3 & 0,0001 & 0,96 & 1012 \\
\hline AMERICAN JOURNAL OF DERMATOPATHOLOGY & 3 & 0,0001 & 0,96 & 1013 \\
\hline AMERICAN JOURNAL OF NEPHROLOGY & 3 & 0,0001 & 0,96 & 1014 \\
\hline AMERICAN JOURNAL OF OTOLARYNGOLOGY & 3 & 0,0001 & 0,96 & 1015 \\
\hline AMERICAN JOURNAL OF OTOLOGY & 3 & 0,0001 & 0,96 & 1016 \\
\hline AMERICAN JOURNAL OF PHYSIOLOGY-LUNG CELLULAR AND MOLECULAR P & 3 & 0,0001 & 0,96 & 1017 \\
\hline
\end{tabular}




\begin{tabular}{|c|c|c|c|c|}
\hline AMERICAN JOURNAL OF RESPIRATORY CELL AND MOLECULAR BIOLOGY & 3 & 0,0001 & 0,96 & 1018 \\
\hline AMERICAN JOURNAL ON MENTAL RETARDATION & 3 & 0,0001 & 0,96 & 1019 \\
\hline ANDROLOGIA & 3 & 0,0001 & 0,96 & 1020 \\
\hline ANNALES DE DERMATOLOGIE ET DE VENEREOLOGIE & 3 & 0,0001 & 0,96 & 1021 \\
\hline ANNALI DI CHIMICA & 3 & 0,0001 & 0,96 & 1022 \\
\hline ANNALS OF EPIDEMIOLOGY & 3 & 0,0001 & 0,96 & 1023 \\
\hline APPETITE & 3 & 0,0001 & 0,96 & 1024 \\
\hline ARCHIVES OF DERMATOLOGY & 3 & 0,0001 & 0,97 & 1025 \\
\hline ARCHIVES OF GYNECOLOGY AND OBSTETRICS & 3 & 0,0001 & 0,97 & 1026 \\
\hline ARCHIVES OF INTERNAL MEDICINE & 3 & 0,0001 & 0,97 & 1027 \\
\hline ARTIFICIAL INTELLIGENCE IN MEDICINE & 3 & $0,0 \odot \odot 1$ & 0,97 & 1028 \\
\hline ARZNEIMITTEL-FORSCHUNG -DRUG RESEARCH & 3 & 0,0001 & 0,97 & 1029 \\
\hline ARZNEIMITTEL - FORSCHUNG/DRUG RESEARCH & 3 & 0,0001 & 0,97 & 1030 \\
\hline AUSTRALIAN JOURNAL OF ECOLOGY & 3 & 0,0001 & 0,97 & 1031 \\
\hline BIOELECTROMAGNETICS & 3 & 0,0001 & 0,97 & 1032 \\
\hline BIOFUTUR & 3 & 0,0001 & 0,97 & 1033 \\
\hline BIOMASS & 3 & 0,0001 & 0,97 & 1034 \\
\hline BIOSYSTEMS & 3 & 0,0001 & 0,97 & 1035 \\
\hline BRAIN & 3 & 0,0001 & $\odot, 97$ & 1036 \\
\hline BRITISH JOURNAL OF RADIOLOGY & 3 & 0,0001 & 0,97 & 1037 \\
\hline CANADIAN JOURNAL OF CARDIOLOGY & 3 & 0,0001 & 0,97 & 1038 \\
\hline CANCER DETECTION AND PREVENTION & 3 & 0,0001 & 0,97 & 1039 \\
\hline CARDIOVASCULAR AND INTERVENTIONAL RADIOLOGY & 3 & 0,0001 & 0,97 & 1040 \\
\hline CELL STRESS \& CHAPERONES & 3 & 0,0001 & 0,97 & 1041 \\
\hline CELLULAR PHYSIOLOGY AND BIOCHEMISTRY & 3 & 0,0001 & 0,97 & 1042 \\
\hline CEREBROVASCULAR DISEASES & 3 & 0,0001 & 0,97 & 1043 \\
\hline CHEMOTHERAPY & 3 & 0,0001 & 0,97 & 1044 \\
\hline CIRCULATION RESEARCH & 3 & 0,0001 & 0,97 & 1045 \\
\hline CLADISTICS-THE INTERNATIONAL JOURNAL OF THE WILLI HENNIG SOC & 3 & 0,0001 & $\odot, 97$ & 1046 \\
\hline CLINICAL BIOMECHANICS & 3 & 0,0001 & 0,97 & 1047 \\
\hline CLINICAL MICROBIOLOGY REVIEWS & 3 & 0,0001 & 0,97 & 1048 \\
\hline CLINICAL ORAL IMPLANTS RESEARCH & 3 & 0,0001 & $\odot, 97$ & 1049 \\
\hline CLINICAL PEDIATRICS & 3 & 0,0001 & $\odot, 97$ & 1050 \\
\hline CLINICAL PHARMACOLOGY \& THERAPEUTICS & 3 & 0,0001 & 0,97 & 1051 \\
\hline CLINICAL PHYSIOLOGY & 3 & 0,0001 & 0,97 & 1052 \\
\hline CONTROLLED CLINICAL TRIALS & 3 & 0,0001 & 0,97 & 1053 \\
\hline CORONARY ARTERY DISEASE & 3 & 0,0001 & 0,97 & 1054 \\
\hline CORTEX & 3 & 0,0001 & 0,97 & 1055 \\
\hline CRITICAL CARE & 3 & 0,0001 & 0,97 & 1056 \\
\hline CRITICAL REVIEWS IN FOOD SCIENCE AND NUTRITION & 3 & 0,0001 & 0,97 & 1057 \\
\hline CULTURE MEDICINE AND PSYCHIATRY & 3 & 0,0001 & 0,97 & 1058 \\
\hline CURRENT OPINION IN PSYCHIATRY & 3 & 0,0001 & 0,97 & 1059 \\
\hline DEUTSCHE LEBENSMITTEL-RUNDSCHAU & 3 & 0,0001 & 0,97 & 1060 \\
\hline DIABETES OBESITY \& METABOLISM & 3 & 0,0001 & 0,97 & 1061 \\
\hline DODO-JOURNAL OF THE WILDLIFE PRESERVATION TRUSTS & 3 & 0,0001 & 0,97 & 1062 \\
\hline ECOLOGICAL MODELLING & 3 & 0,0001 & 0,97 & 1063 \\
\hline ECOLOGY OF FOOD AND NUTRITION & 3 & 0,0001 & 0,97 & 1064 \\
\hline ENVIRONMENTAL TOXICOLOGY & 3 & 0,0001 & 0,97 & 1065 \\
\hline ENVIRONMENTAL TOXICOLOGY AND PHARMACOLOGY & 3 & 0,0001 & 0,97 & 1066 \\
\hline EUROPEAN ARCHIVES OF PSYCHIATRY AND CLINICAL NEUROSCIENCE & 3 & 0,0001 & 0,97 & 1067 \\
\hline EUROPEAN JOURNAL OF CLINICAL INVESTIGATION & 3 & 0,0001 & 0,97 & 1068 \\
\hline EUROPEAN JOURNAL OF GYNAECOLOGICAL ONCOLOGY & 3 & 0,0001 & 0,97 & 1069 \\
\hline EUROPEAN JOURNAL OF OPHTHALMOLOGY & 3 & 0,0001 & $\odot, 97$ & 1070 \\
\hline EUROPEAN JOURNAL OF PEDIATRICS & 3 & 0,0001 & 0,97 & 1071 \\
\hline EUROPEAN JOURNAL OF PHARMACEUTICAL SCIENCES & 3 & 0,0001 & 0,97 & 1072 \\
\hline EUROPEAN NEUROLOGY & 3 & 0,0001 & 0,97 & 1073 \\
\hline EXPERIMENTAL AND CLINICAL ENDOCRINOLOGY & 3 & 0,0001 & 0,97 & 1074 \\
\hline EXPERIMENTAL AND CLINICAL IMMUNOGENETICS & 3 & 0,0001 & 0,97 & 1075 \\
\hline EXPERIMENTAL PHYSIOLOGY & 3 & 0,0001 & 0,97 & 1076 \\
\hline FUNDAMENTAL \& CLINICAL PHARMACOLOGY & 3 & 0,0001 & $\odot, 97$ & 1077 \\
\hline FUNGAL GENETICS AND BIOLOGY & 3 & 0,0001 & 0,97 & 1078 \\
\hline GLOBAL ENVIRONMENTAL CHANGE-HUMAN AND POLICY DIMENSIONS & 3 & 0,0001 & 0,97 & 1079 \\
\hline GYNECOLOGICAL ENDOCRINOLOGY & 3 & 0,0001 & $\odot, 97$ & 1080 \\
\hline HAEMOSTASIS & 3 & 0,0001 & 0,97 & 1081 \\
\hline HEALTH POLICY & 3 & 0,0001 & 0,97 & 1082 \\
\hline HORMONE RESEARCH & 3 & 0,0001 & 0,97 & 1083 \\
\hline HUMAN GENE THERAPY & 3 & 0,0001 & 0,97 & 1084 \\
\hline HUMAN PSYCHOPHARMACOLOGY-CLINICAL AND EXPERIMENTAL & 3 & 0,0001 & 0,97 & 1085 \\
\hline IMMUNOLOGICAL REVIEWS & 3 & 0,0001 & 0,97 & 1086 \\
\hline IN VITRO CELLULAR \& DEVELOPMENTAL BIOLOGY-ANIMAL & 3 & 0,0001 & 0,97 & 1087 \\
\hline INDUSTRIE ALIMENTARI & 3 & 0,0001 & 0,97 & 1088 \\
\hline INTERNATIONAL JOURNAL OF BIOMETEOROLOGY & 3 & 0,0001 & 0,97 & 1089 \\
\hline INTERNATIONAL JOURNAL OF FOOD SCIENCES AND NUTRITION & 3 & 0,0001 & 0,97 & 1090 \\
\hline
\end{tabular}




\begin{tabular}{|c|c|c|c|c|}
\hline INTERNATIONAL JOURNAL OF GERIATRIC PSYCHIATRY & 3 & 0,0001 & 0,97 & 1091 \\
\hline INTERNATIONAL JOURNAL OF MEDICAL INFORMATICS & 3 & 0,0001 & 0,97 & 1092 \\
\hline INTERNATIONAL JOURNAL OF PEDIATRIC HEMATOLOGY/ONCOLOGY & 3 & 0,0001 & 0,97 & 1093 \\
\hline INTERNATIONAL JOURNAL OF SOCIAL PSYCHIATRY & 3 & 0,0001 & 0,97 & 1094 \\
\hline INTERNATIONAL OPHTHALMOLOGY CLINICS & 3 & 0,0001 & 0,97 & 1095 \\
\hline JAPANESE HEART JOURNAL & 3 & 0,0001 & 0,97 & 1096 \\
\hline JCR-JOURNAL OF CLINICAL RHEUMATOLOGY & 3 & 0,0001 & 0,97 & 1097 \\
\hline JOURNAL FUR PRAKTISCHE CHEMIE-CHEMIKER-ZEITUNG & 3 & 0,0001 & 0,97 & 1098 \\
\hline JOURNAL OF AAPOS & 3 & 0,0001 & $\odot, 97$ & 1099 \\
\hline JOURNAL OF ANDROLOGY & 3 & 0,0001 & 0,97 & 1100 \\
\hline JOURNAL OF AUTISM AND DEVELOPMENTAL DISORDERS & 3 & 0,0001 & 0,97 & 1101 \\
\hline JOURNAL OF BIOSCIENCE AND BIOENGINEERING & 3 & 0,0001 & 0,97 & 1102 \\
\hline JOURNAL OF CANCER RESEARCH AND CLINICAL ONCOLOGY & 3 & 0,0001 & 0,97 & 1103 \\
\hline JOURNAL OF CLINICAL ANESTHESIA & 3 & 0,0001 & 0,97 & 1104 \\
\hline JOURNAL OF CLINICAL PHARMACY AND THERAPEUTICS & 3 & 0,0001 & 0,97 & 1105 \\
\hline JOURNAL OF COMPARATIVE PHYSIOLOGY A-SENSORY NEURAL ANDBEHAVI & 3 & 0,0001 & 0,97 & 1106 \\
\hline JOURNAL OF COMPUTATIONAL BIOLOGY & 3 & 0,0001 & 0,97 & 1107 \\
\hline JOURNAL OF COMPUTER-AIDED MOLECULAR DESIGN & 3 & 0,0001 & 0,97 & 1108 \\
\hline JOURNAL OF CRANIO-MAXILLOFACIAL SURGERY & 3 & 0,0001 & $\odot, 97$ & 1109 \\
\hline JOURNAL OF DIGITAL IMAGING & 3 & 0,0001 & 0,97 & 1110 \\
\hline JOURNAL OF ENTOMOLOGICAL SCIENCE & 3 & 0,0001 & 0,97 & 1111 \\
\hline JOURNAL OF EXPERIMENTAL \& CLINICAL CANCER RESEARCH & 3 & 0,0001 & 0,97 & 1112 \\
\hline JOURNAL OF EXPERIMENTAL PSYCHOLOGY-HUMAN PERCEPTION AND PERF & 3 & 0,0001 & 0,97 & 1113 \\
\hline JOURNAL OF INTERVENTIONAL CARDIAC ELECTROPHYSIOLOGY & 3 & 0,0001 & 0,97 & 1114 \\
\hline JOURNAL OF MATHEMATICAL CHEMISTRY & 3 & 0,0001 & 0,97 & 1115 \\
\hline JOURNAL OF MOLECULAR MODELING & 3 & 0,0001 & $\odot, 97$ & 1116 \\
\hline JOURNAL OF NEUROENDOCRINOLOGY & 3 & 0,0001 & 0,97 & 1117 \\
\hline JOURNAL OF NEUROGENETICS & 3 & 0,0001 & 0,97 & 1118 \\
\hline JOURNAL OF NUCLEAR CARDIOLOGY & 3 & $0,0 \odot \odot 1$ & 0,97 & 1119 \\
\hline JOURNAL OF PHYSIOLOGY-PARIS & 3 & 0,0001 & $\odot, 97$ & 1120 \\
\hline JOURNAL OF PUBLIC HEALTH DENTISTRY & 3 & 0,0001 & 0,97 & 1121 \\
\hline JOURNAL OF REPRODUCTIVE IMMUNOLOGY & 3 & 0,0001 & $\odot, 97$ & 1122 \\
\hline JOURNAL OF SEX RESEARCH & 3 & 0,0001 & $\odot, 97$ & 1123 \\
\hline JOURNAL OF SLEEP RESEARCH & 3 & 0,0001 & 0,97 & 1124 \\
\hline JOURNAL OF STEROID BIOCHEMISTRY AND MOLECULAR BIOLOGY & 3 & 0,0001 & 0,97 & 1125 \\
\hline JOURNAL OF THE AIR \& WASTE MANAGEMENT ASSOCIATION & 3 & 0,0001 & 0,97 & 1126 \\
\hline JOURNAL OF THE ROYAL SOCIETY OF MEDICINE & 3 & 0,0001 & 0,97 & 1127 \\
\hline JOURNAL OF VASCULAR AND INTERVENTIONAL RADIOLOGY & 3 & 0,0001 & 0,97 & 1128 \\
\hline JOURNAL OF VECTOR ECOLOGY & 3 & 0,0001 & 0,97 & 1129 \\
\hline JOURNAL OF VIRAL HEPATITIS & 3 & 0,0001 & 0,97 & 1130 \\
\hline LAIT & 3 & 0,0001 & 0,97 & 1131 \\
\hline LASERS IN MEDICAL SCIENCE & 3 & 0,0001 & 0,97 & 1132 \\
\hline LUMINESCENCE & 3 & 0,0001 & 0,97 & 1133 \\
\hline LUNG CANCER & 3 & 0,0001 & 0,97 & 1134 \\
\hline M D COMPUTING & 3 & 0,0001 & 0,97 & 1135 \\
\hline MAGNETIC RESONANCE IN MEDICINE & 3 & 0,0001 & $\odot, 97$ & 1136 \\
\hline MAMMALIAN GENOME & 3 & 0,0001 & 0,97 & 1137 \\
\hline MECHANISMS OF DEVELOPMENT & 3 & 0,0001 & 0,97 & 1138 \\
\hline MICROBIOLOGICA & 3 & 0,0001 & 0,97 & 1139 \\
\hline MICROVASCULAR RESEARCH & 3 & 0,0001 & 0,97 & 1140 \\
\hline MILCHWISSENSCHAFT-MILK SCIENCE INTERNATIONAL & 3 & 0,0001 & 0,97 & 1141 \\
\hline MOLECULAR HUMAN REPRODUCTION & 3 & 0,0001 & 0,97 & 1142 \\
\hline MOLECULAR REPRODUCTION AND DEVELOPMENT & 3 & 0,0001 & $\odot, 97$ & 1143 \\
\hline MUTATION RESEARCH-REVIEWS IN MUTATION RESEARCH & 3 & 0,0001 & 0,97 & 1144 \\
\hline NEURAL COMPUTATION & 3 & 0,0001 & 0,97 & 1145 \\
\hline NEUROGASTROENTEROLOGY AND MOTILITY & 3 & 0,0001 & $\odot, 97$ & 1146 \\
\hline NEUROLOGICAL RESEARCH & 3 & 0,0001 & 0,97 & 1147 \\
\hline ORYX & 3 & 0,0001 & 0,97 & 1148 \\
\hline PANMINERVA MEDICA & 3 & 0,0001 & 0,97 & 1149 \\
\hline PATHOLOGY & 3 & 0,0001 & $\odot, 97$ & 1150 \\
\hline PHARMACOGENETICS & 3 & 0,0001 & 0,97 & 1151 \\
\hline PHARMACOLOGY \& TOXICOLOGY & 3 & 0,0001 & 0,97 & 1152 \\
\hline PHYSICAL THERAPY & 3 & 0,0001 & 0,98 & 1153 \\
\hline PLACENTA & 3 & 0,0001 & 0,98 & 1154 \\
\hline PROGRESS IN RETINAL AND EYE RESEARCH & 3 & 0,0001 & 0,98 & 1155 \\
\hline PSYCHIATRY AND CLINICAL NEUROSCIENCES & 3 & 0,0001 & 0,98 & 1156 \\
\hline PSYCHIATRY RESEARCH-NEUROIMAGING & 3 & 0,0001 & 0,98 & 1157 \\
\hline PSYCHOLOGICAL MEDICINE & 3 & 0,0001 & 0,98 & 1158 \\
\hline PSYCHOSOMATIC MEDICINE & 3 & 0,0001 & 0,98 & 1159 \\
\hline QUALITY OF LIFE RESEARCH & 3 & 0,0001 & 0,98 & 1160 \\
\hline RESEARCH QUARTERLY FOR EXERCISE AND SPORT & 3 & 0,0001 & 0,98 & 1161 \\
\hline RESOURCES CONSERVATION AND RECYCLING & 3 & 0,0001 & 0,98 & 1162 \\
\hline RHEUMATIC DISEASE CLINICS OF NORTH AMERICA & 3 & 0,0001 & 0,98 & 1163 \\
\hline
\end{tabular}




\begin{tabular}{|c|c|c|c|c|}
\hline RNA-A PUBLICATION OF THE RNA SOCIETY & 3 & 0,0001 & 0,98 & 1164 \\
\hline SALUD MENTAL & 3 & 0,0001 & 0,98 & 1165 \\
\hline SARSIA & 3 & 0,0001 & 0,98 & 1166 \\
\hline SCIENCES DES ALIMENTS & 3 & 0,0001 & 0,98 & 1167 \\
\hline SEMINARS IN CANCER BIOLOGY & 3 & 0,0001 & 0,98 & 1168 \\
\hline SEXUALLY TRANSMITTED INFECTIONS & 3 & 0,0001 & 0,98 & 1169 \\
\hline SKULL BASE SURGERY & 3 & 0,0001 & 0,98 & 1170 \\
\hline SOIL TECHNOLOGY & 3 & 0,0001 & 0,98 & 1171 \\
\hline SOUTHERN MEDICAL JOURNAL & 3 & 0,0001 & 0,98 & 1172 \\
\hline SPORTS MEDICINE & 3 & 0,0001 & 0,98 & 1173 \\
\hline STARCH-STARKE & 3 & 0,0001 & 0,98 & 1174 \\
\hline STP PHARMA SCIENCES & 3 & 0,0001 & 0,98 & 1175 \\
\hline THERAPIE & 3 & 0,0001 & 0,98 & 1176 \\
\hline TRANSFUSION SCIENCE & 3 & 0,0001 & 0,98 & 1177 \\
\hline UROLOGIC CLINICS OF NORTH AMERICA & 3 & 0,0001 & 0,98 & 1178 \\
\hline UROLOGICAL RESEARCH & 3 & 0,0001 & 0,98 & 1179 \\
\hline VIE ET MILIEU-LIFE AND ENVIRONMENT & 3 & 0,0001 & 0,98 & 1180 \\
\hline WASTE MANAGEMENT & 3 & 0,0001 & 0,98 & 1181 \\
\hline ABDOMINAL IMAGING & 2 & 0,0001 & 0,98 & 1182 \\
\hline ACTA ANAESTHESIOLOGICA SCANDINAVICA & 2 & 0,0001 & 0,98 & 1183 \\
\hline ACTA NEUROLOGICA BELGICA & 2 & 0,0001 & 0,98 & 1184 \\
\hline ADOLESCENCE & 2 & 0,0001 & 0,98 & 1185 \\
\hline AIDS CARE-PSYCHOLOGICAL AND SOCIO-MEDICAL ASPECTS OF AIDS/HI & 2 & 0,0001 & 0,98 & 1186 \\
\hline AKTUELLE UROLOGIE & 2 & 0,0001 & 0,98 & 1187 \\
\hline AMERICAN JOURNAL OF PSYCHIATRY & 2 & 0,0001 & 0,98 & 1188 \\
\hline AMERICAN JOURNAL OF REPRODUCTIVE IMMUNOLOGY & 2 & 0,0001 & 0,98 & 1189 \\
\hline AMERICAN JOURNAL OF THE MEDICAL SCIENCES & 2 & 0,0001 & 0,98 & 1190 \\
\hline AMYLOID-INTERNATIONAL JOURNAL OF EXPERIMENTAL AND CLINICAL I & 2 & 0,0001 & 0,98 & 1191 \\
\hline ANAESTHESIA AND INTENSIVE CARE & 2 & 0,0001 & 0,98 & 1192 \\
\hline ANNALES DE PATHOLOGIE & 2 & 0,0001 & 0,98 & 1193 \\
\hline ANNALS OF EMERGENCY MEDICINE & 2 & 0,0001 & 0,98 & 1194 \\
\hline ANNALS OF MEDICINE & 2 & 0,0001 & 0,98 & 1195 \\
\hline ANNALS OF SURGICAL ONCOLOGY & 2 & 0,0001 & 0,98 & 1196 \\
\hline ANNUAL REVIEW OF MICROBIOLOGY & 2 & 0,0001 & 0,98 & 1197 \\
\hline ANTI-CANCER DRUGS & 2 & 0,0001 & 0,98 & 1198 \\
\hline ARCHIVES OF ANDROLOGY & 2 & 0,0001 & 0,98 & 1199 \\
\hline ARCHIVES OF DERMATOLOGICAL RESEARCH & 2 & 0,0001 & 0,98 & 1200 \\
\hline ARCHIVES OF SEXUAL BEHAVIOR & 2 & 0,0001 & 0,98 & 1201 \\
\hline ARTERIOSCLEROSIS THROMBOSIS AND VASCULAR BIOLOGY & 2 & 0,0001 & 0,98 & 1202 \\
\hline AUDIOLOGY & 2 & 0,0001 & 0,98 & 1203 \\
\hline AUSTRALIAN AND NEW ZEALAND JOURNAL OF PSYCHIATRY & 2 & 0,0001 & 0,98 & 1204 \\
\hline AUSTRALIAN JOURNAL OF ENTOMOLOGY & 2 & 0,0001 & 0,98 & 1205 \\
\hline BIOCHIMICA ET BIOPHYSICA ACTA-BIOENERGETICSFatty acid cyclin & 2 & 0,0001 & 0,98 & 1206 \\
\hline BIOCYCLE & 2 & 0,0001 & 0,98 & 1207 \\
\hline BIOESSAYS & 2 & 0,0001 & 0,98 & 1208 \\
\hline BIOETHICS & 2 & 0,0001 & 0,98 & 1209 \\
\hline BIOPHARMACEUTICS \& DRUG DISPOSITION & 2 & 0,0001 & 0,98 & 1210 \\
\hline BIRTH-ISSUES IN PERINATAL CARE & 2 & 0,0001 & 0,98 & 1211 \\
\hline BRAIN AND LANGUAGE & 2 & 0,0001 & 0,98 & 1212 \\
\hline BRAIN INJURY & 2 & 0,0001 & 0,98 & 1213 \\
\hline BRITISH JOURNAL OF GENERAL PRACTICE & 2 & 0,0001 & 0,98 & 1214 \\
\hline BRITISH MEDICAL BULLETIN & 2 & 0,0001 & 0,98 & 1215 \\
\hline CAHIERS DE PSYCHOLOGIE COGNITIVE-CURRENT PSYCHOLOGY OFCOGNIT & 2 & 0,0001 & 0,98 & 1216 \\
\hline CANADIAN ENTOMOLOGIST & 2 & 0,0001 & 0,98 & 1217 \\
\hline CANADIAN JOURNAL OF GASTROENTEROLOGY & 2 & 0,0001 & 0,98 & 1218 \\
\hline CANCER JOURNAL & 2 & 0,0001 & 0,98 & 1219 \\
\hline CANCER NURSING & 2 & 0,0001 & 0,98 & 1220 \\
\hline CELL & 2 & 0,0001 & 0,98 & 1221 \\
\hline CELL ADHESION AND COMMUNICATION & 2 & 0,0001 & 0,98 & 1222 \\
\hline CELLULAR AND MOLECULAR LIFE SCIENCES & 2 & 0,0001 & 0,98 & 1223 \\
\hline CHEMICAL REVIEWS & 2 & 0,0001 & 0,98 & 1224 \\
\hline CHEMICKE LISTY & 2 & 0,0001 & 0,98 & 1225 \\
\hline CHEMISTRY \& INDUSTRY & 2 & 0,0001 & 0,98 & 1226 \\
\hline CHEMISTRY LETTERS & 2 & 0,0001 & 0,98 & 1227 \\
\hline CHILD CARE HEALTH AND DEVELOPMENT & 2 & 0,0001 & 0,98 & 1228 \\
\hline CLINICAL ANATOMY & 2 & 0,0001 & 0,98 & 1229 \\
\hline CLINICAL BIOCHEMISTRY & 2 & 0,0001 & 0,98 & 1230 \\
\hline CLINICAL OBSTETRICS AND GYNECOLOGY & 2 & 0,0001 & 0,98 & 1231 \\
\hline CLINICAL THERAPEUTICS & 2 & 0,0001 & 0,98 & 1232 \\
\hline CNS DRUGS & 2 & 0,0001 & 0,98 & 1233 \\
\hline CRITICAL REVIEWS IN BIOTECHNOLOGY & 2 & 0,0001 & 0,98 & 1234 \\
\hline CROATIAN MEDICAL JOURNAL & 2 & 0,0001 & 0,98 & 1235 \\
\hline CRYO-LETTERS & 2 & 0,0001 & 0,98 & 1236 \\
\hline
\end{tabular}




\begin{tabular}{|c|c|c|c|c|}
\hline CURRENT MEDICINAL CHEMISTRY & 2 & 0,0001 & 0,98 & 1237 \\
\hline CURRENT OPINION IN MICROBIOLOGY & 2 & 0,0001 & 0,98 & 1238 \\
\hline DEMENTIA AND GERIATRIC COGNITIVE DISORDERS & 2 & 0,0001 & 0,98 & 1239 \\
\hline DEPRESSION AND ANXIETY & 2 & 0,0001 & 0,98 & 1240 \\
\hline DERMATOLOGIC CLINICS & 2 & 0,0001 & 0,98 & 1241 \\
\hline DEVELOPMENTAL NEUROPSYCHOLOGY & 2 & $0,0 \odot \odot 1$ & 0,98 & 1242 \\
\hline DEVELOPMENTAL PSYCHOBIOLOGY & 2 & 0,0001 & 0,98 & 1243 \\
\hline DIABETES-METABOLISM RESEARCH AND REVIEWS & 2 & 0,0001 & 0,98 & 1244 \\
\hline DIAGNOSTIC MOLECULAR PATHOLOGY & 2 & 0,0001 & 0,98 & 1245 \\
\hline DISABILITY AND REHABILITATION & 2 & 0,0001 & 0,98 & 1246 \\
\hline DRUG AND ALCOHOL REVIEW & 2 & $0,0 \odot \odot 1$ & 0,98 & 1247 \\
\hline DRUGS \& AGING & 2 & 0,0001 & 0,98 & 1248 \\
\hline DYSPHAGIA & 2 & 0,0001 & 0,98 & 1249 \\
\hline EAST AFRICAN MEDICAL JOURNAL & 2 & 0,0001 & 0,98 & 1250 \\
\hline ECOLOGICAL RESEARCH & 2 & 0,0001 & 0,98 & 1251 \\
\hline ECOSCIENCE & 2 & 0,0001 & 0,98 & 1252 \\
\hline ENDOCRINE-RELATED CANCER & 2 & 0,0001 & 0,98 & 1253 \\
\hline ENDOCRINOLOGY AND METABOLISM CLINICS OF NORTH AMERICA & 2 & 0,0001 & 0,98 & 1254 \\
\hline ENDOCYTOBIOSIS AND CELL RESEARCH & 2 & 0,0001 & 0,98 & 1255 \\
\hline ENDOTHELIUM-NEW YORK & 2 & 0,0001 & 0,98 & 1256 \\
\hline ENVIRONMENT & 2 & 0,0001 & 0,98 & 1257 \\
\hline EUROPEAN CHILD \& ADOLESCENT PSYCHIATRY & 2 & $0,0 \odot \odot 1$ & 0,98 & 1258 \\
\hline EUROPEAN JOURNAL OF ENTOMOLOGY & 2 & 0,0001 & 0,98 & 1259 \\
\hline EUROPEAN JOURNAL OF GASTROENTEROLOGY \& HEPATOLOGY & 2 & 0,0001 & 0,98 & 1260 \\
\hline EUROPEAN JOURNAL OF HEART FAILURE & 2 & $0,0 \odot \odot 1$ & 0,98 & 1261 \\
\hline EUROPEAN JOURNAL OF HISTOCHEMISTRY & 2 & 0,0001 & 0,98 & 1262 \\
\hline EUROPEAN JOURNAL OF NEUROLOGY & 2 & 0,0001 & 0,98 & 1263 \\
\hline EUROPEAN JOURNAL OF PEDIATRIC SURGERY & 2 & 0,0001 & 0,98 & 1264 \\
\hline EUROPEAN JOURNAL OF SOIL BIOLOGY & 2 & $0,0 \odot \odot 1$ & 0,98 & 1265 \\
\hline EUROPEAN JOURNAL OF VASCULAR AND ENDOVASCULAR SURGERY & 2 & 0,0001 & 0,98 & 1266 \\
\hline EUROPEAN PSYCHIATRY & 2 & 0,0001 & 0,98 & 1267 \\
\hline EUROPEAN SURGICAL RESEARCH & 2 & 0,0001 & 0,98 & 1268 \\
\hline EVOLUTION AND HUMAN BEHAVIOR & 2 & 0,0001 & 0,98 & 1269 \\
\hline EVOLUTIONARY ECOLOGY & 2 & 0,0001 & 0,98 & 1270 \\
\hline EXPERIMENTAL AGING RESEARCH & 2 & 0,0001 & 0,98 & 1271 \\
\hline EXPERIMENTAL BRAIN RESEARCH & 2 & 0,0001 & 0,98 & 1272 \\
\hline EXPERIMENTAL CELL RESEARCH & 2 & 0,0001 & 0,98 & 1273 \\
\hline FAMILY PRACTICE & 2 & 0,0001 & 0,98 & 1274 \\
\hline FOOD AND AGRICULTURAL IMMUNOLOGY & 2 & $0,0 \odot \odot 1$ & 0,98 & 1275 \\
\hline FOOD BIOTECHNOLOGY & 2 & 0,0001 & 0,98 & 1276 \\
\hline FOOD REVIEWS INTERNATIONAL & 2 & 0,0001 & 0,98 & 1277 \\
\hline FOOD SCIENCE AND TECHNOLOGY INTERNATIONAL & 2 & 0,0001 & 0,98 & 1278 \\
\hline GENERAL AND COMPARATIVE ENDOCRINOLOGY & 2 & $0,0 \odot \odot 1$ & 0,98 & 1279 \\
\hline GENES CHROMOSOMES \& CANCER & 2 & $0,0 \odot 01$ & 0,98 & 1280 \\
\hline GENETICAL RESEARCH & 2 & 0,0001 & 0,98 & 1281 \\
\hline HEALTH PROMOTION INTERNATIONAL & 2 & 0,0001 & 0,98 & 1282 \\
\hline HETEROATOM CHEMISTRY & 2 & 0,0001 & 0,98 & 1283 \\
\hline HUMAN DEVELOPMENT & 2 & 0,0001 & 0,98 & 1284 \\
\hline HUMAN MOVEMENT SCIENCE & 2 & 0,0001 & 0,98 & 1285 \\
\hline HUMAN REPRODUCTION UPDATE & 2 & $0,0 \odot \odot 1$ & 0,98 & 1286 \\
\hline HUMOR-INTERNATIONAL JOURNAL OF HUMOR RESEARCH & 2 & 0,0001 & 0,98 & 1287 \\
\hline HYPERTENSION IN PREGNANCY & 2 & 0,0001 & 0,98 & 1288 \\
\hline IMMUNOGENETICS & 2 & 0,0001 & 0,98 & 1289 \\
\hline IMMUNOLOGY AND CELL BIOLOGY & 2 & 0,0001 & 0,98 & 1290 \\
\hline INFECTION & 2 & 0,0001 & 0,98 & 1291 \\
\hline INFECTIOUS DISEASES IN CLINICAL PRACTICE & 2 & 0,0001 & 0,98 & 1292 \\
\hline INTERNATIONAL DENTAL JOURNAL & 2 & 0,0001 & 0,98 & 1293 \\
\hline INTERNATIONAL JOURNAL OF LAW AND PSYCHIATRY & 2 & 0,0001 & 0,98 & 1294 \\
\hline INTERNATIONAL JOURNAL OF PANCREATOLOGY & 2 & 0,0001 & 0,98 & 1295 \\
\hline INTERNATIONAL JOURNAL OF PSYCHIATRY IN MEDICINE & 2 & 0,0001 & 0,98 & 1296 \\
\hline INTERNATIONAL JOURNAL OF SPORTS MEDICINE & 2 & 0,0001 & 0,98 & 1297 \\
\hline INTERNATIONAL JOURNAL OF TECHNOLOGY ASSESSMENT IN HEALTH CAR & 2 & 0,0001 & 0,98 & 1298 \\
\hline INTERNATIONAL OPHTHALMOLOGY & 2 & 0,0001 & 0,98 & 1299 \\
\hline ITALIAN JOURNAL OF GASTROENTEROLOGY AND HEPATOLOGY & 2 & 0,0001 & 0,98 & 1300 \\
\hline JAPANESE JOURNAL OF OPHTHALMOLOGY & 2 & $0,0 \odot \odot 1$ & 0,98 & 1301 \\
\hline JOURNAL DES MALADIES VASCULAIRES & 2 & 0,0001 & 0,98 & 1302 \\
\hline JOURNAL OF ADDICTIVE DISEASES & 2 & 0,0001 & 0,98 & 1303 \\
\hline JOURNAL OF ANALYTICAL PSYCHOLOGY & 2 & $0,0 \odot 01$ & 0,98 & 1304 \\
\hline JOURNAL OF ATMOSPHERIC CHEMISTRY & 2 & 0,0001 & 0,98 & 1305 \\
\hline JOURNAL OF BIOMEDICAL SCIENCE & 2 & 0,0001 & 0,98 & 1306 \\
\hline JOURNAL OF BIOSOCIAL SCIENCE & 2 & 0,0001 & 0,98 & 1307 \\
\hline JOURNAL OF BONE AND JOINT SURGERY-AMERICAN VOLUME & 2 & $0,0 \odot \odot 1$ & 0,98 & 1308 \\
\hline JOURNAL OF CARDIAC FAILURE & 2 & 0,0001 & 0,98 & 1309 \\
\hline
\end{tabular}




\begin{tabular}{|c|c|c|c|c|}
\hline JOURNAL OF CHEMICAL INFORMATION AND COMPUTER SCIENCES & 2 & 0,0001 & 0,98 & 1310 \\
\hline JOURNAL OF CLINICAL PSYCHOLOGY IN MEDICAL SETTINGS & 2 & 0,0001 & 0,98 & 1311 \\
\hline JOURNAL OF COMMUNICATION DISORDERS & 2 & 0,0001 & 0,98 & 1312 \\
\hline JOURNAL OF CONTAMINANT HYDROLOGY & 2 & 0,0001 & 0,98 & 1313 \\
\hline JOURNAL OF CREATIVE BEHAVIOR & 2 & 0,0001 & 0,98 & 1314 \\
\hline JOURNAL OF CUTANEOUS PATHOLOGY & 2 & 0,0001 & $\odot, 98$ & 1315 \\
\hline JOURNAL OF DAIRY RESEARCH & 2 & 0,0001 & 0,98 & 1316 \\
\hline JOURNAL OF ENVIRONMENTAL MANAGEMENT & 2 & $\odot, 0 \odot 01$ & 0,98 & 1317 \\
\hline JOURNAL OF ENZYME INHIBITION & 2 & $0,0 \odot \odot 1$ & 0,98 & 1318 \\
\hline JOURNAL OF EXPERIMENTAL CHILD PSYCHOLOGY & 2 & 0,0001 & 0,98 & 1319 \\
\hline JOURNAL OF GASTROINTESTINAL SURGERY & 2 & 0,0001 & 0,98 & 1320 \\
\hline JOURNAL OF HISTOCHEMISTRY \& CYTOCHEMISTRY & 2 & 0,0001 & 0,98 & 1321 \\
\hline JOURNAL OF HUMAN NUTRITION AND DIETETICS & 2 & $0,0 \odot \odot 1$ & 0,98 & 1322 \\
\hline JOURNAL OF INTERNAL MEDICINE & 2 & 0,0001 & 0,98 & 1323 \\
\hline JOURNAL OF LIPOSOME RESEARCH & 2 & 0,0001 & 0,98 & 1324 \\
\hline JOURNAL OF MUSCULOSKELETAL PAIN & 2 & 0,0001 & 0,98 & 1325 \\
\hline JOURNAL OF NEPHROLOGY & 2 & 0,0001 & 0,98 & 1326 \\
\hline JOURNAL OF NEURO-ONCOLOGY & 2 & 0,0001 & 0,98 & 1327 \\
\hline JOURNAL OF NEURORADIOLOGY & 2 & 0,0001 & 0,98 & 1328 \\
\hline JOURNAL OF NEUROTRAUMA & 2 & 0,0001 & 0,98 & 1329 \\
\hline JOURNAL OF NUTRITIONAL SCIENCE AND VITAMINOLOGY & 2 & 0,0001 & 0,99 & 1330 \\
\hline JOURNAL OF OTOLARYNGOLOGY & 2 & 0,0001 & 0,99 & 1331 \\
\hline JOURNAL OF PLANT NUTRITION AND SOIL SCIENCE-ZEITSCHRIFT FUR & 2 & $0,0 \odot \odot 1$ & 0,99 & 1332 \\
\hline JOURNAL OF PSYCHOLOGY & 2 & 0,0001 & 0,99 & 1333 \\
\hline JOURNAL OF PSYCHOLOGY AND THEOLOGY & 2 & 0,0001 & 0,99 & 1334 \\
\hline JOURNAL OF PSYCHOSOMATIC OBSTETRICS AND GYNECOLOGY & 2 & 0,0001 & 0,99 & 1335 \\
\hline JOURNAL OF SAFETY RESEARCH & 2 & 0,0001 & 0,99 & 1336 \\
\hline JOURNAL OF SHOULDER AND ELBOW SURGERY & 2 & 0,0001 & 0,99 & 1337 \\
\hline JOURNAL OF TELEMEDICINE AND TELECARE & 2 & 0,0001 & $\odot, 99$ & 1338 \\
\hline JOURNAL OF THE AMERICAN DENTAL ASSOCIATION & 2 & 0,0001 & 0,99 & 1339 \\
\hline JOURNAL OF THORACIC IMAGING & 2 & 0,0001 & 0,99 & 1340 \\
\hline JOURNAL OF THROMBOSIS AND THROMBOLYSIS & 2 & $0,0 \odot \odot 1$ & $\odot, 99$ & 1341 \\
\hline JOURNAL OF WOMENS HEALTH & 2 & 0,0001 & $\odot, 99$ & 1342 \\
\hline LIVER TRANSPLANTATION AND SURGERY & 2 & 0,0001 & 0,99 & 1343 \\
\hline MEDECINE ET MALADIES INFECTIEUSES & 2 & 0,0001 & 0,99 & 1344 \\
\hline MEDICINA-BUENOS AIRES & 2 & 0,0001 & 0,99 & 1345 \\
\hline MELANOMA RESEARCH & 2 & 0,0001 & 0,99 & 1346 \\
\hline MICROBIOLOGY-UK & 2 & 0,0001 & 0,99 & 1347 \\
\hline MICROBIOS & 2 & 0,0001 & 0,99 & 1348 \\
\hline MOLECULAR BIOLOGY REPORTS & 2 & 0,0001 & 0,99 & 1349 \\
\hline MOLECULAR CARCINOGENESIS & 2 & 0,0001 & 0,99 & 1350 \\
\hline MOLECULAR DIAGNOSIS & 2 & 0,0001 & 0,99 & 1351 \\
\hline MOLECULAR DIVERSITY & 2 & 0,0001 & 0,99 & 1352 \\
\hline MOLECULAR MEDICINE & 2 & 0,0001 & 0,99 & 1353 \\
\hline MULTIPLE SCLEROSIS & 2 & 0,0001 & 0,99 & 1354 \\
\hline NATURE BIOTECHNOLOGY & 2 & $0,0 \odot \odot 1$ & 0,99 & 1355 \\
\hline NERVENARZT & 2 & 0,0001 & 0,99 & 1356 \\
\hline NEUROBIOLOGY OF DISEASE & 2 & 0,0001 & 0,99 & 1357 \\
\hline NEUROEPIDEMIOLOGY & 2 & 0,0001 & 0,99 & 1358 \\
\hline NEUROPATHOLOGY AND APPLIED NEUROBIOLOGY & 2 & 0,0001 & 0,99 & 1359 \\
\hline NEUROPSYCHOPHARMACOLOGY & 2 & $0,0 \odot \odot 1$ & 0,99 & 1360 \\
\hline NEW ZEALAND MEDICAL JOURNAL & 2 & 0,0001 & 0,99 & 1361 \\
\hline NORDIC JOURNAL OF PSYCHIATRY & 2 & 0,0001 & 0,99 & 1362 \\
\hline OCCUPATIONAL THERAPY JOURNAL OF RESEARCH & 2 & 0,0001 & 0,99 & 1363 \\
\hline OCL-OLEAGINEUX CORPS GRAS LIPIDES & 2 & 0,0001 & 0,99 & 1364 \\
\hline ONCOLOGY & 2 & 0,0001 & 0,99 & 1365 \\
\hline ORTHOPEDICS & 2 & 0,0001 & 0,99 & 1366 \\
\hline PATHOLOGE & 2 & 0,0001 & 0,99 & 1367 \\
\hline PATHOLOGY INTERNATIONAL & 2 & 0,0001 & 0,99 & 1368 \\
\hline PATIENT EDUCATION AND COUNSELING & 2 & 0,0001 & $\odot, 99$ & 1369 \\
\hline PEDIATRIC NEUROSURGERY & 2 & 0,0001 & 0,99 & 1370 \\
\hline PERCEPTION \& PSYCHOPHYSICS & 2 & 0,0001 & 0,99 & 1371 \\
\hline PHARMACOECONOMICS & 2 & 0,0001 & 0,99 & 1372 \\
\hline PHARMACOEPIDEMIOLOGY AND DRUG SAFETY & 2 & 0,0001 & 0,99 & 1373 \\
\hline PHYSIOLOGICAL MEASUREMENT & 2 & $0,0 \odot \odot 1$ & 0,99 & 1374 \\
\hline PLANTA MEDICA & 2 & 0,0001 & 0,99 & 1375 \\
\hline PROSTAGLANDINS LEUKOTRIENES AND ESSENTIAL FATTY ACIDS & 2 & 0,0001 & 0,99 & 1376 \\
\hline PROSTATE CANCER AND PROSTATIC DISEASES & 2 & 0,0001 & 0,99 & 1377 \\
\hline PSICOLOGIA CONDUCTUAL & 2 & 0,0001 & 0,99 & 1378 \\
\hline PSICOTHEMA & 2 & 0,0001 & $\odot, 99$ & 1379 \\
\hline PSYCHIATRIC SERVICES & 2 & 0,0001 & 0,99 & 1380 \\
\hline PSYCHONEUROENDOCRINOLOGY & 2 & 0,0001 & 0,99 & 1381 \\
\hline PSYCHONOMIC BULLETIN \& REVIEW & 2 & 0,0001 & 0,99 & 1382 \\
\hline
\end{tabular}




\begin{tabular}{|c|c|c|c|c|}
\hline PSYCHOSOMATICS & 2 & 0,0001 & 0,99 & 1383 \\
\hline PSYCHOTHERAPY AND PSYCHOSOMATICS & 2 & $\odot, 0001$ & 0,99 & 1384 \\
\hline QUALITATIVE HEALTH RESEARCH & 2 & 0,0001 & 0,99 & 1385 \\
\hline QUARTERLY JOURNAL OF NUCLEAR MEDICINE & 2 & 0,0001 & 0,99 & 1386 \\
\hline QUARTERLY REVIEWS OF BIOPHYSICS & 2 & 0,0001 & 0,99 & 1387 \\
\hline RADIOTHERAPY AND ONCOLOGY & 2 & 0,0001 & 0,99 & 1388 \\
\hline REGULATORY TOXICOLOGY AND PHARMACOLOGY & 2 & 0,0001 & 0,99 & 1389 \\
\hline RESEARCH IN EXPERIMENTAL MEDICINE & 2 & 0,0001 & 0,99 & 1390 \\
\hline RESPIRATION & 2 & 0,0001 & 0,99 & 1391 \\
\hline RESUSCITATION & 2 & 0,0001 & 0,99 & 1392 \\
\hline REVISTA MEXICANA DE PSICOLOGIA & 2 & 0,0001 & 0,99 & 1393 \\
\hline REVUE DE MEDECINE INTERNE & 2 & 0,0001 & 0,99 & 1394 \\
\hline RHEUMATOLOGY INTERNATIONAL & 2 & 0,0001 & 0,99 & 1395 \\
\hline RUSSIAN CHEMICAL BULLETIN & 2 & 0,0001 & 0,99 & 1396 \\
\hline SCANDINAVIAN JOURNAL OF CLINICAL \& LABORATORY INVESTIGATION & 2 & 0,0001 & 0,99 & 1397 \\
\hline SEMINARS IN ARTHRITIS AND RHEUMATISM & 2 & 0,0001 & 0,99 & 1398 \\
\hline SEMINARS IN RESPIRATORY AND CRITICAL CARE MEDICINE & 2 & 0,0001 & 0,99 & 1399 \\
\hline SEMINARS IN ROENTGENOLOGY & 2 & 0,0001 & 0,99 & 1400 \\
\hline SEMINARS IN THROMBOSIS AND HEMOSTASIS & 2 & 0,0001 & 0,99 & 1401 \\
\hline SEX ROLES & 2 & 0,0001 & 0,99 & 1402 \\
\hline SOLVENT EXTRACTION AND ION EXCHANGE & 2 & 0,0001 & 0,99 & 1403 \\
\hline STEROIDS & 2 & 0,0001 & 0,99 & 1404 \\
\hline SURVEY OF OPHTHALMOLOGY & 2 & 0,0001 & 0,99 & 1405 \\
\hline SYNAPSE & 2 & 0,0001 & 0,99 & 1406 \\
\hline SYSTEMATIC ENTOMOLOGY & 2 & 0,0001 & 0,99 & 1407 \\
\hline THORACIC AND CARDIOVASCULAR SURGEON & 2 & 0,0001 & 0,99 & 1408 \\
\hline TOBACCO CONTROL & 2 & 0,0001 & 0,99 & 1409 \\
\hline TOXICOLOGY IN VITRO & 2 & 0,0001 & 0,99 & 1410 \\
\hline TRANSFUSION CLINIQUE ET BIOLOGIQUE & 2 & 0,0001 & 0,99 & 1411 \\
\hline TRANSFUSION MEDICINE & 2 & 0,0001 & 0,99 & 1412 \\
\hline TRANSGENIC RESEARCH & 2 & 0,0001 & 0,99 & 1413 \\
\hline TRANSPLANT IMMUNOLOGY & 2 & 0,0001 & 0,99 & 1414 \\
\hline TRENDS IN FOOD SCIENCE \& TECHNOLOGY & 2 & 0,0001 & 0,99 & 1415 \\
\hline UROLOGIA INTERNATIONALIS & 2 & 0,0001 & 0,99 & 1416 \\
\hline VASCULAR SURGERY & 2 & 0,0001 & 0,99 & 1417 \\
\hline VISUAL NEUROSCIENCE & 2 & 0,0001 & 0,99 & 1418 \\
\hline WETLANDS & 2 & 0,0001 & 0,99 & 1419 \\
\hline WILDLIFE SOCIETY BULLETIN & 2 & 0,0001 & 0,99 & 1420 \\
\hline ZENTRALBLATT FUR CHIRURGIE & 2 & 0,0001 & 0,99 & 1421 \\
\hline ACAROLOGIA & 1 & 0,0000 & 0,99 & 1422 \\
\hline ACTA ANATOMICA & 1 & 0,0000 & 0,99 & 1423 \\
\hline ACTA BIOCHIMICA POLONICA & 1 & 0,0000 & 0,99 & 1424 \\
\hline ACTA BIOLOGICA HUNGARICA & 1 & 0,0000 & 0,99 & 1425 \\
\hline ACTA CHEMICA SCANDINAVICA & 1 & 0,0000 & 0,99 & 1426 \\
\hline ACTA CHIRURGICA BELGICA & 1 & 0,0000 & 0,99 & 1427 \\
\hline ACTA HYDROCHIMICA ET HYDROBIOLOGICA & 1 & 0,0000 & 0,99 & 1428 \\
\hline ACTA NEUROBIOLOGIAE EXPERIMENTALIS & 1 & 0,0000 & 0,99 & 1429 \\
\hline ACTA PARASITOLOGICA & 1 & 0,0000 & 0,99 & 1430 \\
\hline ADDICTIVE BEHAVIORS & 1 & 0,0000 & 0,99 & 1431 \\
\hline ADVANCES IN NURSING SCIENCE & 1 & 0,0000 & 0,99 & 1432 \\
\hline ADVANCES IN THERAPY & 1 & 0,0000 & 0,99 & 1433 \\
\hline AGE & 1 & 0,0000 & 0,99 & 1434 \\
\hline AGGRESSIVE BEHAVIOR & 1 & 0,0000 & 0,99 & 1435 \\
\hline ALIMENTARY PHARMACOLOGY \& THERAPEUTICS & 1 & 0,0000 & 0,99 & 1436 \\
\hline ALLERGY AND ASTHMA PROCEEDINGS & 1 & 0,0000 & 0,99 & 1437 \\
\hline ALZHEIMER DISEASE \& ASSOCIATED DISORDERS & 1 & 0,0000 & 0,99 & 1438 \\
\hline AMERICAN ANNALS OF THE DEAF & 1 & 0,0000 & 0,99 & 1439 \\
\hline AMERICAN JOURNAL OF CHINESE MEDICINE & 1 & 0,0000 & 0,99 & 1440 \\
\hline AMERICAN JOURNAL OF CLINICAL NUTRITIONNutritional proteic-en & 1 & 0,0000 & 0,99 & 1441 \\
\hline AMERICAN JOURNAL OF DRUG AND ALCOHOL ABUSE & 1 & 0,0000 & 0,99 & 1442 \\
\hline AMERICAN JOURNAL OF GERIATRIC PSYCHIATRY & 1 & 0,0000 & 0,99 & 1443 \\
\hline AMERICAN JOURNAL OF HEALTH-SYSTEM PHARMACY & 1 & 0,0000 & 0,99 & 1444 \\
\hline AMERICAN JOURNAL OF HEALTH BEHAVIOR & 1 & 0,0000 & 0,99 & 1445 \\
\hline AMERICAN JOURNAL OF OCCUPATIONAL THERAPY & 1 & 0,0000 & 0,99 & 1446 \\
\hline AMERICAN JOURNAL OF ORTHOPSYCHIATRY & 1 & 0,0000 & 0,99 & 1447 \\
\hline AMERICAN JOURNAL OF PERIODONTOLOGY & 1 & 0,0000 & 0,99 & 1448 \\
\hline AMERICAN JOURNAL OF PSYCHOLOGY & 1 & 0,0000 & 0,99 & 1449 \\
\hline AMERICAN JOURNAL OF SPORTS MEDICINE & 1 & 0,0000 & 0,99 & 1450 \\
\hline AMERICAN NATURALIST & 1 & 0,0000 & 0,99 & 1451 \\
\hline ANALES DE QUIMICA-INTERNATIONAL EDITION & 1 & 0,0000 & 0,99 & 1452 \\
\hline ANNALES D ENDOCRINOLOGIE & 1 & 0,0000 & 0,99 & 1453 \\
\hline ANNALS OF APPLIED BIOLOGY & 1 & 0,0000 & 0,99 & 1454 \\
\hline ANNALS OF CLINICAL AND LABORATORY SCIENCE & 1 & 0,0000 & 0,99 & 1455 \\
\hline
\end{tabular}




\begin{tabular}{|c|c|c|c|c|}
\hline ANNALS OF CLINICAL BIOCHEMISTRY & 1 & 0,0000 & 0,99 & 1456 \\
\hline ANNALS OF PHARMACOTHERAPY & 1 & 0,0000 & 0,99 & 1457 \\
\hline ANNUAL REVIEW OF BIOPHYSICS AND BIOMOLECULAR STRUCTURE & 1 & 0,0000 & 0,99 & 1458 \\
\hline ANTI-CANCER DRUG DESIGN & 1 & 0,0000 & 0,99 & 1459 \\
\hline ANTIVIRAL RESEARCH & 1 & 0,0000 & 0,99 & 1460 \\
\hline APOPTOSIS & 1 & 0,0000 & 0,99 & 1461 \\
\hline APPLIED ERGONOMICS & 1 & 0,0000 & 0,99 & 1462 \\
\hline ARCHIVES OF ENVIRONMENTAL HEALTH & 1 & 0,0000 & 0,99 & 1463 \\
\hline ARCHIVES OF OTOLARYNGOLOGY-HEAD \& NECK SURGERY & 1 & 0,0000 & 0,99 & 1464 \\
\hline ARCHIVES OF SURGERY & 1 & 0,0000 & 0,99 & 1465 \\
\hline ARCHIVES OF TOXICOLOGY & 1 & 0,0000 & 0,99 & 1466 \\
\hline ARID SOIL RESEARCH AND REHABILITATION & 1 & 0,0000 & 0,99 & 1467 \\
\hline ASAIO JOURNAL & 1 & 0,0000 & 0,99 & 1468 \\
\hline AUDIOLOGY AND NEURO-OTOLOGY & 1 & 0,0000 & 0,99 & 1469 \\
\hline AUSTRALIAN AND NEW ZEALAND JOURNAL OF MEDICINE & 1 & 0,0000 & 0,99 & 1470 \\
\hline AUTOIMMUNITY & 1 & 0,0000 & 0,99 & 1471 \\
\hline BEHAVIORAL MEDICINE & 1 & 0,0000 & 0,99 & 1472 \\
\hline BEHAVIOUR \& INFORMATION TECHNOLOGY & 1 & 0,0000 & 0,99 & 1473 \\
\hline BEST PRACTICE \& RESEARCH IN CLINICAL RHEUMATOLOGY & 1 & 0,0000 & 0,99 & 1474 \\
\hline BIODEGRADATION & 1 & 0,0000 & 0,99 & 1475 \\
\hline BIODRUGS & 1 & 0,0000 & 0,99 & 1476 \\
\hline BIOFIZIKA & 1 & 0,0000 & 0,99 & 1477 \\
\hline BIOLOGICHESKIE MEMBRANY & 1 & 0,0000 & 0,99 & 1478 \\
\hline BIOMARKERS & 1 & 0,0000 & 0,99 & 1479 \\
\hline BIOMEDICAL CHROMATOGRAPHY & 1 & 0,0000 & 0,99 & 1480 \\
\hline BIOMEDICINE \& PHARMACOTHERAPY & 1 & 0,0000 & 0,99 & 1481 \\
\hline BIOMEDIZINISCHE TECHNIK & 1 & 0,0000 & 0,99 & 1482 \\
\hline BIOORGANIC CHEMISTRY & 1 & 0,0000 & 0,99 & 1483 \\
\hline BIORHEOLOGY & 1 & 0,0000 & 0,99 & 1484 \\
\hline BIOSPECTROSCOPY & 1 & 0,0000 & 0,99 & 1485 \\
\hline BIOTECHNIC \& HISTOCHEMISTRY & 1 & 0,0000 & 0,99 & 1486 \\
\hline BIOTECHNOLOGY ADVANCES & 1 & 0,0000 & 0,99 & 1487 \\
\hline BRAIN \& DEVELOPMENT & 1 & 0,0000 & 0,99 & 1488 \\
\hline BRAIN TOPOGRAPHY & 1 & 0,0000 & 0,99 & 1489 \\
\hline BRITISH JOURNAL OF CLINICAL PSYCHOLOGY & 1 & 0,0000 & 0,99 & 1490 \\
\hline BRITISH JOURNAL OF NEUROSURGERY & 1 & 0,0000 & 0,99 & 1491 \\
\hline BRITISH JOURNAL OF ORAL \& MAXILLOFACIAL SURGERY & 1 & 0,0000 & 0,99 & 1492 \\
\hline BULLETIN OF THE AMERICAN MUSEUM OF NATURAL HISTORY & 1 & 0,0000 & 0,99 & 1493 \\
\hline BULLETIN OF THE HISTORY OF MEDICINE & 1 & 0,0000 & 0,99 & 1494 \\
\hline CAMBRIDGE QUARTERLY OF HEALTHCARE ETHICS & 1 & 0,0000 & 0,99 & 1495 \\
\hline CANADIAN ASSOCIATION OF RADIOLOGISTS JOURNAL-JOURNAL DE L AS & 1 & 0,0000 & 0,99 & 1496 \\
\hline CANADIAN JOURNAL OF NEUROLOGICAL SCIENCES & 1 & 0,0000 & 0,99 & 1497 \\
\hline CANADIAN JOURNAL OF PSYCHIATRY-REVUE CANADIENNE DE PSYCHIATR & 1 & 0,0000 & 0,99 & 1498 \\
\hline CANADIAN JOURNAL OF SURGERY & 1 & 0,0000 & 0,99 & 1499 \\
\hline CANCER BIOTHERAPY AND RADIOPHARMACEUTICALS & 1 & 0,0000 & 0,99 & 1500 \\
\hline CANCER CAUSES \& CONTROL & 1 & 0,0000 & 0,99 & 1501 \\
\hline CANCER CHEMOTHERAPY AND PHARMACOLOGY & 1 & 0,0000 & 0,99 & 1502 \\
\hline CANCER IMMUNOLOGY IMMUNOTHERAPY & 1 & 0,0000 & 0,99 & 1503 \\
\hline CANCER INVESTIGATION & 1 & 0,0000 & 0,99 & 1504 \\
\hline CANCER TREATMENT REVIEWS & 1 & 0,0000 & 0,99 & 1505 \\
\hline CATHETERIZATION AND CARDIOVASCULAR INTERVENTIONS & 1 & 0,0000 & 0,99 & 1506 \\
\hline CELL TRANSPLANTATION & 1 & 0,0000 & 0,99 & 1507 \\
\hline CELLULAR SIGNALLING & 1 & 0,0000 & 0,99 & 1508 \\
\hline CHEMICAL SOCIETY REVIEWS & 1 & 0,0000 & 0,99 & 1509 \\
\hline CHEMISTRY IN BRITAIN & 1 & 0,0000 & 0,99 & 1510 \\
\hline CHILD AND ADOLESCENT PSYCHIATRIC CLINICS OF NORTH AMERICA & 1 & 0,0000 & 0,99 & 1511 \\
\hline CHIMIA & 1 & 0,0000 & 0,99 & 1512 \\
\hline CHIRURG & 1 & 0,0000 & 0,99 & 1513 \\
\hline CLINICAL AND EXPERIMENTAL DERMATOLOGY & 1 & 0,0000 & 0,99 & 1514 \\
\hline CLINICAL ELECTROENCEPHALOGRAPHY & 1 & 0,0000 & 0,99 & 1515 \\
\hline CLINICAL HEMORHEOLOGY AND MICROCIRCULATION & 1 & 0,0000 & 0,99 & 1516 \\
\hline CLINICAL JOURNAL OF PAIN & 1 & 0,0000 & 0,99 & 1517 \\
\hline CLINICAL NEUROLOGY AND NEUROSURGERY & 1 & 0,0000 & 0,99 & 1518 \\
\hline CLINICAL NEUROPHARMACOLOGY & 1 & 0,0000 & 0,99 & 1519 \\
\hline CLINICAL RADIOLOGY & 1 & 0,0000 & 0,99 & 1520 \\
\hline CLINICS IN CHEST MEDICINE & 1 & 0,0000 & 0,99 & 1521 \\
\hline CLINICS IN LABORATORY MEDICINE & 1 & 0,0000 & 0,99 & 1522 \\
\hline COGNITION AND INSTRUCTION & 1 & 0,0000 & 0,99 & 1523 \\
\hline COGNITIVE SCIENCE & 1 & 0,0000 & 0,99 & 1524 \\
\hline COMPTES RENDUS DE L ACADEMIE DES SCIENCES SERIE II FASCICULE & 1 & 0,0000 & 0,99 & 1525 \\
\hline CREATIVITY RESEARCH JOURNAL & 1 & 0,0000 & 0,99 & 1526 \\
\hline CRITICAL CARE CLINICS & 1 & 0,0000 & 0,99 & 1527 \\
\hline CRITICAL REVIEWS IN ENVIRONMENTAL SCIENCE AND TECHNOLOGY & 1 & 0,0000 & 0,99 & 1528 \\
\hline
\end{tabular}




\begin{tabular}{|c|c|c|c|c|}
\hline CRITICAL REVIEWS IN ONCOLOGY HEMATOLOGY & 1 & 0,0000 & $\odot, 99$ & 1529 \\
\hline CURRENT BIOLOGY & 1 & 0,0000 & 0,99 & 1530 \\
\hline CURRENT DIRECTIONS IN PSYCHOLOGICAL SCIENCE & 1 & 0,0000 & 0,99 & 1531 \\
\hline CURRENT OPINION IN BIOTECHNOLOGY & 1 & $\odot, 0 \odot \odot \odot$ & $\odot, 99$ & 1532 \\
\hline CURRENT OPINION IN CARDIOLOGY & 1 & 0,0000 & 0,99 & 1533 \\
\hline CURRENT OPINION IN CELL BIOLOGY & 1 & 0,0000 & 0,99 & 1534 \\
\hline CURRENT OPINION IN CHEMICAL BIOLOGY & 1 & 0,0000 & 0,99 & 1535 \\
\hline CURRENT OPINION IN GENETICS \& DEVELOPMENT & 1 & 0,0000 & 0,99 & 1536 \\
\hline CURRENT OPINION IN IMMUNOLOGY & 1 & 0,0000 & 0,99 & 1537 \\
\hline CURRENT OPINION IN NEUROLOGY & 1 & 0,0000 & 0,99 & 1538 \\
\hline CURRENT OPINION IN STRUCTURAL BIOLOGY & 1 & 0,0000 & 0,99 & 1539 \\
\hline CURRENT PROBLEMS IN SURGERY & 1 & 0,0000 & 0,99 & 1540 \\
\hline DAIRY INDUSTRIES INTERNATIONAL & 1 & $\odot, 0 \odot \odot \odot$ & 0,99 & 1541 \\
\hline DEUTSCHE ENTOMOLOGISCHE ZEITSCHRIFT & 1 & 0,0000 & 0,99 & 1542 \\
\hline DEVELOPMENT & 1 & 0,0000 & 0,99 & 1543 \\
\hline DEVELOPMENTAL GENETICS & 1 & 0,0000 & 0,99 & 1544 \\
\hline DEVELOPMENTAL PSYCHOLOGY & 1 & 0,0000 & 0,99 & 1545 \\
\hline DIABETES NUTRITION \& METABOLISM & 1 & $0,000 \odot$ & 0,99 & 1546 \\
\hline DIABETIC MEDICINE & 1 & 0,0000 & 0,99 & 1547 \\
\hline DIFFERENTIATION & 1 & 0,0000 & 0,99 & 1548 \\
\hline DIGESTIVE DISEASES & 1 & 0,0000 & 0,99 & 1549 \\
\hline DISEASE MARKERS & 1 & 0,0000 & 0,99 & 1550 \\
\hline DOCUMENTA OPHTHALMOLOGICA & 1 & 0,0000 & 0,99 & 1551 \\
\hline DRUG DISCOVERY TODAY & 1 & 0,0000 & 0,99 & 1552 \\
\hline DRUG SAFETY & 1 & 0,0000 & 0,99 & 1553 \\
\hline ECOGRAPHY & 1 & 0,0000 & 0,99 & 1554 \\
\hline ECOLOGICAL MONOGRAPHS & 1 & 0,0000 & 0,99 & 1555 \\
\hline ECOLOGY LETTERS & 1 & 0,0000 & 0,99 & 1556 \\
\hline ECOSYSTEM HEALTH & 1 & 0,0000 & 0,99 & 1557 \\
\hline EDUCATIONAL AND PSYCHOLOGICAL MEASUREMENT & 1 & 0,0000 & 0,99 & 1558 \\
\hline ENDOCRINE JOURNAL & 1 & 0,0000 & 0,99 & 1559 \\
\hline ENDODONTICS \& DENTAL TRAUMATOLOGY & 1 & 0,0000 & 0,99 & 1560 \\
\hline ENVIRONMENTAL AND ECOLOGICAL STATISTICS & 1 & 0,0000 & 0,99 & 1561 \\
\hline ENVIRONMENTAL GEOCHEMISTRY AND HEALTH & 1 & 0,0000 & 0,99 & 1562 \\
\hline ENVIRONMENTAL MICROBIOLOGY & 1 & 0,0000 & 0,99 & 1563 \\
\hline EUROPEAN JOURNAL OF MORPHOLOGY & 1 & 0,0000 & $\odot, 99$ & 1564 \\
\hline EUROPEAN JOURNAL OF PSYCHIATRY & 1 & 0,0000 & 0,99 & 1565 \\
\hline EUROPEAN JOURNAL OF PSYCHOLOGY OF EDUCATION & 1 & 0,0000 & 0,99 & 1566 \\
\hline EXPERIMENTAL AND CLINICAL ENDOCRINOLOGY \& DIABETES & 1 & 0,0000 & 0,99 & 1567 \\
\hline EXPERIMENTAL GERONTOLOGY & 1 & 0,0000 & 0,99 & 1568 \\
\hline EXPERT OPINION ON THERAPEUTIC PATENTS & 1 & 0,0000 & 0,99 & 1569 \\
\hline EXTREMOPHILES & 1 & 0,0000 & 0,99 & 1570 \\
\hline FEMS MICROBIOLOGY REVIEWS & 1 & 0,0000 & $\odot, 99$ & 1571 \\
\hline FIBRINOLYSIS & 1 & 0,0000 & 0,99 & 1572 \\
\hline FOLIA BIOLOGICA-KRAKOW & 1 & 0,0000 & 0,99 & 1573 \\
\hline FOLIA PHONIATRICA ET LOGOPAEDICA & 1 & $0,000 \odot$ & 0,99 & 1574 \\
\hline FORTSCHRITTE DER NEUROLOGIE PSYCHIATRIE & 1 & 0,0000 & 0,99 & 1575 \\
\hline FRONTIERS IN NEUROENDOCRINOLOGY & 1 & 0,0000 & 0,99 & 1576 \\
\hline GAIT \& POSTURE & 1 & 0,0000 & 0,99 & 1577 \\
\hline GASTROENTEROLOGIE CLINIQUE ET BIOLOGIQUE & 1 & 0,0000 & 0,99 & 1578 \\
\hline GASTROENTEROLOGY CLINICS OF NORTH AMERICA & 1 & 0,0000 & 0,99 & 1579 \\
\hline GEMATOLOGIYA I TRANSFUZIOLOGIYA & 1 & 0,0000 & 0,99 & 1580 \\
\hline GENE THERAPY & 1 & 0,0000 & 0,99 & 1581 \\
\hline GENERAL PHYSIOLOGY AND BIOPHYSICS & 1 & 0,0000 & 0,99 & 1582 \\
\hline GENES \& DEVELOPMENT & 1 & 0,0000 & 0,99 & 1583 \\
\hline GENES \& GENETIC SYSTEMS & 1 & 0,0000 & 0,99 & 1584 \\
\hline GENETIC ANALYSIS-BIOMOLECULAR ENGINEERING & 1 & 0,0000 & 0,99 & 1585 \\
\hline HASTINGS CENTER REPORT & 1 & 0,0000 & 0,99 & 1586 \\
\hline HEALTH ECONOMICS & 1 & 0,0000 & 0,99 & 1587 \\
\hline HEMATOLOGY AND CELL THERAPY & 1 & 0,0000 & 0,99 & 1588 \\
\hline HIV-I AND HTLV-I/II COINFECTION IN BRAZIL - IV DRUG-USE IS T & 1 & 0,0000 & 0,99 & 1589 \\
\hline HUMAN AND ECOLOGICAL RISK ASSESSMENT & 1 & 0,0000 & 0,99 & 1590 \\
\hline HYPERTENSION RESEARCH-CLINICAL AND EXPERIMENTAL & 1 & 0,0000 & 0,99 & 1591 \\
\hline IMMUNOBIOLOGY & 1 & 0,0000 & 0,99 & 1592 \\
\hline INFANT AND CHILD DEVELOPMENT & 1 & 0,0000 & 0,99 & 1593 \\
\hline INFANT BEHAVIOR \& DEVELOPMENT & 1 & 0,0000 & 0,99 & 1594 \\
\hline INHALATION TOXICOLOGY & 1 & 0,0000 & 0,99 & 1595 \\
\hline INTELLIGENCE & 1 & 0,0000 & 0,99 & 1596 \\
\hline INTERNATIONAL ANESTHESIOLOGY CLINICS & 1 & 0,0000 & $\odot, 99$ & 1597 \\
\hline INTERNATIONAL JOURNAL FOR QUALITY IN HEALTH CARE & 1 & $\odot, 0 \odot \odot \odot$ & 0,99 & 1598 \\
\hline INTERNATIONAL JOURNAL OF BEHAVIORAL DEVELOPMENT & 1 & 0,0000 & 0,99 & 1599 \\
\hline INTERNATIONAL JOURNAL OF BIOCHEMISTRY & 1 & 0,0000 & 0,99 & 1600 \\
\hline INTERNATIONAL JOURNAL OF EATING DISORDERS & 1 & 0,0000 & 0,99 & 1601 \\
\hline
\end{tabular}




\begin{tabular}{|c|c|c|c|c|}
\hline INTERNATIONAL JOURNAL OF GROUP PSYCHOTHERAPY & 1 & 0,0000 & 0,99 & 1602 \\
\hline INTERNATIONAL JOURNAL OF HEMATOLOGY & 1 & $\odot, 0 \odot \odot \odot$ & $\odot, 99$ & 1603 \\
\hline INTERNATIONAL JOURNAL OF HUMAN-COMPUTER STUDIES & 1 & 0,0000 & 0,99 & 1604 \\
\hline INTERNATIONAL JOURNAL OF HYPERTHERMIA & 1 & 0,0000 & 0,99 & 1605 \\
\hline INTERNATIONAL JOURNAL OF LEGAL MEDICINE & 1 & 0,0000 & 0,99 & 1606 \\
\hline INTERNATIONAL JOURNAL OF MENTAL HEALTH & 1 & 0,0000 & 0,99 & 1607 \\
\hline INTERNATIONAL JOURNAL OF NURSING STUDIES & 1 & 0,0000 & 0,99 & 1608 \\
\hline INTERNATIONAL JOURNAL OF REHABILITATION RESEARCH & 1 & 0,0000 & 0,99 & 1609 \\
\hline INTERNATIONAL JOURNAL OF SPORT PSYCHOLOGY & 1 & 0,0000 & 0,99 & 1610 \\
\hline INTERNATIONAL JOURNAL OF SUSTAINABLE DEVELOPMENT AND WORLD E & 1 & 0,0000 & 0,99 & 1611 \\
\hline INVESTIGATIONAL NEW DRUGS & 1 & $0,0 \odot \odot \odot$ & 0,99 & 1612 \\
\hline INVESTIGATIVE RADIOLOGY & 1 & 0,0000 & 0,99 & 1613 \\
\hline ISOTOPES IN ENVIRONMENTAL AND HEALTH STUDIES & 1 & 0,0000 & 0,99 & 1614 \\
\hline ITALIAN JOURNAL OF NEUROLOGICAL SCIENCES & 1 & 0,0000 & 0,99 & 1615 \\
\hline JAPANESE CIRCULATION JOURNAL-ENGLISH EDITION & 1 & 0,0000 & 0,99 & 1616 \\
\hline JMRI - JOURNAL OF MAGNETIC RESONANCE IMAGING & 1 & 0,0000 & 0,99 & 1617 \\
\hline JOURNAL OF ABNORMAL CHILD PSYCHOLOGY & 1 & 0,0000 & 0,99 & 1618 \\
\hline JOURNAL OF AGING STUDIES & 1 & 0,0000 & 0,99 & 1619 \\
\hline JOURNAL OF ALTERNATIVE AND COMPLEMENTARY MEDICINE & 1 & 0,0000 & $\odot, 99$ & 1620 \\
\hline JOURNAL OF ANTIBIOTICS & 1 & 0,0000 & 0,99 & 1621 \\
\hline JOURNAL OF APPLIED BEHAVIOR ANALYSIS & 1 & 0,0000 & 1,00 & 1622 \\
\hline JOURNAL OF APPLIED DEVELOPMENTAL PSYCHOLOGY & 1 & 0,0000 & 1,00 & 1623 \\
\hline JOURNAL OF APPLIED SOCIAL PSYCHOLOGY & 1 & 0,0000 & $1,0 \odot$ & 1624 \\
\hline JOURNAL OF ARID ENVIRONMENTS & 1 & 0,0000 & $1, \odot \odot$ & 1625 \\
\hline JOURNAL OF BEHAVIOR THERAPY AND EXPERIMENTAL PSYCHIATRY & 1 & 0,0000 & 1,00 & 1626 \\
\hline JOURNAL OF BIOCHEMISTRY & 1 & 0,0000 & 1,00 & 1627 \\
\hline JOURNAL OF BIOLOGICAL EDUCATION & 1 & 0,0000 & 1,00 & 1628 \\
\hline JOURNAL OF BIOLOGICAL RHYTHMS & 1 & 0,0000 & 1,00 & 1629 \\
\hline JOURNAL OF BIOMOLECULAR STRUCTURE \& DYNAMICS & 1 & $0,000 \odot$ & $1, \odot \odot$ & 1630 \\
\hline JOURNAL OF BIOSCIENCES & 1 & 0,0000 & 1,00 & 1631 \\
\hline JOURNAL OF BURN CARE \& REHABILITATION & 1 & 0,0000 & 1,00 & 1632 \\
\hline JOURNAL OF CARDIOTHORACIC AND VASCULAR ANESTHESIA & 1 & 0,0000 & 1,00 & 1633 \\
\hline JOURNAL OF CARDIOVASCULAR RISK & 1 & 0,0000 & $1, \odot \odot$ & 1634 \\
\hline JOURNAL OF CELLULAR PHYSIOLOGY & 1 & 0,0000 & 1,00 & 1635 \\
\hline JOURNAL OF CEREAL SCIENCE & 1 & 0,0000 & 1,00 & 1636 \\
\hline JOURNAL OF CHEMICAL NEUROANATOMY & 1 & 0,0000 & 1,00 & 1637 \\
\hline JOURNAL OF CHEMOTHERAPY & 1 & 0,0000 & $1, \odot \odot$ & 1638 \\
\hline JOURNAL OF CHILD LANGUAGE & 1 & 0,0000 & 1,00 & 1639 \\
\hline JOURNAL OF CHILD NEUROLOGY & 1 & 0,0000 & 1,00 & 1640 \\
\hline JOURNAL OF CLINICAL AND EXPERIMENTAL NEUROPSYCHOLOGY & 1 & 0,0000 & 1,00 & 1641 \\
\hline JOURNAL OF CLINICAL PATHOLOGY-MOLECULAR PATHOLOGY & 1 & 0,0000 & 1,00 & 1642 \\
\hline JOURNAL OF CLINICAL PSYCHOLOGY & 1 & 0,0000 & 1,00 & 1643 \\
\hline JOURNAL OF COMBINATORIAL CHEMISTRY & 1 & 0,0000 & 1,00 & 1644 \\
\hline JOURNAL OF COMMUNITY \& APPLIED SOCIAL PSYCHOLOGY & 1 & 0,0000 & $1,0 \odot$ & 1645 \\
\hline JOURNAL OF COMMUNITY PSYCHOLOGY & 1 & 0,0000 & 1,00 & 1646 \\
\hline JOURNAL OF COMPARATIVE PHYSIOLOGY A-SENSORY NEURAL AND BEHAV & 1 & 0,0000 & 1,00 & 1647 \\
\hline JOURNAL OF COMPUTER ASSISTED TOMOGRAPHY & 1 & 0,0000 & 1,00 & 1648 \\
\hline JOURNAL OF CRITICAL CARE & 1 & 0,0000 & 1,00 & 1649 \\
\hline JOURNAL OF DEVELOPMENTAL AND BEHAVIORAL PEDIATRICS & 1 & 0,0000 & 1,00 & 1650 \\
\hline JOURNAL OF EMERGENCY MEDICINE & 1 & 0,0000 & $1, \odot \odot$ & 1651 \\
\hline JOURNAL OF ENDOTOXIN RESEARCH & 1 & 0,0000 & 1,00 & 1652 \\
\hline JOURNAL OF ENDOVASCULAR SURGERY & 1 & 0,0000 & 1,00 & 1653 \\
\hline JOURNAL OF ENVIRONMENTAL HEALTH & 1 & 0,0000 & 1,00 & 1654 \\
\hline JOURNAL OF EVALUATION IN CLINICAL PRACTICE & 1 & 0,0000 & 1,00 & 1655 \\
\hline JOURNAL OF EVOLUTIONARY BIOLOGY & 1 & 0,0000 & 1,00 & 1656 \\
\hline JOURNAL OF EXPOSURE ANALYSIS AND ENVIRONMENTAL EPIDEMIOLOGY & 1 & 0,0000 & 1,00 & 1657 \\
\hline JOURNAL OF FOOD QUALITY & 1 & 0,0000 & $1, \odot \odot$ & 1658 \\
\hline JOURNAL OF FOOD SAFETY & 1 & 0,0000 & 1,00 & 1659 \\
\hline JOURNAL OF GENE MEDICINE & 1 & 0,0000 & 1,00 & 1660 \\
\hline JOURNAL OF GENERAL INTERNAL MEDICINE & 1 & 0,0000 & 1,00 & 1661 \\
\hline JOURNAL OF GENERAL PSYCHOLOGY & 1 & 0,0000 & 1,00 & 1662 \\
\hline JOURNAL OF GENETIC PSYCHOLOGY & 1 & 0,0000 & $1, \odot \odot$ & 1663 \\
\hline JOURNAL OF GENETICS & 1 & 0,0000 & $1, \odot \odot$ & 1664 \\
\hline JOURNAL OF HEMATOTHERAPY & 1 & 0,0000 & 1,00 & 1665 \\
\hline JOURNAL OF HOMOSEXUALITY & 1 & 0,0000 & 1,00 & 1666 \\
\hline JOURNAL OF HUMAN GENETICS & 1 & 0,0000 & 1,00 & 1667 \\
\hline JOURNAL OF HUMAN VIROLOGY & 1 & $\odot, \odot \odot \odot \odot$ & $1, \odot \odot$ & 1668 \\
\hline JOURNAL OF INTENSIVE CARE MEDICINE & 1 & 0,0000 & 1,00 & 1669 \\
\hline JOURNAL OF INTERNATIONAL MEDICAL RESEARCH & 1 & 0,0000 & 1,00 & 1670 \\
\hline JOURNAL OF LABELLED COMPOUNDS \& RADIOPHARMACEUTICALS & 1 & 0,0000 & $1, \odot \odot$ & 1671 \\
\hline JOURNAL OF LAPAROENDOSCOPIC \& ADVANCED SURGICAL TECHNIQUES-P & 1 & 0,0000 & 1,00 & 1672 \\
\hline JOURNAL OF LARYNGOLOGY AND OTOLOGY & 1 & 0,0000 & 1,00 & 1673 \\
\hline JOURNAL OF MAMMARY GLAND BIOLOGY AND NEOPLASIA & 1 & 0,0000 & 1,00 & 1674 \\
\hline
\end{tabular}




\begin{tabular}{|c|c|c|c|c|}
\hline JOURNAL OF MANIPULATIVE AND PHYSIOLOGICAL THERAPEUTICS & 1 & 0,0000 & $1, \odot \odot$ & 1675 \\
\hline JOURNAL OF MEDICAL ETHICS & 1 & 0,0000 & 1,00 & 1676 \\
\hline JOURNAL OF MEDICAL SCREENING & 1 & $0,0 \odot \odot \odot$ & $1, \odot \odot$ & 1677 \\
\hline JOURNAL OF MOLECULAR ENDOCRINOLOGY & 1 & $0,000 \odot$ & $1, \odot \odot$ & 1678 \\
\hline JOURNAL OF MOLECULAR MEDICINE-JMM & 1 & 0,0000 & 1,00 & 1679 \\
\hline JOURNAL OF NEURO-OPHTHALMOLOGY & 1 & $0, \odot \odot \odot \odot$ & $1, \odot \odot$ & 1680 \\
\hline JOURNAL OF NEUROVIROLOGY & 1 & 0,0000 & $1, \odot \odot$ & 1681 \\
\hline JOURNAL OF NURSING ADMINISTRATION & 1 & 0,0000 & $1, \odot \odot$ & 1682 \\
\hline JOURNAL OF OCULAR PHARMACOLOGY AND THERAPEUTICS & 1 & $\odot, \odot \odot \odot \odot$ & $1, \odot \odot$ & 1683 \\
\hline JOURNAL OF ORGANIZATIONAL BEHAVIOR & 1 & 0,0000 & 1,00 & 1684 \\
\hline JOURNAL OF OROFACIAL PAIN & 1 & 0,0000 & 1,00 & 1685 \\
\hline JOURNAL OF ORTHOPAEDIC RESEARCH & 1 & 0,0000 & 1,00 & 1686 \\
\hline JOURNAL OF PAEDIATRICS AND CHILD HEALTH & 1 & $\odot, \odot \odot \odot \odot$ & $1, \odot \odot$ & 1687 \\
\hline JOURNAL OF PALEOLIMNOLOGY & 1 & 0,0000 & 1,00 & 1688 \\
\hline JOURNAL OF PARAPSYCHOLOGY & 1 & 0,0000 & 1,00 & 1689 \\
\hline JOURNAL OF PEDIATRIC ORTHOPAEDICS-PART B & 1 & 0,0000 & 1,00 & 1690 \\
\hline JOURNAL OF PEPTIDE SCIENCE & 1 & 0,0000 & $1, \odot \odot$ & 1691 \\
\hline JOURNAL OF PSYCHIATRY \& NEUROSCIENCE & 1 & $0,0 \odot \odot \odot$ & $1, \odot \odot$ & 1692 \\
\hline JOURNAL OF PSYCHOLINGUISTIC RESEARCH & 1 & 0,0000 & $1, \odot \odot$ & 1693 \\
\hline JOURNAL OF RANGE MANAGEMENT & 1 & 0,0000 & 1,00 & 1694 \\
\hline JOURNAL OF RAPID METHODS AND AUTOMATION IN MICROBIOLOGY & 1 & 0,0000 & 1,00 & 1695 \\
\hline JOURNAL OF SCHOOL HEALTH & 1 & 0,0000 & $1, \odot \odot$ & 1696 \\
\hline JOURNAL OF SOCIAL BEHAVIOR AND PERSONALITY & 1 & $\odot, \odot \odot \odot \odot$ & $1, \odot \odot$ & 1697 \\
\hline JOURNAL OF SPEECH LANGUAGE AND HEARING RESEARCH & 1 & 0,0000 & $1, \odot \odot$ & 1698 \\
\hline JOURNAL OF SPORTS MEDICINE AND PHYSICAL FITNESS & 1 & 0,0000 & 1,00 & 1699 \\
\hline JOURNAL OF STUDIES ON ALCOHOL & 1 & $0,000 \odot$ & $1, \odot \odot$ & 1700 \\
\hline JOURNAL OF SURGICAL RESEARCH & 1 & $0,0 \odot \odot \odot$ & $1, \odot \odot$ & 1701 \\
\hline JOURNAL OF TEXTURE STUDIES & 1 & $0,0 \odot \odot \odot$ & $1, \odot \odot$ & 1702 \\
\hline JOURNAL OF THE AMERICAN DIETETIC ASSOCIATION & 1 & 0,0000 & $1, \odot \odot$ & 1703 \\
\hline JOURNAL OF THE AMERICAN PSYCHOANALYTIC ASSOCIATION & 1 & 0,0000 & 1,00 & 1704 \\
\hline JOURNAL OF THE AMERICAN SOCIETY FOR PSYCHICAL RESEARCH & 1 & 0,0000 & $1, \odot \odot$ & 1705 \\
\hline JOURNAL OF THE CHINESE CHEMICAL SOCIETY & 1 & $0, \odot \odot \odot \odot$ & $1, \odot \odot$ & 1706 \\
\hline JOURNAL OF THE INSTITUTE OF BREWING & 1 & 0,0000 & 1,00 & 1707 \\
\hline JOURNAL OF THE PERIPHERAL NERVOUS SYSTEM & 1 & $0,0 \odot \odot \odot$ & $1, \odot \odot$ & 1708 \\
\hline JOURNAL OF TOXICOLOGY-CLINICAL TOXICOLOGY & 1 & 0,0000 & $1, \odot \odot$ & 1709 \\
\hline JOURNAL OF TRACE ELEMENTS IN EXPERIMENTAL MEDICINE & 1 & 0,0000 & 1,00 & 1710 \\
\hline JOURNAL OF TRAVEL MEDICINE & 1 & 0,0000 & $1, \odot \odot$ & 1711 \\
\hline KIDNEY \& BLOOD PRESSURE RESEARCH & 1 & 0,0000 & $1,0 \odot$ & 1712 \\
\hline KLINISCHE MONATSBLATTER FUR AUGENHEILKUNDE & 1 & 0,0000 & 1,00 & 1713 \\
\hline LANDSCAPE ECOLOGY & 1 & $0,000 \odot$ & $1, \odot \odot$ & 1714 \\
\hline LEARNING AND MOTIVATION & 1 & 0,0000 & 1,00 & 1715 \\
\hline MAGNETIC RESONANCE IMAGING & 1 & 0,0000 & 1,00 & 1716 \\
\hline MATRIX BIOLOGY & 1 & 0,0000 & 1,00 & 1717 \\
\hline MAYO CLINIC PROCEEDINGS & 1 & $0,0 \odot \odot \odot$ & $1, \odot \odot$ & 1718 \\
\hline MEDICAL CLINICS OF NORTH AMERICA & 1 & 0,0000 & 1,00 & 1719 \\
\hline MEDICAL DECISION MAKING & 1 & $\odot, \odot \odot \odot \odot$ & $1, \odot \odot$ & 1720 \\
\hline MEDICINAL RESEARCH REVIEWS & 1 & 0,0000 & $1,0 \odot$ & 1721 \\
\hline MEDICINE SCIENCE AND THE LAW & 1 & 0,0000 & 1,00 & 1722 \\
\hline MEDSCAPE WOMENS HEALTH & 1 & 0,0000 & 1,00 & 1723 \\
\hline METHODS-A COMPANION TO METHODS IN ENZYMOLOGY & 1 & 0,0000 & $1, \odot \odot$ & 1724 \\
\hline METHODS AND FINDINGS IN EXPERIMENTAL AND CLINICAL PHARMACOLO & 1 & $\odot, \odot \odot \odot \odot$ & $1, \odot \odot$ & 1725 \\
\hline MICROBIOLOGY AND MOLECULAR BIOLOGY REVIEWS & 1 & 0,0000 & $1, \odot \odot$ & 1726 \\
\hline MICROCIRCULATION & 1 & 0,0000 & 1,00 & 1727 \\
\hline MIDWIFERY & 1 & 0,0000 & $1, \odot \odot$ & 1728 \\
\hline MINERAL AND ELECTROLYTE METABOLISM & 1 & 0,0000 & $1, \odot \odot$ & 1729 \\
\hline MINIMALLY INVASIVE NEUROSURGERY & 1 & $\odot, \odot \odot \odot \odot$ & $1, \odot \odot$ & 1730 \\
\hline MOLECULAR MEMBRANE BIOLOGY & 1 & 0,0000 & $1, \odot \odot$ & 1731 \\
\hline MONATSSCHRIFT FUR BRAUWISSENSCHAFT & 1 & 0,0000 & 1,00 & 1732 \\
\hline NAHRUNG - FOOD & 1 & 0,0000 & 1,00 & 1733 \\
\hline NATURAL IMMUNITY & 1 & $\odot, \odot \odot \odot \odot$ & $1, \odot \odot$ & 1734 \\
\hline NATURE MEDICINE & 1 & 0,0000 & $1, \odot \odot$ & 1735 \\
\hline NATURE STRUCTURAL BIOLOGY & 1 & 0,0000 & $1, \odot \odot$ & 1736 \\
\hline NEOPLASMA & 1 & 0,0000 & $1, \odot \odot$ & 1737 \\
\hline NEURO - OPHTHALMOLOGY & 1 & 0,0000 & $1, \odot \odot$ & 1738 \\
\hline NEUROLOGIC CLINICS & 1 & $\odot, \odot \odot \odot \odot$ & $1, \odot \odot$ & 1739 \\
\hline NEUROPSYCHIATRY NEUROPSYCHOLOGY AND BEHAVIORAL NEUROLOGY & 1 & 0,0000 & $1,0 \odot$ & 1740 \\
\hline NEUROSCIENCE RESEARCH COMMUNICATIONS & 1 & 0,0000 & 1,00 & 1741 \\
\hline NEUROSURGERY CLINICS OF NORTH AMERICA & 1 & 0,0000 & 1,00 & 1742 \\
\hline NEWS IN PHYSIOLOGICAL SCIENCES & 1 & 0,0000 & $1, \odot \odot$ & 1743 \\
\hline NURSING HISTORY REVIEW & 1 & 0,0000 & $1, \odot \odot$ & 1744 \\
\hline NUTRITION METABOLISM AND CARDIOVASCULAR DISEASES & 1 & 0,0000 & 1,00 & 1745 \\
\hline ONCOLOGY-NEW YORK & 1 & 0,0000 & 1,00 & 1746 \\
\hline ONCOLOGY RESEARCH & 1 & 0,0000 & $1, \odot \odot$ & 1747 \\
\hline
\end{tabular}




\begin{tabular}{|c|c|c|c|c|}
\hline OPHTHALMOLOGICA & 1 & $0,0 \odot \odot \odot$ & $1, \odot \odot$ & 1748 \\
\hline ORL-JOURNAL FOR OTO-RHINO-LARYNGOLOGY AND ITS RELATED SPECIA & 1 & 0,0000 & 1,00 & 1749 \\
\hline ORTHOPEDIC CLINICS OF NORTH AMERICA & 1 & 0,0000 & 1,00 & 1750 \\
\hline PAEDIATRIC ANAESTHESIA & 1 & 0,0000 & 1,00 & 1751 \\
\hline PAEDIATRIC AND PERINATAL EPIDEMIOLOGY & 1 & 0,0000 & $1, \odot \odot$ & 1752 \\
\hline PAIN & 1 & 0,0000 & 1,00 & 1753 \\
\hline PAN-PACIFIC ENTOMOLOGIST & 1 & 0,0000 & 1,00 & 1754 \\
\hline PARASITOLOGY TODAY & 1 & 0,0000 & 1,00 & 1755 \\
\hline PATHOBIOLOGY & 1 & 0,0000 & $1, \odot \odot$ & 1756 \\
\hline PEDIATRIC NEPHROLOGY & 1 & 0,0000 & 1,00 & 1757 \\
\hline PERIODONTOLOGY 2000 & 1 & 0,0000 & 1,00 & 1758 \\
\hline PHILOSOPHICAL PSYCHOLOGY & 1 & 0,0000 & 1,00 & 1759 \\
\hline PHILOSOPHICAL TRANSACTIONS OF THE ROYAL SOCIETY OF LONDON SE & 1 & 0,0000 & 1,00 & 1760 \\
\hline PHLEBOLOGY & 1 & 0,0000 & 1,00 & 1761 \\
\hline PHYSIOLOGICAL REVIEWS & 1 & 0,0000 & 1,00 & 1762 \\
\hline PLASMID & 1 & 0,0000 & 1,00 & 1763 \\
\hline PREPARATIVE BIOCHEMISTRY & 1 & 0,0000 & 1,00 & 1764 \\
\hline PROCEEDINGS OF THE ACADEMY OF NATURAL SCIENCES OF PHILADELPH & 1 & 0,0000 & 1,00 & 1765 \\
\hline PSYCHIATRIC ANNALS & 1 & $0,000 \odot$ & $1, \odot \odot$ & 1766 \\
\hline PSYCHIATRIE DE L ENFANT & 1 & 0,0000 & 1,00 & 1767 \\
\hline PSYCHOLOGICAL REVIEW & 1 & 0,0000 & 1,00 & 1768 \\
\hline PSYCHOLOGY OF WOMEN QUARTERLY & 1 & 0,0000 & 1,00 & 1769 \\
\hline QUARTERLY JOURNAL OF EXPERIMENTAL PSYCHOLOGY SECTION B-COMPA & 1 & 0,0000 & $1, \odot \odot$ & 1770 \\
\hline REGULATED RIVERS-RESEARCH \& MANAGEMENT & 1 & 0,0000 & 1,00 & 1771 \\
\hline REPRODUCTIVE TOXICOLOGY & 1 & 0,0000 & 1,00 & 1772 \\
\hline RESTORATION ECOLOGY & 1 & 0,0000 & 1,00 & 1773 \\
\hline REVIEWS ON HETEROATOM CHEMISTRY & 1 & 0,0000 & 1,00 & 1774 \\
\hline REVISTA DE INVESTIGACION CLINICA & 1 & 0,0000 & $1, \odot \odot$ & 1775 \\
\hline REVUE DES MALADIES RESPIRATOIRES & 1 & $\odot, \odot \odot \odot \odot$ & $1, \odot \odot$ & 1776 \\
\hline REVUE ROUMAINE DE CHIMIE & 1 & 0,0000 & $1, \odot \odot$ & 1777 \\
\hline SCANDINAVIAN JOURNAL OF CARING SCIENCES & 1 & 0,0000 & 1,00 & 1778 \\
\hline SCANDINAVIAN JOURNAL OF PUBLIC HEALTH & 1 & 0,0000 & $1, \odot \odot$ & 1779 \\
\hline SCANDINAVIAN JOURNAL OF WORK ENVIRONMENT \& HEALTH & 1 & 0,0000 & $1, \odot \odot$ & 1780 \\
\hline SCHIZOPHRENIA BULLETIN & 1 & 0,0000 & 1,00 & 1781 \\
\hline SCHOOL PSYCHOLOGY INTERNATIONAL & 1 & 0,0000 & $1, \odot \odot$ & 1782 \\
\hline SCHWEIZERISCHE MEDIZINISCHE WOCHENSCHRIFT & 1 & 0,0000 & 1,00 & 1783 \\
\hline SCIENTIST & 1 & 0,0000 & $1,0 \odot$ & 1784 \\
\hline SEIZURE-EUROPEAN JOURNAL OF EPILEPSY & 1 & 0,0000 & $1, \odot \odot$ & 1785 \\
\hline SEMINARS IN HEMATOLOGY & 1 & 0,0000 & 1,00 & 1786 \\
\hline SEMINARS IN NUCLEAR MEDICINE & 1 & $0,000 \odot$ & $1, \odot \odot$ & 1787 \\
\hline SEMINARS IN PERINATOLOGY & 1 & 0,0000 & 1,00 & 1788 \\
\hline SOMATOSENSORY AND MOTOR RESEARCH & 1 & 0,0000 & $1, \odot \odot$ & 1789 \\
\hline SOUTH AFRICAN MEDICAL JOURNAL & 1 & 0,0000 & 1,00 & 1790 \\
\hline SOUTHWESTERN ENTOMOLOGIST & 1 & 0,0000 & 1,00 & 1791 \\
\hline SPRINGER SEMINARS IN IMMUNOPATHOLOGY & 1 & 0,0000 & 1,00 & 1792 \\
\hline STATISTICAL METHODS IN MEDICAL RESEARCH & 1 & 0,0000 & 1,00 & 1793 \\
\hline STRUCTURE WITH FOLDING \& DESIGN & 1 & 0,0000 & $1,0 \odot$ & 1794 \\
\hline SURGERY TODAY-THE JAPANESE JOURNAL OF SURGERY & 1 & 0,0000 & 1,00 & 1795 \\
\hline SYSTEM FAMILIE & 1 & 0,0000 & 1,00 & 1796 \\
\hline THEORETICAL POPULATION BIOLOGY & 1 & 0,0000 & $1,0 \odot$ & 1797 \\
\hline TOXICOLOGICAL SCIENCES & 1 & 0,0000 & 1,00 & 1798 \\
\hline TRANSACTIONS OF THE AMERICAN ENTOMOLOGICAL SOCIETY & 1 & 0,0000 & $1, \odot \odot$ & 1799 \\
\hline TRANSFUSION MEDICINE REVIEWS & 1 & 0,0000 & $1, \odot \odot$ & 1800 \\
\hline TRENDS IN CARDIOVASCULAR MEDICINE & 1 & 0,0000 & 1,00 & 1801 \\
\hline TRENDS IN COGNITIVE SCIENCES & 1 & 0,0000 & 1,00 & 1802 \\
\hline TRENDS IN ENDOCRINOLOGY AND METABOLISM & 1 & 0,0000 & $1, \odot \odot$ & 1803 \\
\hline VISUAL COGNITION & 1 & $0,0 \odot \odot \odot$ & $1, \odot \odot$ & 1804 \\
\hline WASTE MANAGEMENT \& RESEARCH & 1 & 0,0000 & $1, \odot \odot$ & 1805 \\
\hline WESTERN JOURNAL OF MEDICINE & 1 & 0,0000 & 1,00 & 1806 \\
\hline WORLD JOURNAL OF UROLOGY & 1 & 0,0000 & $1, \odot \odot$ & 1807 \\
\hline WOUND REPAIR AND REGENERATION & 1 & 0,0000 & $1, \odot \odot$ & 1808 \\
\hline ZEITSCHRIFT FUR GASTROENTEROLOGIE & 1 & $0,0 \odot \odot \odot$ & $1, \odot \odot$ & 1809 \\
\hline ZEITSCHRIFT FUR KARDIOLOGIE & 1 & 0,0000 & $1, \odot \odot$ & 1810 \\
\hline ZEITSCHRIFT FUR KINDER-UND JUGENDPSYCHIATRIE UND PSYCHOTHERA & 1 & 0,0000 & $1,0 \odot$ & 1811 \\
\hline ZEITSCHRIFT FUR ORTHOPADIE UND IHRE GRENZGEBIETE & 1 & 0,0000 & 1,00 & 1812 \\
\hline ZUCKERINDUSTRIE & 1 & $0,000 \odot$ & $1, \odot \odot$ & 1813 \\
\hline Total & 12482 & & & \\
\hline
\end{tabular}


ANEXO 3 - Descritores em ordem decrescente de freqüência até 15 ocorrências

\begin{tabular}{|c|c|c|c|c|c|}
\hline 743 & BRAZIL & 87 & LYMPHOCYTE & 56 & BIOLOGICAL CONTROL \\
\hline 407 & EPIDEMIOLOGY & 86 & EPILEPSY & 55 & THERAPY \\
\hline 401 & RAT & 86 & DEVELOPMENT & 55 & ENDOTHELIN \\
\hline 359 & INSULIN/DIABETES & 84 & APOPTOSIS & 54 & TREATMENT \\
\hline 327 & TRYPANOSOMA & 83 & THYROID & 54 & IMMUNODEFICIENCY VIRUS \\
\hline 294 & $\mathrm{HIV} / \mathrm{AIDS}$ & 82 & CHROMOSOME & 54 & EOSINOPHIL \\
\hline 275 & NITRIC OXIDE & 82 & CHILDREN & 53 & TREHALOSE \\
\hline 249 & AMAZONIA & 82 & AGING & 53 & TRANSMISSION \\
\hline 217 & SCHISTOSOMA & 79 & NITROGEN & 53 & POLYMORPHISM \\
\hline 192 & LEISHMANIA & 78 & ELECTRON MICROSCOPY & 52 & VIRULENCE \\
\hline 189 & CALCIUM & 78 & ATP/ATPASE & 52 & SURGERY \\
\hline 188 & ANTIBODY & 77 & PROTEIN & 52 & SUPEROXIDE \\
\hline 178 & INFLAMMATION/INFLAMMATORY & 76 & SEROTONIN & 52 & PROGNOSIS \\
\hline 167 & GLUTAMINE/GLUTAMATE & 76 & ALCOHOLISM/ALCOHOL & 52 & PARASITOLOGY \\
\hline 160 & HYPERTENSION & 74 & SACCHAROMYCES & 52 & MORPHOLOGY \\
\hline 156 & MORTALITY & 74 & FLUORESCENCE & 52 & CHEMOTHERAPY \\
\hline 155 & DNA & 74 & BEE & 51 & SOYBEAN \\
\hline 155 & CHAGAS & 73 & SNAKE VENOM & 50 & WATER INTAKE \\
\hline 146 & PCR & 71 & ZINC & 50 & RENAL FAILURE \\
\hline 134 & STRESS & 71 & AEDES & 50 & PESTICIDE \\
\hline 132 & NUTRITION/MALNUTRITION & 70 & DIARRHEA & 50 & AMYGDALA \\
\hline 131 & CYTOKINE & 70 & COLLAGEN & 49 & TOXICITY \\
\hline 126 & MYCOBACTERIUM/TUBERCULOSIS & 68 & PREVENTION & 49 & RETINA \\
\hline 121 & MITOCHONDRIA & 67 & ETHANOL & 49 & PROLACTIN \\
\hline 121 & ANXIETY & 66 & FATTY ACID & 49 & CAUSES OF DEATH \\
\hline 117 & ULTRASTRUCTURE & 65 & VECTORS & 49 & BIOMPHALARIA \\
\hline 117 & MICE & 64 & OBESITY & 48 & MORBIDITY \\
\hline 116 & FISH & 63 & TEMPERATURE & 48 & MACROPHAGE \\
\hline 112 & RISK FACTORS & 62 & YEAST & 48 & HEART RATE \\
\hline 110 & PARACOCCIDIOIDES & 61 & OCCUPATIONAL HEALTH & 48 & CIRCADIAN RHYTHM \\
\hline 110 & ANGIOTENSIN & 60 & RECEPTOR & 48 & ANATOMY \\
\hline 109 & MERCURY & 60 & MACROPHAGES & 47 & RESISTANCE \\
\hline 108 & MALARIA & 60 & EXTRACELLULAR MATRIX & 47 & MOUSE \\
\hline 108 & DENTAL & $6 \odot$ & BENZODIAZEPINE & 47 & DEPRESSION \\
\hline 106 & PREGNANCY & 59 & VACCINE & 47 & ANOPHELES \\
\hline 106 & ESCHERICHIA COLI & 59 & PROTEASE & 46 & TESTOSTERONE \\
\hline 103 & DIAGNOSIS & 59 & INFANT & 46 & MORPHOMETRY \\
\hline 103 & BLOOD PRESSURE & 58 & SOCIOECONOMIC FACTORS & 46 & LECTINS \\
\hline 103 & ACETYLCHOLINE & 58 & MEMBRANE & 46 & GLYCINE \\
\hline 101 & MEMORY & 58 & DIET & 46 & ATLANTIC FOREST \\
\hline 100 & ECOLOGY & 58 & ADOLESCENT & 46 & ASTHMA \\
\hline 97 & NEUTROPHIL & 57 & MALNUTRITION & 46 & ANTI CD20 MONOCLONAL ANTIBODY \\
\hline 97 & DOPAMINE & 57 & LIVER & 45 & SPERMA \\
\hline 97 & BRADYKININ & 57 & KIDNEY & 45 & SPECTROPHOTOMETRY \\
\hline 96 & HIPPOCAMPUS & 57 & INSECT & 45 & PERIAQUEDUCTAL GRAY \\
\hline 93 & CHOLESTEROL & 57 & ELISA & 45 & LEPROSY \\
\hline 91 & CHROMATOGRAPHY & 57 & ANTINOCICEPTION & 45 & CYTOSKELETON \\
\hline 90 & IMMUNOHISTOCHEMISTRY & 56 & TAXONOMY & 44 & STAPHYLOCOCCUS \\
\hline 89 & PREVALENCE STUDIES & 56 & CERRADO REGION & 44 & MYOCARDIAL INFARCTION \\
\hline
\end{tabular}




\begin{tabular}{|c|c|c|c|c|c|}
\hline 44 & LIPIDS & 38 & ULTRASOUND & 32 & MOSQUITO \\
\hline 44 & LIPID PEROXIDATION & 38 & HEPARIN & 32 & LEARNING \\
\hline 44 & FREE RADICALS & 38 & BLOOD & 32 & IMMUNOSUPPRESSION \\
\hline 44 & ELEVATED PLUS-MAZE & 38 & ADENOSINE & 32 & GLUCOSE \\
\hline 44 & CANCER & 37 & SOIL & 32 & FLOW CYTOMETRY \\
\hline 44 & ANALYSIS & 37 & SARCOPLASMIC RETICULUM & 32 & EXERCISE \\
\hline 43 & SMOOTH MUSCLE & 37 & ROTAVIRUS & 32 & ENDOTOXIN \\
\hline 43 & SMOKING & 37 & PHEROMONE & 32 & CHILD \\
\hline 43 & REACTIVE OXYGEN SPECIES & 37 & IRON & 32 & CDATACHAGAS' DISEASE \\
\hline 43 & PROPOLIS & 37 & HEALTH ECONOMICS/PLANNING & 31 & RHODNIUS \\
\hline 43 & PHYLOGENY & 37 & GLUTATHIONE & 31 & NMR \\
\hline 43 & HYPOTHALAMUS & 37 & FEAR & 31 & MELATONIN \\
\hline 43 & GROWTH & 37 & CATECHOLAMINE & 31 & LIPOPOLYSACCHARIDE \\
\hline 43 & FLAVONOIDS & 37 & CARDIOVASCULAR & 31 & COMPLICATION \\
\hline 42 & URINE & 37 & ARTERIAL PRESSURE & 31 & COMPLEMENT \\
\hline 42 & PHAGOCYTOSIS & 36 & RABIES & 31 & CARCINOMA \\
\hline 42 & PAIN & 36 & PHOSPHORYLATION & 31 & BACTERIA \\
\hline 42 & MUTATION & 36 & METABOLISM & 31 & ATHEROSCLEROSIS \\
\hline 42 & MILK & 36 & MAIZE & 31 & ANEMIA \\
\hline 42 & LACTATION & 36 & ISCHEMIA & 30 & SURVIVAL \\
\hline 42 & HYBRID SYSTEM & 36 & EVOLUTION & 30 & RIO DE JANEIRO \\
\hline 42 & СYTOTOXICITY & 35 & SYSTEMIC LUPUS ERYTHEMATOSUS & 30 & REPRODUCTION \\
\hline 41 & SALMONELLA & 35 & PROSTATE PROSTATIC & 30 & QUALITY OF LIFE \\
\hline 41 & RISK & 35 & PILOCARPINE & 30 & $\mathrm{P} 53$ \\
\hline 41 & RAPD & 35 & PHOSPHORUS & 30 & MEDICINAL PLANT \\
\hline 41 & PROGESTERONE & 35 & NORADRENALINE & 30 & LIPOPROTEIN \\
\hline 41 & PHOSPHOLIPASES & 35 & MASS SPECTROMETRY & 30 & HEART \\
\hline 41 & INHIBITORY AVOIDANCE & 35 & HYPOXIA & 30 & ANTS \\
\hline 41 & HYBRIDIZATION & 35 & HYDROGEN PEROXIDE & 30 & ANIMAL MODEL \\
\hline 41 & HPLC & 35 & GLYCOSAMINOGLYCANS & 29 & TROPICAL FOREST \\
\hline 41 & FUNGI & 35 & CENTRAL NERVOUS SYSTEM & 29 & SERTOLI CELLS \\
\hline 41 & COLLICULUS & 35 & AGE & 29 & SEIZURES \\
\hline 40 & TRANSPLANTATION & 34 & UTILIZATION & 29 & SCHIZOPHRENIA \\
\hline 40 & TISSUE CULTURE CELLS & 34 & PHARMACOKINETICS & 29 & MORPHINE \\
\hline $4 \odot$ & TESTIS & 34 & METHODS & 29 & LIPASE \\
\hline 40 & SOUTH AMERICAN & 34 & GENE EXPRESSION & 29 & IMMOBILIZATION \\
\hline 40 & LAPAROSCOPY & 34 & GENE & 29 & HISTAMINE \\
\hline 40 & ISOLATION & 34 & DIPTERA & 29 & GANGLIOSIDE \\
\hline 40 & INFECTION & 34 & CARBOHYDRATE & 29 & DRUG \\
\hline 40 & GERMINATION & 33 & VENOM & 29 & CELL CULTURE \\
\hline 40 & COPPER & 33 & SKELETAL MUSCLE & 29 & CADMIUM \\
\hline 40 & BRAIN & 33 & SAVANNA & 29 & ANALGESIA \\
\hline 40 & BEHAVIOR & 33 & RADIOGRAPHY & 28 & VAS DEFERENS \\
\hline 39 & PROSTAGLANDIN & 33 & KINETIC & 28 & PROTEIN PHOSPHORYLATION \\
\hline 39 & $\mathrm{PH}$ & 33 & HEMODIALYSIS & 28 & NEUROTRANSMITTER \\
\hline 39 & PEPTIDE & 33 & FERMENTATION & 28 & IMMUNOLOGY \\
\hline 39 & IMMUNOCYTOCHEMISTRY & 33 & CAFFEINE & 28 & CONSERVATION \\
\hline 39 & HEPARAN SULFATE & 33 & ALLERGY & 28 & BIOMASS \\
\hline 39 & FORMATION & 32 & TRENDS & 28 & AMINO ACIDS \\
\hline 38 & XYLANASE & 32 & PROTOZOA & 27 & XYLITOL \\
\hline
\end{tabular}




\begin{tabular}{|c|c|c|c|c|c|}
\hline 27 & TOXOPLASMA GONDII & 24 & CONVERTING ENZYME & 21 & PROTEIN KINASE C \\
\hline 27 & THYROID HORMONE & 24 & CELL PROLIFERATION & 21 & PRACTICE \\
\hline 27 & SUGAR CANE & 24 & BIOAVAILABILITY & 21 & PLATELET AGGREGATION \\
\hline 27 & RNA & 23 & SERODIAGNOSIS & 21 & PLASMA \\
\hline 27 & PURIFICATION & 23 & POPULATION GENETICS & 21 & PATHOLOGY \\
\hline 27 & LOCOMOTOR ACTIVITY & 23 & $\mathrm{NA}+$ & 21 & PARASITE \\
\hline 27 & IMMUNITY & 23 & MELIPONINI & 21 & OSTEOPOROSIS \\
\hline 27 & HEART FAILURE & 23 & INTERFERON GAMMA & 21 & NALOXONE \\
\hline 27 & GENETIC & 23 & HYPOTHERMIA & 21 & MINAS GERAIS \\
\hline 27 & DENGUE & 23 & GROWTH HORMONE & 21 & MAST CELLS \\
\hline 27 & 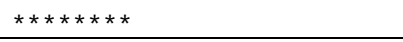 & 23 & GENETIC POLYMORPHISM & 21 & LOSARTAN \\
\hline 26 & PROPIONIC ACID & 23 & GASTRIC EMPTYING & 21 & LEGUMINOSAE \\
\hline 26 & PLACENTA & 23 & DEFORESTATION & 21 & L-NAME \\
\hline 26 & NMDA RECEPTOR & 23 & CORN & 21 & KALLIKREIN \\
\hline 26 & GABA & 23 & CHEMOTAXONOMY & 21 & HEALTH SURVEYS \\
\hline 26 & FEEDING & 23 & CAMP & 21 & HEALTH EDUCATION \\
\hline 26 & EXCITATORY AMINO ACID & 23 & ANTIDEPRESSANT & 21 & GENETIC VARIABILITY \\
\hline 26 & DEXAMETHASONE & 23 & AIR POLLUTION & 21 & GENDER \\
\hline 26 & DEVELOPING COUNTRIES & 22 & VISCERAL LEISHMANIASIS & 21 & ESSENTIAL OIL \\
\hline 26 & CORONARY ARTERY & 22 & VASOPRESSIN & 21 & DIVERSITY \\
\hline 26 & CEREBRAL CORTEX & 22 & RHEUMATOID ARTHRITIS & 21 & DIALYSIS \\
\hline 26 & ASTERACEAE & 22 & PROPRANOLOL & 21 & DEFENSIVE BEHAVIOR \\
\hline 25 & SUBSTANCE $\mathrm{P}$ & 22 & PROLIFERATION & 21 & CYTOGENETIC \\
\hline 25 & SPINAL CORD & 22 & PLOIDY & 21 & CATTLE \\
\hline 25 & PLEURAL EFFUSION & 22 & PHASEOLUS VULGARIS & 21 & BINDING \\
\hline 25 & PATHOGENICITY & 22 & LEISHMANIA AMAZONENSIS & 21 & AMINO ACID SEQUENCE \\
\hline 25 & NEUROTOXICITY & 22 & LATIN AMERICA & 21 & AMERINDIAN \\
\hline 25 & INDOMETHACIN & 22 & KNOWLEDGE & 21 & ACCIDENTS \\
\hline 25 & HUMAN LACTATION & 22 & INSECT VECTORS & 20 & VISCOELASTICITY \\
\hline 25 & HELICOBACTER PYLORI & 22 & IMMUNOGLOBULIN & 20 & VENTILATION \\
\hline 25 & HEAT SHOCK PROTEIN & 22 & HYPERALGESIA & 20 & STEREOLOGY \\
\hline 25 & HALOPERIDOL & 22 & HYMENOPTERA & 20 & SLEEP \\
\hline 25 & CUTANEOUS LEISHMANIASIS & 22 & HUMAN & 20 & SEED DISPERSAL \\
\hline 25 & BREAST CANCER & 22 & FREEZING & 20 & PLEURODESIS \\
\hline 25 & AVERSION & 22 & FIBRONECTIN & 20 & PLASMODIUM FALCIPARUM \\
\hline 25 & ABORTION & 22 & ENDOCYTOSIS & 20 & PHLEBOTOMINAE \\
\hline 24 & ULTRASONOGRAPHY & 22 & DOG & 20 & PEANUT \\
\hline 24 & SPREADING DEPRESSION & 22 & CULICIDAE & 20 & NOREPINEPHRINE \\
\hline 24 & SEASONALITY & 22 & CHEMILUMINESCENCE & 20 & NEOTROPICAL \\
\hline 24 & RETINOL & 22 & CANDIDA ALBICANS & 20 & MUSCARINIC RECEPTOR \\
\hline 24 & RESIDENCE CHARACTERISTICS & 22 & CA2+-ATPASE & 20 & LUPUS \\
\hline 24 & PHYSIOLOGY & 22 & BIODIVERSITY & 20 & LARVA \\
\hline 24 & OUABAIN & 22 & AUTOIMMUNITY & 20 & K+-ATPASE \\
\hline 24 & MODELING & 22 & APIS MELLIFERA & 20 & IMMUNE RESPONSE \\
\hline 24 & MENTAL RETARDATION & 22 & ANTIOXIDANTS & 20 & GLIAL FIBRILLARY ACIDIC PROTEIN \\
\hline 24 & LEAD & 22 & ANTHROPOMETRY & 20 & ESTRADIOL \\
\hline 24 & LAMININ RECEPTOR & 22 & ANGIOTENSIN-(1-7) & 20 & ENZYME \\
\hline \multirow[t]{2}{*}{24} & HEMOGLOBIN & 22 & ADVERSE EFFECTS & 20 & DITERPENE \\
\hline & 24 HEAVY METALS & 21 & STRUCTURE & 20 & CAROTENOID \\
\hline 24 & GENETIC DIVERSITY & 21 & STANDARD & 20 & BRAZILIAN POPULATION \\
\hline 24 & FLOW INJECTION & 21 & SIGNAL TRANSDUCTION & 20 & BINDING ANTIBODIES \\
\hline
\end{tabular}




\begin{tabular}{|c|c|c|c|c|c|}
\hline 20 & ATTITUDES & 18 & BOVINE & 16 & UASB REACTOR \\
\hline 20 & ANTIMICROBIAL ACTIVITY & 18 & ASTROCYTES & 16 & TRIATOMINAE \\
\hline 20 & ANGIOGENESIS & 18 & ALZHEIMERS DISEASE & 16 & STRIATUM \\
\hline 20 & AFLATOXINS & 18 & ALKALOIDS & 16 & STREPTOZOTOCIN \\
\hline 19 & TOLERANCE & 18 & ALKALINE PHOSPHATASE & 16 & STARCH \\
\hline 19 & TNF-ALPHA & 17 & TOMOGRAPHY & 16 & SPONTANEOUSLY HYPERTENSIVE RATS \\
\hline 19 & TITYUS SERRULATUS & 17 & THROMBOSIS & 16 & SOLID STATE FERMENTATION \\
\hline 19 & SYNAPTOSOME & 17 & SIALIC ACID & 16 & SEROLOGY \\
\hline 19 & STATISTICS & 17 & RENIN - ANGIOTENSIN SYSTEM & 16 & SEDIMENT \\
\hline 19 & PLUS MAZE & 17 & REGENERATION & 16 & RT -PCR \\
\hline 19 & PENIS & 17 & PSYCHODIDAE & 16 & RENAL TRANSPLANTATION \\
\hline 19 & NEW SPECIES & 17 & PROTEIN MALNUTRITION & 16 & RENAL FUNCTION \\
\hline 19 & NEISSERIA & 17 & POTASSIUM & 16 & PSYCHIATRIC DISORDER \\
\hline 19 & MIGRAINE & 17 & PLATELET & 16 & PROTEINASE \\
\hline 19 & LPS & 17 & NICOTINE & 16 & PROTEIN KINASE \\
\hline 19 & LITHIUM & 17 & NEUROMUSCULAR JUNCTION & 16 & POLYMER \\
\hline 19 & INHIBITOR & 17 & NEOTROPICS & 16 & PLUS MAZE/T MAZE \\
\hline 19 & HORMONE & 17 & NATRIURESIS & 16 & PLANT \\
\hline 19 & GROWTH FACTOR & 17 & MIDAZOLAM & 16 & PHENYLEPHRINE \\
\hline 19 & EVALUATION & 17 & MICRODIALYSIS & 16 & PHENYLALANINE \\
\hline 19 & DIETARY INTAKE & 17 & MICROBIOLOGY & 16 & PANIC \\
\hline 19 & CORTISOL & 17 & LEPIDOPTERA & 16 & NUTRIENTS \\
\hline 19 & CANDIDA GUILLIERMONDII & 17 & ISOZYMES & 16 & NMDA \\
\hline 19 & $\mathrm{CA} 2+$ & 17 & HISTOPATHOLOGY & 16 & NEWBORN \\
\hline 19 & BARORECEPTOR & 17 & HEPATITIS B & 16 & NEUROPROTECTION \\
\hline 19 & AUTONOMIC & 17 & GLYCOPROTEIN & 16 & MYOCARDITIS \\
\hline 19 & ANTIOXIDANT & 17 & GLUCOSE METABOLISM & 16 & MULTIVARIATE ANALYSIS \\
\hline 19 & ANTIGEN & 17 & FUROSEMIDE & 16 & MODEL \\
\hline 19 & $5-\mathrm{HT}$ & 17 & FORMALIN & 16 & METHOTREXATE \\
\hline 19 & 3 & 17 & ENTORHINAL CORTEX & 16 & MAST CELL \\
\hline 18 & TRIATOMA INFESTANS & 17 & EDEMA & 16 & LIGNIN \\
\hline 18 & SYNTHESIS & 17 & ECHOCARDIOGRAPHY & 16 & KINETICS \\
\hline 18 & SALIVARY GLANDS & 17 & DRUGS & 16 & ISOENZYME \\
\hline 18 & SALIVA & 17 & DEHYDRATION & 16 & HABITAT FRAGMENTATION \\
\hline 18 & RISK FACTOR & 17 & CYSTEINE PROTEINASE & 16 & GLUCAGON \\
\hline 18 & RADIOTHERAPY & 17 & CYCLOSPORIN A & 16 & GFAP \\
\hline 18 & PLEURISY & 17 & CYCLOPHOSPHAMIDE & 16 & ESCHERICHIA-COLI \\
\hline 18 & OXYGEN CONSUMPTION & 17 & CYCLIC AMP & 16 & EICOSANOIDS \\
\hline 18 & MYOCARDIUM & 17 & CRYSTAL STRUCTURE & 16 & DISEASE \\
\hline 18 & MARMOSET & 17 & CROTOXIN & 16 & CONTRACEPTION \\
\hline 18 & L-ARGININE & 17 & CHARACTERIZATION & 16 & COCAINE \\
\hline 18 & KIDNEY TRANSPLANTATION & 17 & CATALEPSY & 16 & CLASSIFICATION \\
\hline 18 & KARYOTYPE & 17 & CARBACHOL & 16 & CHEMORECEPTOR \\
\hline 18 & INSECTICIDE & 17 & CAPTOPRIL & 16 & CARRAGEENAN \\
\hline 18 & GLUCOCORTICOIDS & 17 & BREAST FEEDING & 16 & CAPSAICIN \\
\hline 18 & GLUCOAMYLASE & 17 & BODY TEMPERATURE & 16 & BIODEGRADATION \\
\hline 18 & FEEDING BEHAVIOR & 17 & AUTOSOMAL RECESSIVE INHERITANCE & 16 & BAROREFLEX \\
\hline 18 & EDUCATION & 17 & ASPERGILLUS NIDULANS & 16 & APYRASE \\
\hline 18 & CYTOCHEMISTRY & 17 & ADRENALINE & 16 & АСTH \\
\hline 18 & CELL DEATH & 17 & ADAPTATION & 16 & ACID PHOSPHATASE \\
\hline 18 & CASE-CONTROL STUDIES & 16 & UREA & 15 & WATER \\
\hline
\end{tabular}




\section{ANEXO 4 - AUTORES E FREQUÊNCIA DE \\ ARTIGOS - “CLUSTER ECOLOGY”}

\begin{tabular}{|c|c|c|c|}
\hline Frequência & Autor & Frequência & AUTORES \\
\hline 66 & DESOUZA W & 6 & SHELLEY, AJ \\
\hline 52 & FORATTINI OP & 6 & SILVA-VERGARA， ML \\
\hline 51 & JULIANO L & 6 & SILVA JG \\
\hline 48 & SIMPSON AJG & 6 & SANTORO MM \\
\hline 45 & TRAVASSOS LR & 6 & PRATISSOLI， D \\
\hline 33 & PREVIATO J0 & 6 & MUSSURY, RM \\
\hline 30 & MASSAD E & 6 & MEDEIROS MA \\
\hline 28 & ZUCOLOTO S & 6 & MAIA-HERZOG, M \\
\hline 28 & ENGLAND & 6 & LOYOLA, AM \\
\hline 27 & TAKAHASHI HK & 6 & LOPES, CM \\
\hline 26 & ZANUNCIO JC & 6 & LEAL MD \\
\hline 26 & HAGLER AN & 6 & HAMADA, $\mathrm{N}$ \\
\hline 26 & FERREIRA MU & 6 & GUIMARAES RC \\
\hline 25 & PEREIRA, $\mathrm{AC}$ & 6 & GONCALVES MF \\
\hline 25 & KAKITANI I & 6 & GOLDANI LZ \\
\hline 23 & LENZI HL & 6 & GESZTESI JL \\
\hline 21 & TOLEDO MS & 6 & FALCA0, $A L$ \\
\hline 21 & MARIANO M & 6 & COELHO PMZ \\
\hline 21 & FRANCO M & 6 & CHAVES MM \\
\hline 20 & STRAUS, $\mathrm{AH}$ & 6 & CARVALHO, MS \\
\hline 20 & SILVA CL & 6 & CARVALHO, AT \\
\hline 20 & BRAZ， $\mathrm{R}$ & 6 & BETTIOL, $\mathrm{H}$ \\
\hline 19 & ROSA CA & 6 & BALDANI VLD \\
\hline 18 & UNTERKIRCHER CS & 6 & ABAD-FRANCH, $F$ \\
\hline 18 & MARTINEZ $\mathrm{R}$ & 5 & VIEIRA, IJC \\
\hline 18 & DOBEREINER J & 5 & SPINOSA RP \\
\hline 18 & CHIMELLI L & 5 & SINGERVERMES LM \\
\hline 17 & NICOLI JR & 5 & ROTENBERG L \\
\hline 17 & MOMEN H & 5 & ROCHA, DD \\
\hline 17 & MENDONCAHAGLER LC & 5 & POVOA, MM \\
\hline 17 & FIGUEIREDO LTM & 5 & PEREIRA, $\mathrm{A}$ \\
\hline 16 & ZINGALES B & 5 & PERACOLI, MTS \\
\hline 16 & SANTOS RV & 5 & PELAJO-MACHADO M \\
\hline 16 & FELIPE MSS & 5 & NOGUEIRA RMR \\
\hline 15 & SUZUKI E & 5 & NATAL D \\
\hline 15 & FERREIRA CS & 5 & MOSCARDI $\mathrm{F}$ \\
\hline 15 & COIMBRA CEA & 5 & MONTEIRO, PCF \\
\hline 15 & CARMONA AK & 5 & MIAGOSTOVICH, MP \\
\hline 15 & CALICH VLG & 5 & MESQUITA, RA \\
\hline 15 & BENARD G & 5 & MATHIAS, L \\
\hline 14 & SOARES MJ & 5 & LOZOVEI AL \\
\hline 14 & PANIZZI AR & 5 & LOPES CE \\
\hline 14 & MARUCCI D & 5 & LODUCCA, SVL \\
\hline 14 & LOURENCO-DE-OLIVEIRA R & 5 & LEMOS FJA \\
\hline 14 & GOTLIEB SLD & 5 & JESUIN0, RSA \\
\hline 14 & DUARTE, AJS & 5 & JARED C \\
\hline 14 & CURI PR & 5 & HEUKELBACH， J \\
\hline 14 & CAMARGO ZP & 5 & GOULART, MOF \\
\hline 14 & ALVES MJM & 5 & GENTILE, $\mathrm{C}$ \\
\hline 13 & YOSHIDA CFT & 5 & FISCHMAN 0 \\
\hline 13 & SALLUM MAM & 5 & FELDMEIER， $\mathrm{H}$ \\
\hline 13 & LEVERY, SB & 5 & DE BRITO T \\
\hline 13 & LAURANCE WF & 5 & DANSA-PETRETSKI， M \\
\hline 13 & FIGUEIREDO $\mathrm{F}$ & 5 & DA FONSECA, BAL \\
\hline 13 & DELOLIO CA & 5 & CORDEIRO, $\mathrm{R}$ \\
\hline 12 & TEODORO U & 5 & CONTEL EPB \\
\hline 12 & SALOMAO, $\mathrm{R}$ & 5 & CISALPINO, PS \\
\hline 12 & PEREIRA M & 5 & CARCAVALL0， RU \\
\hline 12 & NETO ED & 5 & BETHONY, J \\
\hline 12 & GASPAR AMC & 5 & BARUZZI RG \\
\hline 12 & FOSS NT & 5 & BARBOSA AD \\
\hline 12 & BURGER E & 5 & BARBIERI， MA \\
\hline 12 & ANDRADE, ZA & 5 & ARRUDA MSP \\
\hline 11 & VIDIGAL THDA & 5 & ALEXANDER, $\mathrm{B}$ \\
\hline
\end{tabular}


11

11

11
VASCONCELOS PFC

ROMANHA, AJ

PUCCIA R
ZACHARIAS, $\mathrm{F}$

VAZ CAC

VALLE D 


\begin{tabular}{|c|c|c|c|}
\hline Frequência & Autor & Frequência & AUTORES \\
\hline 11 & PAULA, CR & 4 & THIENGO, SC \\
\hline 11 & LOPES JD & 4 & SUJII ER \\
\hline 11 & KATZIN AM & 4 & SOUZA AR \\
\hline 11 & KATZ N & 4 & SILVA-SOUZA, AT \\
\hline 11 & DUARTE MIS & 4 & SILVA, CG \\
\hline 11 & CARVALHO, OS & 4 & SILVA MF \\
\hline 11 & CAMARGO LMA & 4 & RUFFINONETTO A \\
\hline 11 & BARRET0, ML & 4 & ROMANO, CC \\
\hline 11 & $\mathrm{BAO}, \mathrm{SN}$ & 4 & REY, L \\
\hline 10 & TORRES JB & 4 & REGIS, L \\
\hline 10 & SILVA ME & 4 & RAMIREZ, LE \\
\hline 10 & SICHIERI R & 4 & RAMINA R \\
\hline 10 & PARRA JRP & 4 & PIVELLO VR \\
\hline 10 & NOIREAU, $\mathrm{F}$ & 4 & PIERI, OS \\
\hline 10 & MORAIS PB & 4 & PEREIRA， ES \\
\hline 10 & MARINOTTI 0 & 4 & PEREIRA PM \\
\hline 10 & MAGALHAES LA & 4 & ONO, MA \\
\hline 10 & LUQUE JL & 4 & OLIVEIRA， LC \\
\hline 10 & GUEDES RNC & 4 & NISHIMURA， K \\
\hline 10 & GOMES UA & 4 & MONTENEGRO MR \\
\hline 10 & GAMBALE, $W$ & 4 & MIRANDA C \\
\hline 10 & FACCIOLI LH & 4 & MINEO JR \\
\hline 10 & CORREA， L & 4 & MENESES MS \\
\hline 10 & BARATA JMS & 4 & MENDES-GIANNINI， MJS \\
\hline 10 & BALDANI JI & 4 & MENDES, RP \\
\hline 10 & ANDRADE $\mathrm{HF}$ & 4 & MARRELLI MT \\
\hline 10 & ALMEIDA IC & 4 & LOPES J \\
\hline 9 & STRAUS AH & 4 & LAZERA， MS \\
\hline 9 & SOUSA MV & 4 & LASALVIA V \\
\hline 9 & SILVA, CL & 4 & $\mathrm{KLOOS}, \mathrm{H}$ \\
\hline 9 & SHIKANAIYASUDA MA & 4 & ITANO, EN \\
\hline 9 & RODRIGUES, $\mathrm{V}$ & 4 & GUIMARAES, CT \\
\hline 9 & OLIVEIRA， $\mathrm{PL}$ & 4 & GUIMARAES, AE \\
\hline 9 & MARTINS RP & 4 & GLASSER, CM \\
\hline 9 & GOMES AD & 4 & GIOVANELLI, $\mathrm{A}$ \\
\hline 9 & FERGUSON MAJ & 4 & GAZZINELLI， $A$ \\
\hline 9 & DECARVALHO JF & 4 & FRANC0, MF \\
\hline 9 & DE SOUSA, SOM & 4 & FLOETER-WINTER， LM \\
\hline 9 & CALDEIRA， RL & 4 & FERREIRA，JM \\
\hline 9 & BRAGA FJHN & 4 & FERNANDES，WD \\
\hline 8 & TELES HMS & 4 & DUARTE， R \\
\hline 8 & SCHATZMAYR, $\mathrm{HG}$ & 4 & DOS SANTOS, RL \\
\hline 8 & SANO A & 4 & DINIZ， SN \\
\hline 8 & LIMA JBP & 4 & DEOLIVEIRA JM \\
\hline 8 & JURBERG，J & 4 & DELIMA EM \\
\hline 8 & GOTTLIEB, OR & 4 & DEGALLIER $\mathrm{N}$ \\
\hline 8 & GALVAO, C & 4 & DEEPE，GS \\
\hline 8 & FIGUEIREDO JFD & 4 & DE PAULA， SO \\
\hline 8 & FERNANDEZ， MA & 4 & DE MELLO, RP \\
\hline 8 & DASILVA AM & 4 & DE LIMA, VR \\
\hline 8 & CONSOLI FL & 4 & DE CARVALHO, ME \\
\hline 8 & COLOMBO, $\mathrm{AL}$ & 4 & COUTINHO, FAB \\
\hline 8 & CHAMONE, DAF & 4 & CAMPEAS AE \\
\hline 8 & BURATTINI， MN & 4 & BRAGANCA， MAL \\
\hline 8 & BORGES M & 4 & BOCCA AL \\
\hline 8 & ALVIANO CS & 4 & BARBOSA, HS \\
\hline 7 & ZANCOPE-OLIVEIRA， RM & 4 & BARBOSA, CS \\
\hline 7 & WANDERLEY DMV & 4 & BAGAGLI, $\mathrm{E}$ \\
\hline 7 & TONHASCA, A & 4 & ARRUDA WO \\
\hline 7 & SZWARCWALD CL & 4 & ARAUJO, A \\
\hline 7 & SOTTO, MN & 4 & ANDRADE，CFS \\
\hline 7 & SOCCOL, VT & 3 & YANG, HM \\
\hline 7 & SOARES, CMA & 3 & VON ZUBEN CJ \\
\hline 7 & ROSSI, CL & 3 & VENANCIO, EJ \\
\hline 7 & PASSOS ADC & 3 & VARGAS, $\mathrm{F}$ \\
\hline 7 & MARQUES GRAM & 3 & VANDERBORGHT BOM \\
\hline 7 & KLOETZEL JK & 3 & UENO, HM \\
\hline
\end{tabular}




\begin{tabular}{l|l|l|l}
\hline Frequência & Autor & Frequência & AUTORES \\
\hline 7 & IAZIGI N & 3 & THOMAZ-SOCCOL, V \\
\hline 7 & GASCON C & 3 & TEIXEIRA, FF \\
\hline 7 & GALATI EAB & 3 & SUGIZAKI MF \\
\hline 7 & DOLDER, H & 3 & SOUZA, WV \\
\hline 7 & DE SOUZA, CP & 3 & SOUZA AM \\
\hline 7 & CAMARGO EE & 3 & SOARES, MS \\
\hline 6 & ZARBIN PHG & 3 & SOARES, DD \\
\hline 6 & ZANOTTIMAGALHAES EM & 3 & SILVA, JR \\
\hline 6 & WANKE, B & 3 & SILVA, DF \\
\hline 6 & VASCONCELOS HL & 3 & SILVA, AF \\
\hline 6 & UMEZAWA ES & 3 & SHAW, JJ \\
\hline 6 & SOUZA, LR & 3 & SEGURADO AAC \\
\hline 6 & SOARES, AMVC & 3 & ROSA-FREITAS MG \\
\hline
\end{tabular}


ANEXO 5

Grupo 2: soft core

\begin{tabular}{|c|c|c|}
\hline Campo do Conhecimento & Artigos & $\%$ \\
\hline 3iochemistry and Biophysics & 1197 & $9,2 \%$ \\
\hline Zardiovascular and Respiratory System & 1091 & $8,4 \%$ \\
\hline Vedical Research, Organs and Systems & 1065 & $8,2 \%$ \\
\hline zardiovascular and Hematology research & 999 & $7,7 \%$ \\
\hline veuroscience and Behavior & 995 & $7,7 \%$ \\
\hline$\underline{\text { nicrobiology }}$ & 980 & $7,6 \%$ \\
\hline [mmunology & 860 & $6,6 \%$ \\
\hline गharmacology and Toxicology & 850 & $6,6 \%$ \\
\hline Environment Ecology & 747 & $5,8 \%$ \\
\hline nolecular Biology and Genetics & 542 & $4,2 \%$ \\
\hline Zhemistry and Analysis & 541 & $4,2 \%$ \\
\hline Yedical Research General Topics & 520 & $4,0 \%$ \\
\hline 3iotechnology and Applied Microbiology & 474 & $3,7 \%$ \\
\hline 3 iology & 473 & $3,7 \%$ \\
\hline Jentistry Oral surgery medicine & 436 & $3,4 \%$ \\
\hline Vedical Research, Diagnosis and Treatment & 390 & $3, \odot \%$ \\
\hline Entomology Pest Control & 368 & $2,8 \%$ \\
\hline =ood Science Nutrition & 350 & $2,7 \%$ \\
\hline zell e Developmental Biology & 319 & $2,5 \%$ \\
\hline Endocrinology, Nutrition and Metabolism & 309 & $2,4 \%$ \\
\hline Endocrinology, Metabolism and Nutrition & 285 & $2,2 \%$ \\
\hline Jrology and Nephrology & 268 & $2,1 \%$ \\
\hline Research Laboratory Medicine and Medical Technology & 242 & $1,9 \%$ \\
\hline Ilinical Immunology and Infectious Disease & 229 & $1,8 \%$ \\
\hline गhysicology & 216 & $1,7 \%$ \\
\hline Environmental Medicine and Public Health & 172 & $1,3 \%$ \\
\hline jastroenterology and Hepatology & 168 & $1,3 \%$ \\
\hline Jeneral and Internal Medicine & 159 & $1,2 \%$ \\
\hline zhemistry & 149 & $1,2 \%$ \\
\hline Jediatrics & 138 & $1,1 \%$ \\
\hline Anaesthesia e Intensive Care & 126 & $1, \odot \%$ \\
\hline$\underline{\text { Jncogenesis and Cancer Research }}$ & 114 & $\odot, 9 \%$ \\
\hline Rheumatology & 99 & $\odot, 8 \%$ \\
\hline tematology & 96 & $\odot, 7 \%$ \\
\hline surgery & 95 & $\odot, 7 \%$ \\
\hline veurology & 87 & $\odot, 7 \%$ \\
\hline Experimental Biology & 71 & $0,5 \%$ \\
\hline دsychiatry & 57 & $\odot, 4 \%$ \\
\hline
\end{tabular}




\begin{tabular}{lrc}
\hline \multicolumn{1}{c}{ Campo do Conhecimento } & Artigos & $\%$ \\
\hline Radiology, Nuclear Medicine and Imaging & 57 & $\odot, 4 \%$ \\
\hline Reprodutive medicine & 40 & $0,3 \%$ \\
\hline
\end{tabular}

Grupo 3: periféricos

\begin{tabular}{|c|c|c|}
\hline Campo do Conhecimento & Artigos & $\%$ \\
\hline Neuroscience and Behavior & 1020 & $8,2 \%$ \\
\hline Environment Ecology & 800 & $6,4 \%$ \\
\hline Pharmacology and Toxicology & 638 & $5,1 \%$ \\
\hline Medical Research, Diagnosis and Treatment & 629 & $5, \odot \%$ \\
\hline Microbiology & 620 & $5, \odot \%$ \\
\hline Medical Research, Organs and Systems & 614 & $4,9 \%$ \\
\hline Biochemistry and Biophysics & 517 & $4,1 \%$ \\
\hline Entomology Pest Control & 435 & $3,5 \%$ \\
\hline Medical Research General Topics & 429 & $3,4 \%$ \\
\hline Cardiovascular and Respiratory System & 426 & $3,4 \%$ \\
\hline$\underline{\text { Immunology }}$ & 406 & $3,3 \%$ \\
\hline Biology & 404 & $3,2 \%$ \\
\hline Molecular Biology and Genetics & 393 & $3,1 \%$ \\
\hline Endocrinology, Nutrition e Metabolism & 381 & $3,1 \%$ \\
\hline Oncogenesis and Cancer Research & 353 & $2,8 \%$ \\
\hline Food Science Nutrition & 336 & $2,7 \%$ \\
\hline Chemistry & 330 & $2,6 \%$ \\
\hline Surgery & 323 & $2,6 \%$ \\
\hline Cardiovascular and Hematology research & 307 & $2,5 \%$ \\
\hline Chemistry and Analysis & 291 & $2,3 \%$ \\
\hline Physiology & 291 & $2,3 \%$ \\
\hline Dentistry oral surgery medicine & 285 & $2,3 \%$ \\
\hline $\begin{array}{l}\text { Research Laboratory Medicine and Medical } \\
\text { Technology }\end{array}$ & 263 & $2,1 \%$ \\
\hline Cell e Developmental Biology & 262 & $2,1 \%$ \\
\hline Neurology & 256 & $2,1 \%$ \\
\hline Oncology & 246 & $2, \odot \%$ \\
\hline Biotechnology e Applied Microbiology & 208 & $1,7 \%$ \\
\hline Gastroenterology and Hepatology & 208 & $1,7 \%$ \\
\hline$\underline{\text { Radiology, Nuclear Medicine and Imaging }}$ & 207 & $1,7 \%$ \\
\hline Physicology & 196 & $1,6 \%$ \\
\hline Ophthalmology & 195 & $1,6 \%$ \\
\hline Environmental Medicine and Public Health & 189 & $1,5 \%$ \\
\hline Public Health and Health Care Science & 185 & $1,5 \%$ \\
\hline General and Internal Medicine & 183 & $1,5 \%$ \\
\hline
\end{tabular}




\begin{tabular}{lrc}
\hline \multicolumn{1}{c}{ Campo do Conhecimento } & Artigos & $\%$ \\
\hline Otolaryngology & 180 & $1,4 \%$ \\
\hline Reprodutive medicine & 180 & $1,4 \%$ \\
\hline Clinical Immunology e Infectious Disease & 175 & $1,4 \%$ \\
\hline Psychiatry & 166 & $1,3 \%$ \\
\hline
\end{tabular}




\begin{tabular}{lrr}
\hline \multicolumn{1}{c}{ Campo do Conhecimento } & Artigos & $\%$ \\
\hline Urology and Nephrology & 153 & $1,2 \%$ \\
\hline Dermatology & 152 & $1,2 \%$ \\
\hline Experimental Biology & 150 & $1,2 \%$ \\
\hline Pediatrics & 142 & $1,1 \%$ \\
\hline Endocrinology, Metabolism e Nutrition & 138 & $1,1 \%$ \\
\hline Anaesthesia and Intensive Care & 128 & $1,0 \%$ \\
\hline Mrthopedics, Rehabilitation and Sport & 82 & $0,7 \%$ \\
\hline Rheumatology & 74 & $0,6 \%$ \\
\hline Hematology & 71 & $0,6 \%$ \\
\hline Clinical Psychology and Psychiatry & 62 & $0,5 \%$ \\
\hline Rehabilitation & 27 & $0,2 \%$ \\
\hline Health Care Science and services & 10 & $0,1 \%$ \\
\hline
\end{tabular}

